Coastal Inlets Research Program

Wave Modeling for Jetty Rehabilitation at the Mouth of the Columbia River, Washington/Oregon, USA

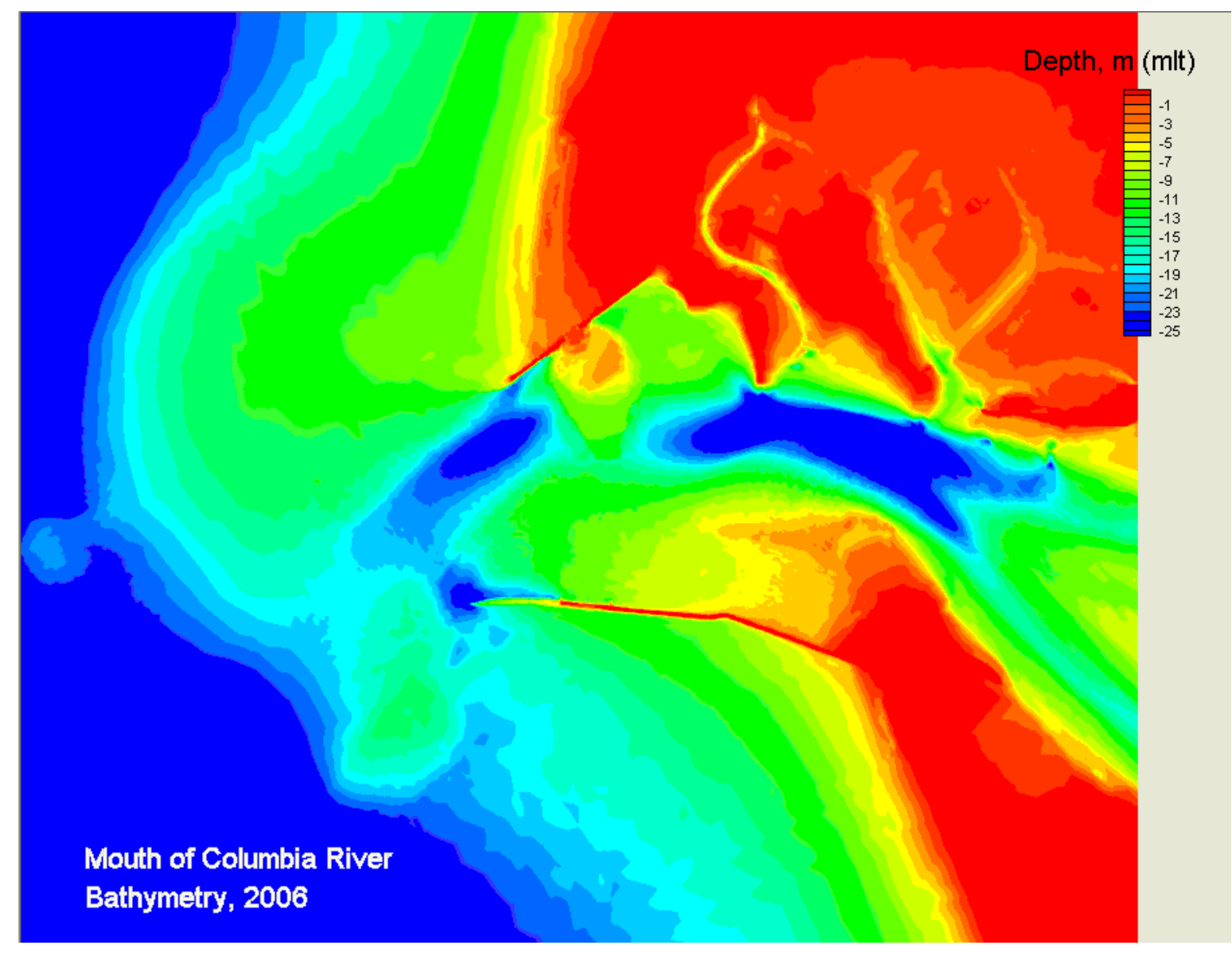




\section{Wave Modeling for Jetty Rehabilitation at the Mouth of the Columbia River, Washington/Oregon, USA}

Zeki Demirbilek and Lihwa Lin

Coastal and Hydraulics Laboratory

U.S. Army Engineer Research and Development Center

3909 Halls Ferry Road

Vicksburg, MS 39180-6199

Okey G. Nwogu

University of Michigan

Department of Naval Architecture and Marine Engineering

2600 Draper Road

Ann Arbor, MI 48109-2145

Final report

Approved for public release; distribution is unlimited.

Prepared for U.S. Army Engineer District, Portland

P.O. Box 2946

Portland, OR 97208-2946 


\begin{abstract}
The U.S. Army Engineer District, Portland (NWP), maintains three rubble-mound jetties at the Mouth of the Columbia River (MCR) in support of the Federal navigation project. The north and south entrance jetties constrain the current to scour the navigation channel, stabilize the location of the channel and entrance, and provide wave protection to vessels transiting the MCR. A third jetty (Jetty A) inside the MCR serves primarily as a training structure for the navigation channel to direct the flow away from the foundation of the north jetty. The jetties have significantly degraded during the past several decades. A maintenance plan is being developed to manage the jetties at the MCR to best support the Federal navigation project.
\end{abstract}

The U.S. Army Engineer Research and Development Center's Coastal and Hydraulics Laboratory established numerical wave models for the MCR to evaluate the regional implications of potential future (no-action) conditions, jetty rehabilitation, and additional structures added to the jetties. The wave models were validated with NWP's "mega-transect" data obtained during August-September 2005. The validated models were operated to obtain estimates of typical winter storm effects from northwest and southwest. Modifications to the jetties, specifically jetty length rebuilds (north jetty and south jetty) and jetty breach in the north and south jetties, were evaluated with applicable models. The changes considered in jetty length were within the original authorized lengths of those jetties. This report provides wave estimates for each jetty modification by means of two wave models, BOUSS-2D and STWAVE.

DISCLAIMER: The contents of this report are not to be used for advertising, publication, or promotional purposes. Citation of trade names does not constitute an official endorsement or approval of the use of such commercial products. All product names and trademarks cited are the property of their respective owners. The findings of this report are not to be construed as an official Department of the Army position unless so designated by other authorized documents. 


\section{Contents}

Figures and Tables........................................................................................................................

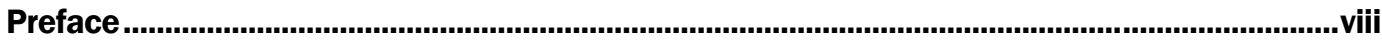

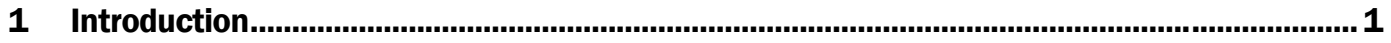

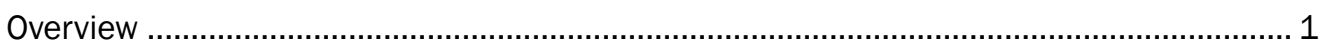

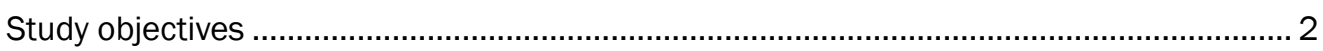

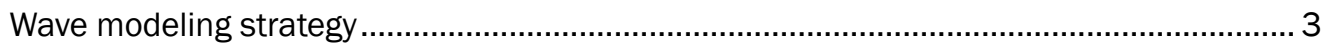

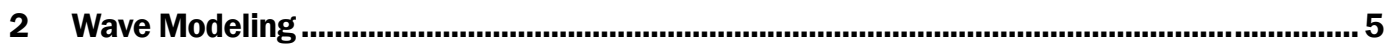

Description of wave modeling area ............................................................................. 5

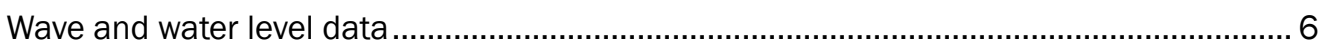

Wave modeling approach ....................................................................................... 10

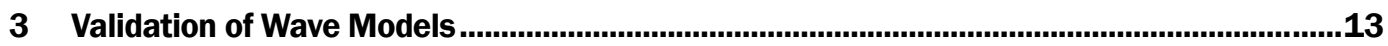

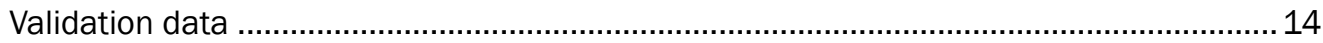

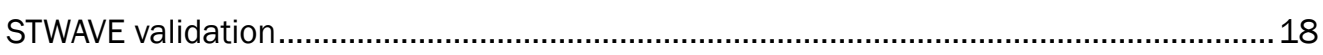

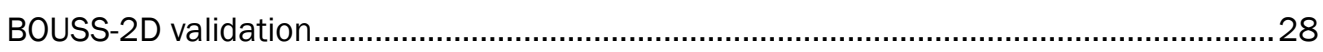

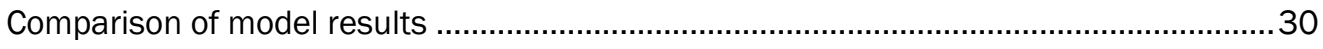

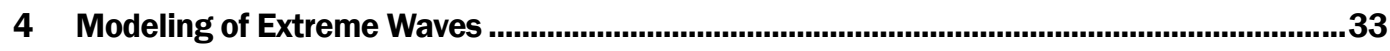

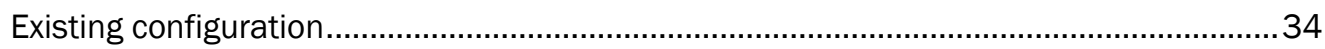

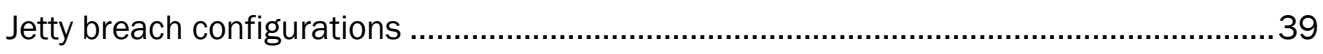

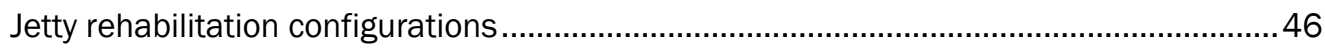

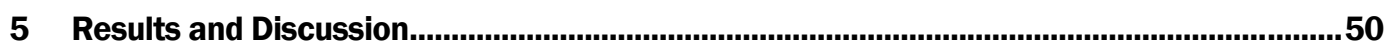

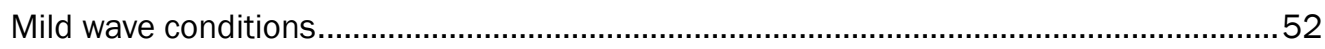

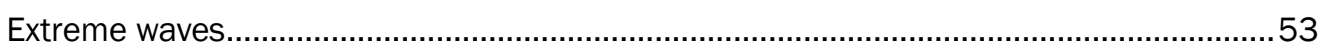

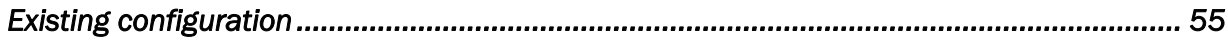

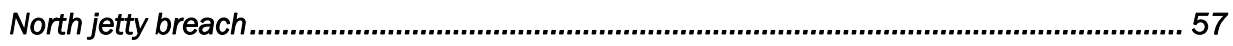

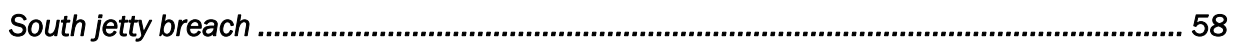

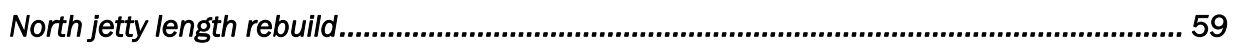

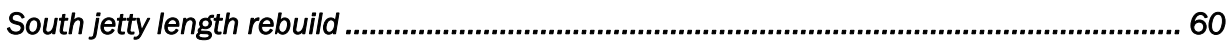

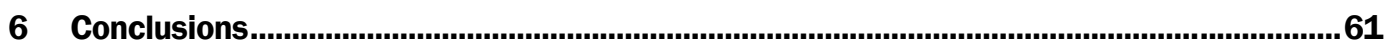

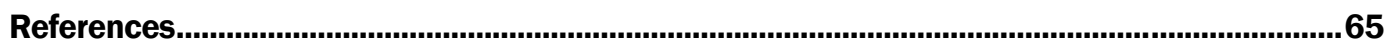

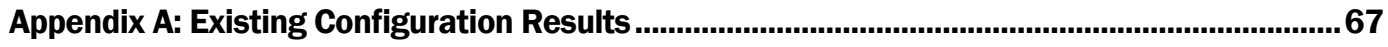

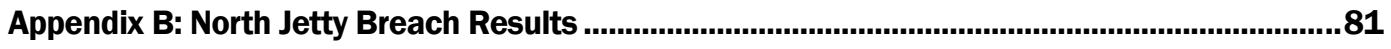

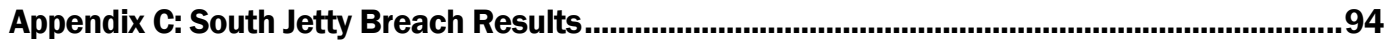




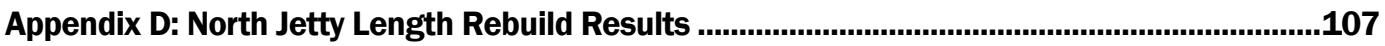

Appendix E: South Jetty Length Rebuild Results ................................................................. 119

Report Documentation Page 


\section{Figures and Tables}

\section{Figures}

Figure 1. Location map for wave modeling at MCR.

Figure 2. Location and layout of mega-transect stations at MCR. ...................................................... 7

Figure 3. Location of NOAA and USGS stations............................................................................. 8

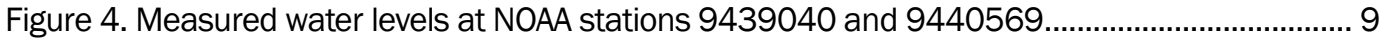

Figure 5. Computational grids for BOUSS-2D and STWAVE models. ............................................. 14

Figure 6. Wind and wave data collected at Buoy 46029 and mega-transect sta 4 and 5

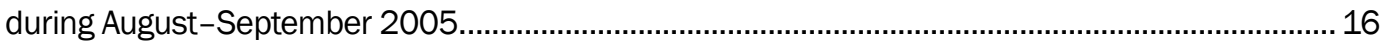

Figure 7. Calculated current field for wave condition at 10:00 GMT on 7 August 2005................... 17

Figure 8. Calculated current field for wave condition at 00:00 GMT on 30 August 2005................ 17

Figure 9. Calculated current field at 18:00 GMT on 9 September 2005 ....................................... 18

Figure 10. (a) Buoy spectrum and (b) transformed spectrum at sta A in Figure 5 for wave condition at 18:00 GMT on 9 September 2005.

Figure 11. STWAVE calculated spectra at sta A in Figure 5 for wave condition at 18:00 GMT on 9 September 2005 (a) without wind and (b) with wind input.....

Figure 12. (a) Measured and (b) STWAVE-calculated spectra at mega-transect sta 1 for wave condition at 10:00 GMT on 7 August 2005.

Figure 13. (a) Measured and (b) STWAVE-calculated spectra at mega-transect sta 2 for wave condition at 10:00 GMT on 7 August 2005.

Figure 14. (a) Measured and (b) STWAVE-calculated spectra at mega-transect sta 3 for wave condition at 10:00 GMT on 7 August 2005.

Figure 15. (a) Measured and (b) STWAVE-calculated spectra at mega-transect sta 4 for wave condition at 10:00 GMT on 7 August 2005.

Figure 16. (a) Measured and (b) STWAVE-calculated spectra at mega-transect sta 5 for wave condition at 10:00 GMT on 7 August 2005.

Figure 17. (a) Measured and (b) STWAVE-calculated spectra at mega-transect sta 1 for wave condition at 00:00 GMT on 30 August 2005.

Figure 18. (a) Measured and (b) STWAVE-calculated spectra at mega-transect sta 2 for wave condition at 00:00 GMT on 30 August 2005.

Figure 19. (a) Measured and (b) STWAVE-calculated spectra at mega-transect sta 3 for wave condition at 00:00 GMT on 30 August 2005.

Figure 20. (a) Measured, and (b) STWAVE-calculated spectra at mega-transect sta 4 for wave condition at 00:00 GMT on 30 August 2005.

Figure 21. (a) Measured and (b) STWAVE-calculated spectra at mega-transect sta 5 for wave condition at 00:00 GMT on 30 August 2005.

Figure 22. (a) Measured and (b) STWAVE-calculated spectra at mega-transect sta 4 for wave condition at 18:00 GMT on 9 September 2005. 
Figure 23. (a) Measured and (b) STWAVE-calculated spectra at mega-transect sta 5 for wave condition at 18:00 GMT on 9 September 2005.

Figure 24. (a) STWAVE and (b) BOUSS-2D calculated wave fields for wave condition at 10:00 GMT on 7 August 2005.

Figure 25. (a) STWAVE and (b) BOUSS-2D calculated wave fields for wave condition at 00:00 GMT on 30 August 2005.

Figure 26. (a) STWAVE and (b) BOUSS-2D calculated wave fields for wave condition at 18:00 GMT on 9 September 2005.

Figure 27. STWAVE calculated wave fields for (a) Event 4 at 12:00 GMT on 14 December 2001 and (b) Event 6 at 13:00 GMT on 4 February 2006.

Figure 28. BOUSS-2D calculated wave fields for (a) Event 4 at 12:00 GMT on 14 December 2001 and (b) Event 6 at 13:00 GMT on 4 February 2006. 35

Figure 29. Wave modeling output locations (red circles) for extreme events. 36

Figure 30. Wave model output locations placed over DWS 36

Figure 31. Wave model output locations in vicinity of SWS. 37

Figure 32. Wave model output locations in vicinity of SJRS. 37

Figure 33. Wave model output locations in vicinity of north jetty....................................................38

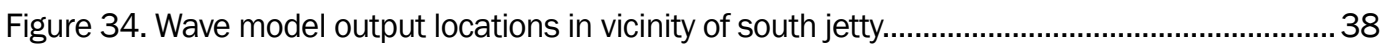

Figure 35. North jetty breach configuration with depth contours. ...................................................40

Figure 36. South jetty breach configuration with depth contours.....................................................40

Figure 37. North jetty breach (a) STWAVE and (b) BOUSS-2D calculated wave fields for NW storm Event 4 at 12:00 GMT on 14 December 2001.

Figure 38. North jetty breach (a) STWAVE and (b) BOUSS-2D calculated wave fields for SW storm Event 6 at 13:00 GMT on 4 February 2006.

Figure 39. South jetty breach (a) STWAVE and (b) BOUSS-2D calculated wave fields for NW storm Event 4 at 12:00 GMT on 14 December 2001.

Figure 40. South jetty breach (a) STWAVE and (b) BOUSS-2D calculated wave fields for SW storm Event 6 at 13:00 GMT on 4 February 2006.

Figure 41. Three-dimensional view of bathymetry in south jetty breach configuration

Figure 42. Three-dimensional view of wave field from BOUSS-2D for Event 6 at 13:00 GMT on 4 February 2006 for south jetty breach.

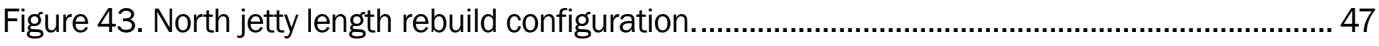

Figure 44. South jetty length rebuild configuration.

\section{Tables}

Table 1. Coordinates and depth of mega-transect stations at MCR for measurement performed in August-September 2005.

Table 2. Three wave conditions (Buoy 46029) selected for validation of wave models.

Table 3. Comparison of calculated significant wave height $(\mathrm{m})$ and spectral peak direction (deg) and data.

Table 4. Extreme wave events observed offshore of the MCR at Buoy 46029, 1998-2006...........33

Table 5. Ten sub-areas of interest and output stations. 
Table 6. Calculated wave parameters at mega-transect stations for north and south jetty breach configurations.

Table 7. Calculated wave parameters at mega-transect stations for north and south jetty length rebuild configurations.

Table A1. Special output locations.

Table A2. Event 4 results for existing configuration. ..................................................................... 71

Table A3. Event 6 results for existing configuration. ...................................................................... 76

Table A4. Statistics of wave parameters (STWAVE versus BOUSS-2D) for existing configuration 80

Table B1. Event 4 results for north jetty breach configuration. ........................................................ 81

Table B2. Event 6 results for north jetty breach configuration. ......................................................... 86

Table B3. Statistics of wave parameters (STWAVE versus BOUSS-2D) for north jetty breach

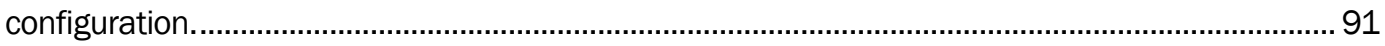

Table B4. Event 4 statistics for north jetty breach versus existing configuration. ............................92

Table B5. Event 6 statistics for north jetty breach versus existing configuration. .............................93

Table C1. Event 4 results for south jetty breach configuration........................................................94

Table C2. Event 6 results for south jetty breach configuration..........................................................99

Table C3. Statistics of wave parameters (STWAVE versus BOUSS-2D) for south jetty

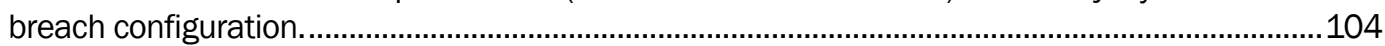

Table C4. Event 4 statistics for south jetty breach versus existing configuration...........................105

Table C5. Event 6 statistics for south jetty breach versus existing configuration. ...........................106

Table D1. Event 4 results for north jetty length rebuild configuration. .......................................... 107

Table D2. Event 6 results for north jetty length rebuild configuration. .........................................112

Table D3. Statistics of wave parameters (STWAVE versus BOUSS-2D) for north jetty length rebuild configuration....................................................................................................................116

Table D4. Statistics of wave parameters for Event 4 for north jetty length rebuild versus existing configuration..................................................................................................................... 117

Table D5. Statistics of wave parameters for Event 6 for north jetty length rebuild versus

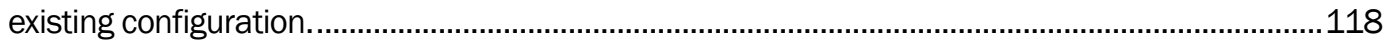

Table E1. Event 4 results for south jetty length rebuild configuration. ...........................................119

Table E2. Event 6 results for south jetty length rebuild configuration. ..........................................124

Table E3. Statistics of wave parameters (STWAVE versus BOUSS-2D) for south jetty length

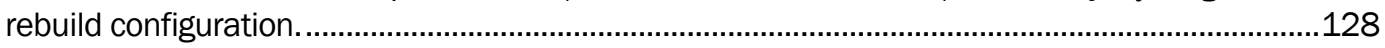

Table E4. Statistics of wave parameters for Event 4 for south jetty length rebuild versus existing configuration.

Table E5. Statistics of wave parameters for Event 6 for south jetty length rebuild versus existing configuration. 


\section{Preface}

This report documents a joint effort commissioned by the U.S. Army Engineer District, Portland (NWP), and supported in part for predictive model testing and development by the Coastal Inlets Research Program (CIRP). Project Manager for the Jetty Rehabilitation Program at the NWP is Laura Hicks (NWP-PM-F), and H. "Rod" Moritz (NWP-EC-HY) is the Technical Project Manager. The CIRP is administered by Headquarters, U.S. Army Corps of Engineers (HQUSACE). Work described in this report was conducted by the Coastal and Hydraulics Laboratory (CHL), U.S. Army Engineer Research and Development Center (ERDC), Vicksburg, MS, in collaboration with NWP staff. ERDC administers the CIRP for HQUSACE under the Navigation Systems Program. James E. Walker is HQUSACE lead Technical Monitor, and James E. Clausner, CHL, is the acting Technical Director for the Navigation Systems Program. Dr. Nicholas C. Kraus, Senior Scientists Group, CHL, is the CIRP Program Manager.

The mission of the CIRP is to conduct applied research to improve USACE capability to manage Federally maintained inlets, which are present on all coasts of the United States, including the Atlantic Ocean, Gulf of Mexico, Pacific Ocean, Great Lakes, and U.S. territories. CIRP objectives are to advance knowledge and provide quantitative predictive tools to (a) make management of Federal coastal inlet navigation projects, principally the design, maintenance, and operation of channels and jetties, more effective and reduce the cost of dredging and (b) preserve the adjacent beaches and estuary in a systems approach that treats the inlet, beaches, and estuary as sediment-sharing components. To achieve these objectives, the CIRP is organized in work units conducting research and development in hydrodynamic, sediment transport, and morphology change modeling; navigation channels and adjacent beaches; navigation channels and estuaries; inlet structures and scour; laboratory and field investigations; and technology transfer.

This report was prepared by Dr. Zeki Demirbilek of the Harbors, Entrances, and Structures Branch (HN-H), and Dr. Lihwa Lin of the Coastal Engineering Branch (HN-C), ERDC-CHL, Vicksburg, MS, and by 
Dr. Okey G. Nwogu, Department of Naval Architecture and Marine Engineering, University of Michigan, Ann Arbor. Work at CHL was performed under the general supervision of Jose E. Sanchez, Chief, HN-H; Dr. Lisa Hubbard, Chief, HN-C; and Dr. Rose Kress, Chief, Navigation Division, CHL. Heidi Moritz and Rod Moritz, NWP, and Drs. Jane Smith and Nicholas Kraus, ERDC-CHL, provided peer review. J. Holley Messing, $\mathrm{HN}-\mathrm{C}$, typed the equations and formatted and edited the draft report. Thomas W. Richardson was Director, CHL, and Dr. William D. Martin, Deputy Director, CHL, during the study and preparation of this report.

COL Richard B. Jenkins was Commander and Executive Director of ERDC. Dr. James R. Houston was Director. 


\section{Introduction}

\section{Overview}

The U.S. Army Engineer District, Portland (hereafter, the Portland District), maintains three rubble-mound jetties at the Mouth of the Columbia River (MCR) in support of the Federal navigation project. The south jetty was constructed in 1895, with jetty elevation increased by 1913 . A second jetty was needed to increase depth of the channel, and the north jetty was completed in 1917. These two jetties constrain the current to scour the navigation channel, stabilize the location of the channel and entrance, and provide wave protection to vessels transiting the MCR. A third jetty (Jetty A) inside the MCR serves primarily as a training structure for the navigation channel to direct flow away from the foundation of the north jetty (Figure 1).

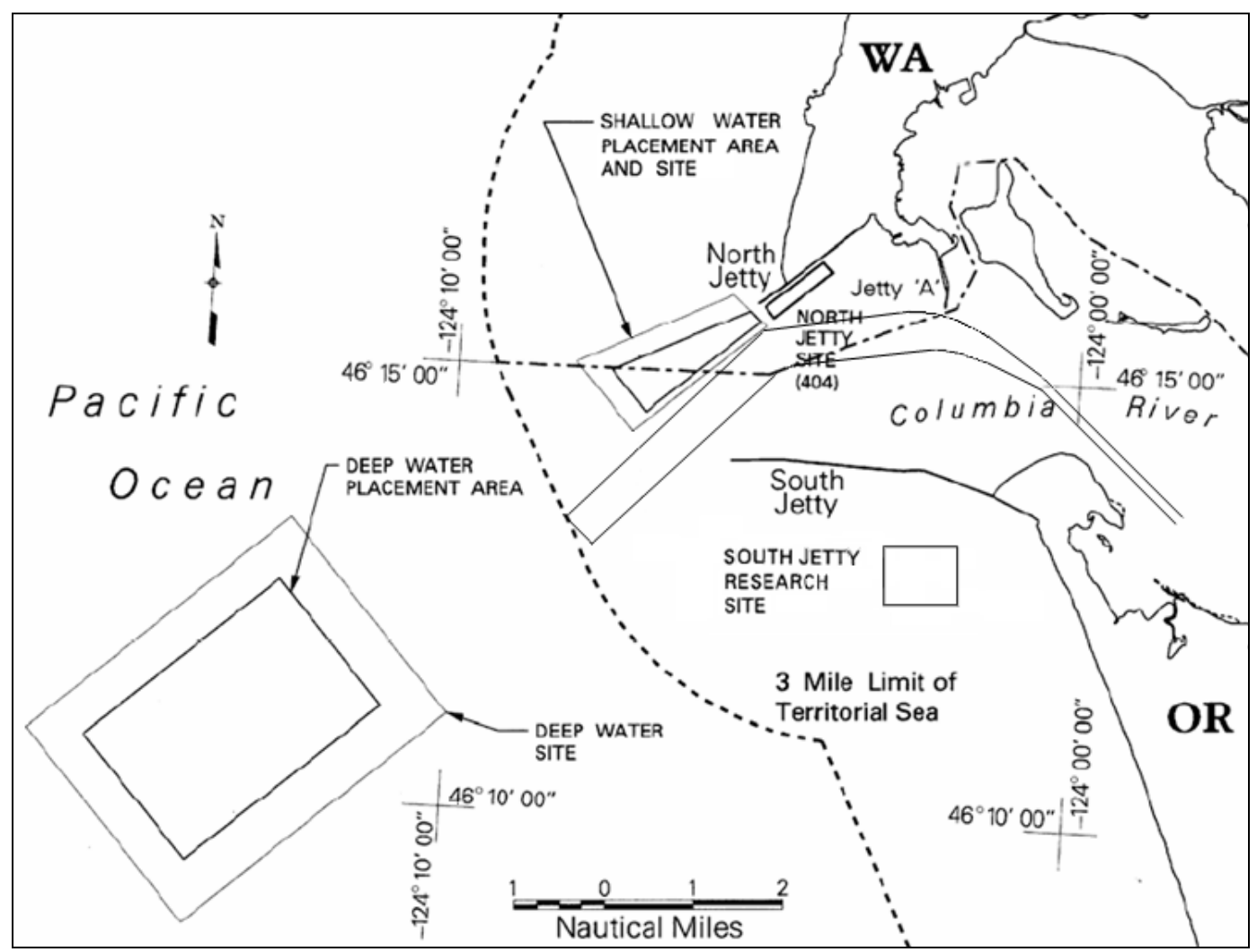

Figure 1. Location map for wave modeling at MCR (1 nautical mile $=1,852 \mathrm{~m})$. 
The jetties have significantly degraded during the past several decades. Questions arise as to the necessity, form, and consequences of engineering actions to be taken to rehabilitate or modify the structures (Moritz et al. 2003). A maintenance plan is being developed to manage the jetties at the MCR to best support the Federal navigation project and answer such questions as:

1. Should the jetties be maintained in place, rehabilitated in place, or modified?

2. With jetty maintenance, rehabilitation, or modification, what are the short- and long-term consequences for the patterns and magnitudes of change in waves, current, salinity (in bay), and sediment transport at the entrance, and how will these changes affect structure stability?

3. How can the roots of the jetties be best protected?

4. What is the functioning of spurs on jetties, and can short, submerged spurs that presently exist on the south jetty protect all the jetties?

5. What consequences would result if one or both jetties suffered a breach?

\section{Study objectives}

The U.S. Army Engineer Research and Development Center (ERDC), Coastal and Hydraulics Laboratory (CHL) assisted the Portland District in evaluating wave, current, circulation, sediment transport, and salinity changes associated with proposed alternative jetty modifications and possible future jetty degradation. This study established numerical wave modeling technology, validated the models, and conducted existing and possible future alternatives to evaluate:

1. The potential wave-related effects of a jetty breach.

2. Jetty length rebuilds to the north and south jetties.

3. Jetty spur performance.

4. Consequences of jetty breach (considering one breach on each the north and south jetty), for which the locations, geometry, and resulting bathymetry for two breaches were defined.

Changes in estuarine waves were investigated for each of these alternatives. Wave models were validated for mild wave conditions, and jetty alternatives were evaluated with severe storms. 
The objective of the present study was to evaluate waves associated with proposed jetty modifications and possible future jetty degradation. In coordination with NWP, CHL established Surface-water Modeling System (SMS) based numerical wave models, validated the models, and conducted simulations with existing and possible future modifications to evaluate: (a) jetty length rebuilds to the north jetty and south jetty, and (b) consequences of jetty breach (considering one breach on each the north and south jetty), for which the locations and geometry for two breaches were defined. This report describes details of evaluated modifications to each jetty by means of two wave models, BOUSS-2D and STWAVE.

The regional ADvanced CIRCulation (ADCIRC) model (Luettich et al. 1991) grid already established for the site was extended to assure full representation of wind forcing. The regional circulation model provided input to local models in the SMS (Zundel 2006) that couples models of waves and circulation (water level and current). The spectral wave model STWAVE (Smith et al. 1999, Smith 2001) was applied for transformation of deepwater waves into the MCR. The Boussinesq two-dimensional (2D) wave model BOUSS-2D was run to generate detailed information on wave transformation through breaches and as necessary in other aspects of the project.

This report documents results of the wave modeling conducted by CHL in support of the Portland District's long-range management plan for the MCR. Changes to the wave field for each jetty modification were evaluated by means of BOUSS-2D and STWAVE.

\section{Wave modeling strategy}

It was assumed that coastal spectral wave models [e.g., STWAVE (Resio 1987, 1988); SWAN (Booij et al. 1996); and WABED (Mase et al. 2005)] could describe the open-ocean wave field in the MCR estuary for a range of storm conditions. These models are appropriate for wave transformation from deep water to the nearshore. Portland District selected STWAVE for this study. It is a steady-state, finite-difference model based on the wave action balance equation. The model computes depth and current-induced refraction and shoaling, depth and steepness-induced wave breaking, wind-wave growth, and whitecapping. Spectral wave models can describe variation of the sea state as a function of time through an integration scheme. These models can include wave setup in the surf zone and 
nonlinear wave-wave interactions (Booij et al. 1999). Phase-averaged wave models are efficient and have been validated with field studies (e.g., Resio 1988, Ris et al. 1999, Smith and Smith 2001). However, they do not fully represent diffraction and reflection from surface-piercing structures.

Recent advances in Boussinesq models allow for modeling of nonlinear and weakly dispersive long and short waves over variable bathymetry, as well as wetting and drying of the coastal land. Examples of these models include MIKE21 (www.dhigroup.com), FUNWAVE (Kirby et al. 1998), BOUSS2D (Nwogu and Demirbilek 2001), and COULWAVE (Lynett and Liu 2002). BOUSS-2D was applied in the present study because it has robust algorithms for calculation of waves in inlets and harbors, and shallowwater nonlinear wave processes in the vicinity of submerged and surfacepiercing structures. The BOUSS-2D formulation provides the optimum agreement of the governing equations with the linear dispersion relation, and wave breaking is not approximated by depth limitation or wavesteepness. The dissipation is empirical. In contrast to the spectral wave models, Boussinesq models provide a wave-by-wave description of the processes in the surf and swash zones.

BOUSS-2D and STWAVE are widely used in practice. These models have been verified and validated with laboratory and field data. However, they have not yet been thoroughly examined for highly energetic conditions similar to those in the MCR. The present study is the first in applying these models to the MCR and evaluating their performance against field measurements. The reason for using two different classes of wave models at the MCR was to ensure that processes that might not be represented by one model would be captured by the other. 


\section{Wave Modeling}

In collaboration with the Portland District, CHL conducted a systematic wave modeling study to assist with project planning for the MCR entrance. Specifically, this study evaluated wave transformation in the vicinity of three MCR dredged material placement sites and modifications to the wave climate in the navigation channel resulting from jetty rehabilitation and hypothetical jetty breach situations. This report documents a comprehensive modeling effort investigating wave-related issues at different areas of MCR using two numerical wave models, BOUSS-2D and STWAVE. Results provide a relative comparison of jetty modifications at MCR with an emphasis on changes to waves near jetties and in the navigation channel.

\section{Description of wave modeling area}

The MCR area considered for wave modeling study is shown in Figure 1. Two rubble-mound jetties, constructed between 1895 and 1917, protect the entrance channel. The north jetty is relatively short compared with the south jetty. Original lengths of the north and south jetties were $4 \mathrm{~km}$ and $9.6 \mathrm{~km}$, respectively. The distance between seaward ends of the two jetties is approximately $3 \mathrm{~km}$. Since the initial construction, both jetties have deteriorated and have been repaired numerous times. The original seaward end segments of the jetties are now mostly disintegrated and below mean sea level (msl). Presently, the north jetty length is approximately $2.9 \mathrm{~km}$ long, and the south jetty is $8.2 \mathrm{~km}$ long.

The approach channel outside the MCR is approximately $5 \mathrm{~km}$ long and $800 \mathrm{~m}$ wide, and the channel depth varies between 17 and $22 \mathrm{~m}$. The channel is oriented southwest over the entrance bar and is exposed to all incident waves reaching the MCR. The approach channel connects with the main navigation channel approximately $1.6 \mathrm{~km}$ northwest from the submerged tip of south jetty (Figure 1). The main channel in the Columbia River is $200 \mathrm{~m}$ wide and $13 \mathrm{~m}$ deep.

Maintenance of the navigation channel at the authorized depth at the MCR requires annual dredging of 3 to 4 million $\mathrm{cu} \mathrm{m}$ of fine to medium sand. The dredged material has been placed in both offshore and nearshore sites 
since the dredging began in 1904. At present, the Deep Water Site (DWS) and Shallow Water Site (SWS) are the primary dredged material disposal sites (Figure 1).

The dredged material disposal sites may influence current and wave fields outside the MCR, and large waves and strong currents can potentially disperse some of the dredged material at the DWS and SWS. The SWS reduces operation and maintenance cost because of its closer proximity to the channel, keeps sediment in the littoral system, and potentially reduces damage to the north jetty. The SWS has two competing objectives (Moritz et al. 2003): maximize use of the site to retain as much dredged material as possible in the littoral system, and minimize the hazardous wave climate at the entrance channel by dissipating wave energy. Besides the DWS and SWS, a South Jetty Research Site (SJRS) is being considered as an area for future dredged material disposal.

The DWS is located roughly $13.5 \mathrm{~km}$ offshore west-southwest of the MCR between 60 and $90 \mathrm{~m}$ depth contours. The SWS is approximately $1.5 \mathrm{~km}$ west-southwest of the north jetty in 15 to $20 \mathrm{~m}$ depths (Figure 1). Both sites are expected to accommodate sand dredged from the navigation channel, and the SWS is concurrently intended to serve as a sand source ("feeder") to beaches north and south of the MCR.

Preliminary numerical wave model test results showed that dredged material placement mounds, jetty restoration, and breach of the jetties may cause significant changes to waves in the vicinity of these features. Wave refraction, shoaling, and breaking at the dredged material disposal areas and jetties could affect the sediment budget for the navigation channel and nearby beaches. The wave model domains in the present study include these distinguishing bathymetric features (submerged disposal mounds and jetties) that are expected to substantially modify local waves.

\section{Wave and water level data}

Deepwater wind and wave information for this wave modeling study was obtained from data available from the National Oceanic and Atmospheric Administration (NOAA) Buoy $46029\left(46^{\circ} 7^{\prime} \mathrm{N}, 124^{\circ} 30.6^{\prime} \mathrm{W}\right)$. This buoy has been in operation since 1984, providing valuable historical wind wave data 
for the MCR project. Buoy 46029 is $37 \mathrm{~km}$ offshore in $128 \mathrm{~m}$ water depth (http://www.ndbc.noaa.gov).

Local wave data were collected between the north and south jetties at the MCR by the Portland District in a field data collection program conducted in August-September 2005. The field data collection also included water level, salinity, and current profile measurements, referred to henceforth as the mega-transect data (Moritz 2005). Five bottom-mounted Acoustic Doppler Profilers and Velocimeters were placed across the entrance channel. Figure 2 shows the location and layout of these instruments. Table 1 lists the coordinates and nominal depth of the mega-transect stations.

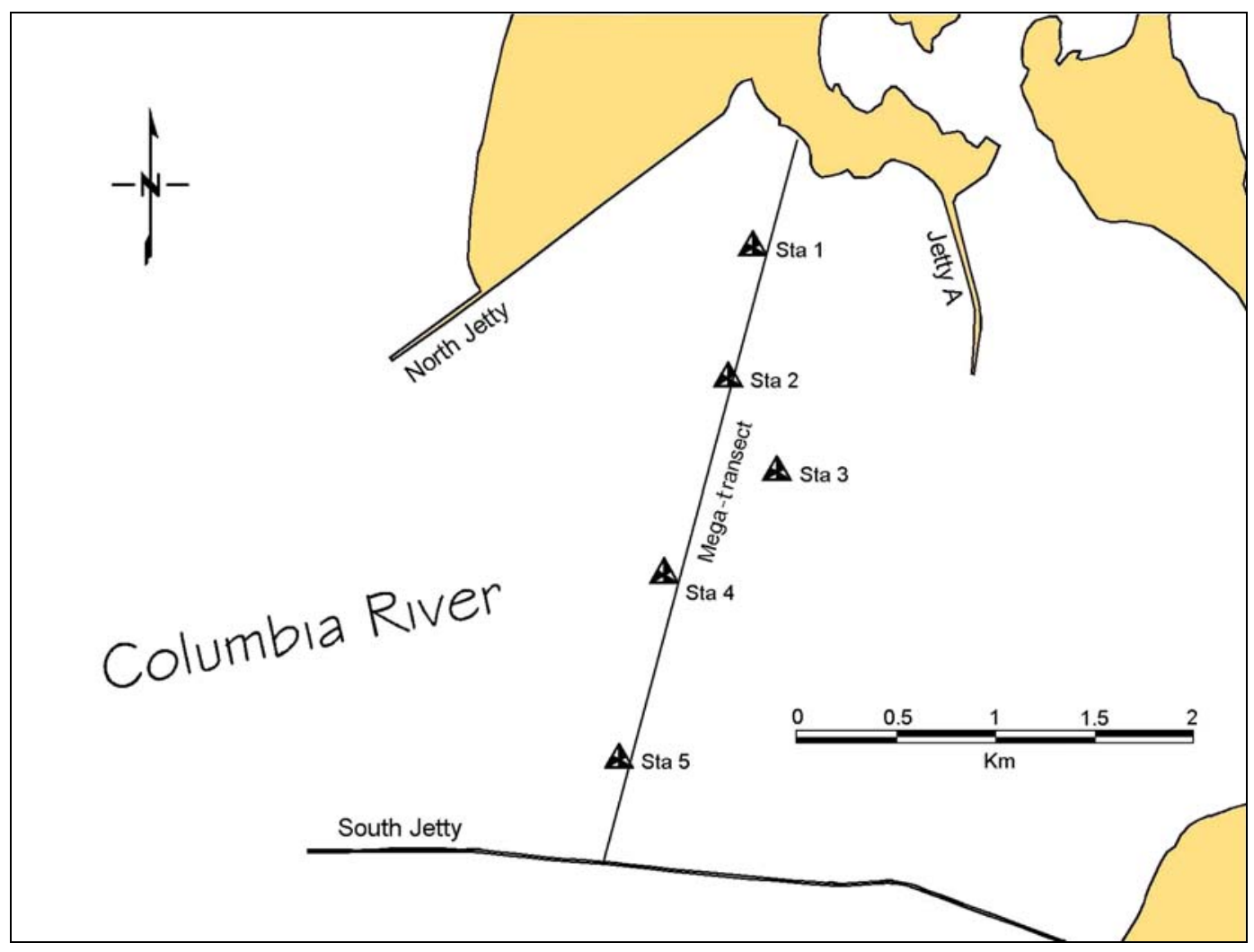

Figure 2. Location and layout of mega-transect stations at MCR.

Table 1. Coordinates and depth of mega-transect stations at MCR for measurement performed in August-September 2005.

\begin{tabular}{|l|l|c|}
\hline Station & Coordinates & Nominal Depth, m \\
\hline 1 & $46^{\circ} 16^{\prime} 16^{\prime \prime} \mathrm{N}, 124^{\circ} 03^{\prime} 23^{\prime \prime} \mathrm{W}$ & 9.7 \\
\hline 2 & $46^{\circ} 15^{\prime} 47^{\prime \prime} \mathrm{N}, 124^{\circ} 03^{\prime} 29^{\prime \prime} \mathrm{W}$ & 12.9 \\
\hline 3 & $46^{\circ} 15^{\prime} 27^{\prime \prime} \mathrm{N}, 124^{\circ} 03^{\prime} 13^{\prime \prime} \mathrm{W}$ & 21.7 \\
\hline 4 & $46^{\circ} 15^{\prime} 04^{\prime \prime} \mathrm{N}, 124^{\circ} 03^{\prime} 46^{\prime \prime} \mathrm{W}$ & 14.2 \\
\hline 5 & $46^{\circ} 14^{\prime} 24^{\prime \prime} \mathrm{N}, 124^{\circ} 03^{\prime} 58^{\prime \prime} \mathrm{W}$ & 10.4 \\
\hline
\end{tabular}


The tide along this portion of west coast of the United States is mixed semidiurnal, with a period of approximately one-half tidal day (12.24 hr). The NOAA National Ocean Service (NOS) maintains seven active tidal stations in the MCR estuary (Figure 3). The National Data Buoy Center (NDBC) and the Coastal Data Information Program (CDIP) buoy stations are also shown. The mean tide range, difference between mean high water and mean low water, calculated from the record at Astoria, OR (sta 9439040), is $2.1 \mathrm{~m}$. River flow stations maintained by the U.S. Geological Survey (USGS) at the MCR are also shown in Figure 3. Figure 4 shows sample water level data collected at two NOS stations, 9439040 and 9440569, at Skamokawa, WA, during August-September 2005, relative to mean tide level (mtl).

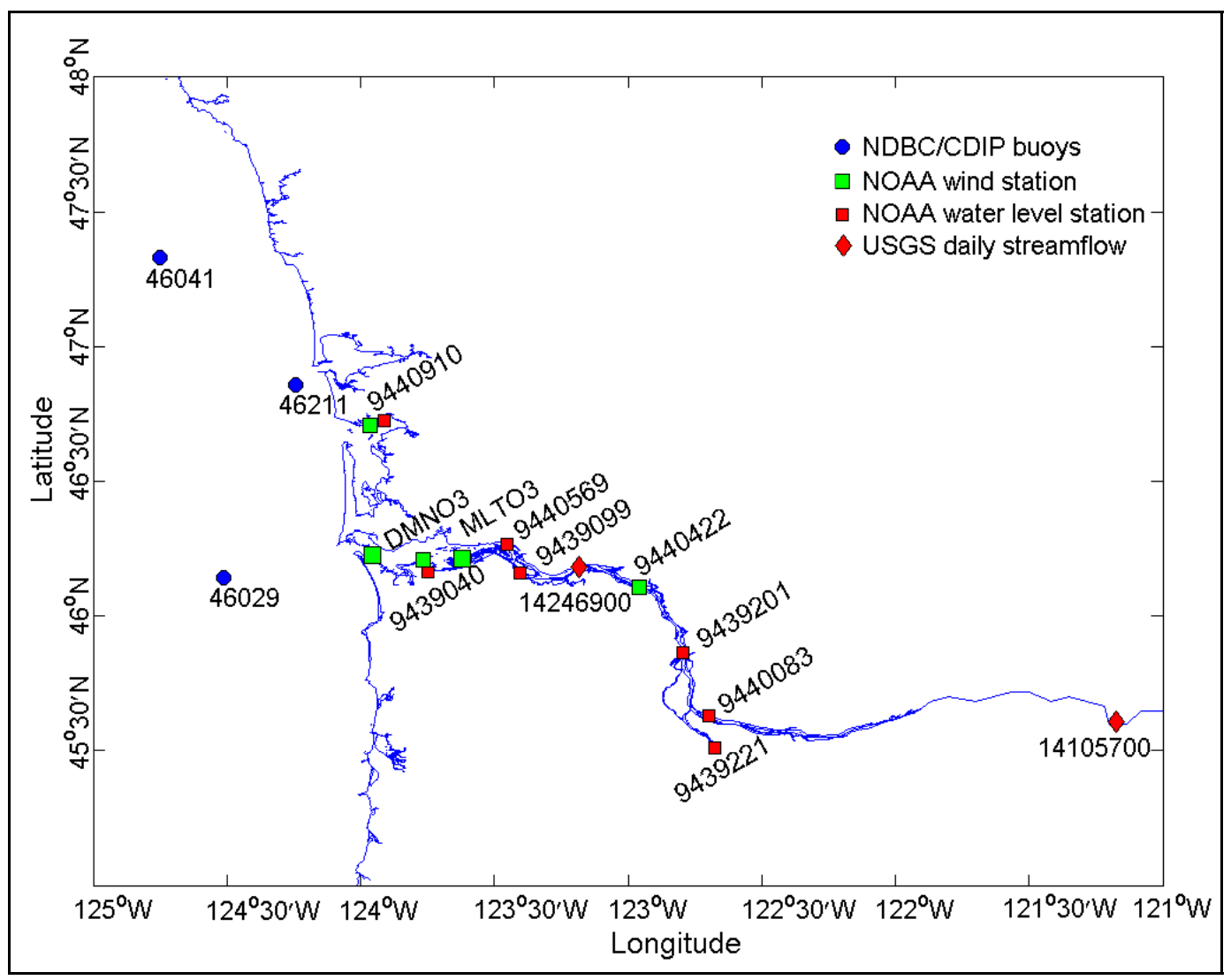

Figure 3. Location of NOAA and USGS stations. 


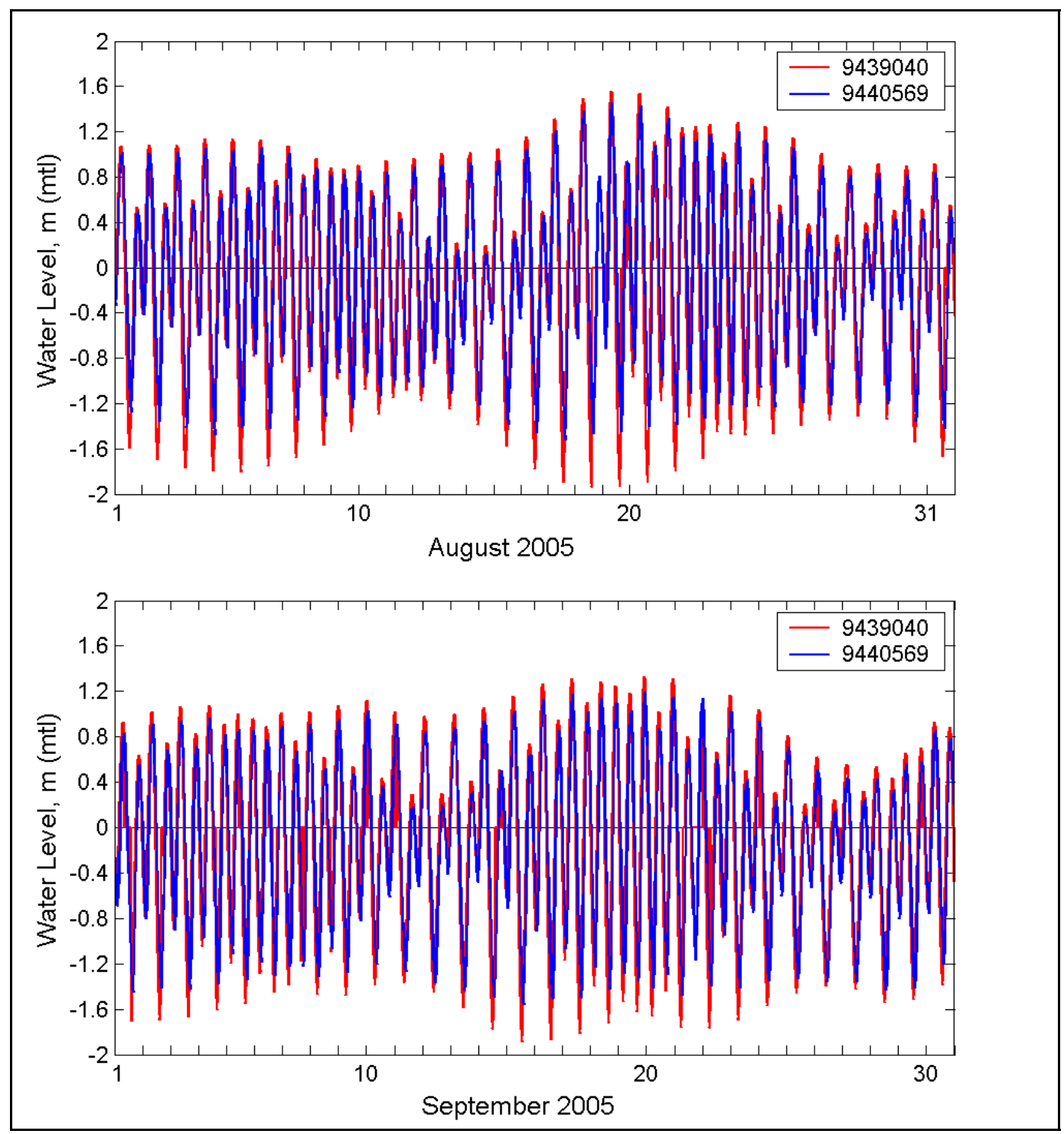

Figure 4. Measured water levels at NOAA stations 9439040 and 9440569.

Strong winds along the Washington and Oregon coasts often dominate water level response in the shallow areas of the MCR estuary and in the river mouth. Seasonal river flows are significant during times of heavy rain, altering water levels and currents throughout the estuary. Water levels and background (tidal) currents at the MCR can play an important role in the overall dynamics of this estuary because these can modify waves arriving at the mouth of the river and moving up through the estuary. These effects have been taken into account in the model validation discussed in this report. 


\section{Wave modeling approach}

The wave modeling task at the MCR consisted of two components:

(a) wave transformation from deep to shallow water, and (b) local wave simulations around jetties and through the navigation channel. One of the objectives of the wave transformation component was to evaluate STWAVE with field data collected at mega-transect stations. The primary objective of the deep to shallow water wave transformation was to develop reliable wave information for more refined local nearshore wave simulations at the MCR. The local wave simulations were performed with BOUSS-2D. The Portland District selected BOUSS-2D and STWAVE models for this study. The input wind and directional wave information to STWAVE were based on the data collected from the offshore Buoy 46029. Input to BOUSS-2D was based on the wave parameters calculated from STWAVE simulations at the deepwater boundary of the Boussinesq model.

STWAVE (Smith et al. 1999, Smith 2001) is a half-plane, 2D (horizontal) model that solves the steady-state conservation of phase-averaged spectral energy. It simulates depth-induced wave refraction and shoaling, currentinduced refraction and shoaling, depth- and steepness-induced wave breaking, diffraction, wave growth because of wind input, and wave-wave interaction and white capping that redistribute and dissipate energy in a growing wave field. STWAVE is computationally robust and suitable for wave transformation from the deep or intermediate depth to shallow water. Wave diffraction is simulated in a simple manner by smoothing of wave energy surrounding structures.

STWAVE is a finite-difference model formulated on a Cartesian grid. Variable grid resolution can be obtained by nesting model runs. Nesting is accomplished by running the model at a coarse resolution and saving a spectrum at the nearshore location as the input boundary condition to the finer resolution grid. Both coarse and fine grids need to have the same orientation. For the half-plane version of STWAVE applied in this study, wave energy is linearly transformed from offshore toward the coastline in a -90 to 90 deg sector of the primary incident wave direction in deep water. The grid needs to be oriented within a +45 to -45 deg sector of the incident mean wave direction.

For this study, STWAVE grids are oriented in a west-to-east direction because majority incident waves are from the south-west to north-west 
sector. A coarse grid, covering $700 \mathrm{~km}^{2}$, with $50-\mathrm{m}$ cell sizes is applied in the model validation. A fine grid, covering $572 \mathrm{~km}^{2}$, with $20-\mathrm{m}$ cell sizes is applied in the simulation of jetty alternatives. Wave reflection from the shoreline or from steep bottom features traveling in a direction outside the half plane is neglected. Wave reflection off a structure is also neglected.

The incident wave spectrum to STWAVE is required at the offshore boundary of model grid. Wind input is an optional input for wave growth. The nonlinear wave-wave interaction is approximated by an empirical formulation and is only triggered under wind-wave generation. The primary output parameters from STWAVE are significant wave height $\mathrm{H}_{\mathrm{S}}$, equal to four times the square root of total wave energy density, peak period $\mathrm{T} p$, and mean direction $\theta_{\mathrm{m}}$. The calculated directional wave spectrum, radiation stresses, and wave breaking index information may also be output.

The second component of wave modeling at the MCR consisted of modeling local nearshore waves around the jetties and navigation channel. For this purpose, BOUSS-2D was used for calculating pertinent wave processes. BOUSS-2D is a phase-resolving, half-plane model and is appropriate for simulating nonlinear wave propagation in the nearshore in the time domain (Nwogu and Demirbilek 2001; Demirbilek et al. 2005a, 2005b; Demirbilek et al. 2007a, 2007b). It is based on the 2D Boussinesq equations implemented in a finite-difference solution scheme. The model can simulate shallow-water wave processes including (a) nonlinear wavewave and wave-structure interactions, and (b) wave-induced water level and wave-induced current. Wind input is not included in BOUSS-2D.

As a time-dependent wave model, BOUSS-2D solves the continuity and two horizontal momentum equations in a 2D (horizontal) space. Incident wave conditions may be specified either as parameters (significant wave height, peak period, and peak wave direction) or 2D spectra (energy density in frequency and direction spaces). Input to BOUSS-2D is specified by a wave maker, which is generally positioned near the offshore boundary of the numerical grid. Regular or irregular waves can be simulated either as unidirectional or multi-directional sea states. The input peak wave direction is assumed to be normal to the wave maker. In modeling oblique waves, the numerical grid needs to be oriented appropriately such that oblique incident waves are nearly perpendicular to the seaward boundary (e.g., grids B and C in Figure 5 shown on page 14). 
Output from BOUSS-2D consists of time histories of the sea surface elevation, water particle velocity, and mean current fields. These primary output variables may be processed to produce any other derived quantities of engineering interest such as wave spectra, pressure force, and runup. At any point in space and time, some wave parameters may be extracted from the saved time histories, and others may be derived from the postprocessed wave height and direction, mean current, and spectrum.

Adequate resolution of the BOUSS-2D computational grids ensures numerical convergence and stable solutions. In this study, model grid cell sizes range from 8 to $20 \mathrm{~m}$, and results presented in this report are with 10-m cell sizes. In the case of jetty breaches, this resolution was necessary to accurately model waves through and around the breached area. The run time for a 30-min typical BOUSS-2D simulation (a record consisting of 300 waves for a 10 -sec peak period) at the MCR varied between 4 to $40 \mathrm{hr}$ on desktop PCs for grids covering modeling areas of approximately 10 to $100 \mathrm{~km}^{2}$, respectively. Additional information about BOUSS-2D and STWAVE is available in Smith et al. (1999), Smith (2001), and Nwogu and Demirbilek (2001). 


\section{Validation of Wave Models}

Several wave model grids covering different domains and cell sizes were developed for the project's requirements (i.e., project alternatives, configurations, and wave processes of interest). The grid bathymetry in the offshore and surrounding area of the MCR was based on the surveys conducted and database compiled by the Portland District. This includes three bathymetry data sets from 2000, 2005, and 2006 surveys covering DWS, SWS, SJRS, and the entrance navigation channel area. The state plane coordinate system and vertical datum are North American Datum of 1927 (NAD27) and National Geodetic Vertical Datum of 1929 (NGVD29), respectively.

Two rectangular grids of different resolution were developed for validation of STWAVE. The coarse grid, extending from the 128-m depth to the entrance area of MCR, had a 50-m cell size. The coarse grid is offset significantly to the north for simulation of incident waves from the northwest. Buoy 46029 wave measurements were input to the coarse grid, covering a modeling domain of approximately $35 \mathrm{~km}$ cross-shore and $20 \mathrm{~km}$ along shore. The coarse grid was used in model validation and for wave transformation from the deepwater buoy to the intermediate water. The fine grid, starting offshore from the 100-m-depth contour to the back isle area of the MCR, had a 20-m cell size. It covers an area of approximately 26 by $22 \mathrm{~km}$ area. Figure 5 shows the coarse and fine grids used in the STWAVE model.

Two BOUSS-2D grids were developed for the validation of local nearshore wave simulations. These grids were rotated so that the seaward boundary of each grid was approximately normal to the incident waves to be simulated. This ensured consistency for proper usage of STWAVE input and comparing model results with STWAVE at the mega-transect locations. Both grids consisted of 10-m square cells and covered an area of approximately 12 by $15 \mathrm{~km}$ (Figure 5). The first grid (marked as B in Figure 5) was designed for incident waves approaching from the northwest (NW) and the second grid ( $\mathrm{C}$ in Figure 5) for incident waves from west-northwest (WNW) direction. 


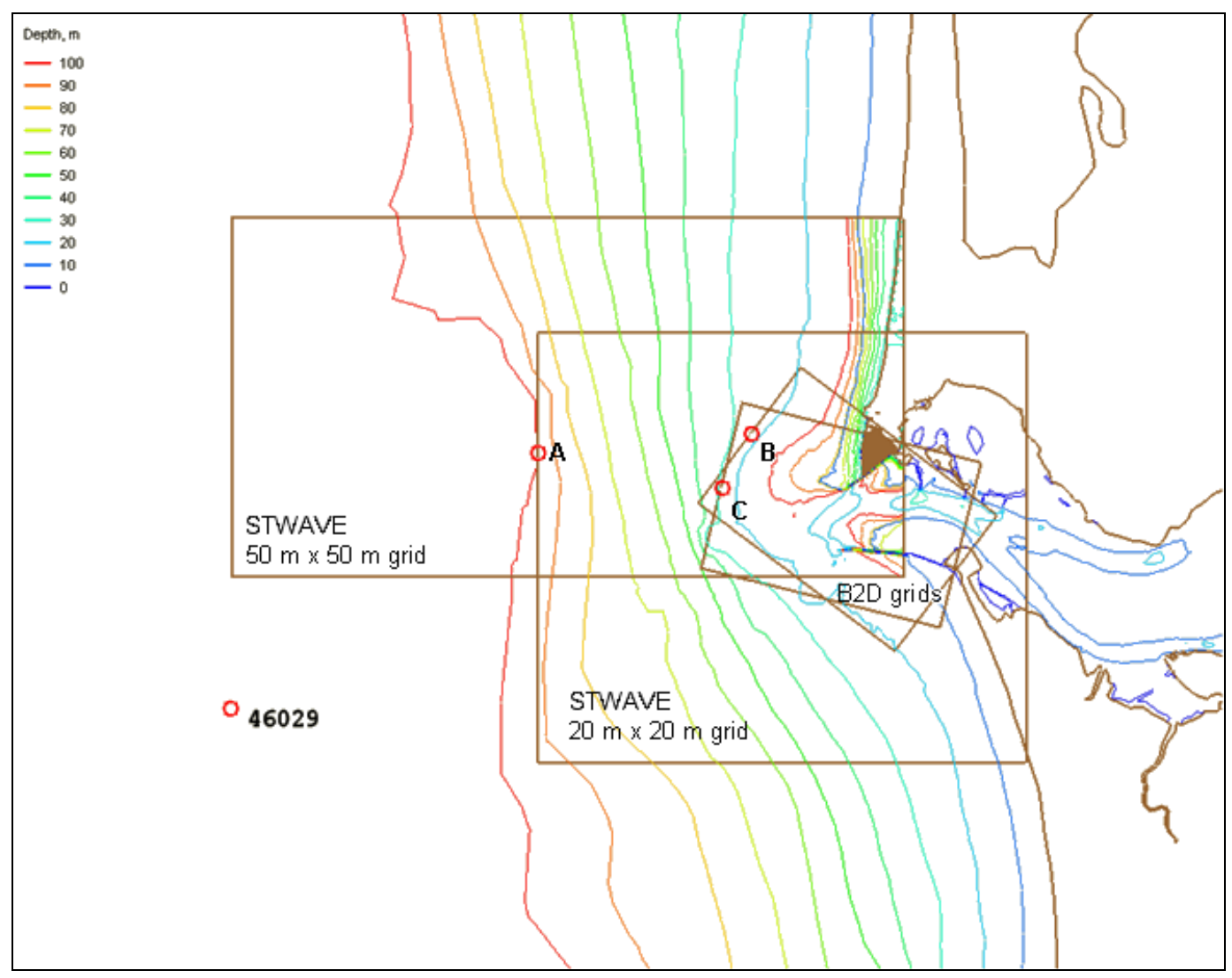

Figure 5. Computational grids for BOUSS-2D and STWAVE models.

The grids described above, used only in the model validation, were designed for modeling the three largest waves from the northwest that occurred during the measurement period. For this reason, the STWAVE coarse grid was offset to the north, and the two BOUSS-2D grids were orientated in the northwest to southeast direction (Figure 5) to best represent the mega-transect area where field measurements were made. The two STWAVE grids were used for all wave directions from the west half plane.

\section{Validation data}

BOUSS-2D and STWAVE have been widely applied in practice and validated with laboratory and field data. Therefore, the validation of the two numerical wave models was performed for only three large wave conditions (Table 2) during slack tide (weak tidal current) measured during the mega-transect data collection period. The first condition occurred at 10:00 Greenwich Mean Time (GMT) on 7 August 2005, the second condition at 00:00 GMT on 30 August 2005, and the third condition at 18:00 GMT on 9 September 2005. 
Table 2. Three wave conditions (Buoy 46029) selected for validation of wave models.

\begin{tabular}{|l|l|l|l|l|l|l|}
\hline $\begin{array}{l}\text { Wave } \\
\text { Condition }\end{array}$ & $\begin{array}{l}\text { Date/Time } \\
\text { GMT }\end{array}$ & $\begin{array}{l}\text { Wind Speed } \\
\mathrm{m} / \mathrm{sec}\end{array}$ & $\begin{array}{l}\text { Wind } \\
\text { Direction } \\
\text { deg }^{1}\end{array}$ & $\begin{array}{l}\text { Wave } \\
\text { Height } \\
\mathrm{m}\end{array}$ & $\begin{array}{l}\text { Wave } \\
\text { Period } \\
\text { sec }\end{array}$ & $\begin{array}{l}\text { Wave } \\
\text { Direction } \\
\text { deg }^{1}\end{array}$ \\
\hline 1 & $\begin{array}{l}7 \text { Aug 05 } \\
10: 00\end{array}$ & 7.7 & 344 & 2 & 8.3 & 299 \\
\hline 2 & $\begin{array}{l}30 \text { Aug 05 } \\
\text { 00:00 }\end{array}$ & 3.3 & 235 & 2.2 & 11.1 & 284 \\
\hline 3 & $\begin{array}{l}9 \text { Sep 05 } \\
18: 00\end{array}$ & 7.6 & 311 & 4 & 10 & 307 \\
\hline 1
\end{tabular}

It was desirable to consider slack tide to avoid model differences in calculating wave-current interaction at varying water level. Water level and current were set to mtl and zero, respectively, in model validation.

Figure 6 shows sample time series of wind and wave data collected at Buoy 46029 and data at mega-transect sta 4 and 5 . The variation (increase or decrease) in wave heights due to the tidal current at mega-transect sta 4 and 5 are clearly seen in the data when compared to the offshore buoy wave heights. The wave forcing at the model grid seaward boundary is based on the directional spectrum measured from Buoy 46029. The wind forcing to the model is the buoy wind, adjusted to a 10-m elevation, based on the 1/7-th power law wind profile as described in the Coastal Engineering Manual (Headquarters, U.S. Army Corps of Engineers (HQUSACE) 2002).

The selection of the three large wave conditions for validation of the models (Table 2) was based on analysis of the measured wave, water level, and tidal current from the mega-transect field data. Although the goal in the validation was to analyze the highest possible observed waves during the measurement period, it was necessary to select waves at the weakest current state (i.e., slack tide) to eliminate complicated effects of wavecurrent interaction on the wave prediction by the models. The choice of slack tide reduces the number of forcing parameters on the waves. The determination of slack tide was made by running the ADCIRC model (Luettich et al. 1991) and comparing calculated water levels and currents to the measurements. This comparison allowed identification of the time of the slack tide at the mega-transect site. 


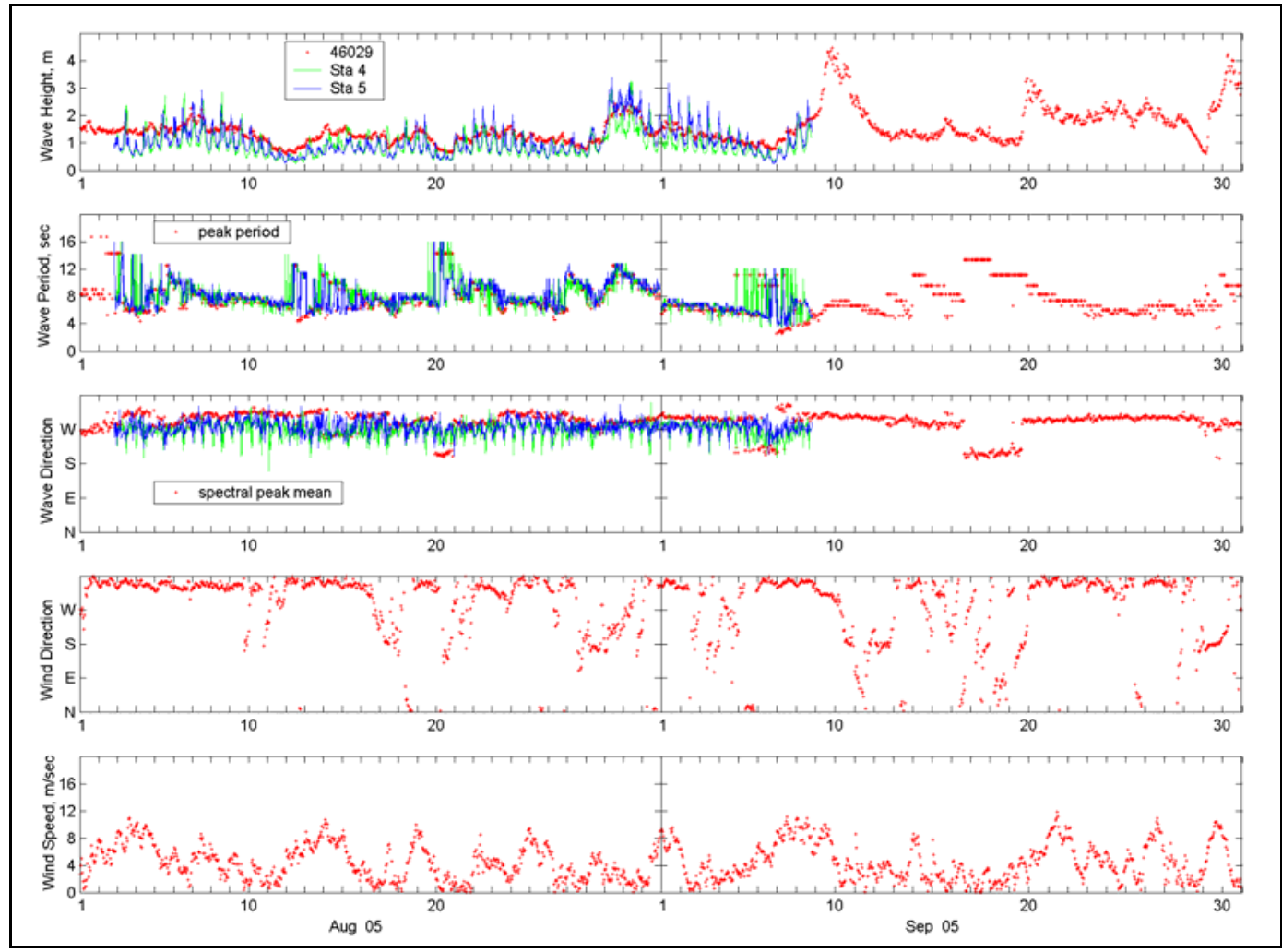

Figure 6. Wind and wave data collected at Buoy 46029 and mega-transect sta 4 and 5 during August-September 2005.

Figures 7 to 9 show snapshots of calculated current fields corresponding to three simulated wave conditions (Table 2). The magnitude of the current corresponding to these three wave conditions is small (less than $0.35 \mathrm{~m} / \mathrm{sec}$ ) at the mega-transect stations if compared to the average normal tide current magnitude, approximately $2 \mathrm{~m} / \mathrm{sec}$, occurring between the MCR jetties. This weak current was the main reason for not considering wave-current interaction in the wave model validation. BOUSS-2D and STWAVE simulations were performed without wave-current interaction as requested by Portland District. 


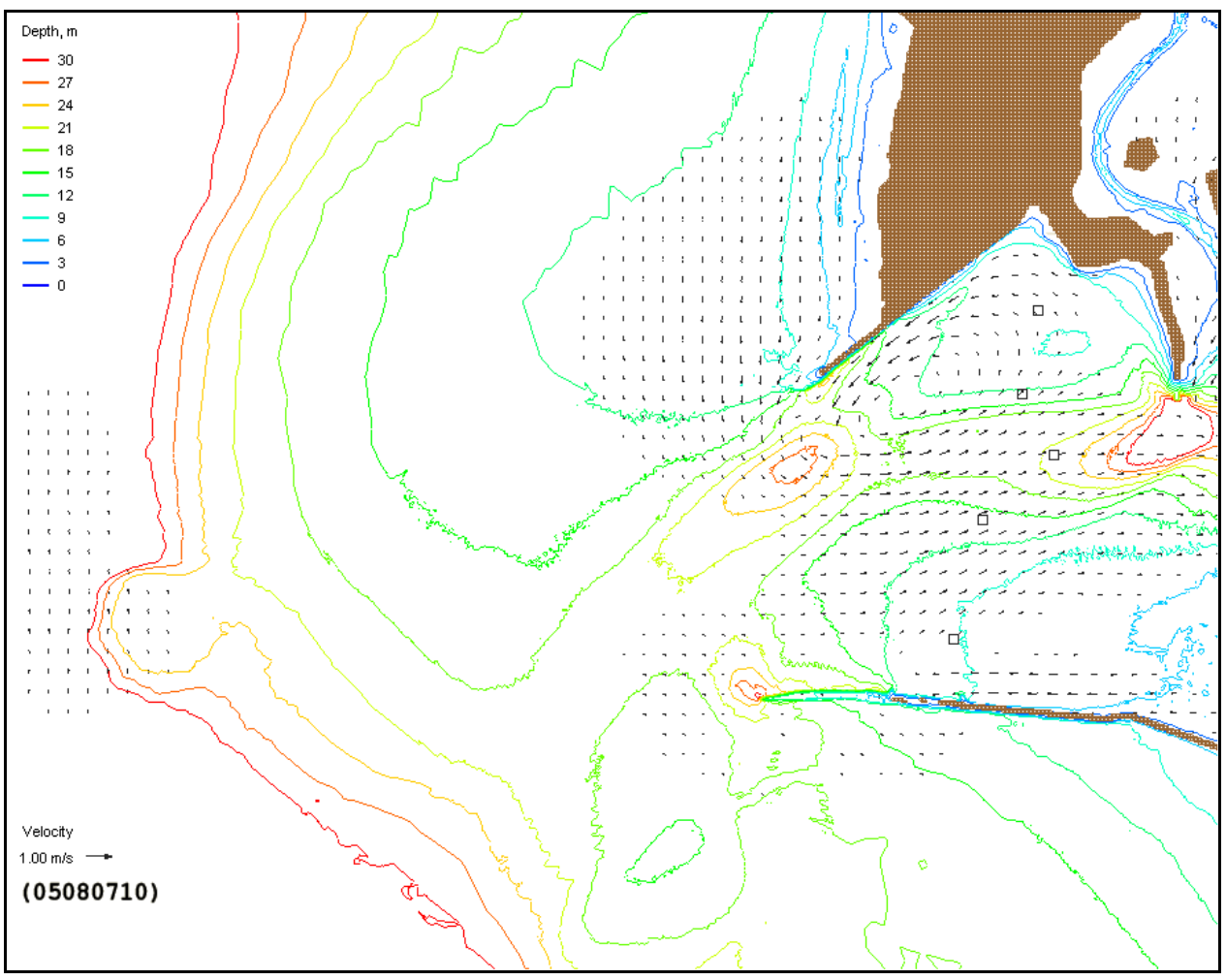

Figure 7. Calculated current field for wave condition at 10:00 GMT on 7 August 2005.

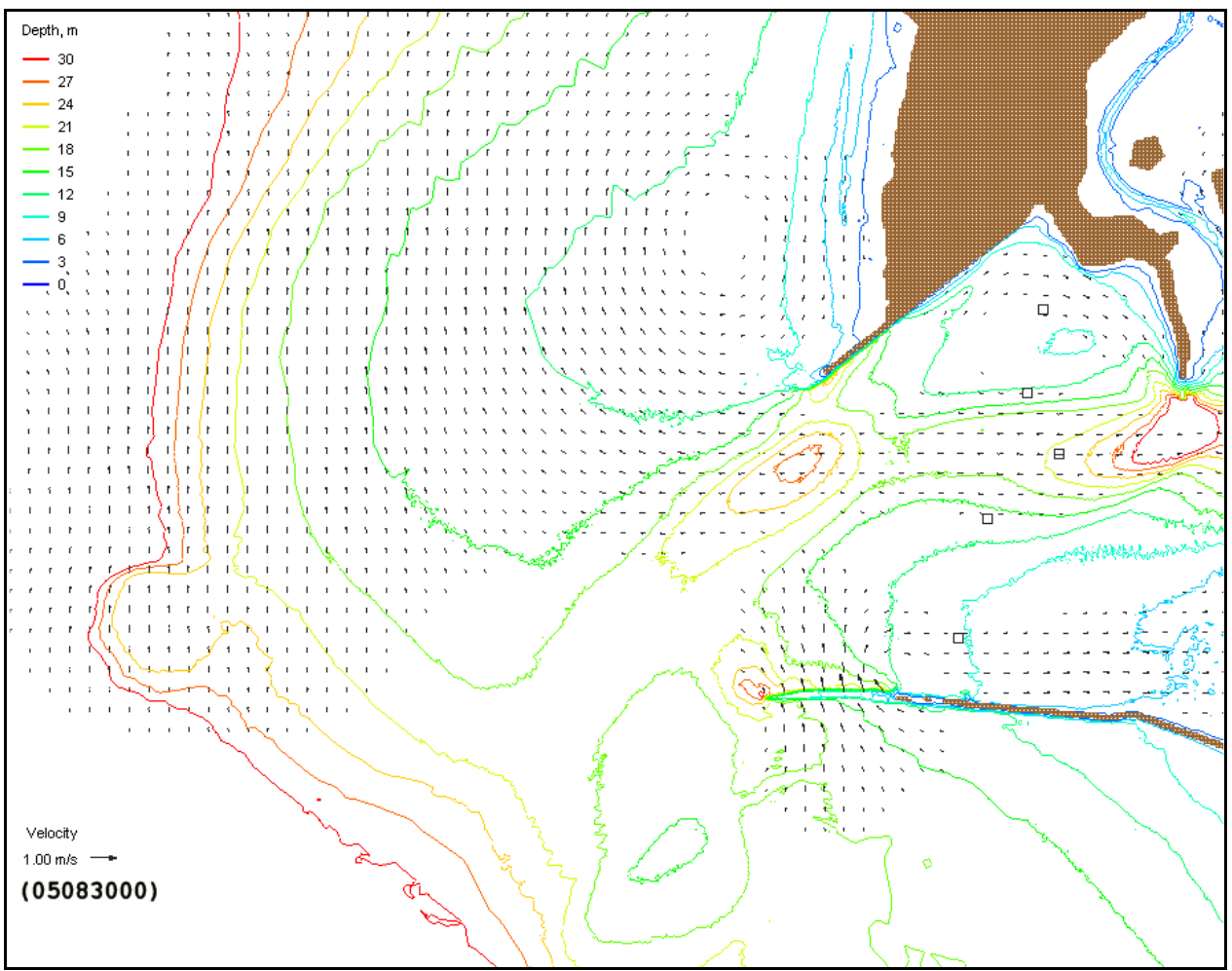

Figure 8. Calculated current field for wave condition at 00:00 GMT on 30 August 2005. 


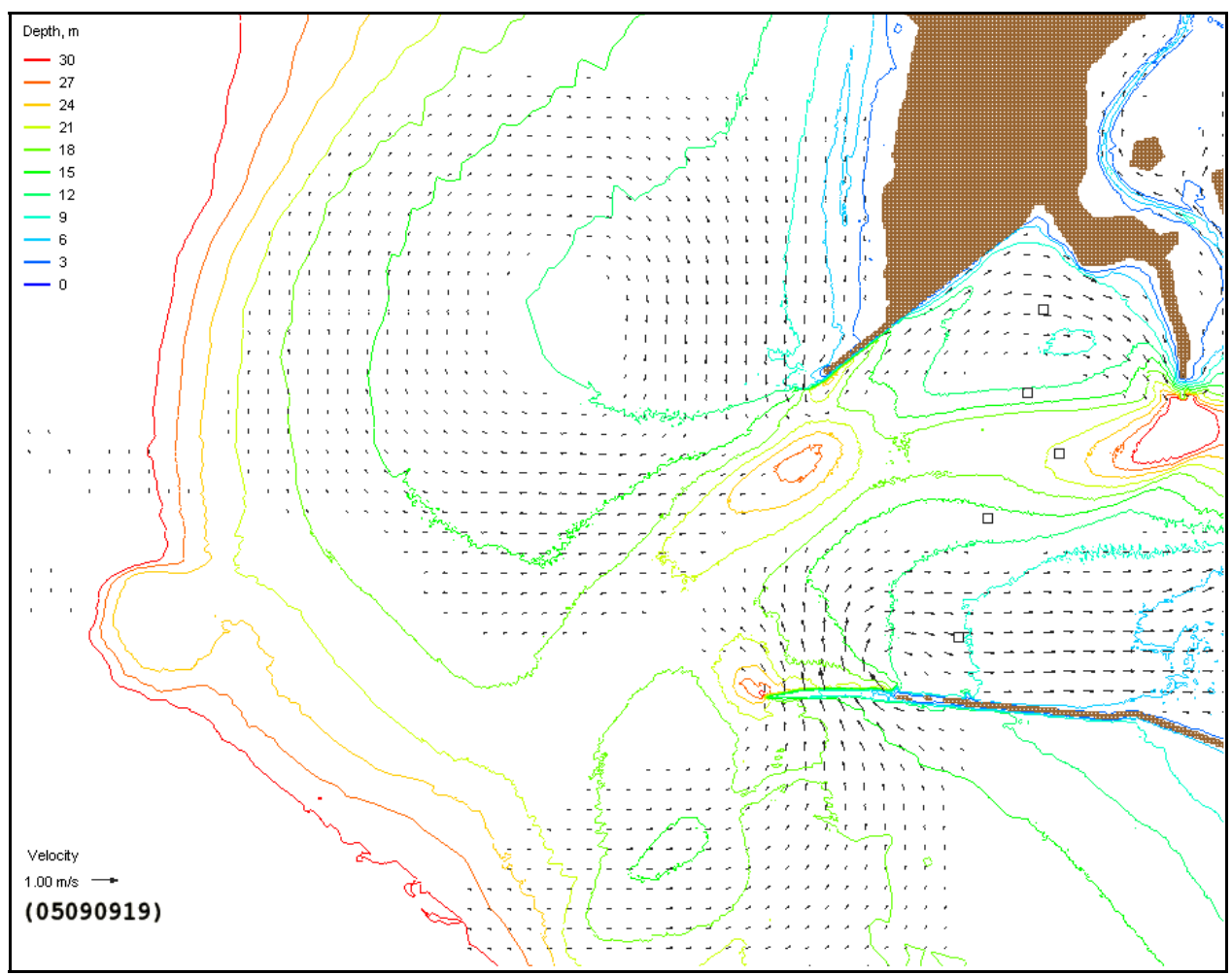

Figure 9. Calculated current field at 18:00 GMT on 9 September 2005.

For the wave condition of 10:00 GMT on 7 August 2005, the wave parameters (considering waves in a shoreward half-plane) measured at Buoy 46029 were $2.0 \mathrm{~m}$ (significant wave height), $8.3 \mathrm{sec}$ (spectral peak period), and 300 deg WNW spectral mean direction. It had a moderate steady wind speed of $7.7 \mathrm{~m} / \mathrm{sec}$ blowing from 344 deg north-northwest (NNW). For the condition of oo:00 GMT on 30 August 2005, the wave parameters reported at the buoy were $2.2 \mathrm{~m}, 11.1 \mathrm{sec}$, and $284 \mathrm{deg} \mathrm{WNW}$. A weak wind of $3.3 \mathrm{~m} / \mathrm{sec}$ from $235 \mathrm{deg}$ southwest (SW) was observed at the buoy. For the condition of 18:00 GMT on 9 September 2005, the buoyreported wave parameters were $4.0 \mathrm{~m}, 10 \mathrm{sec}$, and $307 \mathrm{deg}$ NW. The corresponding buoy wind was $7.6 \mathrm{~m} / \mathrm{sec}$ and $311 \mathrm{deg}$ NW.

\section{STWAVE validation}

In STWAVE simulations, the incident wave input at the coarse grid seaward boundary was the directional spectrum measured from Buoy 46029 at $128-\mathrm{m}$ depth. The wave input to the fine grid was the directional spectra transformed from the buoy to the seaward boundary of the fine grid, located at 100-m contour. This transformation assumed shore-parallel depth contours and used linear wave theory with source terms (wind input 
and wave breaking). The wave input spectrum to the fine grid boundary could also be obtained from the spectra calculated by the coarse grid simulations. The direct spectral transformation from buoy to the fine grid seaward boundary was computationally efficient, and the difference between direct spectral transformation and the coarse grid simulation (STWAVE) spectrum at sta A (Figure 5) was negligible. Therefore, this approach was adopted in the generation of incident wave spectra for the fine grid simulations.

Figure 10 shows sample directional spectra transformed from Buoy 46029 (128-m contour) to the STWAVE fine grid seaward boundary (100-m contour) for the wave condition of 18:00 GMT on 9 September 2005. The wind is not included in the spectral transformation calculation. Figure 11 shows STWAVE-calculated spectra for this condition at sta A (Figure 5) from the coarse grid simulations made with and without wind input. The difference among spectra measured at the buoy location and that calculated at the fine grid seaward boundary (sta A, Figure 5) was negligible regardless of whether the wind was represented or not, and wave height and peak period did not change.

Validation of STWAVE was performed by comparing the calculated spectra and three wave parameters (significant height, spectral peak period, and mean wave direction) to wave measurements at the megatransect stations. Both near-bed measured pressure $\mathrm{p}$ and horizontal velocity components $\mathrm{u}$ and $\mathrm{v}$ were analyzed to reconstruct the directional spectra at each mega-transect station. The wave height and peak direction $\theta_{\mathrm{p}}$ determined from these calculated spectra of measurements were used in the model validation study. For completeness and future reference, values of the analyzed wave height and direction are listed in Table 3 with corresponding wave model estimates. 


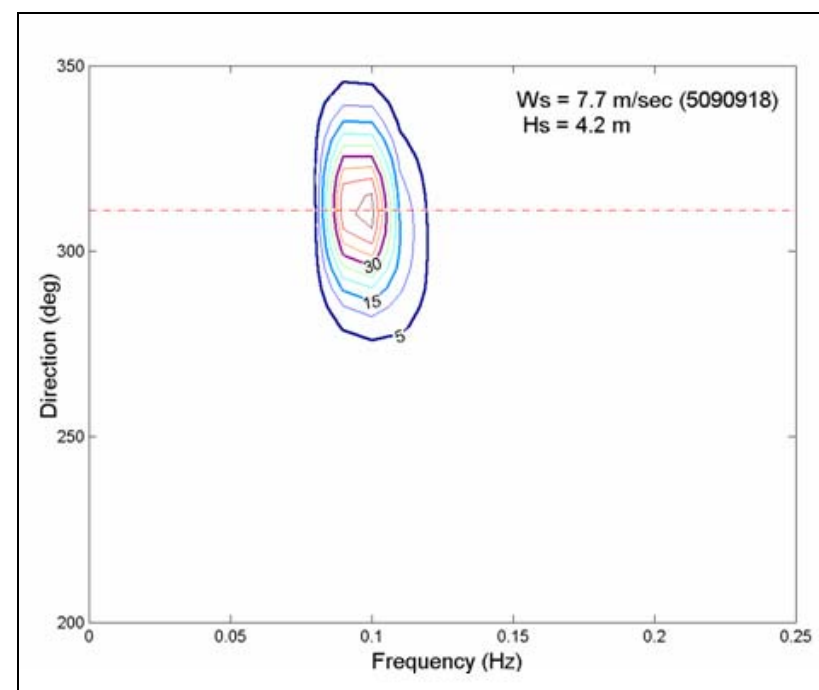

(a) Buoy spectrum

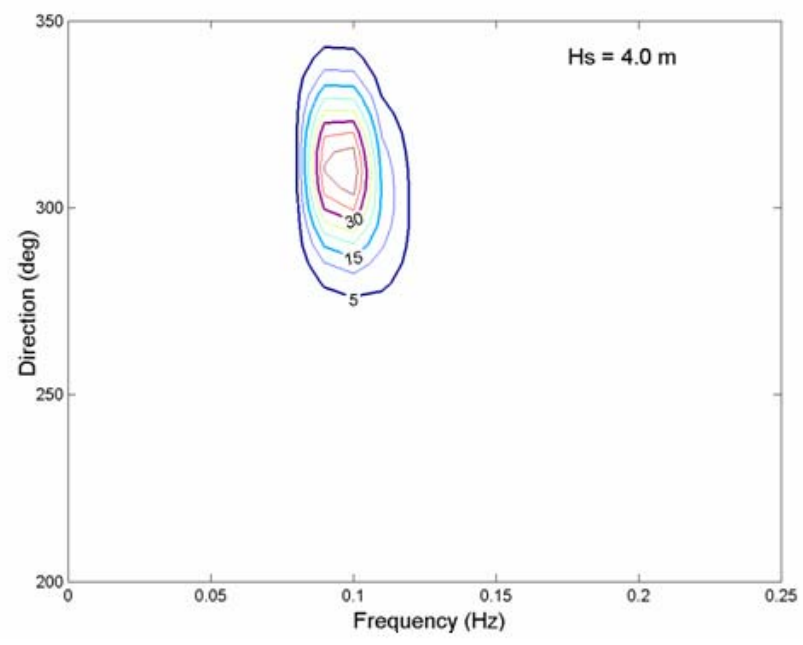

(b) Model seaward boundary spectrum

Figure 10. (a) Buoy spectrum and (b) transformed spectrum at sta A in Figure 5 for wave condition at 18:00 GMT on 9 September 2005.

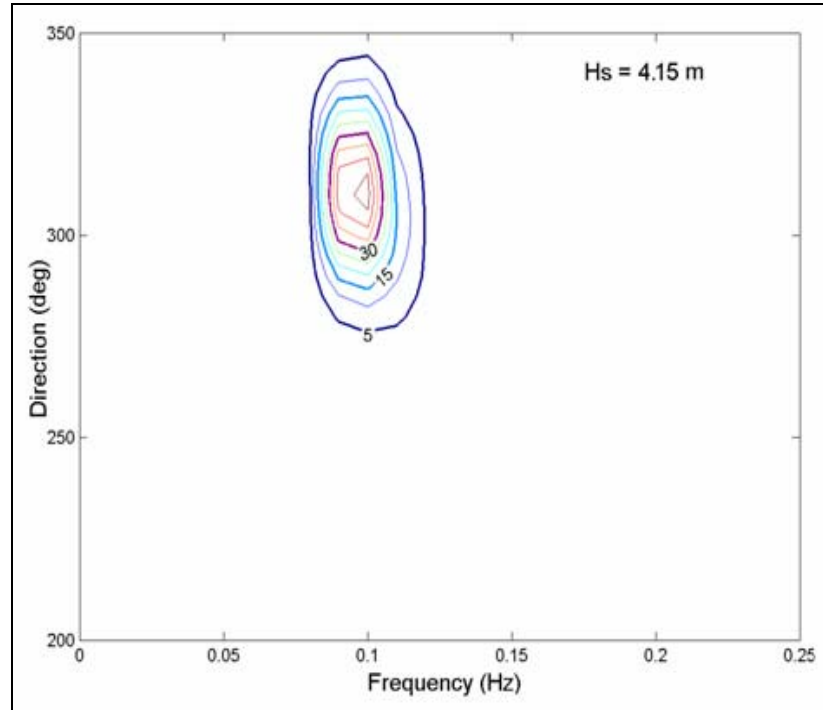

(a) Without wind input

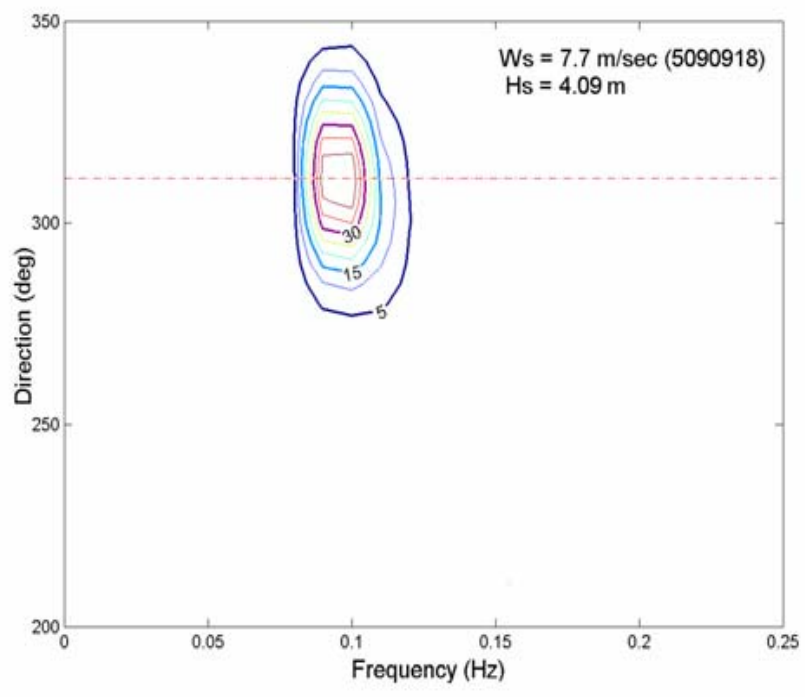

(b) With wind input

Figure 11. STWAVE calculated spectra at sta A in Figure 5 for wave condition at 18:00 GMT on 9 September 2005 (a) without wind and (b) with wind input. 
Table 3. Comparison of calculated significant wave height $(m)$ and spectral peak direction (deg) and data.

\begin{tabular}{|c|c|c|c|c|c|c|}
\hline \multirow[b]{2}{*}{ Station } & \multicolumn{2}{|c|}{ STWAVE Coarse Grid } & \multicolumn{2}{|c|}{ STWAVE Fine Grid } & \multirow[b]{2}{*}{ BOUSS-2D } & \multirow[b]{2}{*}{ Data } \\
\hline & Wind & No Wind & Wind & No Wind & & \\
\hline \multicolumn{7}{|c|}{ Wave Condition 1} \\
\hline 1 & $\begin{array}{l}0.77 \\
(246)\end{array}$ & $\begin{array}{l}0.82 \\
(245)\end{array}$ & \begin{tabular}{|l|}
0.88 \\
$(240)$
\end{tabular} & $\begin{array}{l}0.91 \\
(240)\end{array}$ & $\begin{array}{l}0.70 \\
(243)\end{array}$ & $\begin{array}{l}0.85 \\
(240)\end{array}$ \\
\hline 2 & $\begin{array}{l}1.00 \\
(250) \\
\end{array}$ & $\begin{array}{l}1.04 \\
(250) \\
\end{array}$ & $\begin{array}{l}0.98 \\
(246) \\
\end{array}$ & $\begin{array}{l}1.00 \\
(246) \\
\end{array}$ & $\begin{array}{l}0.98 \\
(245) \\
\end{array}$ & $\begin{array}{l}0.82 \\
(240) \\
\end{array}$ \\
\hline 3 & $\begin{array}{l}1.04 \\
(270)\end{array}$ & $\begin{array}{l}1.08 \\
(268)\end{array}$ & $\begin{array}{l}1.04 \\
(270)\end{array}$ & $\begin{array}{l}1.07 \\
(269)\end{array}$ & $\begin{array}{l}0.91 \\
(271)\end{array}$ & $\begin{array}{l}0.98 \\
(260)\end{array}$ \\
\hline 4 & $\begin{array}{l}1.43 \\
(288)\end{array}$ & $\begin{array}{l}1.47 \\
(286)\end{array}$ & $\begin{array}{l}1.44 \\
(287)\end{array}$ & $\begin{array}{l}1.46 \\
(286)\end{array}$ & $\begin{array}{l}1.15 \\
(295)\end{array}$ & $\begin{array}{l}1.38 \\
(285)\end{array}$ \\
\hline 5 & $\begin{array}{l}2.05 \\
(286)\end{array}$ & $\begin{array}{l}2.05 \\
(284)\end{array}$ & $\begin{array}{l}2.00 \\
(284)\end{array}$ & $\begin{array}{l}1.99 \\
(283)\end{array}$ & $\begin{array}{l}2.02 \\
(281)\end{array}$ & $\begin{array}{l}1.67 \\
(285)\end{array}$ \\
\hline \multicolumn{7}{|c|}{ Wave Condition 2} \\
\hline 1 & $\begin{array}{l}1.35 \\
(243)\end{array}$ & $\begin{array}{l}1.35 \\
(243)\end{array}$ & $\begin{array}{l}1.56 \\
(239)\end{array}$ & $\begin{array}{l}1.57 \\
(239)\end{array}$ & $\begin{array}{l}1.76 \\
(243)\end{array}$ & $\begin{array}{l}1.44 \\
(240)\end{array}$ \\
\hline 2 & $\begin{array}{l}1.19 \\
(244)\end{array}$ & $\begin{array}{l}1.19 \\
(242)\end{array}$ & $\begin{array}{l}1.10 \\
(240)\end{array}$ & $\begin{array}{l}1.10 \\
(240)\end{array}$ & $\begin{array}{l}0.69 \\
(238)\end{array}$ & $\begin{array}{l}1.05 \\
(230)\end{array}$ \\
\hline 3 & $\begin{array}{l}1.15 \\
(260)\end{array}$ & $\begin{array}{l}1.15 \\
(260)\end{array}$ & $\begin{array}{l}1.19 \\
(262)\end{array}$ & $\begin{array}{l}1.19 \\
(263)\end{array}$ & $\begin{array}{l}0.80 \\
(270)\end{array}$ & $\begin{array}{l}1.05 \\
(270)\end{array}$ \\
\hline 4 & $\begin{array}{l}1.82 \\
(275)\end{array}$ & $\begin{array}{l}1.81 \\
(275)\end{array}$ & $\begin{array}{l}1.85 \\
(275)\end{array}$ & $\begin{array}{l}1.85 \\
(276)\end{array}$ & $\begin{array}{l}1.48 \\
(285)\end{array}$ & $\begin{array}{l}1.75 \\
(276)\end{array}$ \\
\hline 5 & $\begin{array}{l}2.32 \\
(269)\end{array}$ & $\begin{array}{l}2.33 \\
(270)\end{array}$ & $\begin{array}{l}2.36 \\
(271)\end{array}$ & $\begin{array}{l}2.37 \\
(271)\end{array}$ & $\begin{array}{l}2.16 \\
(266)\end{array}$ & $\begin{array}{l}2.07 \\
(269)\end{array}$ \\
\hline \multicolumn{7}{|c|}{ Wave Condition 3} \\
\hline $2^{1}$ & $\begin{array}{l}1.82 \\
(245)\end{array}$ & $\begin{array}{l}1.98 \\
(245)\end{array}$ & $\begin{array}{l}1.63 \\
(242)\end{array}$ & $\begin{array}{l}1.78 \\
(242)\end{array}$ & $\begin{array}{l}2.07 \\
(243)\end{array}$ & $\begin{array}{l}1.71 \\
(245)\end{array}$ \\
\hline 3 & $\begin{array}{l}1.76 \\
(268)\end{array}$ & $\begin{array}{l}1.93 \\
(267)\end{array}$ & $\begin{array}{l}1.80 \\
(269)\end{array}$ & $\begin{array}{l}1.96 \\
(269)\end{array}$ & $\begin{array}{l}1.81 \\
(272)\end{array}$ & $\begin{array}{l}1.92 \\
(280)\end{array}$ \\
\hline
\end{tabular}

Figures 12 to 16 show measured and STWAVE-calculated directional spectra with the fine grid for the wave condition of 10:00 GMT on 7 August 2005 at the five mega-transect stations (sta 1 to 5 ). Figures 17 to 21 show calculated and measured directional spectra for the wave condition of 00:00 GMT on 30 August 2005 at the five mega-transect stations. For the wave condition of 18:00 GMT on 9 September 2005, the directional wave data were available only at mega-transect sta 4 and 5 . Figures 22 and 23 show measured and calculated spectra at these two stations for this wave condition. Both magnitude and direction of calculated spectra are in agreement with the measured spectra. 


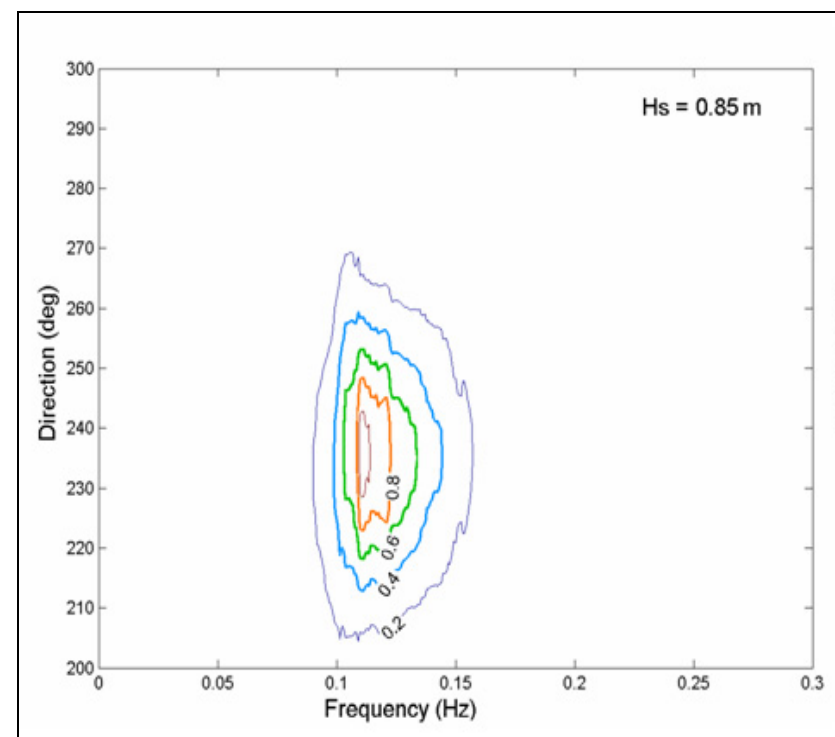

(a) Measured

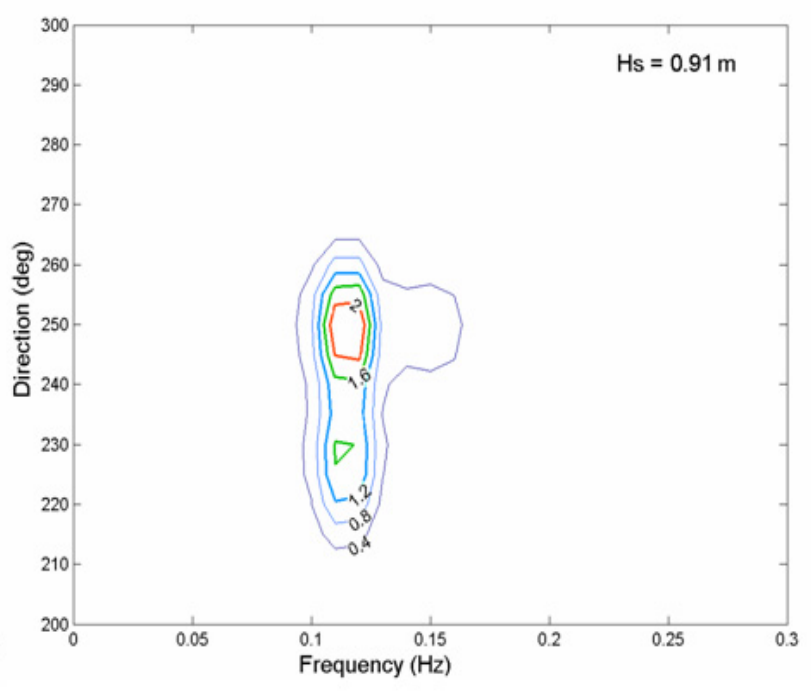

(b) Calculated

Figure 12. (a) Measured and (b) STWAVE-calculated spectra at mega-transect sta 1 for wave condition at 10:00 GMT on 7 August 2005.

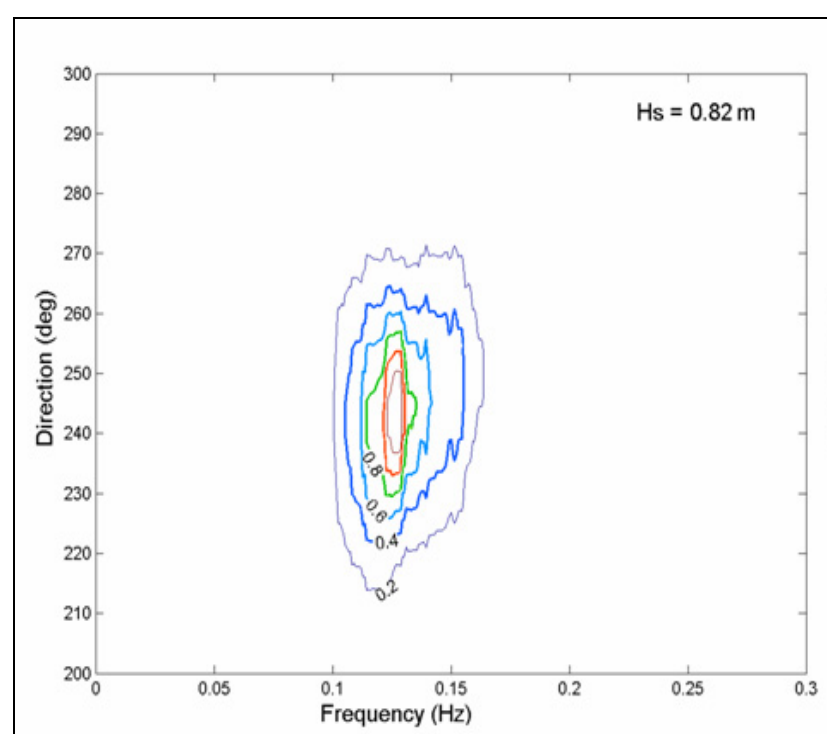

(a) Measured

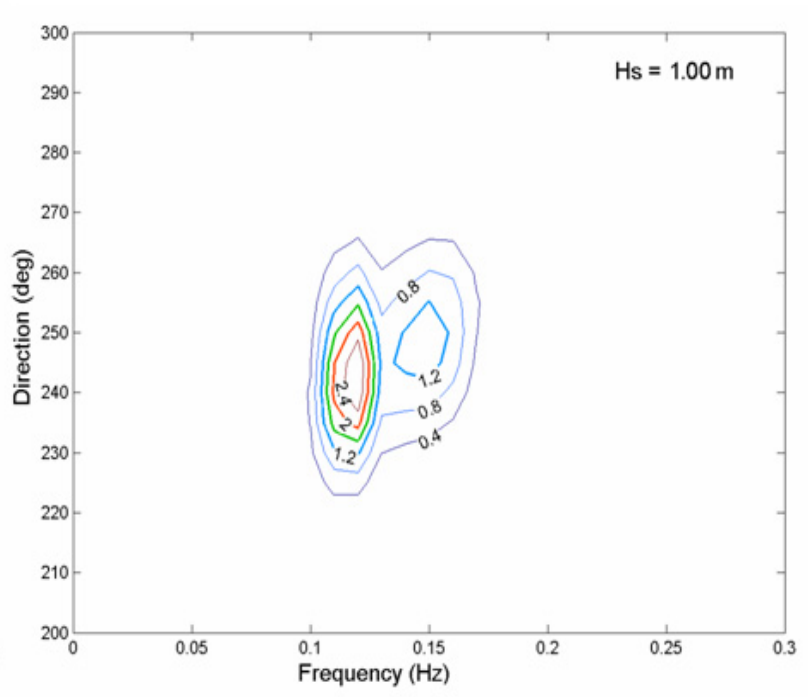

(b) Calculated

Figure 13. (a) Measured and (b) STWAVE-calculated spectra at mega-transect sta 2 for wave condition at 10:00 GMT on 7 August 2005. 


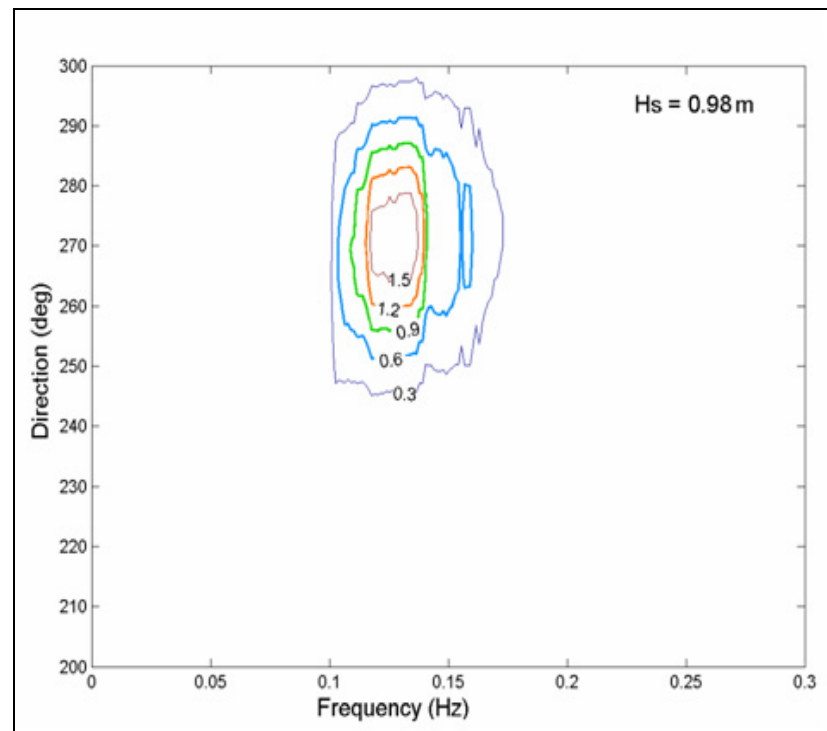

(a) Measured

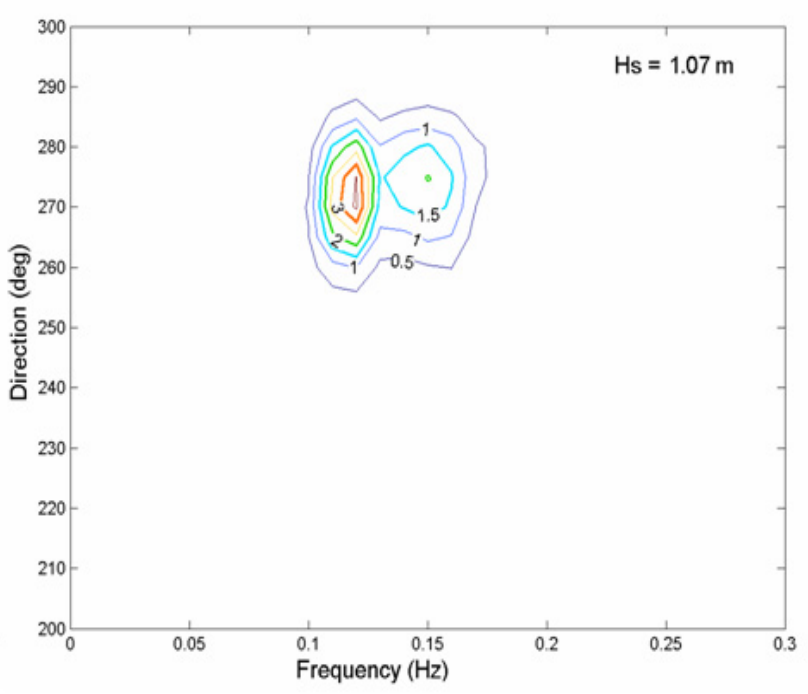

(b) Calculated

Figure 14. (a) Measured and (b) STWAVE-calculated spectra at mega-transect sta 3 for wave condition at 10:00 GMT on 7 August 2005.

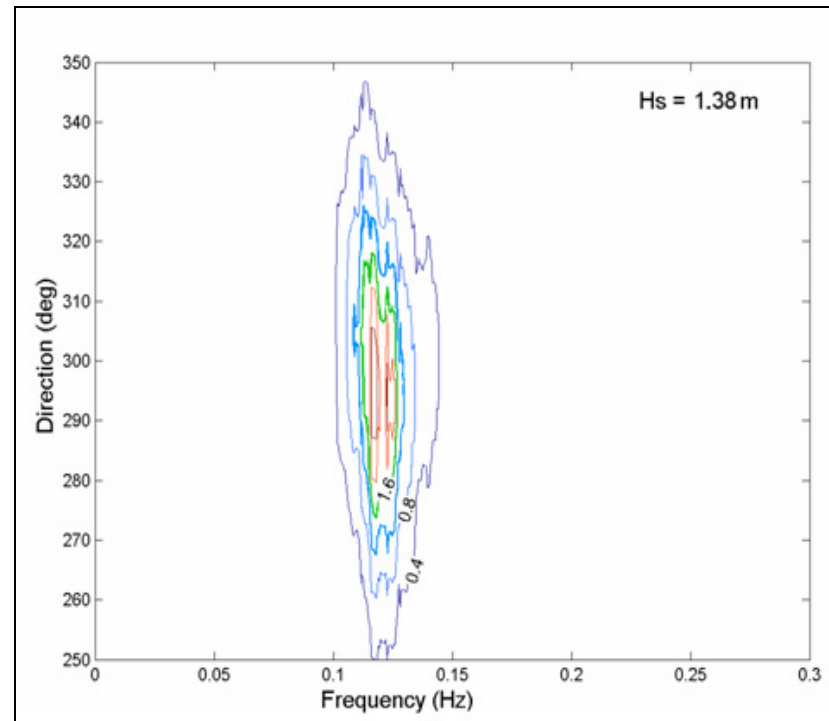

(a) Measured

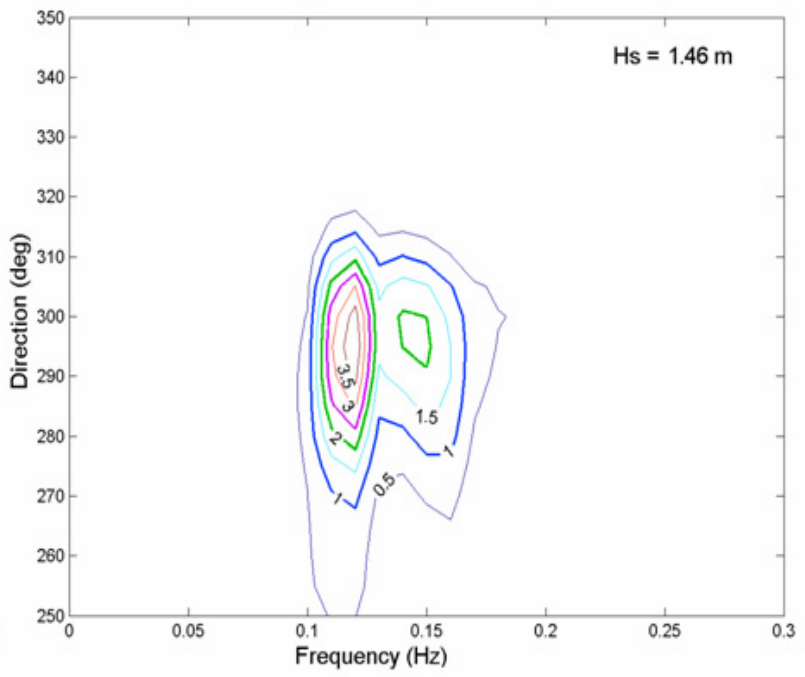

(b) Calculated

Figure 15. (a) Measured and (b) STWAVE-calculated spectra at mega-transect sta 4 for wave condition at 10:00 GMT on 7 August 2005. 


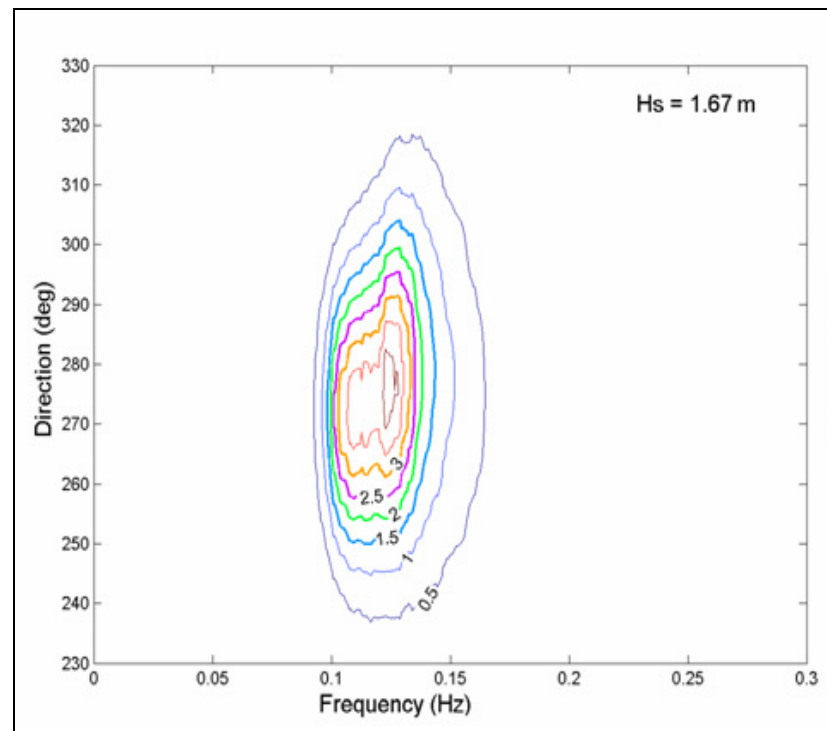

(a) Measured

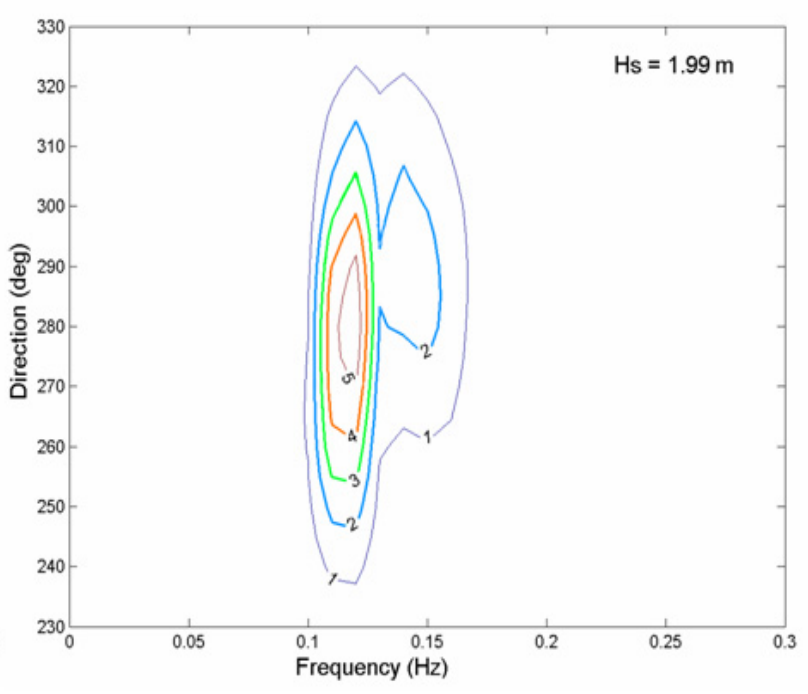

(b) Calculated

Figure 16. (a) Measured and (b) STWAVE-calculated spectra at mega-transect sta 5 for wave condition at 10:00 GMT on 7 August 2005.

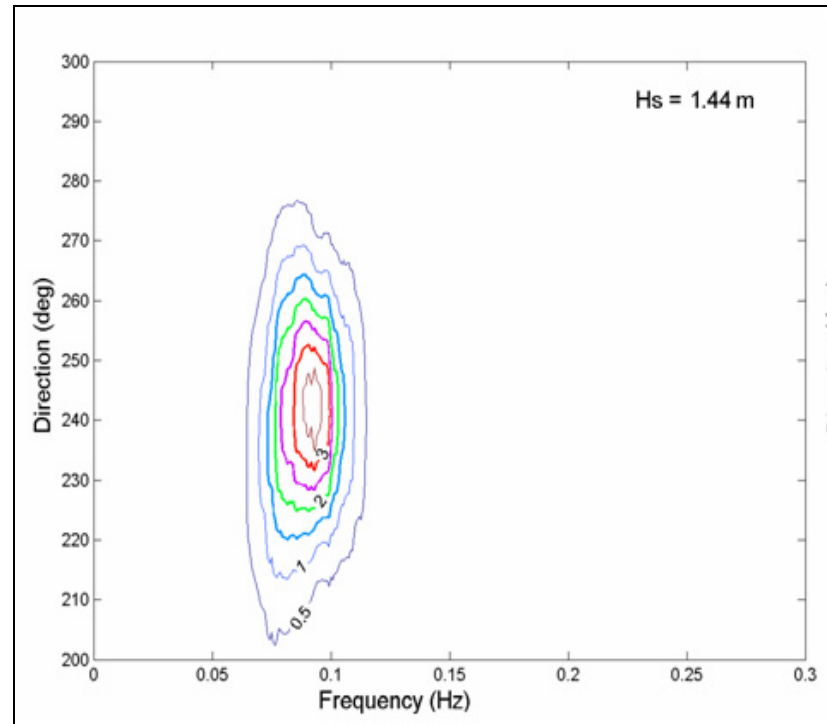

(a) Measured

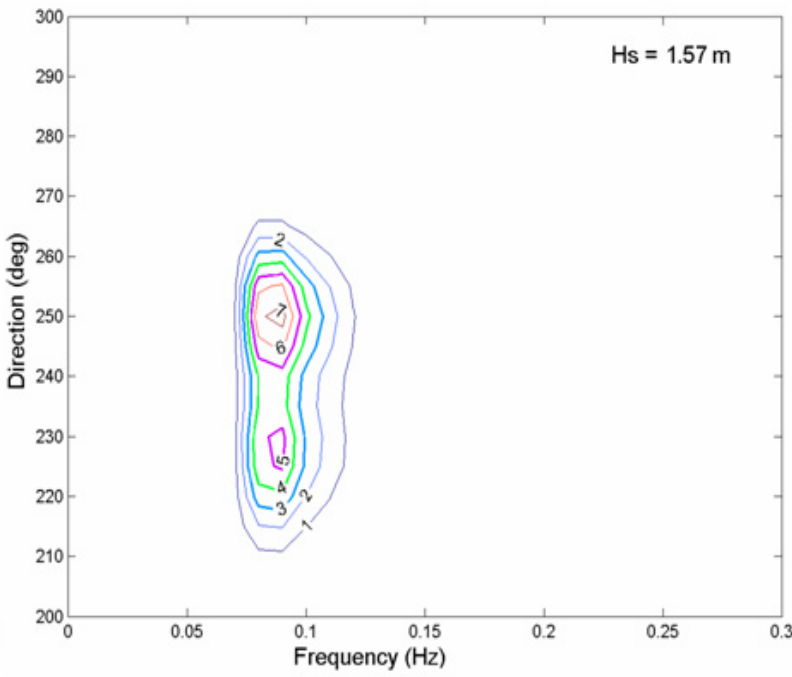

(b) Calculated

Figure 17. (a) Measured and (b) STWAVE-calculated spectra at mega-transect sta 1 for wave condition at 00:00 GMT on 30 August 2005. 


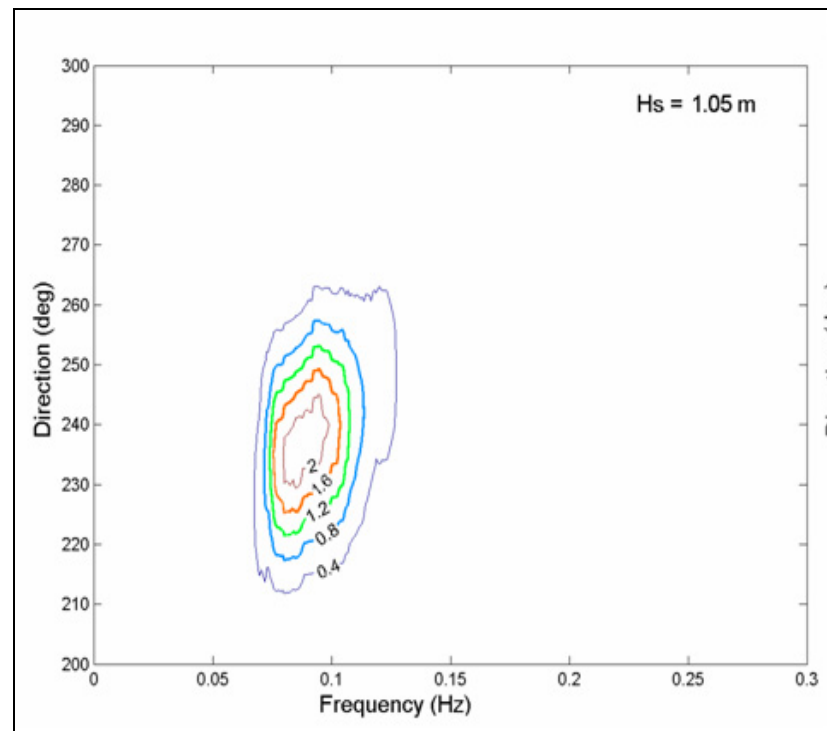

(a) Measured

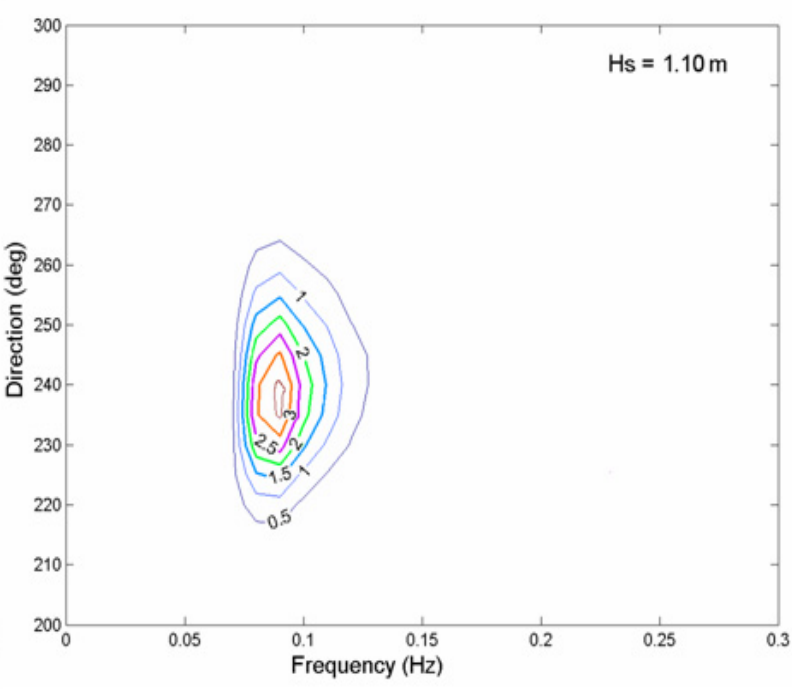

(b) Calculated

Figure 18. (a) Measured and (b) STWAVE-calculated spectra at mega-transect sta 2 for wave condition at 00:00 GMT on 30 August 2005.

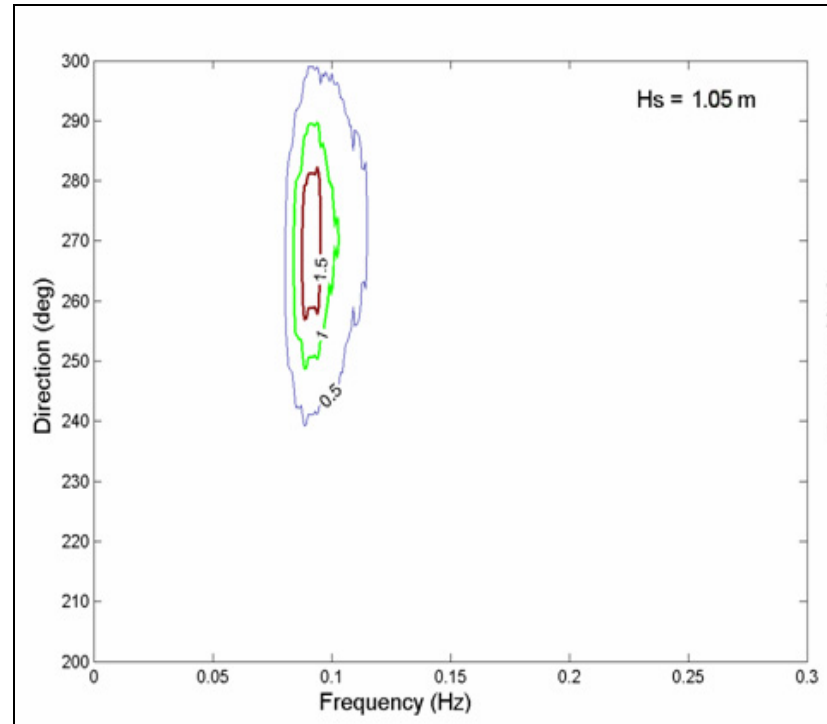

(a) Measured

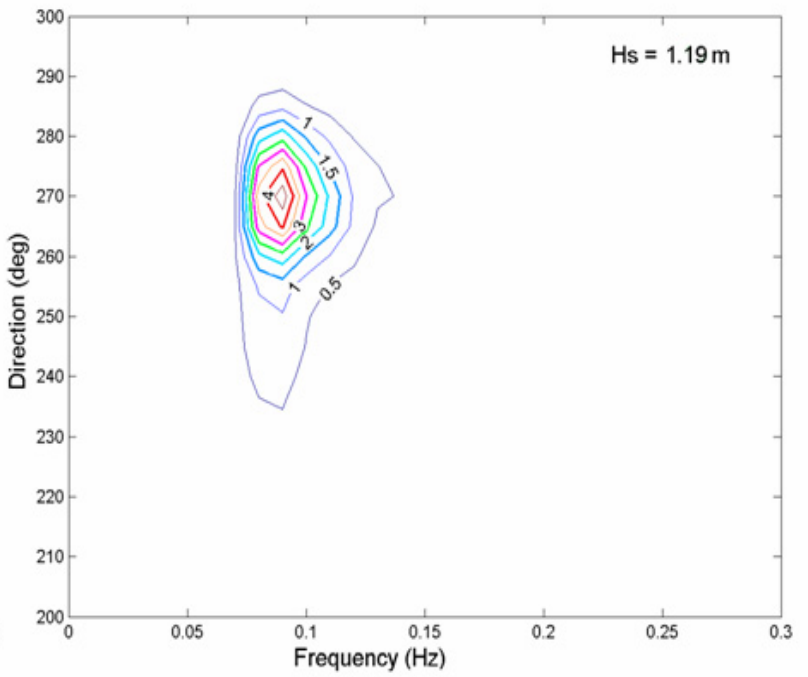

(b) Calculated

Figure 19. (a) Measured and (b) STWAVE-calculated spectra at mega-transect sta 3 for wave condition at 00:00 GMT on 30 August 2005. 


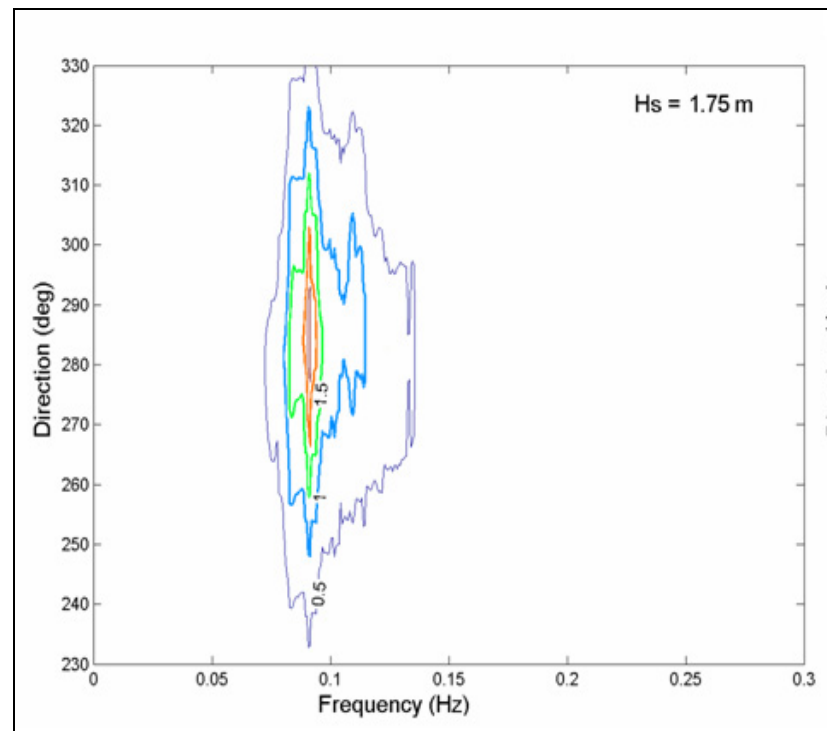

(a) Measured

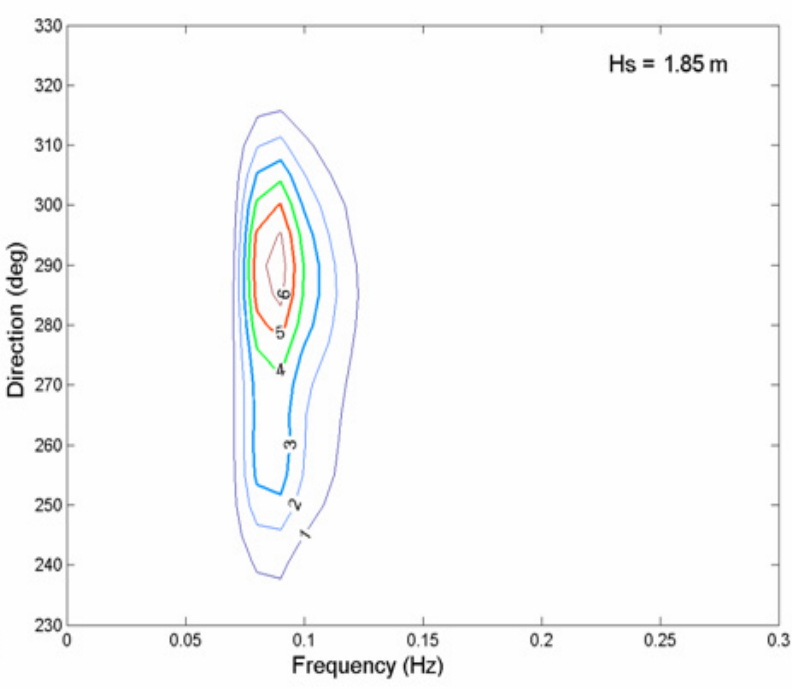

(b) Calculated

Figure 20. (a) Measured, and (b) STWAVE-calculated spectra at mega-transect sta 4 for wave condition at 00:00 GMT on 30 August 2005.

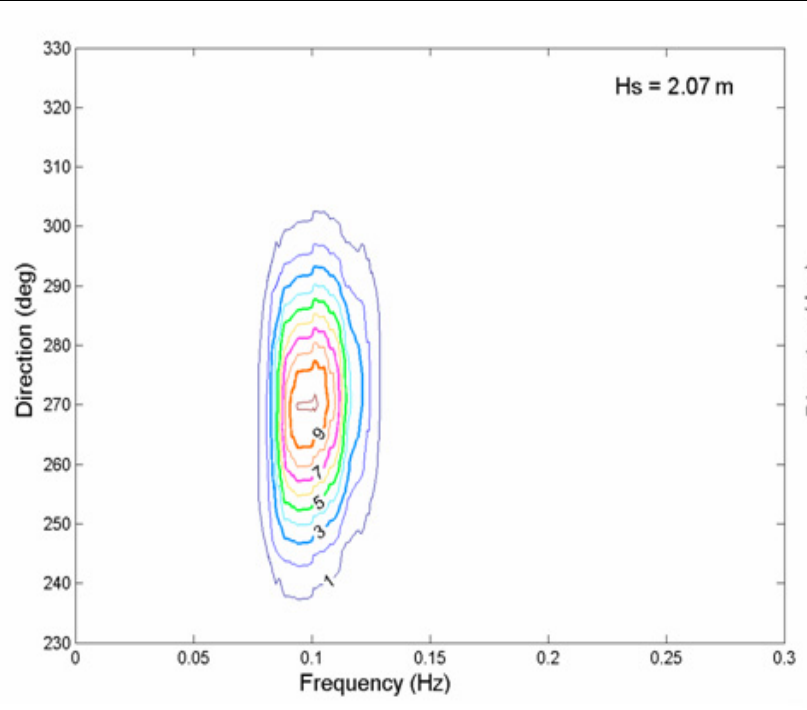

(a) Measured

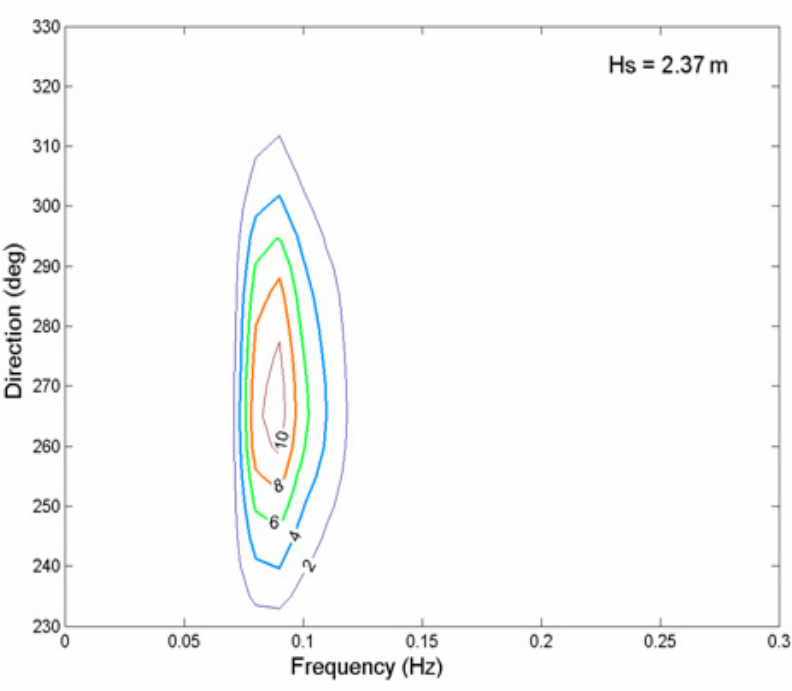

(b) Calculated

Figure 21. (a) Measured and (b) STWAVE-calculated spectra at mega-transect sta 5 for wave condition at 00:00 GMT on 30 August 2005. 


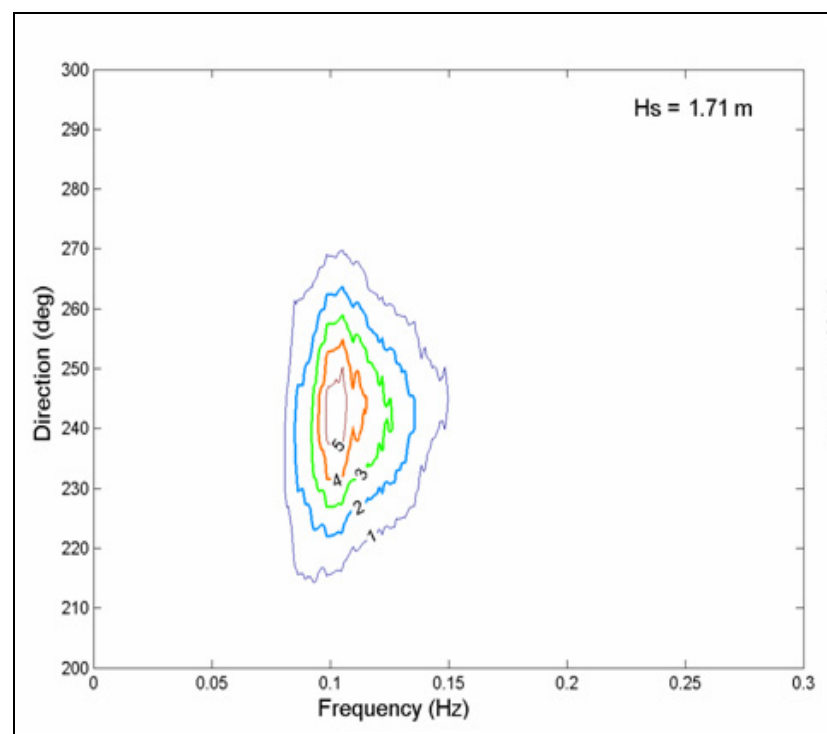

(a) Measured

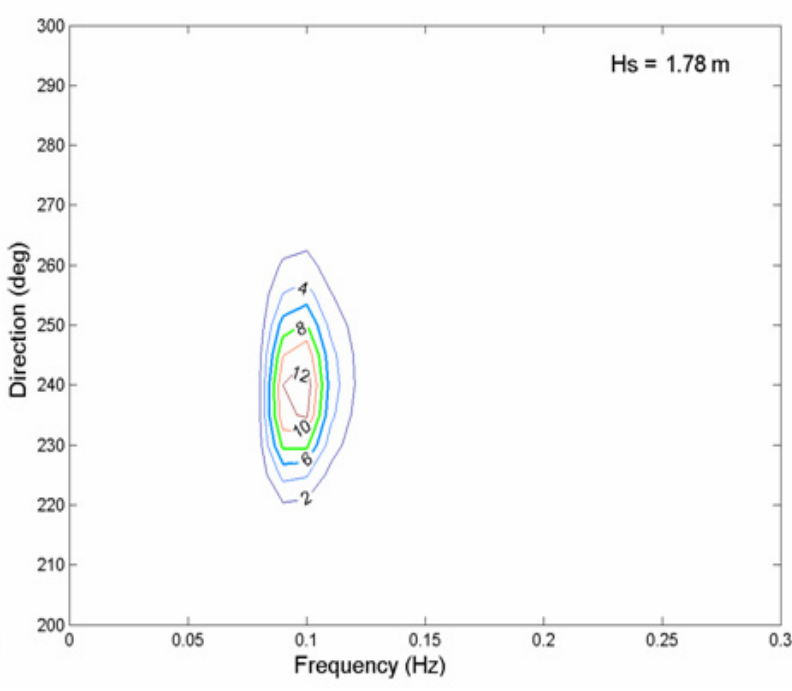

(b) Calculated

Figure 22. (a) Measured and (b) STWAVE-calculated spectra at mega-transect sta 4 for wave condition at 18:00 GMT on 9 September 2005.

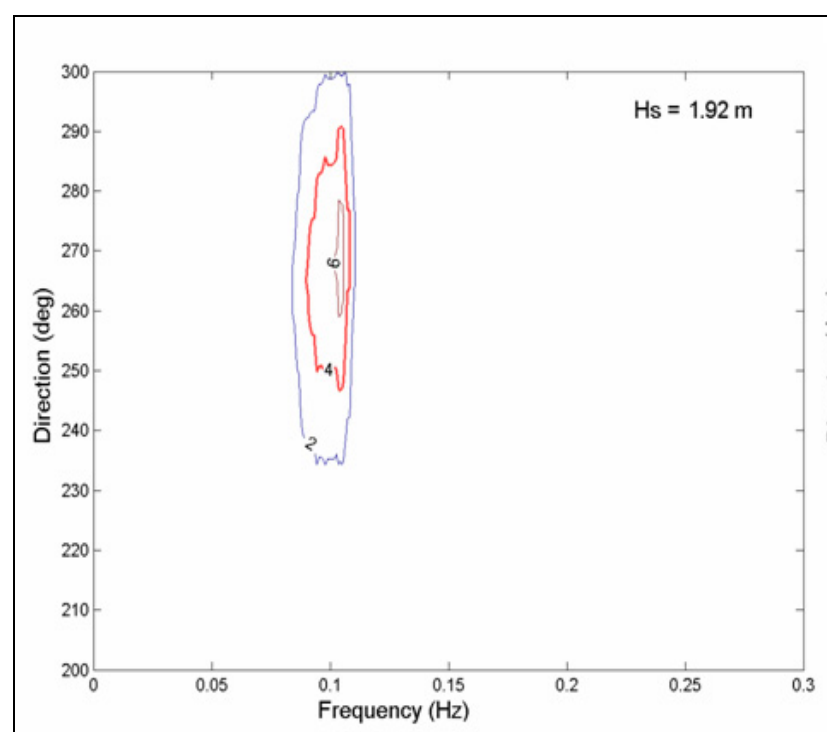

(a) Measured

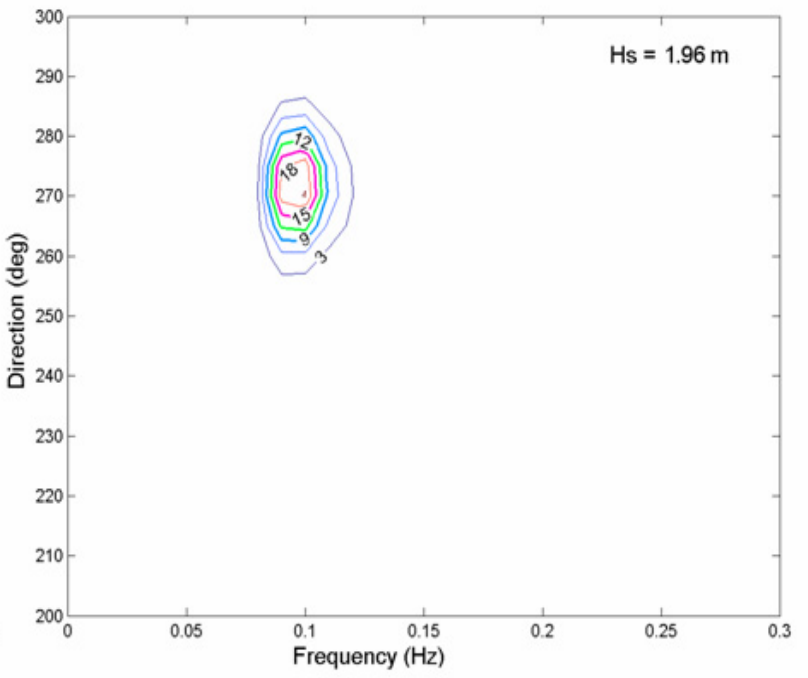

(b) Calculated

Figure 23. (a) Measured and (b) STWAVE-calculated spectra at mega-transect sta 5 for wave condition at 18:00 GMT on 9 September 2005. 
All of the measured spectra in Figures 12-23 are broader, both in frequency and direction, as compared to the calculated spectra from STWAVE. The measured spectra have high frequency and direction resolution. The difference in directional spread between the measured and calculated spectra is possibly the result of nonlinear wave-wave interactions not calculated in STWAVE.

\section{BOUSS-2D validation}

The incident wave input to BOUSS-2D model simulations consisted of three wave parameters - significant wave height, peak period, and peak direction. These parameters were obtained from STWAVE fine grid simulations at the model's offshore boundary (sta B or C in Figure 5). For large waves, spectral peak and mean wave directions are generally similar, and STWAVE-calculated mean wave directions served as input to BOUSS-2D. STWAVE simulations produced similar results with and without wind input at the MCR. Wave heights calculated by STWAVE with wind were smaller than those obtained without wind. If the sea state is saturated and the wind input option is turned on in STWAVE, predicted wave heights may decrease because of the nonlinear energy transfer and dissipation at high frequencies. The wave field may not be able to accept much additional energy due to saturation, but still dissipate energy at high frequencies due to large wave steepness. Consequently, overall wave height may be reduced. For this reason, and the fact that wind input is not considered in the BOUSS-2D model, it was decided to compare the two numerical wave models and data based on simulations without wind. STWAVE results with wind are provided for reference only.

Validation of BOUSS-2D was performed in the same manner as for STWAVE. The wave input to BOUSS-2D was obtained from the STWAVE fine grid simulations without wind. The model was started at the offshore boundary with multi-directional random sea states generated from STWAVE output parameters (significant wave height, peak period, and mean direction). For the three selected wave conditions, Figures 24 to 26 show comparison of BOUSS-2D and STWAVE calculated wave fields in the nearshore areas of MCR. Table 3 provides BOUSS-2D and STWAVE results and measurements at the five mega-transect stations. STWAVE results for both with and without wind input are presented. 


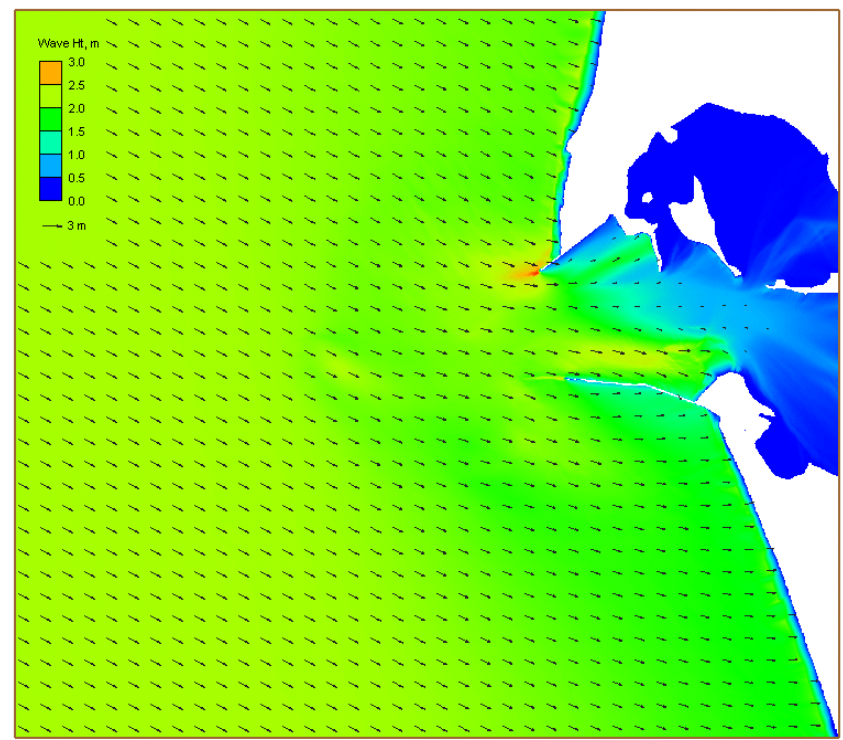

(a) STWAVE

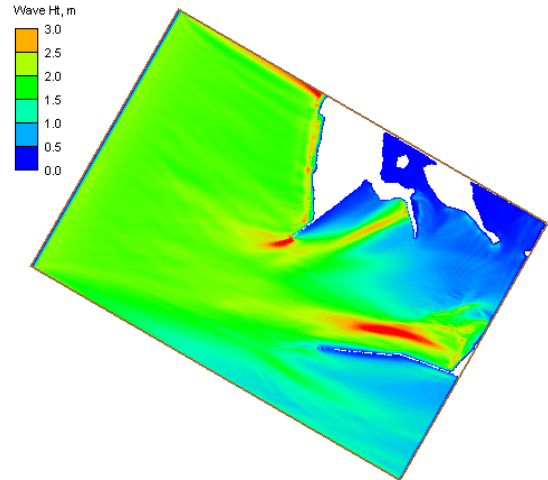

(b) BOUSS-2D

Figure 24. (a) STWAVE and (b) BOUSS-2D calculated wave fields for wave condition at 10:00 GMT on 7 August 2005.

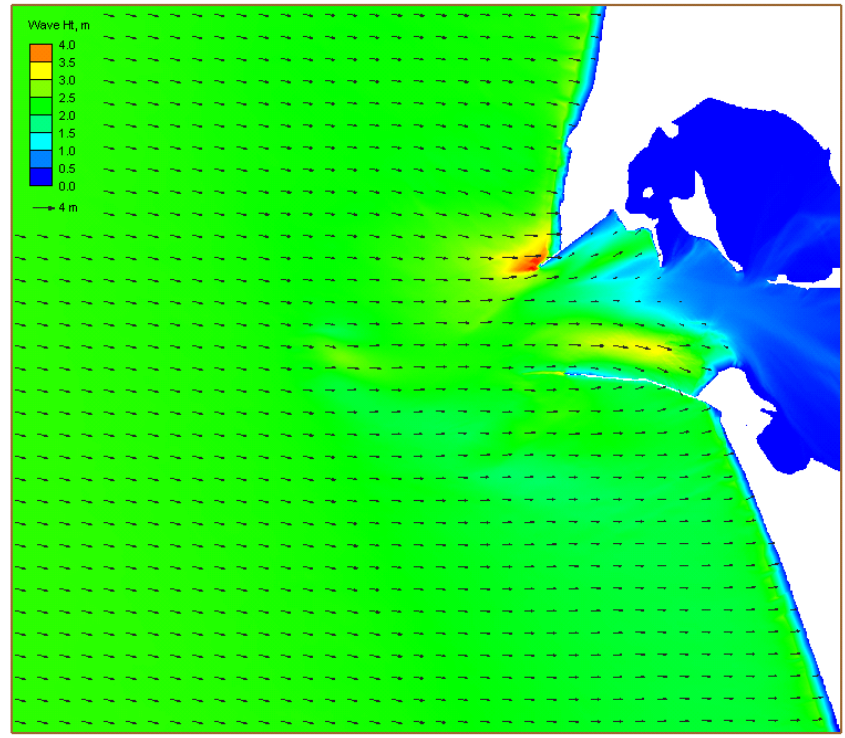

(a) STWAVE

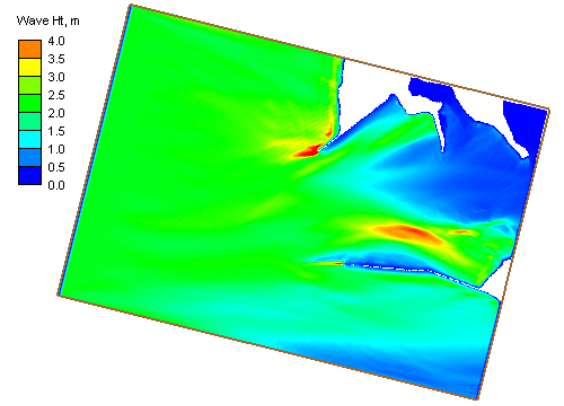

(b) BOUSS-2D

Figure 25. (a) STWAVE and (b) BOUSS-2D calculated wave fields for wave condition at 00:00 GMT on 30 August 2005. 


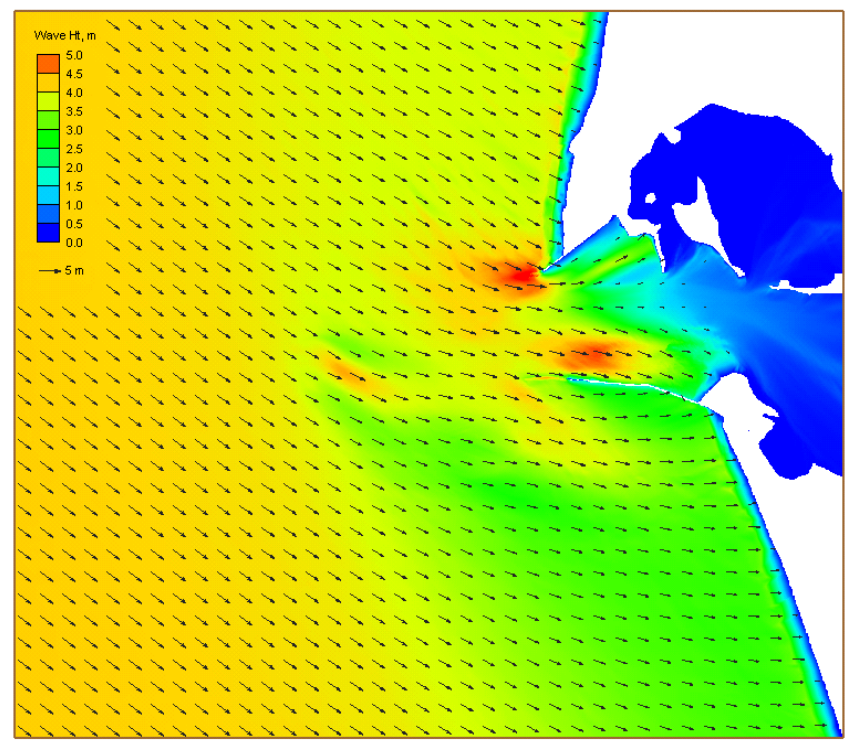

(a) STWAVE

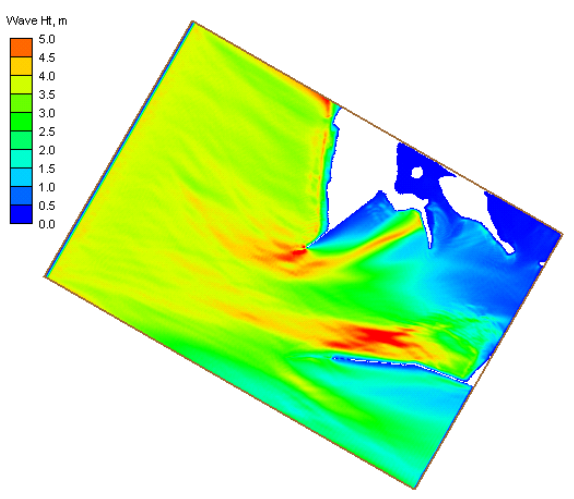

Figure 26. (a) STWAVE and (b) BOUSS-2D calculated wave fields for wave condition at 18:00 GMT on 9 September 2005.

Because the spatial scale of the BOUSS-2D grid is usually limited in applications, wind effects are not considered in the model theory, and model estimates provided correspond to the condition of no wind. Likewise, STWAVE results with wind are provided for information only and are not used in comparison to BOUSS-2D. Overall, both models produced comparable results for the three wave conditions selected for validation. A comparison of model results is described next.

\section{Comparison of model results}

BOUSS-2D predictions in the validation study agreed with the STWAVE results obtained without wind. Overall, the maximum difference between BOUSS-2D and STWAVE predicted wave heights was $0.32 \mathrm{~m}$, and the average difference was $0.14 \mathrm{~m}$. This result is considered to be a favorable outcome. Some potential causes of the resulting differences are discussed next.

Mega-transect stations are located between jetties in a region of irregular bathymetry with steep gradients. The stations are relatively close to the deep-draft navigation channel, where current can vary significantly and affect waves at different mega-transect locations. Wave reflection and 
diffraction may result from the proximity of the stations to shorelines and structures. BOUSS-2D and STWAVE predictions are expected to differ in the mega-transect area because of the complicated wave diffraction, nonlinearity, shoaling, and refraction and breaking of waves occurring in this area. Overall, BOUSS-2D and STWAVE-calculated wave parameters in the validation study are similar and compare well to measurements in simulations made without wind and wave-current interaction (tidal current).

STWAVE Version 3.o has no parameters to adjust. The predicted wave heights by STWAVE at the mega-transect stations were slightly less with stronger wind (wave conditions 1 and 3 in Table 2) than heights obtained without wind (Table 3 ). Wave conditions 1 and 3 had comparatively greater wind speeds (twice the wind speed of wave condition 2). In addition, STWAVE-predicted wave heights and directions with the fine grid agreed slightly better with the measurements than results from the coarse grid. STWAVE generally overestimated wave heights (Table 3), and the model produced similar results to BOUSS-2D for weak wind.

Slightly larger differences occur in calculated wave heights between BOUSS-2D and measurements. These larger differences can be attributed to exclusion of wind input, orientation of model grids, and running the model with default parameters (no calibration). Consequently, the two model predictions (wave height and direction) are different, 5 to 20 percent (compared to each other), in different water depths and near structures, with an average difference of 15 percent for all conditions and stations. However, the simulated three mild wave conditions are not representative of the harsh wave environment typically occurring in fall and winter months at the MCR. If more severe waves had occurred during the field data collection period, this outcome could be different, because wave nonlinearities at the mega-transect stations are expected to increase for severe wave conditions.

Given that Table 3 has a limited population set (three wave conditions and five stations), it is not appropriate to perform a statistical comparison between models and measurements. Trends in the individual model estimates were examined by combining results for three wave conditions at five locations (Table 3). The central tendency (mean or Central Limit Theory average value) and the spreading (standard deviation) between model predictions and measurements were calculated. The overall mean 
difference between STWAVE calculated significant wave heights and measurements (Table 3) was $0.095 \mathrm{~m}$, and the root-mean-square error (RMSE) was $0.11 \mathrm{~m}$. Likewise, the overall mean difference between BOUSS-2D and measurements was -0.013 $\mathrm{m}$, and the RMSE was $0.19 \mathrm{~m}$. Therefore, significant wave heights predicted with BOUSS-2D had a comparatively smaller mean difference and a larger spread than STWAVE. Overall, these trends for the simulated wave conditions by both models did not differ greatly.

In summary, the BOUSS-2D and STWAVE models produced similar results in the validation phase of this study for three selected mild wave conditions that occurred during the field data collection period in AugustSeptember 2005. The spatial variation of calculated wave height in the numerical model grids is depicted in Figures 24 to 26. As described in the Results and Discussion chapter, the two wave model estimates had comparatively greater differences for extreme waves. Additional specifics of extreme wave simulations are presented in Chapters 4 and 5 and Appendices A through E. 


\section{Modeling of Extreme Waves}

Extremely large storm waves occur during winter months at the MCR. Table 4 lists representative large waves that have been documented (Moritz et al. 2003) since 1998, with the recorded offshore wave height in excess of $8 \mathrm{~m}$ at Buoy 46029. These events do not occur often, but can be harmful to MCR jetties and beaches on the north and south sides of the entrance. These largest storm waves can originate from the northwest or southwest directions.

Table 4. Extreme wave events observed offshore of the MCR at Buoy 46029, 1998-2006.

\begin{tabular}{|l|l|l|l|l|l|}
\hline Event No. & $\begin{array}{l}\text { Date/Time } \\
\text { GMT }\end{array}$ & Condition & $\begin{array}{l}\text { Wave Height } \\
\mathrm{m}\end{array}$ & $\begin{array}{l}\text { Wave Period } \\
\text { sec }\end{array}$ & $\begin{array}{l}\text { Wave Direction } \\
\text { deg}^{1}\end{array}$ \\
\hline $\begin{array}{l}24 \\
\text { W Nov } 98\end{array}$ & $\begin{array}{l}\text { winter } \\
\text { storm }\end{array}$ & 8.9 & 14.3 & 262 \\
\hline $\begin{array}{l}2 \\
\text { WSW }\end{array}$ & $\begin{array}{l}16 \text { Feb } 99 \\
18: 00\end{array}$ & $\begin{array}{l}\text { winter } \\
\text { storm }\end{array}$ & 9.8 & 20.0 & 245 \\
\hline $\begin{array}{l}3 \\
\text { SW }\end{array}$ & $\begin{array}{l}3 \text { Mar } 99 \\
08: 00\end{array}$ & $\begin{array}{l}\text { winter } \\
\text { storm }\end{array}$ & 12.8 & 16.7 & 222 \\
\hline $\begin{array}{l}4 \\
\text { NW }\end{array}$ & $\begin{array}{l}14 \text { Dec 01 } \\
12: 00\end{array}$ & $\begin{array}{l}\text { winter } \\
\text { storm }\end{array}$ & 10.1 & 14.3 & 297 \\
\hline 5 & $\begin{array}{l}7 \text { Jan 02 } \\
22: 00\end{array}$ & $\begin{array}{l}\text { winter } \\
\text { storm }\end{array}$ & 8.3 & 16.7 & 260 \\
W & $\begin{array}{l}\text { 4 Feb 06 } \\
13: 00\end{array}$ & $\begin{array}{l}\text { winter } \\
\text { storm }\end{array}$ & 13.8 & 16.7 & 230 \\
\hline $\begin{array}{l}6 \\
\text { SW }\end{array}$ & & & \\
\hline 1 Wave direction is from and relative to north. &
\end{tabular}

For investigation of the effects of extreme waves on jetties and beaches, the two largest waves in Table 4 (Events 4 and 6) from the northwest and southwest, were chosen for wave modeling. These simulations were performed with the BOUSS-2D and STWAVE models for five project configurations:

1. Existing configuration.

2. North jetty breach configuration.

3. South jetty breach configuration.

4. North jetty length rebuild configuration.

5. South jetty length rebuild configuration. 
The rebuilt jetty lengths of the north and south jetties in the model grids were within the original authorized lengths.

\section{Existing configuration}

Numerical simulations for the existing configuration include the entrance channel, DWS, and SWS dredged material disposal mounds. Figure 27 shows the STWAVE wave fields calculated with the fine grid without wind input for Events 4 and 6 in Table 4. For these events, STWAVE simulations without wind consistently produced larger wave heights than with wind because of the wave saturation limit implemented in the model. Figure 28 shows the BOUSS-2D calculated wave fields for these events. Overall, calculated wave fields for these storms from both models are similar. Specific differences between wave model predictions and related statistics are presented in the Results and Discussion chapter.

The current input was set to zero, and a storm surge value of $1.85 \mathrm{~m}$ as specified by the Portland District was input in these extreme wave simulations. Model results were saved over the entire numerical modeling domain of each wave model grid. Results were also saved at 148 stations, henceforth referred to as "special output locations" selected by the Portland District. The information saved for the entire grid includes significant wave height, spectral peak period, and mean direction (STWAVE) and peak direction (BOUSS-2D). Both the wave parameters and calculated directional spectra were saved at special output locations.

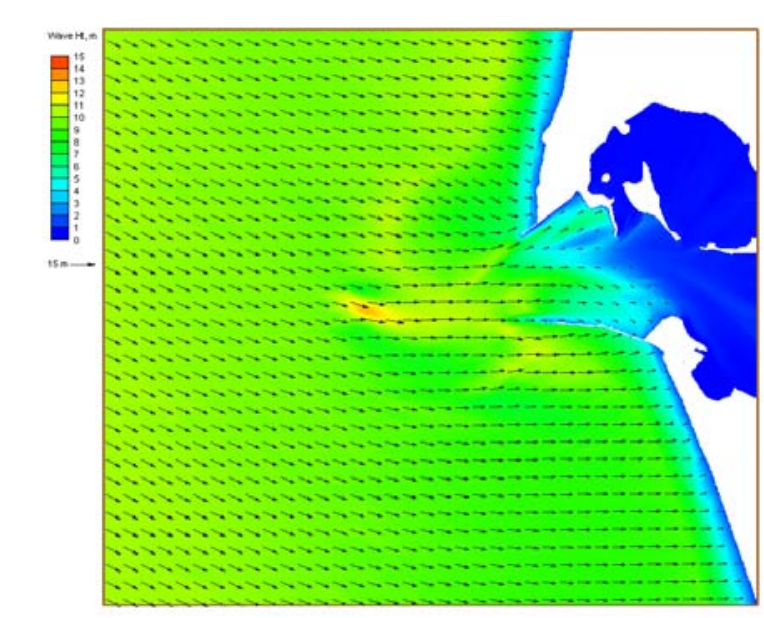

(a) 12:00 GMT, 14 Dec 01

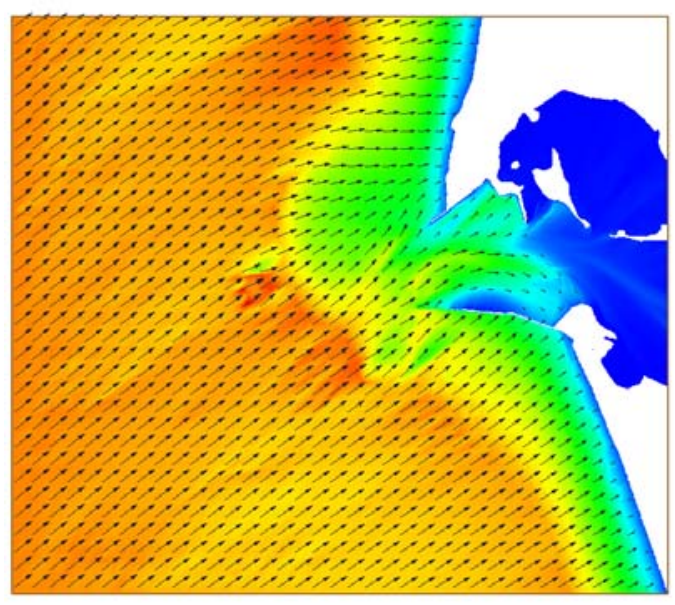

(b) 13:00 GMT, 4 Feb 06

Figure 27. STWAVE calculated wave fields for (a) Event 4 at 12:00 GMT on 14 December 2001 and (b) Event 6 at 13:00 GMT on 4 February 2006. 


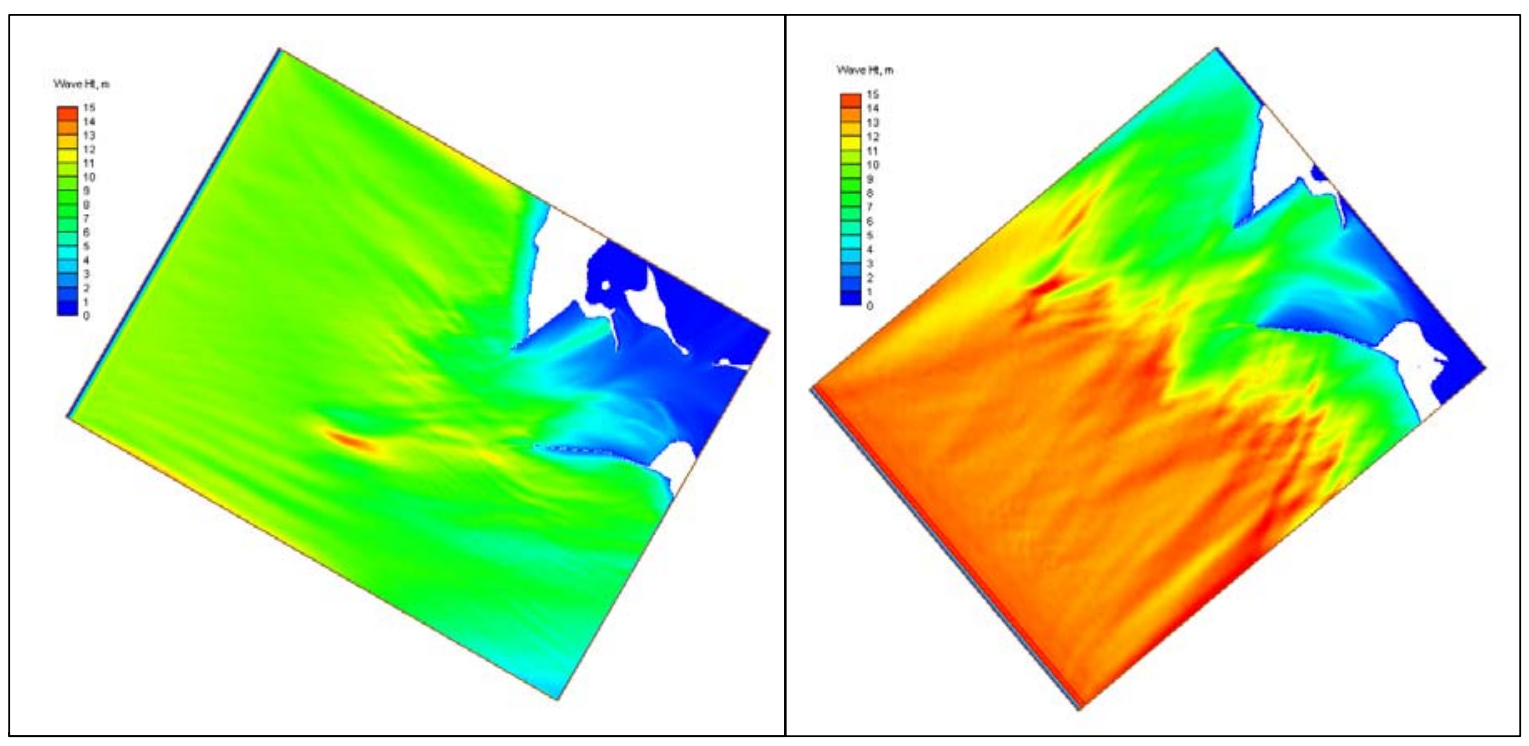

(a) 12:00 GMT, 14 Dec 01

(b) 13:00 GMT, 4 Feb 06

Figure 28. BOUSS-2D calculated wave fields for (a) Event 4 at 12:00 GMT on 14 December 2001 and (b) Event 6 at 13:00 GMT on 4 February 2006.

The special output locations cover ten sub-areas of interest that include DWS, SWS, SJRS, adjacent beaches, navigation channel, and areas around the north and south jetties. Table A1 in Appendix A lists the coordinates of the special output locations referenced to Oregon North State Plane NAD27 and depths relative to $\mathrm{mtl}$.

Figure 29 shows a map of the special output locations. Figures 30 to 32 show special output locations (with labels) for each of the areas of DWS, SWS, and SJRS, respectively. Figures 33 and 34 show special output locations (with labels) covering the north and south jetty areas, and potential breach areas in this study.

Calculated wave parameters from BOUSS-2D and STWAVE at the special output locations for Events 4 and 6 of the existing configuration are provided in Tables A2 and A3 (in Appendix A), respectively. Statistical error measures were generated to provide comparison between model predictions for the entire 148 output stations and for the ten sub-areas. Statistics calculated for the ten sub-areas of interest are provided in Table A4. These are analyzed in the Results and Discussion chapter. Table 5 provides the designation (ID), name, and associated output stations for each of the ten sub-areas. 


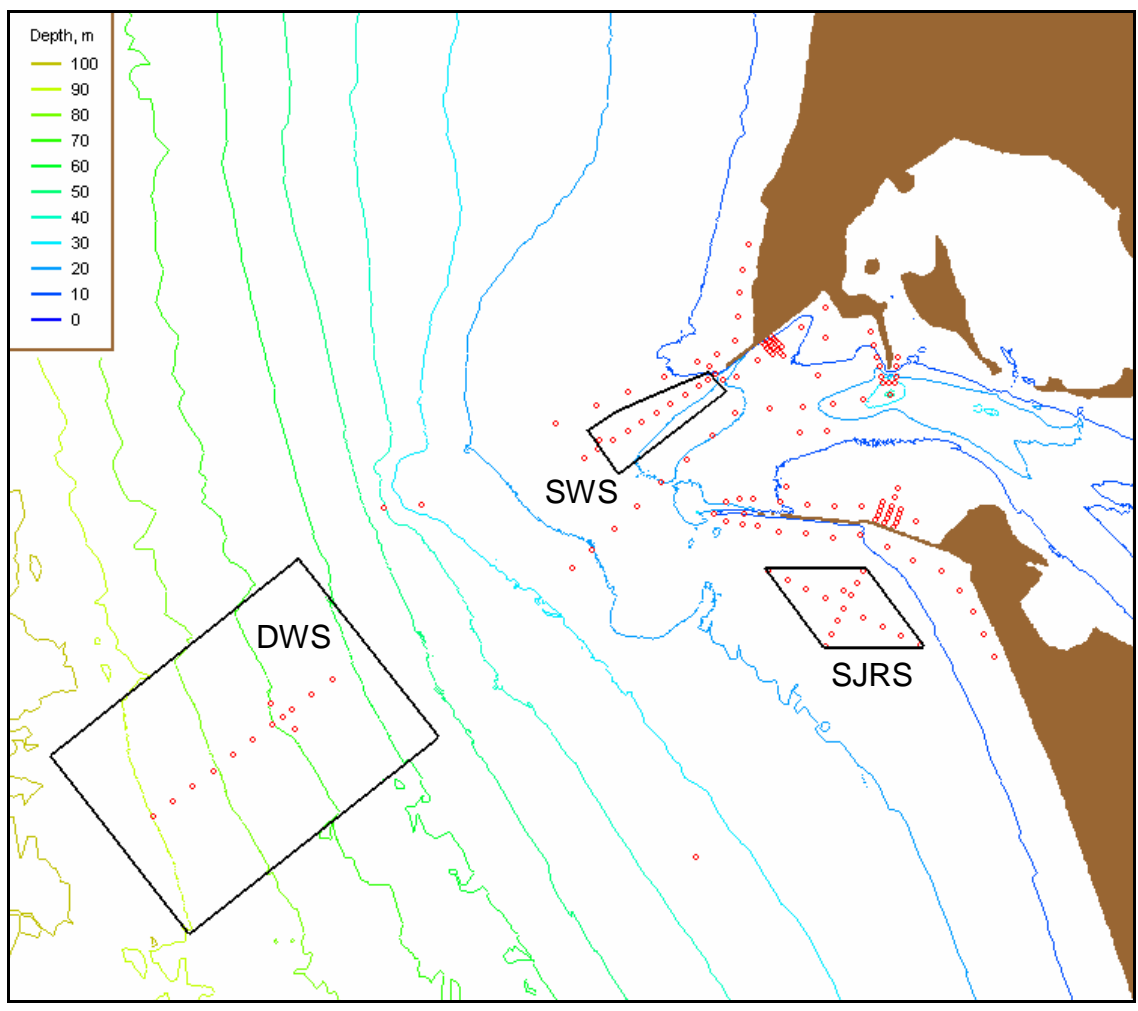

Figure 29. Wave modeling output locations (red circles) for extreme events.

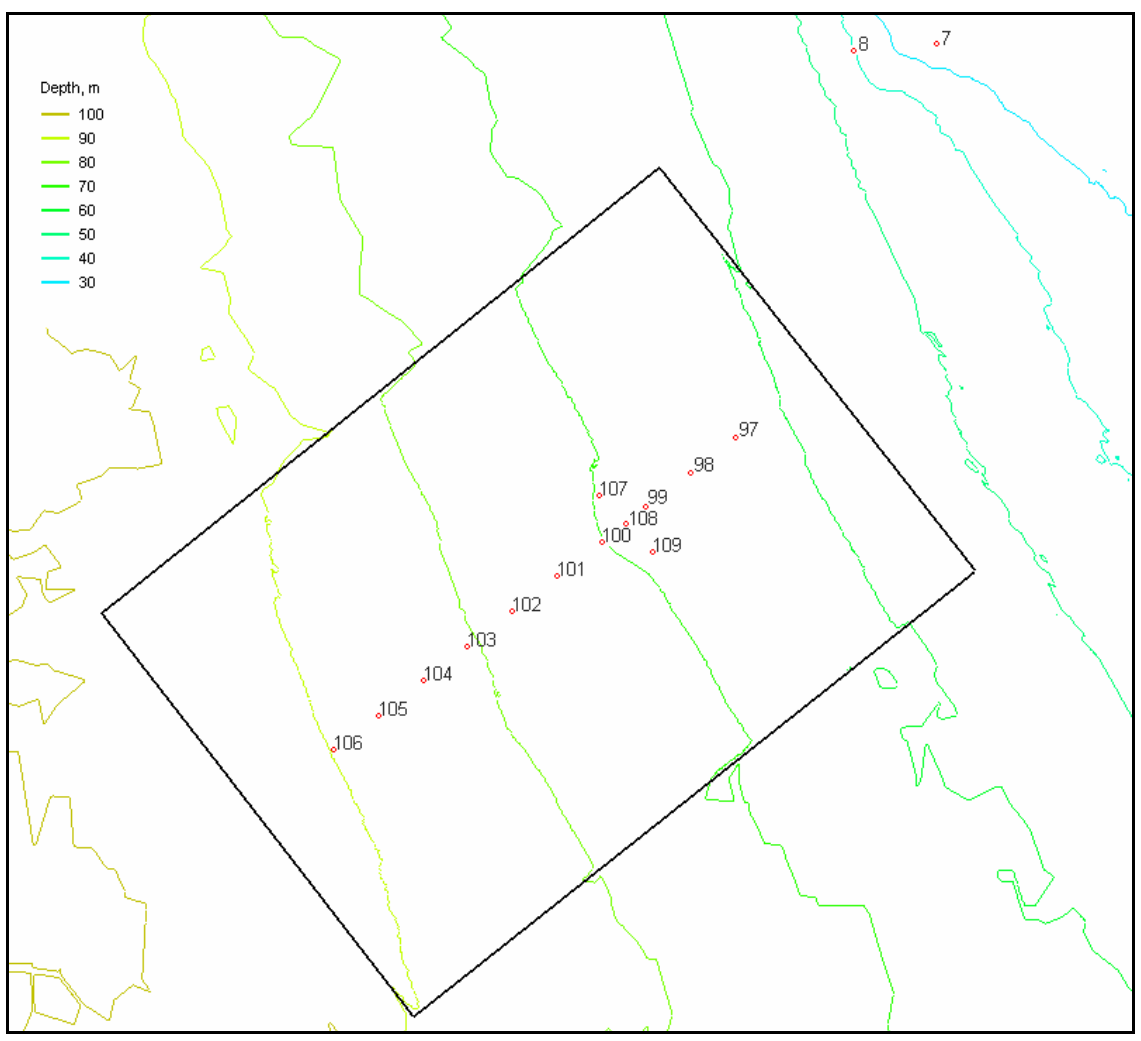

Figure 30. Wave model output locations placed over DWS. 


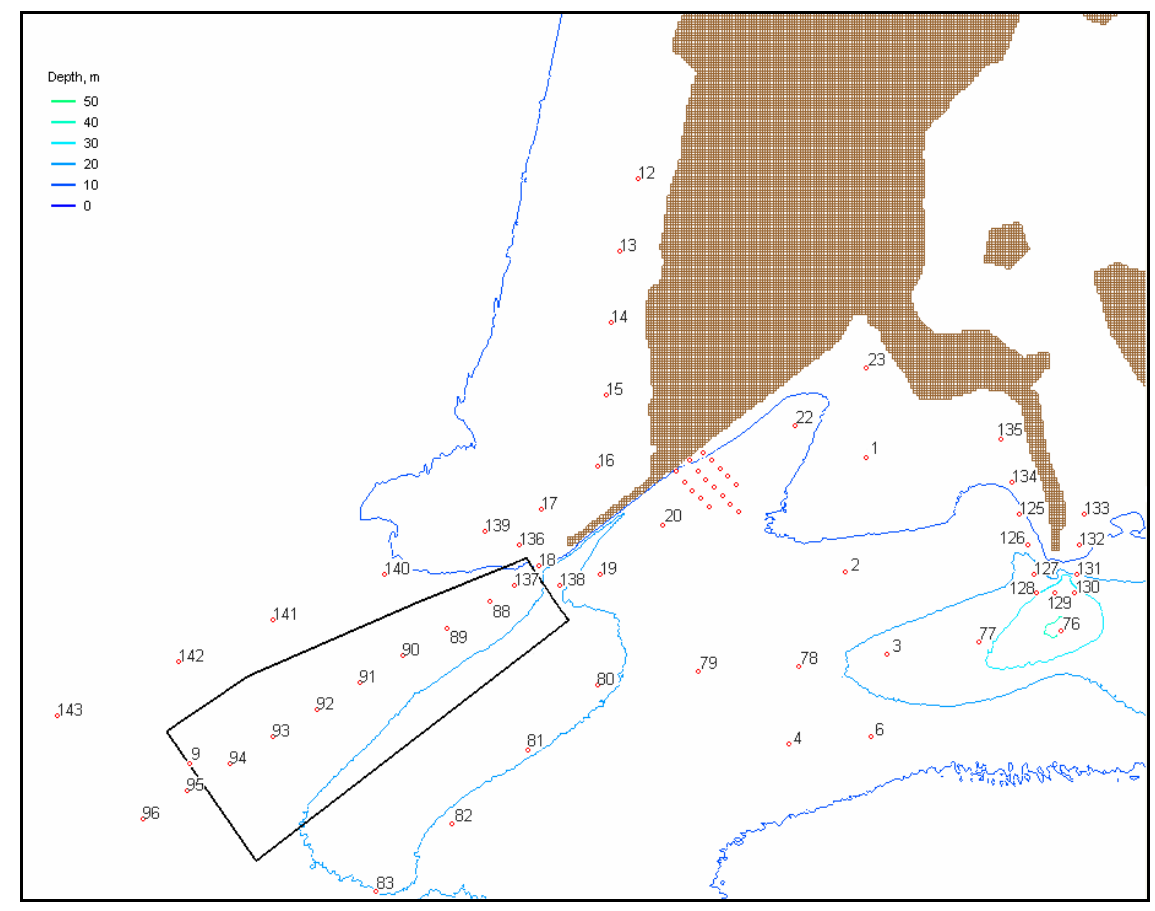

Figure 31. Wave model output locations in vicinity of SWS.

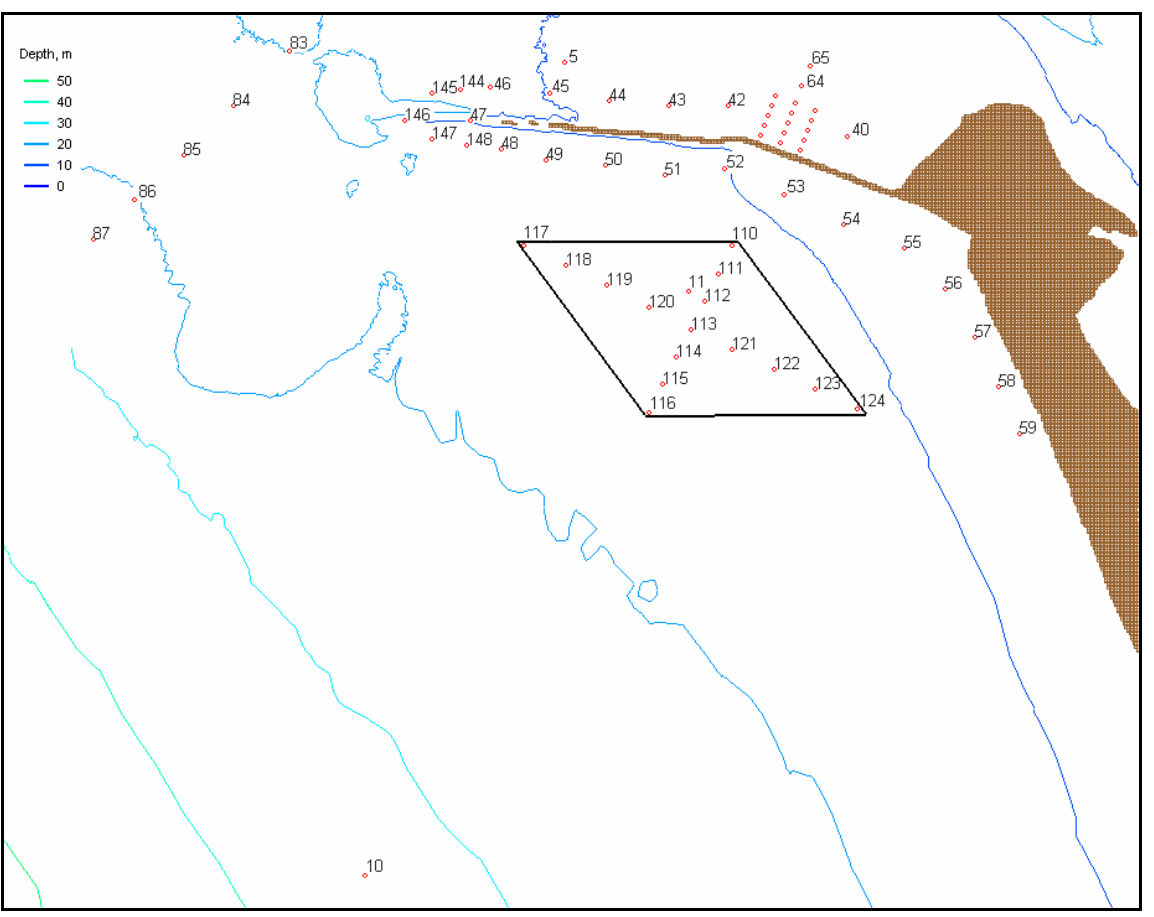

Figure 32. Wave model output locations in vicinity of SJRS. 


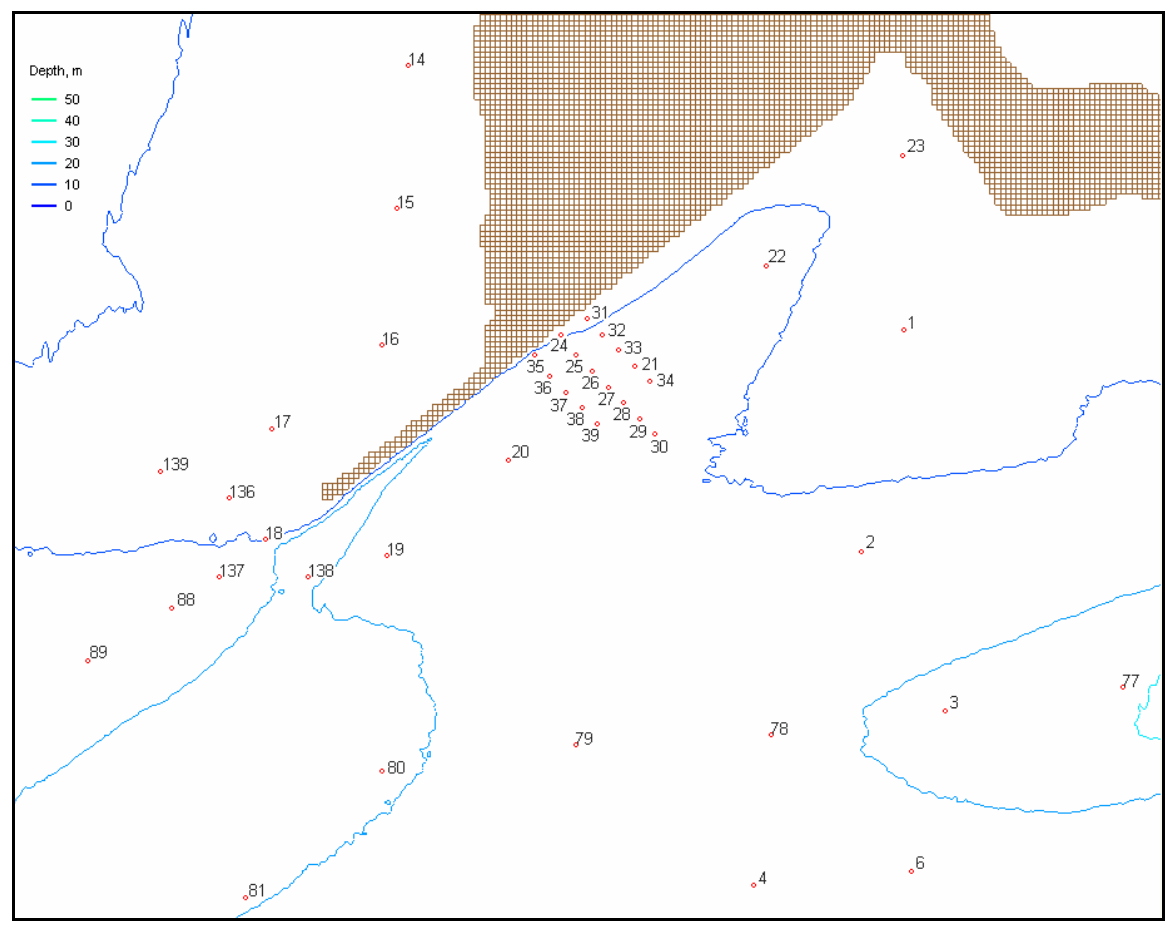

Figure 33. Wave model output locations in vicinity of north jetty.

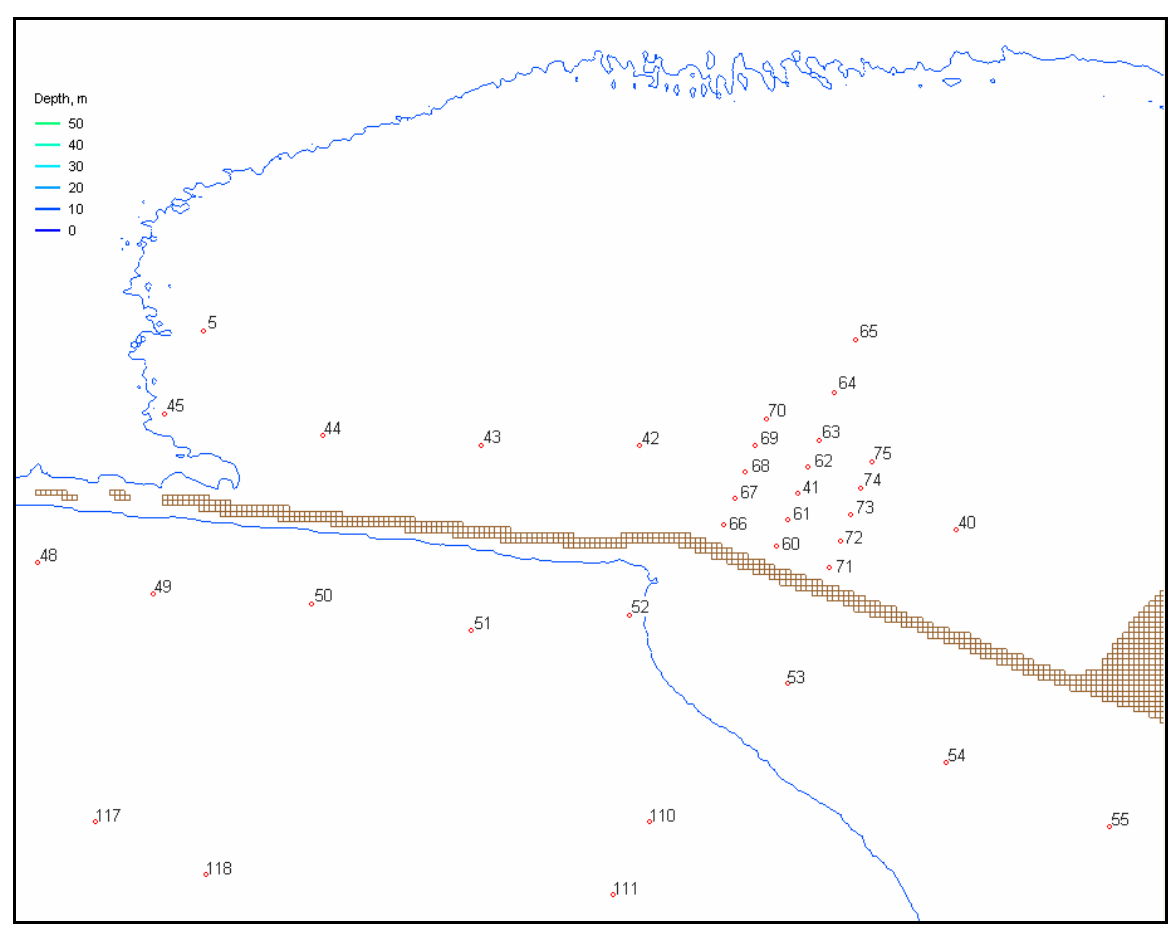

Figure 34. Wave model output locations in vicinity of south jetty. 
Table 5. Ten sub-areas of interest and output stations.

\begin{tabular}{|l|l|l|}
\hline Area ID. & Name & Stations \\
\hline 1 & Mega-transect & 1 to 6 \\
\hline 2 & North beach & 12 to 16 \\
\hline 3 & North jetty & 16 to 39,136 to 138 \\
\hline 4 & South jetty & 40 to 55,60 to 75,144 to 148 \\
\hline 5 & South beach & 56 to 59 \\
\hline 6 & Entrance channel & 3,76 to 87 \\
\hline 7 & SWS & 9,88 to 96,137 \\
\hline 8 & DWS & 97 to 109 \\
\hline 9 & SJRS & 11,110 to 124 \\
\hline 10 & Jetty A & 125 to 135 \\
\hline
\end{tabular}

\section{Jetty breach configurations}

Two jetty breach configurations were considered with extreme waves:

(a) breach in the north jetty, and (b) breach in the south jetty. North and south jetty hypothetical breach configurations are shown in Figures 35 and 36 , respectively. The north jetty breach is a gap $250 \mathrm{~m}$ wide and $1.5 \mathrm{~m}$ deep, representing removal of a small section in the mid-section part of that jetty. The Portland District provided the specifications for each breach configuration, including its location, size, and expected resulting modified bathymetry in the vicinity of the breach.

For the north jetty breach, the Portland District assumed that the beach directly north of the jetty was eroded and the shoreline had receded approximately $1,000 \mathrm{~m}$ from the existing configuration. The eroded material was deposited in the channel side of the gap, creating a crescentic shoal that intercepts and extends across the entrance channel. In contrast, the hypothesized south jetty breach is a 500-m-wide gap with a 4-m-scour depth. The south beach erosion is more severe, and the shoreline recession is approximately $300 \mathrm{~m}$ for a $3-\mathrm{km}$ extent along the south beach. The eroded material is mainly deposited to the seaside of the gap assuming the seaward transport along the jetty is interrupted and trapped by the current across the gap. 


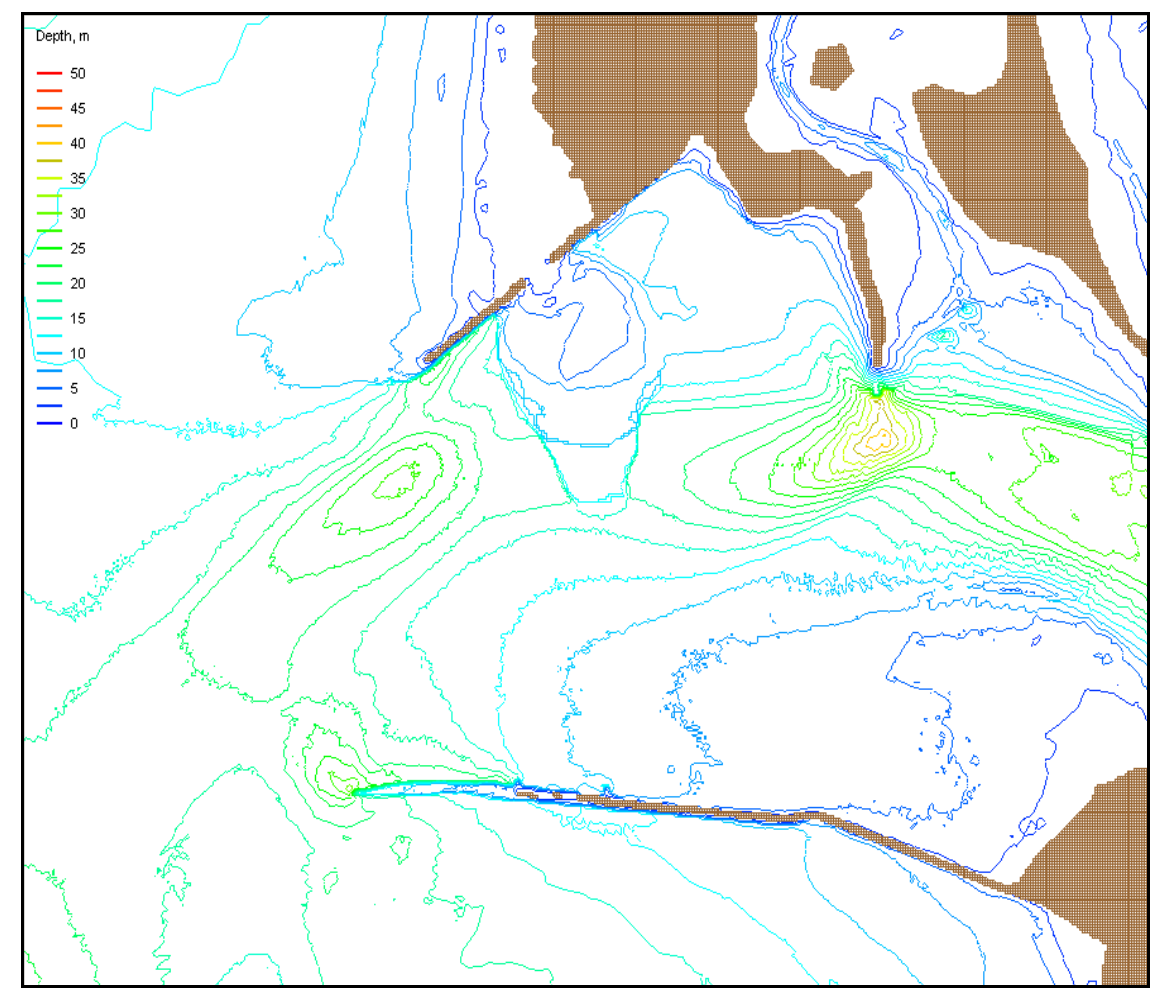

Figure 35. North jetty breach configuration with depth contours.

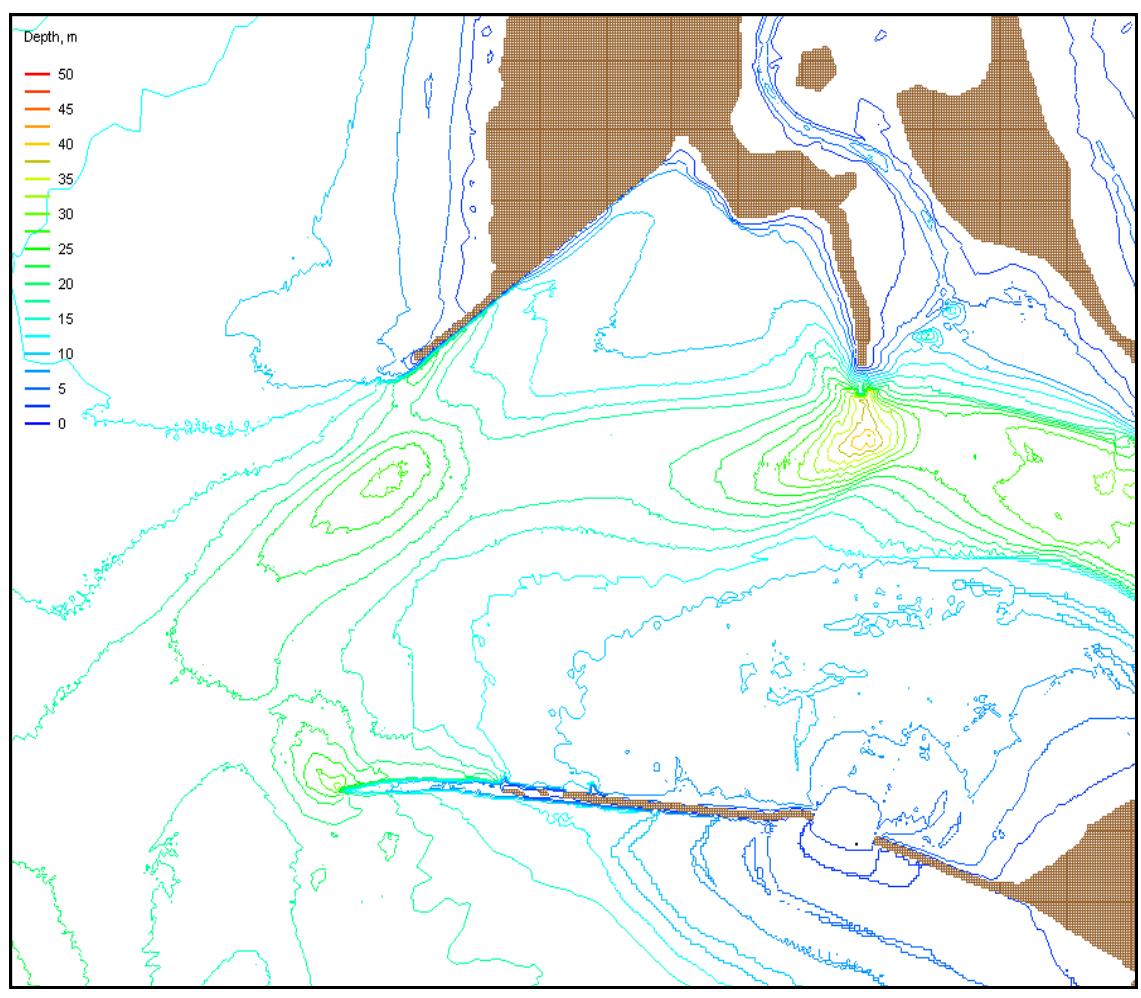

Figure 36. South jetty breach configuration with depth contours. 
Both north and south jetty breach configurations were simulated with Events 4 and 6 (Table 4), which were also used for evaluating the existing configuration. Figures 37 and 38 show calculated wave fields from the BOUSS-2D and STWAVE for Events 4 and 6, respectively, encompassing the north jetty breach area. Figures 39 and 40 show wave fields calculated for the south jetty breach. These figures indicate strong wave refraction, diffraction, and interaction of waves with jetties occurring in and around the jetty breach areas. Figures 41 and 42 show three-dimensional plots of bathymetry and a strong wave diffraction field obtained for Event 6 from a BOUSS-2D simulation for the south jetty breach.

Results from wave model simulations for extreme waves (Events 4 and 6) are presented in Table 6 at the five mega-transect stations for the jetty breach configurations. Special output locations 1 to 5 corresponds to the mega-transect sta 1 to 5 (Table 5), respectively. This comparison has two objectives: (a) demonstrate the degree of variability in wave parameter estimates by two models at different locations along the mega-transect, and (b) show the difference of two wave models performed in the extreme storms at the MCR entrance.

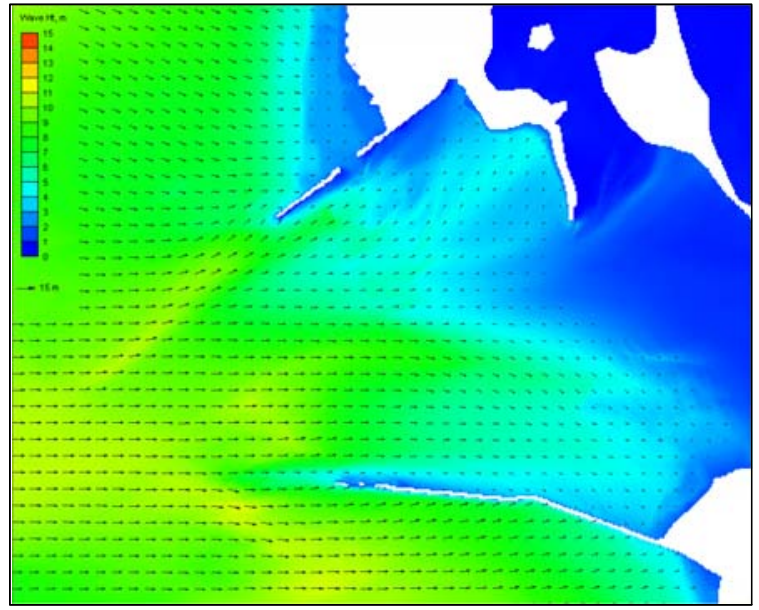

(a) STWAVE

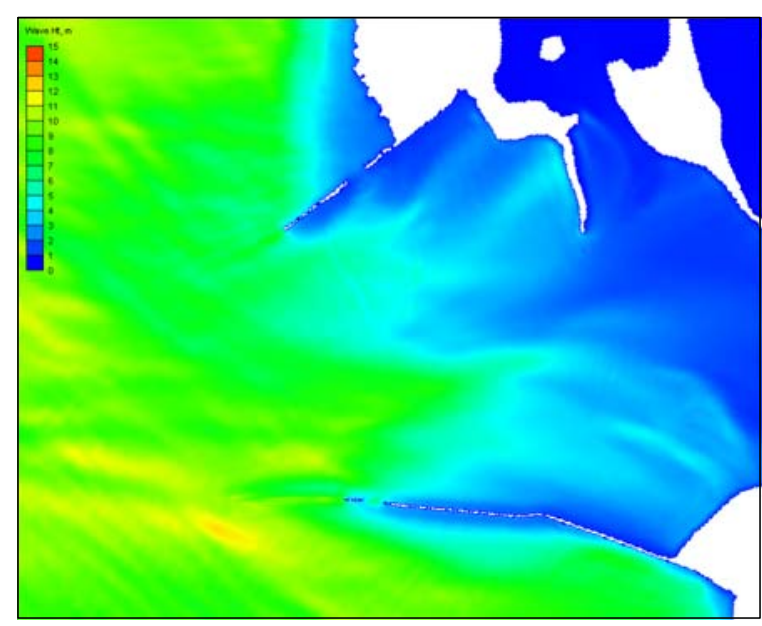

(b) BOUSS-2D

Figure 37. North jetty breach (a) STWAVE and (b) BOUSS-2D calculated wave fields for NW storm Event 4 at 12:00 GMT on 14 December 2001. 


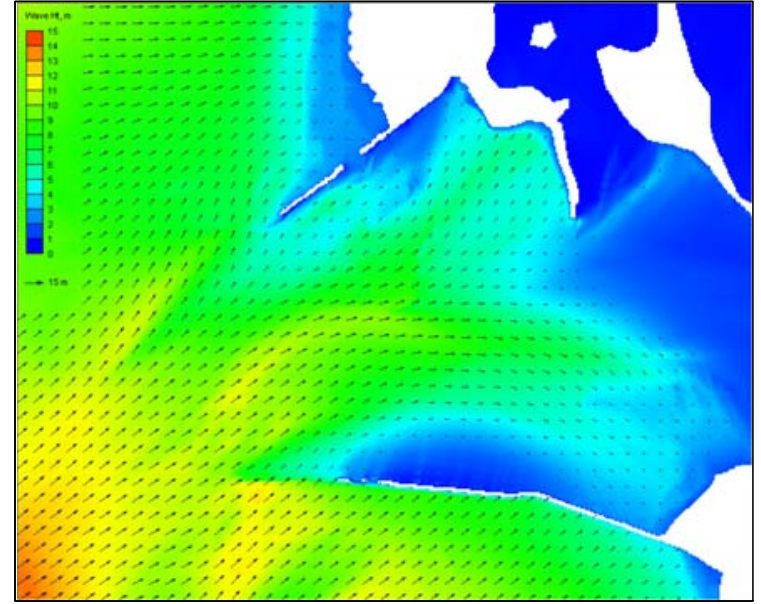

(a) STWAVE

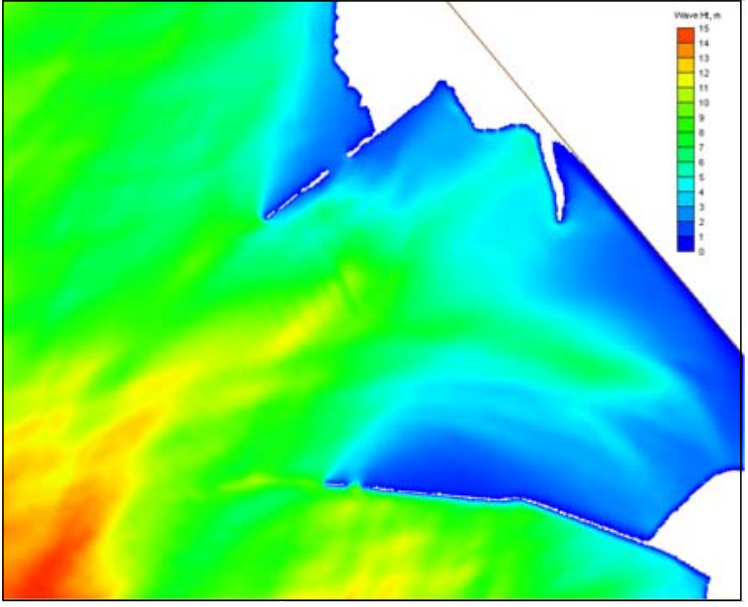

(b) BOUSS-2D

Figure 38. North jetty breach (a) STWAVE and (b) BOUSS-2D calculated wave fields for SW storm Event 6 at 13:00 GMT on 4 February 2006.

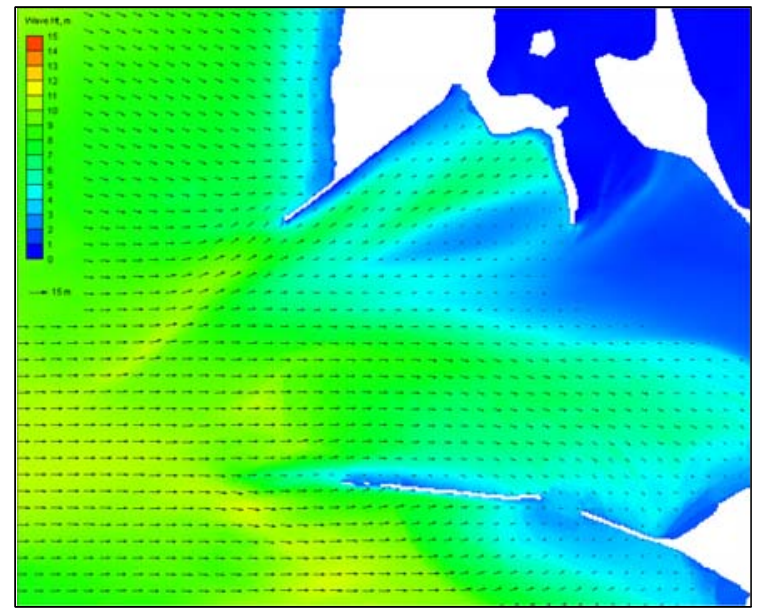

(a) STWAVE

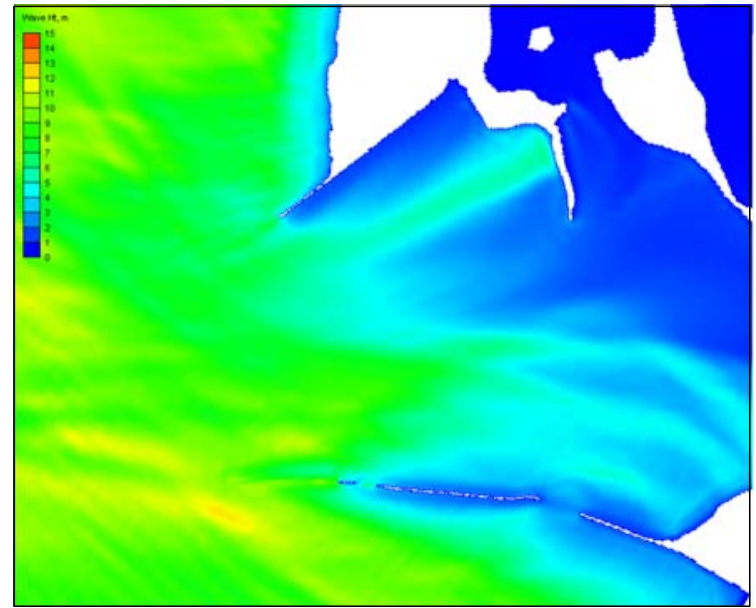

(b) BOUSS-2D

Figure 39. South jetty breach (a) STWAVE and (b) BOUSS-2D calculated wave fields for NW storm Event 4 at 12:00 GMT on 14 December 2001. 


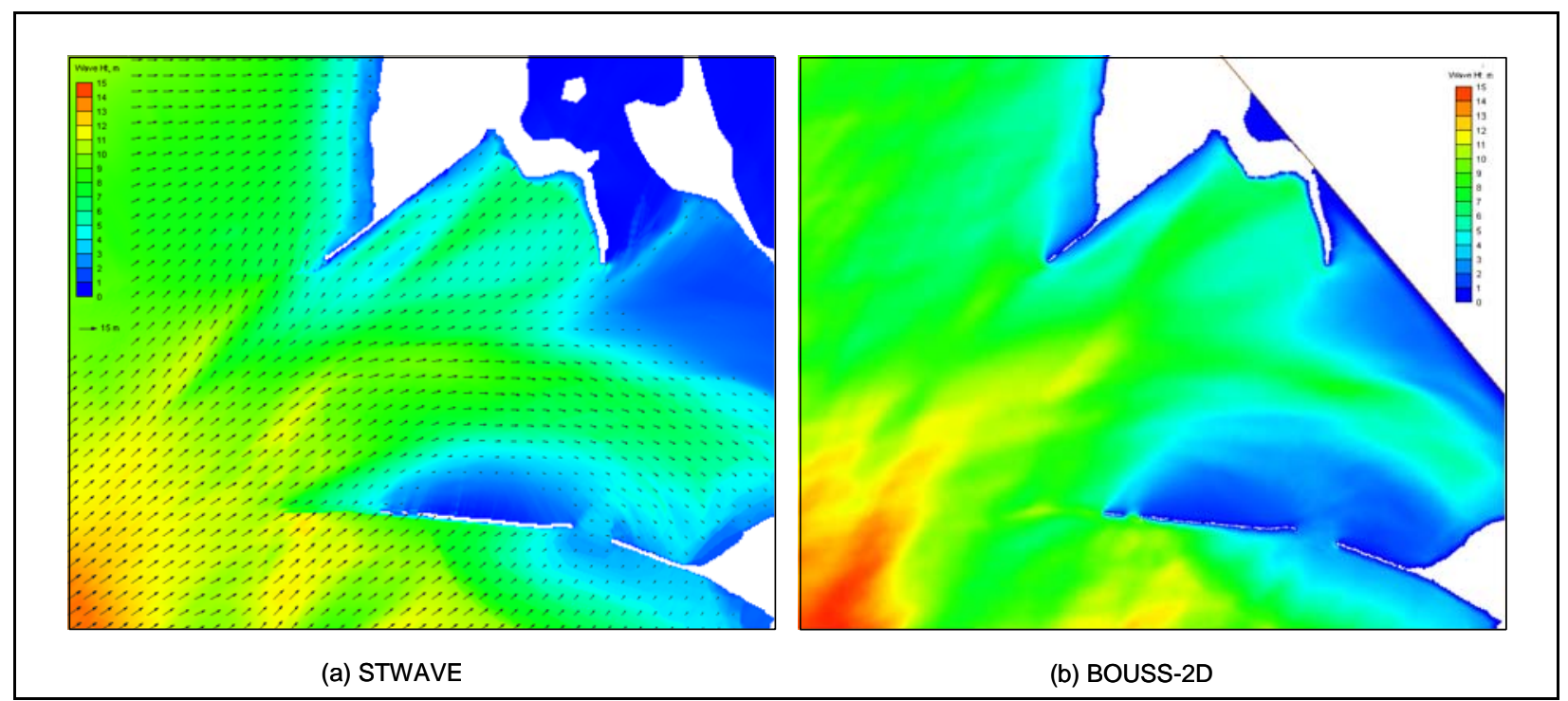

Figure 40. South jetty breach (a) STWAVE and (b) BOUSS-2D calculated wave fields for SW storm Event 6 at 13:00 GMT on 4 February 2006.

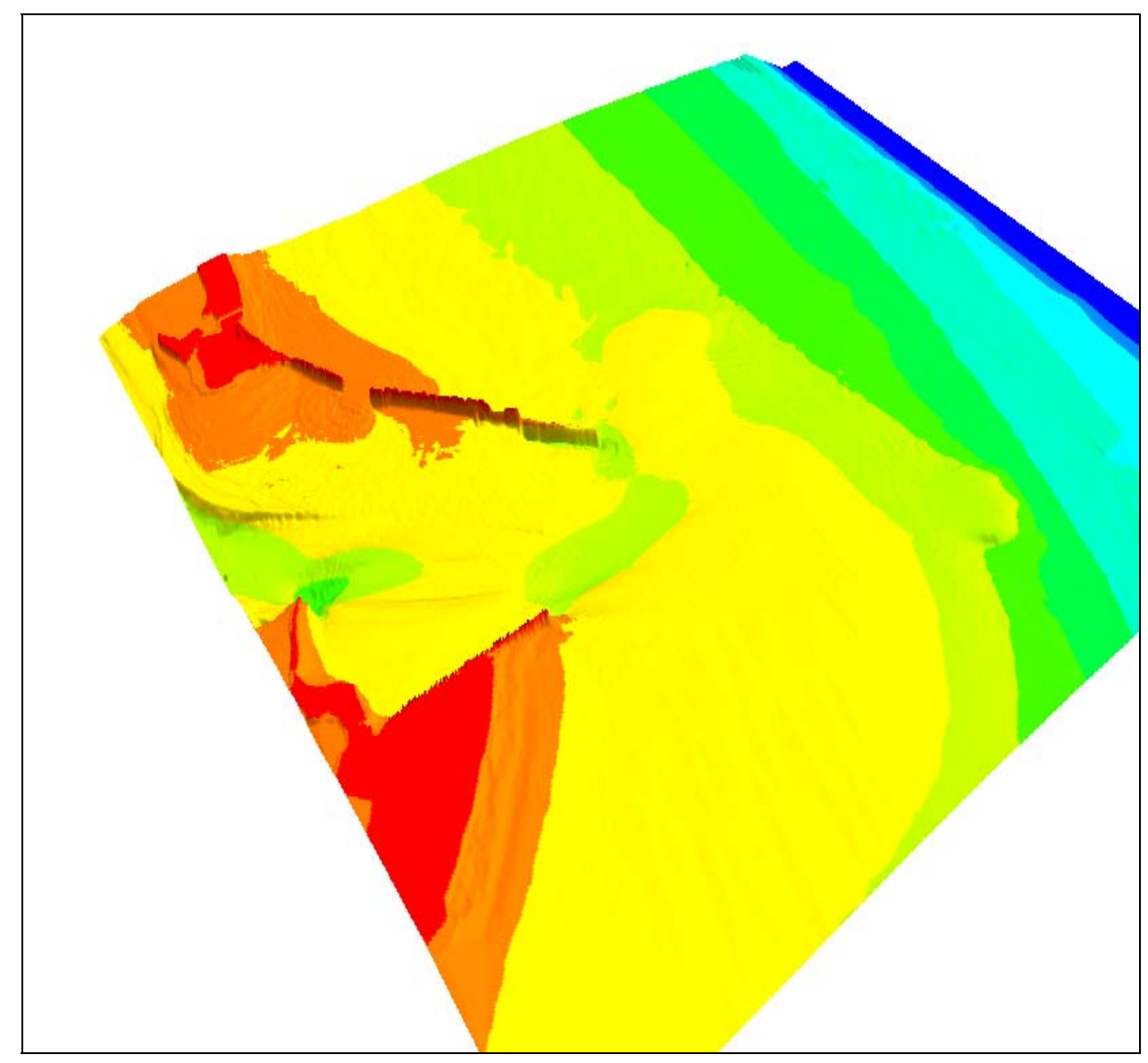

Figure 41. Three-dimensional view of bathymetry in south jetty breach configuration. 


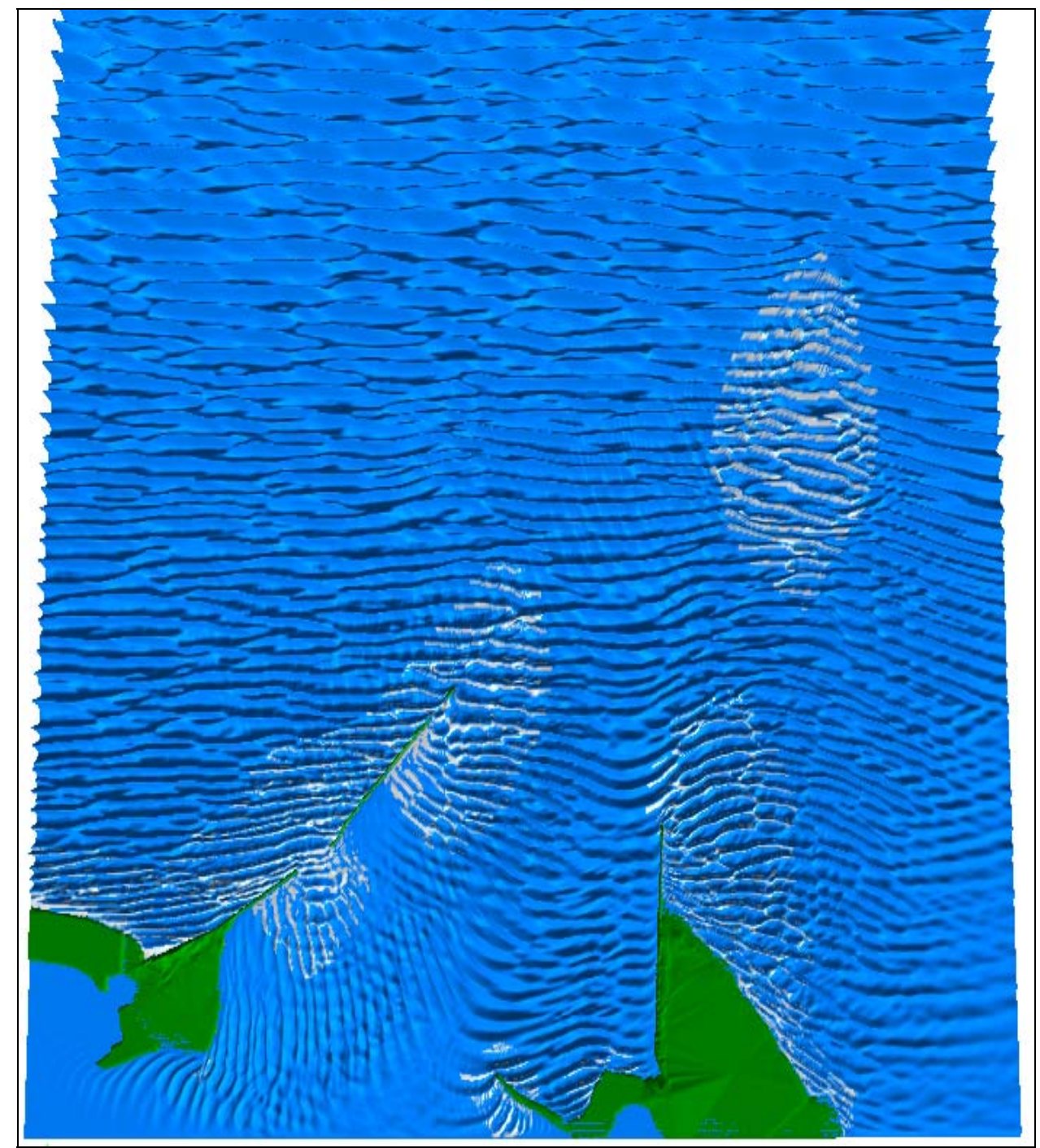

Figure 42. Three-dimensional view of wave field from BOUSS-2D for Event 6 at 13:00 GMT on 4 February 2006 for south jetty breach.

For the north jetty breach, additional results at special output locations from BOUSS-2D and STWAVE are compiled in Appendix B. Table B1 (in Appendix B) provides results for Event 4 and Table B2 for Event 6, respectively. Summary statistics for the ten sub-areas of interest are presented in Table $\mathrm{B}_{3}$. Tables $\mathrm{C}_{1}, \mathrm{C}_{2}$, and $\mathrm{C}_{3}$ (in Appendix C) provide results and statistics for the south jetty breach configuration. Results for the jetty breach configurations are analyzed in the Results and Discussion chapter. 
Table 6. Calculated wave parameters at mega-transect stations for north and south jetty breach configurations.

\begin{tabular}{|c|c|c|c|c|c|c|}
\hline \multirow[b]{2}{*}{ Location No. } & \multicolumn{3}{|c|}{ STWAVE } & \multicolumn{3}{|c|}{ BOUSS-2D } \\
\hline & $H s, \mathrm{~m}$ & $T p, \sec$ & $\theta_{m}$, deg & $H s, \mathrm{~m}$ & $T p, \sec$ & $\theta_{p}$, deg \\
\hline \multicolumn{7}{|c|}{ Event 4 Results with North Jetty Breach } \\
\hline 1 & 3.5 & 14.3 & 226.0 & 3.5 & 16.4 & 237.0 \\
\hline 2 & 3.7 & 14.3 & 226.0 & 2.6 & 16.4 & 237.0 \\
\hline 3 & 3.2 & 14.3 & 255.0 & 2.6 & 14.9 & 270.0 \\
\hline 4 & 6.8 & 14.3 & 276.0 & 4.0 & 13.7 & 283.0 \\
\hline 5 & 6.5 & 14.3 & 266.0 & 6.2 & 18.2 & 276.0 \\
\hline \multicolumn{7}{|c|}{ Event 6 Results with North Jetty Breach } \\
\hline 1 & 4.6 & 16.7 & 214.0 & 2.9 & 87.8 & 216.0 \\
\hline 2 & 5.3 & 16.7 & 217.0 & 5.1 & 21.9 & 223.0 \\
\hline 3 & 5.2 & 16.7 & 247.0 & 4.7 & 16.0 & 253.0 \\
\hline 4 & 8.9 & 16.7 & 262.0 & 6.5 & 21.9 & 256.0 \\
\hline 5 & 4.0 & 16.7 & 249.0 & 3.5 & 21.9 & 252.0 \\
\hline \multicolumn{7}{|c|}{ Event 4 Results with South Jetty Breach } \\
\hline 1 & 5.3 & 14.3 & 241.0 & 3.1 & 18.2 & 237.0 \\
\hline 2 & 2.4 & 14.3 & 235.0 & 2.9 & 16.4 & 240.0 \\
\hline 3 & 3.4 & 14.3 & 261.0 & 2.6 & 14.9 & 268.0 \\
\hline 4 & 6.6 & 14.3 & 276.0 & 4.3 & 14.9 & 285.0 \\
\hline 5 & 6.7 & 14.3 & 267.0 & 6.7 & 18.2 & 278.0 \\
\hline \multicolumn{7}{|c|}{ Event 6 Results with South Jetty Breach } \\
\hline 1 & 6.2 & 16.7 & 229.0 & 6.5 & 16.0 & 229.0 \\
\hline 2 & 4.6 & 16.7 & 225.0 & 5.1 & 16.0 & 228.0 \\
\hline 3 & 5.6 & 16.7 & 249.0 & 5.4 & 16.0 & 252.0 \\
\hline 4 & 8.9 & 16.7 & 261.0 & 6.5 & 21.9 & 253.0 \\
\hline 5 & 3.8 & 16.7 & 249.0 & 3.5 & 21.9 & 251.0 \\
\hline
\end{tabular}

Figures 37-42 show that there are similarities and some noticeable differences between BOUSS-2D and STWAVE results for the jetty breaches. High and low waves occur roughly in the same areas of the two model grids, although magnitude and extent of these are not the same at the disposal mounds, near the jetties, and inside the navigation channel. As a nonlinear wave model, BOUSS-2D is expected to accurately represent effects of wave breaking and dissipation, wave shoaling, wave refraction, diffraction and reflection at the gaps, in shallow water near the jetties, inside the navigation channel, and along the north and south beaches. Results of BOUSS-2D contain infra-gravity (IG) waves, with harmonics 
that include periods 30 to $1,000 \mathrm{sec}$, at the output locations, whereas wave periods from STWAVE remain essentially constant from offshore to nearshore. Therefore, BOUSS-2D predictions should be reliable in shallow water and near structures.

For the breached jetties, predicted wave heights by BOUSS-2D and STWAVE differ significantly (as much as $2 \mathrm{~m}$ ) in some areas of the model computational domains. Wave direction estimates from the two wave models agree better at some deepwater stations, but 10 to 30 deg differences occur at intermediate and shallow-water stations. Such differences in the wave parameters from two models may have consequences on the resulting wave-induced currents, sediment transport, and morphology change at the output locations. The differences between the two wave models are not surprising as they occur mostly in shallow water, near jetties, and along beaches, where wave shoaling, bottom friction, breaking, nonlinearities, and wave diffraction and reflection are dominant wave processes. Because these wave processes are represented by different governing equations and empirical formulas in each model, the two wave models are expected to produce different results. These and other aspects of the two wave model predictions and comparative statistics are presented in the Results and Discussion chapter.

\section{Jetty rehabilitation configurations}

The wave modeling for the jetty rehabilitation was performed for two jetty configurations: (a) rebuild of the north jetty seaward by $240 \mathrm{~m}$ (north jetty length rebuild configuration), and (b) rebuild of the south jetty seaward by $650 \mathrm{~m}$ from the existing fragmented jetty tip (south jetty length rebuild configuration). These rebuilt jetty lengths, as specified by the Portland District, were within the original authorized lengths. Figures 43 and 44 are the plan views of these rebuild jetty configurations, respectively. Extreme wave Events 4 and 6 were simulated to evaluate these configurations with BOUSS-2D and STWAVE. Results and statistics of wave parameters are compiled in Appendices D and E. 


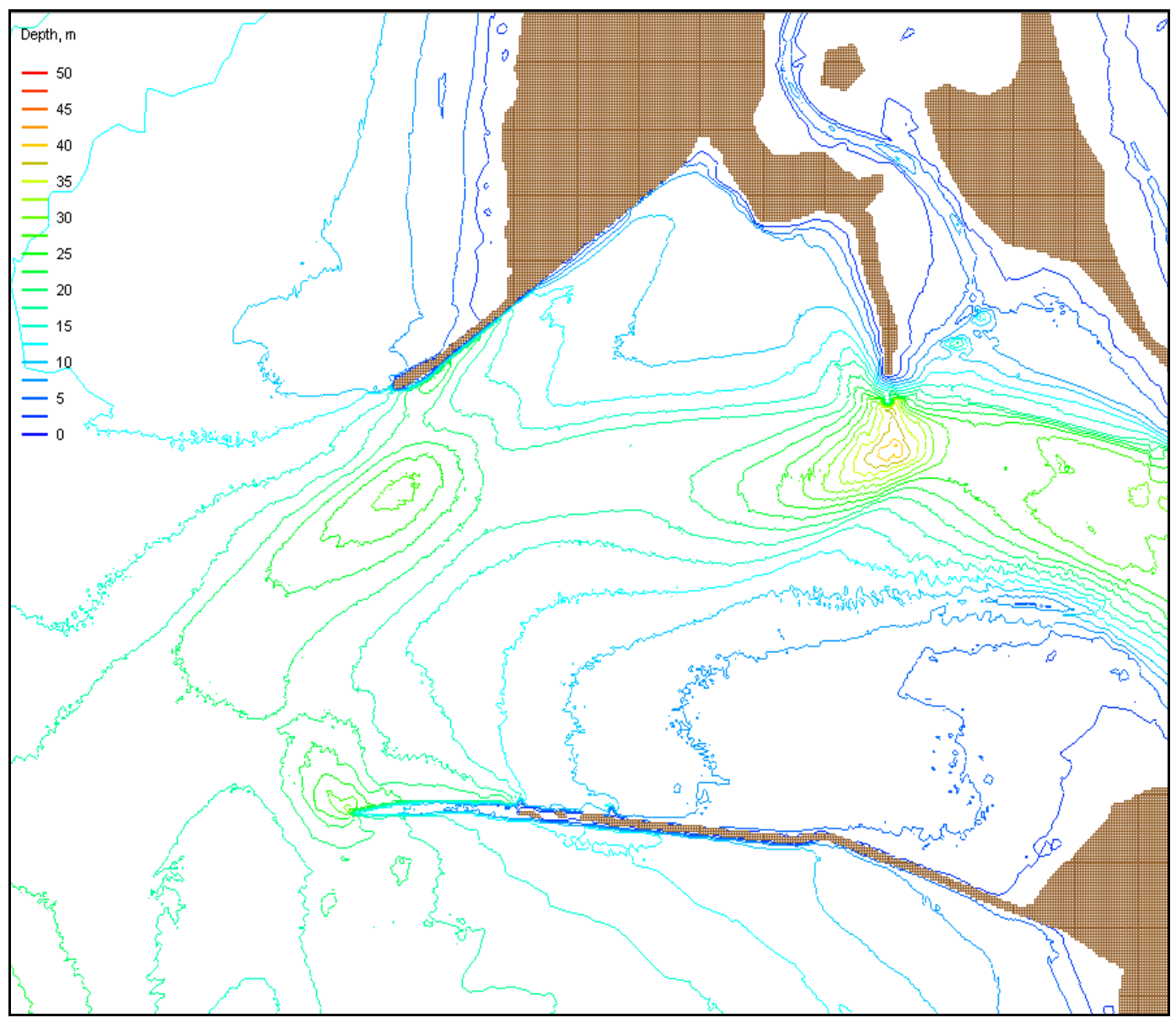

Figure 43. North jetty length rebuild configuration.

Table 7 provides modeling results at the five mega-transect stations for the north and south jetty length rebuild configurations. A complete set of two wave model results for the north jetty length rebuild configuration are compiled in Tables D1 and D2 of Appendix D; statistics are in Table D3. Tables E1 through E3 (Appendix E) present results and statistics for the south jetty length rebuild configuration. In Appendix D and $\mathrm{E}$ tables, calculated wave parameters from the two numerical wave models are listed at special output locations, and statistics are calculated for the ten sub-areas of interest. Statistics computed for these configurations are analyzed in the Results and Discussion chapter. 


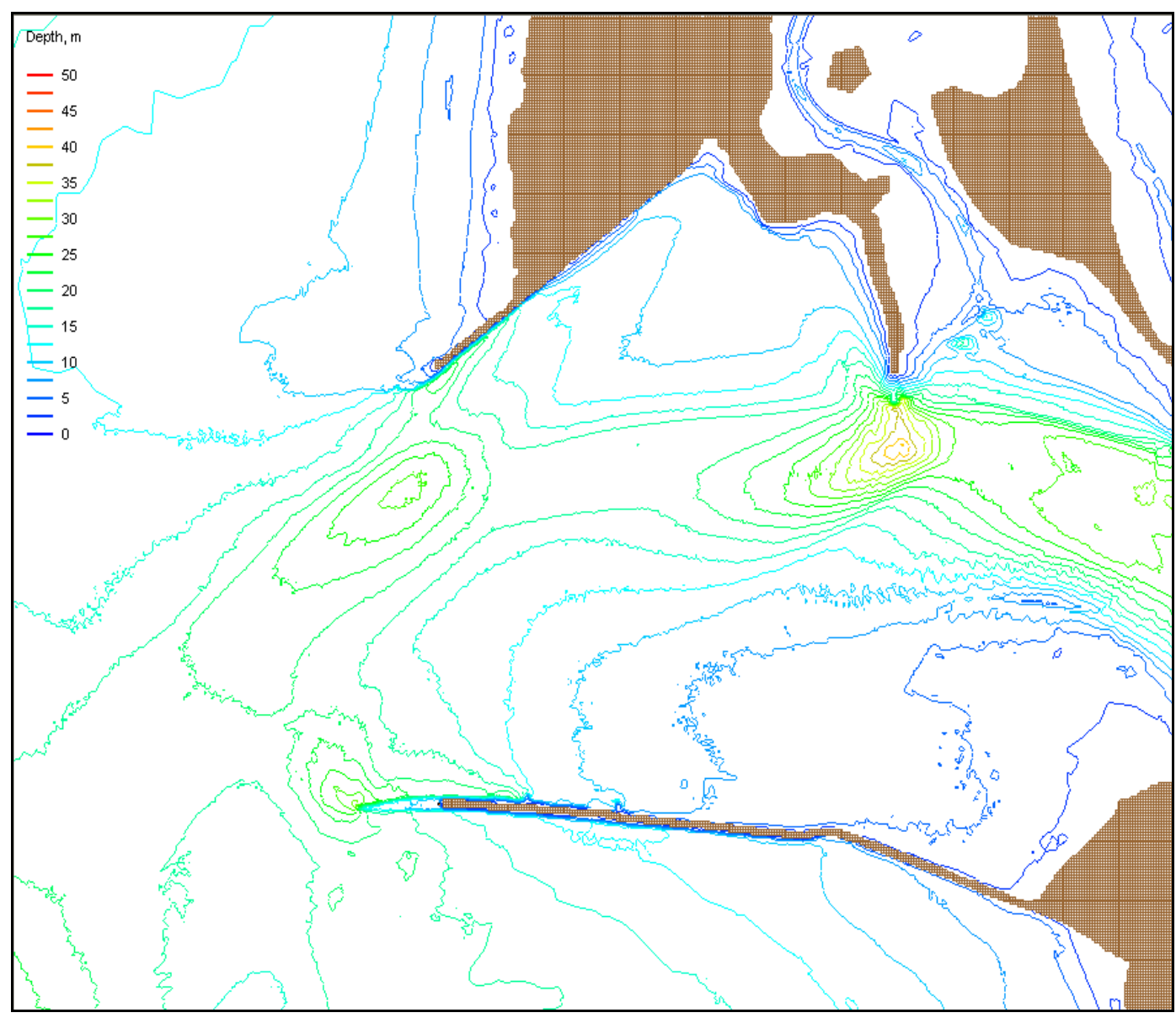

Figure 44. South jetty length rebuild configuration.

The calculated wave directions from the two wave models agree the best among the three wave parameters in Appendices D and E. Predicted wave height estimates from both models in Table 7 and Appendix D are comparable at some deepwater output stations, but there are some large differences between estimates from these models at intermediate and shallow-water locations. STWAVE maintains a constant wave period from deep to shallow water. The estimated peak wave period from BOUSS-2D is greater than the constant wave period from STWAVE because of wave energy transfer, from higher to lower frequencies, due to nonlinear wavewave interactions. Results from both models for the jetty rebuilt configurations are analyzed in the Results and Discussion chapter. 
Table 7. Calculated wave parameters at mega-transect stations for north and south jetty length rebuild configurations.

\begin{tabular}{|c|c|c|c|c|c|c|}
\hline \multirow[b]{2}{*}{ Location No. } & \multicolumn{3}{|c|}{ STWAVE } & \multicolumn{3}{|c|}{ BOUSS-2D } \\
\hline & Hs, m & $T p$, sec & $\theta_{m}$, deg & $H s, \mathrm{~m}$ & $T p$, sec & $\theta_{p}$, deg \\
\hline \multicolumn{7}{|c|}{ Event 4 Results for North Jetty Length Rebuild } \\
\hline 1 & 5.3 & 14.3 & 241.0 & 3.5 & 16.4 & 237.0 \\
\hline 2 & 2.4 & 14.3 & 234.0 & 2.6 & 16.4 & 237.0 \\
\hline 3 & 3.4 & 14.3 & 261.0 & 2.6 & 14.9 & 270.0 \\
\hline 4 & 6.8 & 14.3 & 277.0 & 4.0 & 13.7 & 283.0 \\
\hline 5 & 6.5 & 14.3 & 266.0 & 6.2 & 18.2 & 276.0 \\
\hline \multicolumn{7}{|c|}{ Event 6 Results for North Jetty Length Rebuild } \\
\hline 1 & 6.3 & 16.7 & 229.0 & 7.0 & 16.0 & 228.0 \\
\hline 2 & 4.8 & 16.7 & 225.0 & 5.8 & 16.0 & 228.0 \\
\hline 3 & 5.7 & 16.7 & 250.0 & 5.4 & 16.0 & 252.0 \\
\hline 4 & 8.9 & 16.7 & 262.0 & 6.3 & 21.9 & 256.0 \\
\hline 5 & 4.0 & 16.7 & 249.0 & 3.6 & 21.9 & 252.0 \\
\hline \multicolumn{7}{|c|}{ Event 4 Results for South Jetty Length Rebuild } \\
\hline 1 & 5.3 & 14.3 & 241.0 & 3.0 & 17.6 & 238.0 \\
\hline 2 & 2.4 & 14.3 & 235.0 & 3.1 & 17.6 & 241.0 \\
\hline 3 & 3.4 & 14.3 & 262.0 & 2.7 & 14.6 & 271.0 \\
\hline 4 & 6.8 & 14.3 & 277.0 & 4.3 & 14.6 & 283.0 \\
\hline 5 & 6.5 & 14.3 & 268.0 & 6.2 & 17.6 & 276.0 \\
\hline \multicolumn{7}{|c|}{ Event 6 Results for South Jetty Length Rebuild } \\
\hline 1 & 6.3 & 16.7 & 230.0 & 7.0 & 16.0 & 228.0 \\
\hline 2 & 4.6 & 16.7 & 226.0 & 6.1 & 16.0 & 228.0 \\
\hline 3 & 5.6 & 16.7 & 251.0 & 6.0 & 16.0 & 251.0 \\
\hline 4 & 8.9 & 16.7 & 264.0 & 5.9 & 21.9 & 254.0 \\
\hline 5 & 3.1 & 16.7 & 257.0 & 2.6 & 21.9 & 269.0 \\
\hline
\end{tabular}




\section{Results and Discussion}

Wave modeling results are examined in this chapter by using two wave statistics calculated for the ten sub-areas of particular interest to the Portland District. These wave statistical measures help to analyze and compare numerical model results. The first statistic is the difference between the two wave model predictions, defined as

$$
\Delta(\text { par })=\sum \frac{(\text { par })_{\text {STWAVE }}-(\text { par })_{\text {BOUSS-2D }}}{\mathrm{N}}
$$

where $\Delta$ denotes the average difference for one of the wave parameters (par), representing either the predicted significant wave height or peak wave period or peak wave direction from STWAVE and BOUSS-2D at subarea stations (Table 5), and $\mathrm{N}$ is the sample size (number of stations) for each of the ten sub-areas. The difference in Equation 1 is a positive number if the STWAVE prediction of a wave parameter exceeds BOUSS2D prediction, and negative if the STWAVE prediction is less than the value estimated from BOUSS-2D.

The second statistic calculated for the comparison of two wave model predictions is the RMSE, defined as

$$
\varepsilon_{\text {rms }}(\text { par })=\sqrt{\sum\left[(\text { par })_{\text {STWAVE }}-(\text { par })_{\text {BOUSS- } 2 \mathrm{D}}\right]^{2} / \mathrm{N}}
$$

of each predicted wave parameter from the STWAVE and BOUSS-2D models. Model-to-model comparative statistics are compiled in Appendices A-E for five project configurations. Statistics are provided for the ten sub-areas and also for the 148 special output locations.

The statistical measures defined in Equations 1 and 2 were calculated to quantitatively compare STWAVE and BOUSS-2D predictions locally for each configuration. The parameters compared are significant wave height, peak wave period, and either mean wave direction (STWAVE) or peak wave direction (BOUSS-2D), as predicted from STWAVE and BOUSS-2D at output stations (see Table 5 and Table A1). The statistics for smaller areas located in different parts of grids at different water depths provide 
useful insight into the spatial variation in wave parameters and help to determine statistical variability between the two wave models at the areas of interest to the Portland District.

Potential reasons for differences between BOUSS-2D and STWAVE predictions include the theory of the individual model, assumptions, differences in model grids (resolving features of navigation channel and beaches, grid resolution, different depth at comparison points, resolution of structures and disposal mounds), and computational limitations for representing extreme sea states at the MCR (i.e., exclusion of wind input, running model with default parameters). BOUSS-2D has nonlinear wavewave interactions, whereas STWAVE is a linear model. BOUSS-2D simulates sub- and super-harmonic waves during wave propagation in the nearshore. These harmonics are contained in the model output and may play a role in wave breaking and dissipation, and interaction of waves with structures and beaches.

Wave harmonics include infra-gravity waves with periods 30 to $1,000 \mathrm{sec}$, which are beyond the wind-wave period range ( 5 to $20 \mathrm{sec}$ ). To perform a comparison of the calculated wave periods by two models, the IG wave periods were limited to twice the wind-wave period of the incident waves. This limitation was necessary because wave period estimates from STWAVE remain constant (i.e., no sub-harmonic generation). In addition, special output stations outside BOUSS-2D model grids were omitted in calculation of wave parameter statistics. These points have been left without values (blank) in Tables A2 and A3 and other tables in Appendices B through E. Model results are provided only for stations that were within each model's respective grids (i.e., the omitted stations are not considered in the calculated statistics.)

The difference and RMSE statistics represent either statistical changes in three wave parameters occurring for a given configuration, or changes in wave parameters between a specific configuration and the existing configuration. In the latter case, the predictions for a given wave condition for a configuration are compared with the existing configuration results obtained with the same numerical wave model. The statistics defined in Equations 1 and 2 are first applied to predictions from the two models for the same configuration. For example, STWAVE results are compared to BOUSS-2D results for the north jetty breach configuration. Next, STWAVE 
results for the north jetty breach configuration are compared to STWAVE results for the existing configuration. Using this approach, individual model results and statistics of wave parameters for the five configurations are compiled in Appendices A to E for the ten sub-areas of interest at special output stations. The following discussion further analyzes both mild and extreme storm events, with an emphasis on the resulting changes in wave parameters in the sub-areas of primary interest to the Portland District.

\section{Mild wave conditions}

Three mild wave conditions (Table 2) were simulated in Chapter 3 with the existing configuration for validation of models. The simulated wave conditions during the measurement period were relatively mild. The difference between the calculated wave height from STWAVE (without wind) and measurements, ranged from 5 to 20 percent at the five mega-transect stations (Table 3). Similar differences were obtained from STWAVE simulations with or without wind forcing, and STWAVE fine grid results agreed slightly better with the measurements at the five mega-transect stations when compared to the coarse-grid results. The maximum difference between model and measurements occurred at sta 1, the station closest to the north jetty and land boundary in the model grids at the shallowest water depth. The largest difference between STWAVE wave parameter estimates (significant wave height, peak wave period, and mean direction) and measurements was similar for the three mild incident wave conditions (independent of wave nonlinearity).

BOUSS-2D validation simulations for the existing configuration yielded similar results, showing a stronger spatial variability in the wave fields on the measurement transect as well as in open water. The largest difference for calculated significant wave height and peak wave direction parameters (compared to the mega-transect measurements) is about 30 percent. The agreement between BOUSS-2D calculations and measurements for wave condition 3 did not improve with increasing incident wave height (stronger wave nonlinearities) because the model was run using default parameters. In addition, BOUSS-2D did not include wind forcing. The best agreement between the two wave models was obtained for STWAVE simulations without wind. The largest differences in wave height and direction estimates between the two models are $0.4 \mathrm{~m}$ and $10 \mathrm{deg}$, respecttively. Such differences are considered acceptable given inaccuracies in the 
location of field gauges deployed between jetties on a bathymetry with steep slopes. The proximity of the mega-transect gauges to the navigation channel and neglect of wave-current interaction may also have affected performance of the models.

Results were summarized in Table 3, wherein predictions from BOUSS-2D and STWAVE simulations are compared to the measurements. Because population size in Table 3 is limited (three wave conditions and five stations), a statistical comparison could not be made between models and measurements. A trend analysis was performed in Chapter 3 for individual model predictions by combining results for three wave conditions at five locations. For the trend analysis, the mean and standard deviations between model results and measurements were calculated. The overall mean difference and RMSE for STWAVE-calculated significant wave height and measurements are $0.095 \mathrm{~m}$ and $0.11 \mathrm{~m}$, respectively. The mean difference and RMSE for BOUSS-2D-calculated significant wave height and measurements are $-0.013 \mathrm{~m}$ and $0.19 \mathrm{~m}$, respectively. These values indicate that significant wave heights predicted by BOUSS-2D have a comparatively smaller mean difference than STWAVE but a larger spread. Overall, the predictive measures of trends for both models are similar for the simulated mild wave conditions.

The observed discrepancies between the two wave model estimates and measurements in shallow water and nearshore areas of the MCR are the result of different treatment of nonlinear wave shoaling, wave nonlinearities, and wave reflection and diffraction in each model. In spite of differences in the theory and numerics of the two models, the wave parameter estimates for three mild wave conditions are in good agreement with the measurements. Other potential causes for extreme storm waves are discussed below. These differences may also be partly due to uncertainties in the field measurements and analysis applied to field data. Overall, the two wave models produced similar results in the validation for three mild wave conditions occurring during the field data collection period in August-September 2005.

\section{Extreme waves}

The modeling procedure for extreme storm waves was described in Chapter 4. Extremely large waves have been reported to occur during winter storms at the MCR (Table 4), with wave height and period of 
approximately $14 \mathrm{~m}$ and $20 \mathrm{sec}$ at offshore Buoy 46029 . These storms often originate from the northwest or the southwest. They generate large wave heights and longer wave periods that can be harmful to the MCR jetties and beaches in the north and south sides of the entrance. Appendix A provides existing configuration results from numerical simulations for extreme events (Tables A2-A4), showing greater differences between BOUSS-2D and STWAVE model predictions for severe sea states than those for mild seas. The difference in the wave height estimates between the two wave models varies locally as much as $2 \mathrm{~m}$, and up to a 30-deg difference occurs in the wave direction. In comparison to differences reported for milder wave conditions discussed in the first part of this chapter and also in Chapter 3. The differences between the two models for storm waves are greater. This outcome is much different and is discussed in the next section.

The results provided in Appendices A to $\mathrm{E}$ for extreme waves for all configurations (existing, north jetty breach, south jetty breach, north jetty length rebuild, and south jetty length rebuild) show comparatively greater differences between BOUSS-2D and STWAVE. Calculated error statistics for the ten sub-areas of interest of each configuration are provided in appendices for two extreme storm Events 4 and 6 (Table 4). The differences between wave model predictions for each study configuration's wave parameter statistics are defined and compared to the existing configuration. In Appendices A to E, negative values imply that BOUSS-2D predictions are greater than predictions produced by STWAVE. In comparing a study configuration to an existing configuration, a negative value would indicate that the result for the existing configuration is greater than for that particular study configuration.

The areas most affected by the structural modification of a configuration were identified as those experiencing the greatest wave height difference. Wave period or wave direction differences could also be considered as a measure of the change in the areas of interest for a configuration (with and without project alternatives). Wave modeling results and wave parameter statistics provided in Appendices A to E can be interpreted in a number of ways. The statistics are applied to specific areas of a configuration to:

1. examine differences between wave model predictions,

2. compare a configuration's results to those of the existing configuration, 
3. assess the extent of a structural modification for the five configurations investigated.

The differences between the two wave model results for extreme waves vary locally and are larger compared with the relatively smaller differences reported for three mild wave conditions in the model validation. The potential causes of these differences are analyzed for each configuration in the following sections.

\section{Existing configuration}

The emphasis of numerical simulations for the existing configuration was on the entrance channel and the DWS and SWS dredged material disposal mounds. Because STWAVE simulations without wind produced slightly larger wave heights than with wind for extreme storms, wave fields were calculated for Events 4 and 6 (Table 4) with the fine grid of STWAVE without wind input. Statistics of calculated wave parameters (STWAVE versus BOUSS-2D) for Events 4 and 6 are presented in Table A4.

For Event 4, the largest average difference in the calculated wave height between the two models is $1.7 \mathrm{~m}$ in Area 3 (north jetty). The corresponding $2.1 \mathrm{~m} \mathrm{RMSE}$ is also the largest among the ten sub-areas. The wave period calculated by BOUSS-2D is greater than the value from STWAVE, where the latter is constant with or without wind. Because BOUSS-2D-calculated wave periods include IG waves and those of STWAVE do not, wave period statistics cannot be used in analyzing the merits of a configuration. The maximum difference in wave direction between the two models is -27.3 deg in Area 7 (SWS). Wave direction difference predicted by the two models is greater in shallower water. It is noted that the wave direction from BOUSS-2D is the spectral peak wave direction, whereas STWAVE calculates the spectral mean wave direction. For extreme waves with strong nonlinearities and strong wind, mean and peak wave directions can be different. For Event 6, the largest wave height difference occurs in Area 5 (south beach), which is directly exposed to southwest waves. The corresponding differences in wave height, period, and direction are $-\mathbf{1 . 2} \mathrm{m}$, $-12.5 \mathrm{sec}$, and $9 \mathrm{deg}$, and $1.3 \mathrm{~m}, 14.5 \mathrm{sec}$, and $10.9 \mathrm{deg}$ for the respective corresponding RMSE values. 
The two wave model results show that high and low waves appear approximately in the same areas. The magnitudes and extents of highs and lows are different at the areas of disposal mounds, near both jetties, inside the navigation channel, and along the north and south beaches. Possible explanations for these differences between the two wave model estimates are:

1. BOUSS-2D performs a wave-by-wave analysis to represent wave breaking and dissipation, nonlinear wave shoaling, wave refraction, diffraction, and reflection in shallow water near the jetties, inside the navigation channel, and along north and south beaches,

2. BOUSS-2D solution includes IG waves that may affect nearshore wave estimates,

3. STWAVE provides the phase-averaged estimates for wave propagation based on linear wave theory.

In addition, the nearshore wave processes are represented by a different set of governing equations and empirical formulas in each model. Model computational requirements are also different (grid resolution, orientation, specification of incident waves, water depth at the output locations where model results are extrapolated, etc.). Consequently, predicted significant wave heights by BOUSS-2D and STWAVE can differ by as much as $2 \mathrm{~m}$ in some areas of the individual model grids. In spite of these differences, wave direction estimates produced by the two wave models were in close agreement at deepwater locations. At output stations in close proximity to structures and in shallow water of two beaches, up to 30-deg differences occur. Because wave nonlinearities associated with extreme storm waves affect the nearshore wave processes more, BOUSS-2D predictions near structures and in shallow water at the MCR are expected to be reliable.

In the areas of primary interest (entrance channel, DWS, and SWS), the largest differences in wave height occurred in the SWS. For Events 4 and 6, STWAVE predicted $1.1 \mathrm{~m}$ and $0.5 \mathrm{~m}$, respectively, greater wave heights than BOUSS-2D in this area. The largest wave direction difference between the two models is 27.3 deg, occurring in the SWS for Event 4. In the entrance channel, STWAVE predicted $0.5 \mathrm{~m}$ greater wave height for Event 4, whereas BOUSS-2D predicted $0.8 \mathrm{~m}$ greater wave height for 
Event 6. BOUSS-2D also predicted $0.7 \mathrm{~m}$ greater wave height in the DWS for Event 6.

Results and wave statistics will next be interpreted for the remaining four configurations (see Tables B4, B5, C3, C4, C5, D3, D4, D5, E3, E4, and E5). The reasons discussed in the above analysis of comparative statistics of BOUSS-2D and STWAVE for the existing configuration would also hold in the examination of results for the remaining four configurations to be analyzed next.

\section{North jetty breach}

Examination of the north jetty breach configuration results for Events 4 and 6 (Table B3) shows that the two wave models produce different wave heights around the breached jetty in Areas 1 (mega-transect), 3 (north jetty), and 7 (SWS). For Event 4, the greatest wave height difference between the two wave models occurs in Areas 1, 2 (north beach), 3, 4 (south jetty), 5 (south beach), and 7. Event 6 statistics indicate Areas 1, 5, 6 (entrance channel), 7, and 8 (DWS) have the greatest wave height difference between the two wave models.

Wave statistics for Events 4 and 6 obtained from the two wave models for the north jetty breach versus the existing configurations are compiled in Tables B4 and B5, respectively. For Event 4 (Table B4), STWAVE results indicate that none of the ten sub-areas would experience an increase in wave height; zero change occurs in seven areas (2 and 4 to 9); and wave height decreases in three areas $(1,3$, and 10). The largest change occurs around the north jetty in Area 3. The corresponding differences in wave height, period, and direction are $-0.8 \mathrm{~m}, \mathrm{o} \mathrm{sec}$, and $4.7 \mathrm{deg}$, with the maximum RMSE values of $1.1 \mathrm{~m}$, o sec, and $21.9 \mathrm{deg}$, respectively. These results imply that, for Event 4, a $0.8 \mathrm{~m}$ decrease in wave height occurs for the north jetty breach configuration, no change in wave period, and 4.7 deg increase in wave direction.

BOUSS-2D results for Event 4 indicate three areas of no wave height change (2, 5, and 7), four areas of increasing wave height (3,6, 9, and 10), and two areas with decreasing height (1 and 4). Area 8 (DWS) is not contained in the model grid domain. BOUSS-2D shows the largest wave height increase of $0.2 \mathrm{~m}$ in Area 10 (Jetty A), and a $0.3 \mathrm{~m}$ largest decrease 
in Area 1. These are relatively small changes compared to the existing configuration.

For Event 6 (Table B5), STWAVE results indicate that the ten sub-areas have no increase in wave height compared to the existing configuration. Six areas have no wave height change. The other four areas $(1,3,4$, and 10) have decreasing wave height. The largest changes are -1.0 $\mathrm{m}$ in Area 3 (north jetty) and -0.4 $\mathrm{m}$ in Area 1 (mega-transect). BOUSS-2D shows the five areas have no change in wave height. Four areas $(1,3,6$, and 10) have decreasing height and Area 8 (DWS) has increasing height $(0.1 \mathrm{~m})$. The largest changes are -0.9 $\mathrm{m}$ in Area 1 (mega-transect) and -0.7 $\mathrm{m}$ in Area 10 (Jetty A).

In summary, the two wave models produced different results around the north jetty breach. In the absence of field data, it is not possible to determine which results are more reliable. STWAVE shows no increase in wave height due to breach in the north jetty. This prediction is not consistent with the analytical solution for waves passing through a gap, provided in the Coastal Engineering Manual (HQUSACE 2002), which shows increasing and decreasing wave height areas through the gap and vicinity areas. BOUSS-2D results show spatially varying (both increasing and decreasing) calculated wave fields in and around the gap area. Measurements are needed to verify the resulting calculated changes by both models.

\section{South jetty breach}

Examination of the south jetty breach results for Events 4 and 6 (Table $\mathrm{C}_{3}$ ) shows that the two wave models produce different wave heights in most of ten sub-areas. For Event 4, the greatest wave height difference between the two wave models occurs in Areas 1 (mega-transect), 2 (north beach), 3 (north jetty), and 7 (SWS). Event 6 statistics indicate Areas 1, 5 (south beach), 6 (entrance channel), 7 (SWS), and 8 (DWS) have the greatest wave height difference between the two wave models.

Comparison to the existing configuration for Event 4 (Table $\mathrm{C} 4$ ) shows STWAVE has a $1.2 \mathrm{~m}$ increase in Area 5 (south beach), $0.3 \mathrm{~m}$ decrease in Areas 4 (south jetty) and 9 (SJRS), and no change in other areas. BOUSS2D yielded a $1.5 \mathrm{~m}$ decrease in Area 5 (south beach), $0.2 \mathrm{~m}$ decrease in Area 9 (SJRS), $0.1 \mathrm{~m}$ increase in Areas 1 (mega-transect) and 4 (south 
jetty), and no change in other areas. These predictions from the two wave models agree only in Area 9 (SJRS).

For Event 6 (Table $\mathrm{C}_{5}$ ), STWAVE showed $1.2 \mathrm{~m}$ increase in Area 5 (south beach), 0.1 to $0.2 \mathrm{~m}$ decrease in Areas 1 (mega-transect), 4 (south jetty), 6 (entrance channel), and 10 (Jetty A), and no change in other areas. BOUSS-2D showed $0.7 \mathrm{~m}$ increase in Area 5 (south beach), $0.1 \mathrm{~m}$ increase in Areas 3 (north jetty) and 9 (SJRS), and 0.1 to $0.3 \mathrm{~m}$ decrease in Areas 1 (mega-transect), 4 (south jetty), 6 (entrance channel), 7 (SWS), and 10 (Jetty A). There is no change in Areas 2 (north beach) and 8 (DWS). Although the same trend in wave height increase is predicted in Area 5 (south beach) by both models, the magnitude of change is different by as much as 40 percent $(1.2 \mathrm{~m}$ versus $0.7 \mathrm{~m})$. Although the predictions by the two wave models for other areas do not agree, the magnitudes of changes are small. It can be concluded that the trends predicted by the two wave models are different for the south jetty breach as compared to the existing configuration. However, except for Area 5 (south beach), the differences are small.

\section{North jetty length rebuild}

In the case of the north jetty length rebuild for Events 4 and 6 (Table D3), the two wave models produced different wave heights in all ten sub-areas. For Event 4, the greatest wave height difference between the two wave models is $2 \mathrm{~m}$ in Area 3 (north jetty). Event 6 statistics indicate that Area 5 has the greatest wave height difference $(-1.2 \mathrm{~m})$ between the two wave models.

For Event 4, the north jetty length rebuild as compared to the existing configuration (Table D4), STWAVE indicated $0.1 \mathrm{~m}$ decrease in wave height in Area 3 (north jetty) and no change at the other nine sub-areas. BOUSS-2D showed a larger decrease (0.2 to $0.3 \mathrm{~m}$ ) in Areas 3 (north jetty), 4 (south jetty), and 5 (south beach). For Event 6 (Table D5), STWAVE showed no change in all ten sub-areas of interest, whereas BOUSS-2D had 0.1 and $0.3 \mathrm{~m}$ wave height decreases in Areas 2 (north beach) and 3 (north jetty), respectively. 


\section{South jetty length rebuild}

In the case of the south jetty length rebuild for Events 4 and 6 (Table E3), the two wave models produced different wave heights in all ten sub-areas. For Event 4, the greatest wave height difference between the two wave models is $1.8 \mathrm{~m}$ in Area 3 (north jetty). Event 6 statistics indicate that Area 5 has the greatest wave height difference $(-1.2 \mathrm{~m})$ between the two wave models.

For Event 4, compared to the existing configuration (Table E4), STWAVE showed a $0.1 \mathrm{~m}$ decrease in wave height in Area 4 (south jetty) and no change at other nine sub-areas. BOUSS-2D had a large decrease $(0.4 \mathrm{~m})$ in Area 4, a small decrease (0.1 m) in Area 3 (north jetty), and a small increase $(0.1 \mathrm{~m}$ ) in Areas 1 (mega-transect), 5 (south beach), 6 (entrance channel), and 9 (SJRS). For Event 6 (Table E5), STWAVE showed a 0.2 to $0.3 \mathrm{~m}$ decrease in wave height in Areas 1 and 4 and no change in other sub-areas. BOUSS-2D showed a $0.2 \mathrm{~m}$ decrease in Areas 1 and 3, a $0.2 \mathrm{~m}$ increase in Area 10 (Jetty A), and a smaller change in other sub-areas. 


\section{Conclusions}

This report describes a wave modeling study performed for the MCR with a Boussinesq model (BOUSS-2D) and a spectral model (STWAVE) for coastal wave transformation in a tidally dominated estuary environment exposed to swell and wind waves. Measurements of offshore and nearshore wave conditions at the MCR provided a valuable dataset for evaluation and validation of models. The MCR modeling domain includes dredged material placement sites with steep morphology relative to the regional conditions. It consists of an inlet with a navigation channel that has steep channel banks and is protected by two flanking jetties, and nearshore sloping areas that connect to two shallow coastal beaches.

Existing morphologic features at the MCR present a challenge for application of wave transformation models. Therefore, it was determined that two different categories of wave models should be considered at the MCR, spectral and Boussinesq-type. STWAVE calculated wave transformation from the offshore buoy at $128 \mathrm{~m}$ water depth to the MCR, covering an area approximately 26 by $22 \mathrm{~km}$. BOUSS-2D provided nonlinear wave propagation of waves over highly varying channel bathymetry for five jetty configurations with structural modifications, and covered a smaller nearshore area of approximately 12 by $15 \mathrm{~km}$. The decision by the Portland District to employ two different classes of wave models for the MCR project was a safeguard because of the complexities and challenges involved in modeling waves at MCR.

The two wave models produced similar results in deep to moderate-depth water for typical waves occurring in summer months. The model results were different in the surf zone because of differences in their grid resolution and orientation, predefined breaking criteria and energy dissipation mechanisms, etc. For storm waves occurring in winter months, the two models produced different results at the ten sub-areas of interest of the MCR.

The two wave models were first validated with field measurements; then the model results and comparative wave parameter statistics were developed for ten sub-areas of interest. The models were validated for 
three selected wave conditions with field measurements obtained in August-September 2005 along the mega-transect. Because wave conditions during this measurement period were relatively mild, both models performed well. Differences in calculated wave height at sta 2 to 5 from coarse and fine grids of STWAVE validation runs were small (less than 10 percent). STWAVE produced similar results with and without wind. Overall, STWAVE results from the fine grid agreed slightly better with the measurements at the mega-transect stations. For three mild wave conditions, average differences between wave parameter estimates (significant wave height, peak wave period, and mean direction) by the two models in comparison to measurements were less than 20 percent.

Because the population size in the model validation was limited (three wave conditions and five stations), only a trend analysis of individual model predictions was performed (see Chapter 3 ) by combining results for three wave conditions at five locations. The trends between two model results and a limited set of measurement points were quantified by calculating the mean and standard deviation. The overall mean difference and RMSE for BOUSS-2D-calculated significant wave height and measurements are $-0.013 \mathrm{~m}$ and $0.19 \mathrm{~m}$, and for the STWAVE are $0.095 \mathrm{~m}$ and $0.11 \mathrm{~m}$ (Table 3). These values indicate that significant wave heights predicted by BOUSS-2D have a comparatively smaller mean difference and a larger spread than STWAVE. The overall predictive trends of both models are similar for the three simulated wave conditions.

Although the two wave models produced similar results for mild wave conditions in the validation, it was observed that the difference between model predictions increased with increasing wave height. For storms, the difference in wave height in areas adjacent to the jetty breaches also increased with larger wave height. Simulated jetty breaches with STWAVE showed little or no effect of structural gaps on adjacent beaches and the navigation channel. STWAVE simulations with the jetty length rebuild showed a minor effect on waves in areas between the two jetties, whereas BOUSS-2D showed a comparatively greater wave height change in the same areas. The magnitude and intensity of wave focusing in areas near the DWS and SWS from BOUSS-2D and STWAVE simulations were different. These differences may be attributed to model grids (resolution, orientation, and differences in incident wave forcing), different treatment of wave shoaling, refraction, and breaking and dissipation processes in 
each model that affect wave estimates over these mounds, and also the absence of wind forcing in BOUSS-2D. Because of the observed intensity of wave focusing and resulting wave breaking at DWS and SWS, strong wave-induced currents are expected to occur over these areas. In the shallow water, the largest differences between wave model predictions generally occurred near the north jetty, south jetty, around Jetty A, and along shallow areas of the north and south beaches.

Wave modeling results for various wave conditions and jetty alternatives were compiled in tables in Appendices A to E. From these tables, statistics were calculated for three wave parameters to identify areas most affected by structural modifications to the north and south jetties. Two statistical measures were calculated to quantify changes and differences in predicted results and measurements at 148 selected output stations selected by the Portland District. Statistics were also calculated for the ten sub-areas consisting of a finite number of stations around the DWS, SWS, channel, north jetty, and south jetty. These statistics for each sub-area may be useful to present and future project planning and management.

The statistics were calculated for two severe storms recently occurring at the MCR. These two storms are not representative of typical monthly, seasonal, or annual extreme storms. In the absence of field data for severe storms, relative comparison and reliability of wave model predictions could not be determined for large waves. The calculated results and statistics provide the Portland District wave information to evaluate future project alternatives, and positive, intended or unintended consequences of jetty modifications (breach and length rebuild). The expected variability in wave parameter estimates for mild to severe storms in different areas of the MCR is also presented.

The differences between the two wave model predictions for extreme storms were described in Chapter 4. High and low waves of different magnitude and extent appeared at the disposal sites, near the jetties, inside the navigation channel, and along the north and south beaches. These differences were attributed to different representation of wave transformations and coastal structures in the models. The IG waves in the BOUSS-2D solutions are believed to affect nearshore wave processes in shallow water areas of interest. The largest differences between the two wave model estimates occurred in shallow water, near jetties and land boundaries, and 
along beaches, where wave processes such as shoaling, bottom friction, breaking, nonlinearities, and wave reflection and diffraction are most important.

In summary, the two wave models applied at the MCR performed as expected within their strengths and limitations. These models represent wave processes using different governing equations and empirical formulas. Computational requirements for each model are different, including grid resolution, orientation, incident waves, and depth of the extrapolated results at the output locations. Consequently, models were expected to yield somewhat different estimates of wave height, period, and direction for extreme storms. Although wave height estimates from the models differed in some areas of the computational domains, wave directions were generally in closer agreement at deepwater stations, with comparatively greater differences occurring near structures and in shallow water along the beaches.

Wave nonlinearities in BOUSS-2D for extreme storms would affect nearshore wave processes in the areas of interest. The difference in the wave height, direction, and period estimates from the two models may influence wave-induced currents, sediment transport, and morphology change at the MCR areas of interest. 


\section{References}

Booij, N. C., L. H. Holthuijsen, and R. C. Ris. 1996. The SWAN wave model for shallow water. Proceedings $25^{\text {th }}$ International Conference on Coastal Engineering, American Society of Civil Engineers (ASCE), pp. 668-676.

Booij, N. C., R. C. Ris, and L. H. Holthuijsen. 1999. A third-generation wave model for coastal regions: Part I: Model description and validation. Journal of Geophysical Research 104(C4):7649-7666.

Demirbilek, Z., O. G. Nwogu, and D. L. Ward. 2007a. Laboratory study of wind effect on runup over fringing reefs: Report 1: Data report. Coastal and Hydraulics Laboratory Technical Report ERDC/CHL TR-07-4. Vicksburg, MS: U.S. Army Engineer Research and Development Center.

Demirbilek, Z., O. G. Nwogu, and A. K. Zundel. 2007b. Infra-gravity wave input toolbox: User's guide. Coastal and Hydraulics Laboratory Technical Note ERDC/CHL CHETN-I-73. Vicksburg, MS: U.S. Army Engineer Research and Development Center.

Demirbilek, Z., A. K. Zundel, and O. Nwogu. 2005a. BOUSS-2D model in the SMS: 1. Graphical interface. Coastal and Hydraulics Engineering Technical Note ERDC/CHL CHETN I-69. Vicksburg, MS: U.S. Army Engineer Research and Development Center.

. 2005b. BOUSS-2D model in the SMS: 2. Tutorial with examples. Coastal and Hydraulics Engineering Technical Note ERDC/CHL CHETN I-69. Vicksburg, MS: U.S. Army Engineer Research and Development Center.

Headquarters, U.S. Army Corps of Engineers. 2002. Coastal Engineering Manual. EM 1110-2-110o. Washington, DC (in six volumes).

Kirby, J. T., G. Wei, Q. Chen, A. B. Kennedy, and R. A. Dalrymple. 1998. FUNWAVE 1.0: Fully nonlinear Boussinesq wave model documentation and user's manual. Newark, DE: Center for Applied Coastal Research, University of Delaware.

Luettich, R. A., J. J. Westerink, and N. W. Scheffner. 1991. ADCIRC: An advanced threedimensional circulation model for shelves, coasts and estuaries; Report 1: Theory and methodology of ADCIRC-2DDI and ADCIRC-3DL. Dredging Research Program Technical Report DRP-92-6. Vicksburg, MS: U.S. Army Engineer Waterways Experiment Station.

Lynett, P., and P.-L. F. Liu. 2002. Cornell University long and intermediate wave modeling package (COULWAVE). http://ceprofs.tamu.edu/plynett/COULWAVE/.

Mase, H., H. Amamori, and T. Takayama. 2005. Wave prediction model in wave-current coexisting field. Proceedings $12^{\text {th }}$ Canadian Coastal Conference (CD-ROM). 
Moritz, H. R. 2005. Mouth of the Columbia River mega-transect instrument deployment, internal document. Portland, OR: U.S. Army Engineer District, Portland.

Moritz, H. R., H. P. Moritz, J. R. Hays, and H. R. Sumerell. 2003. Holistic framework for assessing the functional integrity of navigation structures at the Mouth of the Columbia River. Proceedings Coastal Structures, ASCE, 1,299-1,311.

Nwogu, O., and Z. Demirbilek. 2001. BOUSS-2D: A Boussinesq wave model for coastal regions and harbors. Technical Report ERDC/CHL TR-01-25, Vicksburg, MS: U.S. Army Engineer Research and Development Center.

Resio, D. T. 1987. Shallow-water waves. I: Theory. J ournal of Waterway, Port, Coastal, and Ocean Engineering 113(3):264-281. . 1988. Shallow-water waves. II: Data comparisons. J ournal of Waterway, Port, Coastal, and Ocean Engineering 114(1):50-65.

Ris, R. C., L. Holthuijsen, and N. Booij. 1999. A third-generation wave model for coastal regions, Part II, Verification. J ournal of Geophysical Research 104(C4):76677681 .

Smith, J. M. 2001. Modeling nearshore transformation with STWAVE. Coastal and Hydraulics Laboratory Special Report, ERDC/CHL SR-01-01. Vicksburg, MS: U.S. Army Engineer Research and Development Center.

Smith, J. M., D. T. Resio, and A. Zundel. 1999. STWAVE: Steady-state spectral wave model, Report 1: User's manual for STWAVE Version 2.0. Coastal and Hydraulics Laboratory Instruction Report CHL-99-1. Vicksburg, MS: U.S. Army Engineer Research and Development Center.

Smith, S. J., and J. M. Smith. 2001. Numerical modeling of waves at Ponce de Leon Inlet, Florida. J ournal of Waterway, Port, Coastal, and Ocean Engineering 127(3), 176-184.

Zundel, A. 2006. Surface-water Modeling System reference manual - Version 9.2, Brigham Young University Environmental Modeling Research Laboratory, Provo, UT. 


\section{Appendix A: Existing Configuration Results}

Table A1. Special output locations.

\begin{tabular}{|c|c|c|c|}
\hline Location No. & Easting, $\mathrm{m}$ & Northing, $m$ & Depth, $\mathrm{m}$ \\
\hline 1 & 335511.0 & 295452.0 & 9.7 \\
\hline 2 & 335346.0 & 294579.0 & 12.9 \\
\hline 3 & 335672.0 & 293954.0 & 21.7 \\
\hline 4 & 334924.0 & 293275.0 & 14.2 \\
\hline 5 & 334626.0 & 292039.0 & 10.4 \\
\hline 6 & 335543.0 & 293329.0 & 15.5 \\
\hline 7 & 326272.0 & 291631.8 & 24.7 \\
\hline 8 & 325425.0 & 291569.8 & 40.0 \\
\hline 9 & 330341.9 & 293119.3 & 14.3 \\
\hline 10 & 332552.4 & 283554.1 & 34.3 \\
\hline 11 & 335919.8 & 289648.5 & 14.8 \\
\hline 12 & 333771.3 & 297581.6 & 2.7 \\
\hline 13 & 333626.6 & 297023.8 & 3.9 \\
\hline 14 & 333564.7 & 296486.7 & 3.4 \\
\hline 15 & 333523.3 & 295928.9 & 4.7 \\
\hline 16 & 333461.4 & 295391.8 & 4.4 \\
\hline 17 & 333027.5 & 295061.2 & 8.6 \\
\hline 18 & 333006.9 & 294627.4 & 7.9 \\
\hline 19 & 333482.0 & 294565.4 & 16.4 \\
\hline 20 & 333957.2 & 294937.3 & 13.4 \\
\hline 21 & 334453.0 & 295309.1 & 12.1 \\
\hline 22 & 334969.5 & 295701.6 & 10.7 \\
\hline 23 & 335506.6 & 296135.5 & 8.9 \\
\hline 24 & 334163.8 & 295433.1 & 8.8 \\
\hline 25 & 334225.8 & 295350.4 & 12.8 \\
\hline 26 & 334287.7 & 295288.4 & 12.1 \\
\hline 27 & 334349.7 & 295226.5 & 12.4 \\
\hline 28 & 334411.7 & 295164.5 & 12.9 \\
\hline 29 & 334473.7 & 295102.5 & 12.5 \\
\hline 30 & 334535.6 & 295040.5 & 11.7 \\
\hline 31 & 334267.1 & 295495.0 & 8.3 \\
\hline 32 & 334329.0 & 295433.1 & 12.1 \\
\hline 33 & 334391.0 & 295371.1 & 12.6 \\
\hline
\end{tabular}


Table A1. Continued.

\begin{tabular}{|c|c|c|c|}
\hline Location No. & Easting, m & Northing, $m$ & Depth, m \\
\hline 34 & 334515.0 & 295247.1 & 12.3 \\
\hline 35 & 334060.5 & 295350.4 & 14.3 \\
\hline 36 & 334122.4 & 295267.8 & 13.2 \\
\hline 37 & 334184.4 & 295205.8 & 11.8 \\
\hline 38 & 334246.4 & 295143.8 & 12.3 \\
\hline 39 & 334308.4 & 295081.9 & 12.9 \\
\hline 40 & 337572.5 & 291259.9 & 5.0 \\
\hline 41 & 336952.7 & 291404.6 & 5.5 \\
\hline 42 & 336333.0 & 291590.5 & 6.8 \\
\hline 43 & 335713.2 & 291590.5 & 7.0 \\
\hline 44 & 335093.4 & 291631.8 & 8.1 \\
\hline 45 & 334473.7 & 291714.4 & 9.5 \\
\hline 46 & 333853.9 & 291776.4 & 12.5 \\
\hline 47 & 333647.3 & 291425.2 & 6.6 \\
\hline 48 & 333977.8 & 291136.0 & 14.0 \\
\hline 49 & 334432.3 & 291012.0 & 13.4 \\
\hline 50 & 335052.1 & 290970.7 & 12.5 \\
\hline 51 & 335671.9 & 290867.4 & 11.6 \\
\hline 52 & 336291.6 & 290929.4 & 10.3 \\
\hline 53 & 336911.4 & 290660.8 & 8.7 \\
\hline 54 & 337531.2 & 290350.9 & 7.8 \\
\hline 55 & 338171.6 & 290103.0 & 6.1 \\
\hline 56 & 338584.8 & 289669.2 & 4.4 \\
\hline 57 & 338894.7 & 289173.4 & 3.6 \\
\hline 58 & 339142.6 & 288656.9 & 2.6 \\
\hline 59 & 339369.8 & 288161.1 & 2.6 \\
\hline 60 & 336870.1 & 291198.0 & 4.2 \\
\hline 61 & 336911.4 & 291301.3 & 5.3 \\
\hline 62 & 336994.1 & 291507.8 & 5.8 \\
\hline 63 & 337035.4 & 291611.2 & 6.0 \\
\hline 64 & 337097.3 & 291797.1 & 5.9 \\
\hline 65 & 337180.0 & 292003.7 & 5.4 \\
\hline 66 & 336663.5 & 291280.6 & 4.9 \\
\hline 67 & 336704.8 & 291383.9 & 5.7 \\
\hline 68 & 336746.1 & 291487.2 & 6.3 \\
\hline 69 & 336787.5 & 291590.5 & 6.3 \\
\hline 70 & 336828.8 & 291693.8 & 7.0 \\
\hline
\end{tabular}


Table A1. Continued.

\begin{tabular}{|c|c|c|c|}
\hline Location No. & Easting, $\mathrm{m}$ & Northing, $m$ & Depth, $\mathrm{m}$ \\
\hline 71 & 337076.7 & 291115.3 & 3.7 \\
\hline 72 & 337118.0 & 291218.6 & 4.8 \\
\hline 73 & 337159.3 & 291321.9 & 5.2 \\
\hline 74 & 337200.6 & 291425.2 & 5.6 \\
\hline 75 & 337242.0 & 291528.5 & 5.5 \\
\hline 76 & 336994.1 & 294131.5 & 37.7 \\
\hline 77 & 336374.3 & 294048.9 & 27.3 \\
\hline 78 & 334990.1 & 293863.0 & 18.7 \\
\hline 79 & 334225.8 & 293821.7 & 18.1 \\
\hline 80 & 333461.4 & 293718.4 & 21.2 \\
\hline 81 & 332924.2 & 293222.6 & 20.3 \\
\hline 82 & 332345.8 & 292664.8 & 19.6 \\
\hline 83 & 331767.3 & 292148.3 & 20.3 \\
\hline 84 & 331188.9 & 291590.5 & 18.4 \\
\hline 85 & 330672.4 & 291074.0 & 19.1 \\
\hline 86 & 330155.9 & 290598.9 & 20.2 \\
\hline 87 & 329722.1 & 290185.7 & 23.2 \\
\hline 88 & 332635.0 & 294358.8 & 16.6 \\
\hline 89 & 332304.5 & 294152.2 & 15.3 \\
\hline 90 & 331973.9 & 293945.6 & 15.2 \\
\hline 91 & 331643.4 & 293739.0 & 16.0 \\
\hline 92 & 331312.8 & 293532.4 & 16.2 \\
\hline 93 & 330982.3 & 293325.8 & 15.2 \\
\hline 94 & 330651.8 & 293119.3 & 15.4 \\
\hline 95 & 330321.2 & 292912.7 & 15.8 \\
\hline 96 & 329990.7 & 292706.1 & 15.9 \\
\hline 97 & 324226.8 & 287644.6 & 66.8 \\
\hline 98 & 323772.3 & 287293.4 & 70.0 \\
\hline 99 & 323317.8 & 286942.2 & 70.8 \\
\hline 100 & 322863.3 & 286591.0 & 72.4 \\
\hline 101 & 322408.8 & 286239.8 & 72.2 \\
\hline 102 & 321954.3 & 285888.6 & 77.7 \\
\hline 103 & 321499.8 & 285537.4 & 78.9 \\
\hline 104 & 321045.3 & 285186.2 & 84.0 \\
\hline 105 & 320590.8 & 284835.0 & 85.5 \\
\hline 106 & 320136.3 & 284483.8 & 86.4 \\
\hline
\end{tabular}


Table A1. Continued.

\begin{tabular}{|c|c|c|c|}
\hline Location No. & Easting, $\mathrm{m}$ & Northing, $m$ & Depth, $\mathrm{m}$ \\
\hline 107 & 322842.6 & 287066.2 & 72.3 \\
\hline 108 & 323111.2 & 286776.9 & 71.1 \\
\hline 109 & 323379.8 & 286487.7 & 71.8 \\
\hline 110 & 336374.3 & 290123.7 & 12.3 \\
\hline 111 & 336229.7 & 289834.5 & 13.8 \\
\hline 112 & 336085.1 & 289545.3 & 14.9 \\
\hline 113 & 335940.4 & 289256.0 & 15.4 \\
\hline 114 & 335795.8 & 288966.8 & 16.1 \\
\hline 115 & 335651.2 & 288677.6 & 16.8 \\
\hline 116 & 335506.6 & 288388.3 & 17.4 \\
\hline 117 & 334205.1 & 290123.7 & 17.2 \\
\hline 118 & 334638.9 & 289917.1 & 16.8 \\
\hline 119 & 335072.8 & 289710.5 & 16.2 \\
\hline 120 & 335506.6 & 289483.3 & 15.7 \\
\hline 121 & 336374.3 & 289049.4 & 14.8 \\
\hline 122 & 336808.1 & 288842.8 & 14.5 \\
\hline 123 & 337242.0 & 288636.3 & 13.7 \\
\hline 124 & 337675.8 & 288429.7 & 12.7 \\
\hline 125 & 336684.2 & 295019.9 & 11.4 \\
\hline 126 & 336746.1 & 294792.6 & 17.3 \\
\hline 127 & 336787.5 & 294565.4 & 26.9 \\
\hline 128 & 336808.1 & 294420.8 & 30.9 \\
\hline 129 & 336952.7 & 294420.8 & 36.7 \\
\hline 130 & 337097.4 & 294420.8 & 33.0 \\
\hline 131 & 337118.0 & 294565.4 & 20.9 \\
\hline 132 & 337138.7 & 294792.6 & 5.9 \\
\hline 133 & 337178.0 & 295019.9 & 3.6 \\
\hline 134 & 336622.2 & 295267.8 & 8.7 \\
\hline 135 & 336539.6 & 295598.3 & 6.7 \\
\hline 136 & 332862.2 & 294792.6 & 9.2 \\
\hline 137 & 332820.9 & 294482.8 & 15.4 \\
\hline 138 & 333172.1 & 294482.8 & 21.0 \\
\hline 139 & 332593.7 & 294895.9 & 9.1 \\
\hline 140 & 331829.3 & 294565.4 & 10.6 \\
\hline 141 & 330982.3 & 294214.2 & 12.6 \\
\hline 142 & 330259.2 & 293904.3 & 13.3 \\
\hline
\end{tabular}


Table A1. Concluded.

\begin{tabular}{|l|l|l|l|}
\hline Location No. & Easting, $\mathrm{m}$ & Northing, $\mathrm{m}$ & Depth, $\mathrm{m}$ \\
\hline 143 & 329329.6 & 293491.1 & 14.6 \\
\hline 144 & 333544.0 & 291755.8 & 16.2 \\
\hline 145 & 333254.8 & 291714.4 & 18.4 \\
\hline 146 & 332965.6 & 291425.2 & 10.0 \\
\hline 147 & 333254.8 & 291239.3 & 16.8 \\
\hline 148 & 333606.0 & 291177.3 & 15.2 \\
\hline
\end{tabular}

(Sheet 5 of 5 )

Table A2. Event 4 results for existing configuration.

\begin{tabular}{|c|c|c|c|c|c|c|}
\hline \multirow[b]{2}{*}{ Location No. } & \multicolumn{3}{|c|}{ STWAVE } & \multicolumn{3}{|c|}{ BOUSS-2D } \\
\hline & $H_{s}, \mathrm{~m}$ & $T_{p}, \mathrm{sec}$ & $\theta_{m}$, deg & $H_{s}, \mathrm{~m}$ & $T_{p}, \mathrm{sec}$ & $\theta_{p}, \operatorname{deg}$ \\
\hline 1 & 5.3 & 14.3 & 241.0 & 3.1 & 18.2 & 238.0 \\
\hline 2 & 2.4 & 14.3 & 235.0 & 2.9 & 16.4 & 241.0 \\
\hline 3 & 3.4 & 14.3 & 261.0 & 2.6 & 14.9 & 271.0 \\
\hline 4 & 6.8 & 14.3 & 277.0 & 4.2 & 13.7 & 284.0 \\
\hline 5 & 6.5 & 14.3 & 266.0 & 6.2 & 18.2 & 278.0 \\
\hline 6 & 5.5 & 14.3 & 280.0 & 3.6 & 14.9 & 287.0 \\
\hline 7 & 9.5 & 14.3 & 275.0 & 9.0 & 14.9 & 285.0 \\
\hline 8 & 9.0 & 14.3 & 285.0 & 9.1 & 14.9 & 294.0 \\
\hline 9 & 8.9 & 14.3 & 270.0 & 9.9 & 18.2 & 285.0 \\
\hline 10 & 8.2 & 14.3 & 278.0 & & & \\
\hline 11 & 9.2 & 14.3 & 266.0 & 9.2 & 13.7 & 276.0 \\
\hline 12 & 2.8 & 14.3 & 287.0 & 4.3 & 18.2 & 303.0 \\
\hline 13 & 3.5 & 14.3 & 287.0 & 4.8 & 18.2 & 299.0 \\
\hline 14 & 3.2 & 14.3 & 279.0 & 4.1 & 327.6 & 305.0 \\
\hline 15 & 3.9 & 14.3 & 276.0 & 4.3 & 18.2 & 310.0 \\
\hline 16 & 3.8 & 14.3 & 266.0 & 4.9 & 13.7 & 298.0 \\
\hline 17 & 5.9 & 14.3 & 265.0 & 5.8 & 16.4 & 291.0 \\
\hline 18 & 6.0 & 14.3 & 214.0 & 6.1 & 16.4 & 263.0 \\
\hline 19 & 6.5 & 14.3 & 241.0 & 4.5 & 14.9 & 255.0 \\
\hline 20 & 5.9 & 14.3 & 239.0 & 2.5 & 14.9 & 228.0 \\
\hline 21 & 4.8 & 14.3 & 236.0 & 2.0 & 14.9 & 228.0 \\
\hline 22 & 3.5 & 14.3 & 237.0 & 1.4 & 14.9 & 229.0 \\
\hline 23 & 2.5 & 14.3 & 231.0 & 1.1 & 327.6 & 214.0 \\
\hline 24 & 1.1 & 14.3 & 213.0 & 0.7 & 327.6 & 194.0 \\
\hline & & & & & & heet 1 of \\
\hline
\end{tabular}


Table A2. Continued.

\begin{tabular}{|c|c|c|c|c|c|c|}
\hline \multirow[b]{2}{*}{ Location No. } & \multicolumn{3}{|c|}{ STWAVE } & \multicolumn{3}{|c|}{ BOUSS-2D } \\
\hline & $H_{s}, \mathrm{~m}$ & $T_{p}, \sec$ & $\theta_{m}$, deg & $H_{s}, \mathrm{~m}$ & $T_{p}, \mathrm{sec}$ & $\theta_{p}$, deg \\
\hline 25 & 2.5 & 14.3 & 231.0 & 1.3 & 14.9 & 208.0 \\
\hline 26 & 4.2 & 14.3 & 234.0 & 1.7 & 14.9 & 220.0 \\
\hline 27 & 5.1 & 14.3 & 235.0 & 2.0 & 14.9 & 229.0 \\
\hline 28 & 5.3 & 14.3 & 239.0 & 2.3 & 14.9 & 233.0 \\
\hline 29 & 5.1 & 14.3 & 243.0 & 2.6 & 14.9 & 239.0 \\
\hline 30 & 4.9 & 14.3 & 248.0 & 2.8 & 16.4 & 243.0 \\
\hline 31 & 1.6 & 14.3 & 204.0 & 0.8 & 327.6 & 183.0 \\
\hline 32 & 2.5 & 14.3 & 226.0 & 1.2 & 14.9 & 206.0 \\
\hline 33 & 4.0 & 14.3 & 232.0 & 1.6 & 14.9 & 219.0 \\
\hline 34 & 5.1 & 14.3 & 238.0 & 2.2 & 14.9 & 234.0 \\
\hline 35 & 0.8 & 14.3 & 228.0 & 0.7 & 327.6 & 207.0 \\
\hline 36 & 2.6 & 14.3 & 234.0 & 1.3 & 327.6 & 207.0 \\
\hline 37 & 4.3 & 14.3 & 235.0 & 1.7 & 14.9 & 220.0 \\
\hline 38 & 5.4 & 14.3 & 237.0 & 2.2 & 14.9 & 228.0 \\
\hline 39 & 5.6 & 14.3 & 239.0 & 2.5 & 14.9 & 233.0 \\
\hline 40 & 3.5 & 14.3 & 303.0 & 2.1 & 11.7 & 302.0 \\
\hline 41 & 3.8 & 14.3 & 300.0 & 2.0 & 11.7 & 294.0 \\
\hline 42 & 4.2 & 14.3 & 287.0 & 2.5 & 18.2 & 284.0 \\
\hline 43 & 4.5 & 14.3 & 284.0 & 3.1 & 18.2 & 286.0 \\
\hline 44 & 5.0 & 14.3 & 277.0 & 4.1 & 18.2 & 286.0 \\
\hline 45 & 6.2 & 14.3 & 269.0 & 6.0 & 18.2 & 280.0 \\
\hline 46 & 8.1 & 14.3 & 261.0 & 8.9 & 18.2 & 277.0 \\
\hline 47 & 5.0 & 14.3 & 252.0 & 7.8 & 16.4 & 272.0 \\
\hline 48 & 8.1 & 14.3 & 262.0 & 6.3 & 13.7 & 272.0 \\
\hline 49 & 8.4 & 14.3 & 259.0 & 5.9 & 13.7 & 271.0 \\
\hline 50 & 8.2 & 14.3 & 255.0 & 4.3 & 13.7 & 265.0 \\
\hline 51 & 7.7 & 14.3 & 254.0 & 4.7 & 13.7 & 264.0 \\
\hline 52 & 7.0 & 14.3 & 254.0 & 4.2 & 13.7 & 263.0 \\
\hline 53 & 6.2 & 14.3 & 252.0 & 6.6 & 14.9 & 259.0 \\
\hline 54 & 5.8 & 14.3 & 250.0 & 6.7 & 13.7 & 259.0 \\
\hline 55 & 4.7 & 14.3 & 253.0 & 6.1 & 12.6 & 258.0 \\
\hline 56 & 3.8 & 14.3 & 254.0 & 5.0 & 16.4 & 261.0 \\
\hline 57 & 3.3 & 14.3 & 253.0 & 5.0 & 16.4 & 261.0 \\
\hline 58 & 2.7 & 14.3 & 254.0 & & & \\
\hline 59 & 2.7 & 14.3 & 258.0 & & & \\
\hline & & & & & & neet 2 of \\
\hline
\end{tabular}


Table A2. Continued.

\begin{tabular}{|c|c|c|c|c|c|c|}
\hline \multirow[b]{2}{*}{ Location No. } & \multicolumn{3}{|c|}{ STWAVE } & \multicolumn{3}{|c|}{ BOUSS-2D } \\
\hline & $H_{s}, \mathrm{~m}$ & $T_{p}, \sec$ & $\theta_{m}$, deg & $H_{s}, \mathrm{~m}$ & $T_{p}, \mathrm{sec}$ & $\theta_{p}, \operatorname{deg}$ \\
\hline 60 & 3.4 & 14.3 & 311.0 & 1.0 & 163.8 & 333.0 \\
\hline 61 & 3.4 & 14.3 & 305.0 & 1.6 & 11.7 & 302.0 \\
\hline 62 & 4.0 & 14.3 & 297.0 & 2.5 & 11.7 & 289.0 \\
\hline 63 & 4.3 & 14.3 & 293.0 & 2.9 & 14.9 & 288.0 \\
\hline 64 & 4.5 & 14.3 & 290.0 & 3.6 & 12.6 & 289.0 \\
\hline 65 & 4.4 & 14.3 & 289.0 & 3.3 & 13.7 & 292.0 \\
\hline 66 & 3.5 & 14.3 & 305.0 & 1.3 & 163.8 & 317.0 \\
\hline 67 & 3.6 & 14.3 & 300.0 & 1.8 & 11.7 & 295.0 \\
\hline 68 & 3.9 & 14.3 & 295.0 & 2.3 & 11.7 & 289.0 \\
\hline 69 & 4.2 & 14.3 & 290.0 & 2.6 & 18.2 & 288.0 \\
\hline 70 & 4.3 & 14.3 & 287.0 & 3.1 & 18.2 & 286.0 \\
\hline 71 & 3.3 & 14.3 & 316.0 & 1.0 & 163.8 & 330.0 \\
\hline 72 & 3.2 & 14.3 & 308.0 & 1.5 & 163.8 & 305.0 \\
\hline 73 & 3.6 & 14.3 & 305.0 & 1.9 & 11.7 & 296.0 \\
\hline 74 & 3.9 & 14.3 & 300.0 & 2.4 & 11.7 & 292.0 \\
\hline 75 & 4.1 & 14.3 & 295.0 & 2.9 & 11.7 & 291.0 \\
\hline 76 & 1.6 & 14.3 & 258.0 & 1.3 & 16.4 & 251.0 \\
\hline 77 & 2.6 & 14.3 & 256.0 & 2.0 & 14.9 & 259.0 \\
\hline 78 & 4.0 & 14.3 & 265.0 & 3.3 & 14.9 & 274.0 \\
\hline 79 & 4.8 & 14.3 & 266.0 & 4.2 & 14.9 & 276.0 \\
\hline 80 & 5.8 & 14.3 & 268.0 & 5.1 & 14.9 & 282.0 \\
\hline 81 & 7.6 & 14.3 & 272.0 & 6.9 & 14.9 & 282.0 \\
\hline 82 & 8.9 & 14.3 & 270.0 & 8.5 & 14.9 & 285.0 \\
\hline 83 & 9.5 & 14.3 & 269.0 & 8.5 & 18.2 & 284.0 \\
\hline 84 & 10.0 & 14.3 & 269.0 & 9.0 & 14.9 & 276.0 \\
\hline 85 & 9.6 & 14.3 & 269.0 & 9.6 & 14.9 & 274.0 \\
\hline 86 & 8.9 & 14.3 & 271.0 & 9.2 & 13.7 & 276.0 \\
\hline 87 & 7.8 & 14.3 & 272.0 & 8.3 & 13.7 & 279.0 \\
\hline 88 & 8.4 & 14.3 & 236.0 & 6.2 & 18.2 & 283.0 \\
\hline 89 & 9.1 & 14.3 & 245.0 & 6.2 & 18.2 & 284.0 \\
\hline 90 & 9.3 & 14.3 & 252.0 & 7.0 & 16.4 & 283.0 \\
\hline 91 & 9.1 & 14.3 & 261.0 & 7.0 & 16.4 & 281.0 \\
\hline 92 & 9.2 & 14.3 & 266.0 & 8.2 & 16.4 & 288.0 \\
\hline 93 & 9.1 & 14.3 & 268.0 & 8.8 & 18.2 & 288.0 \\
\hline 94 & 9.1 & 14.3 & 269.0 & 9.6 & 18.2 & 288.0 \\
\hline & & & & & & eeet 3 of \\
\hline
\end{tabular}


Table A2. Continued.

\begin{tabular}{|c|c|c|c|c|c|c|}
\hline \multirow[b]{2}{*}{ Location No. } & \multicolumn{3}{|c|}{ STWAVE } & \multicolumn{3}{|c|}{ BOUSS-2D } \\
\hline & $H_{s}, \mathrm{~m}$ & $T_{p}, \sec$ & $\theta_{m}$, deg & $H_{s}, \mathrm{~m}$ & $T_{p}, \mathrm{sec}$ & $\theta_{p}$, deg \\
\hline 95 & 9.1 & 14.3 & 268.0 & 8.9 & 13.7 & 287.0 \\
\hline 96 & 9.7 & 14.3 & 270.0 & 8.8 & 16.4 & 291.0 \\
\hline 97 & 9.1 & 14.3 & 291.0 & & & \\
\hline 98 & 9.1 & 14.3 & 292.0 & & & \\
\hline 99 & 9.1 & 14.3 & 292.0 & & & \\
\hline 100 & 9.2 & 14.3 & 292.0 & & & \\
\hline 101 & 9.3 & 14.3 & 293.0 & & & \\
\hline 102 & 9.3 & 14.3 & 293.0 & & & \\
\hline 103 & 9.4 & 14.3 & 294.0 & & & \\
\hline 104 & 9.5 & 14.3 & 294.0 & & & \\
\hline 105 & 9.6 & 14.3 & 295.0 & & & \\
\hline 106 & 9.6 & 14.3 & 295.0 & & & \\
\hline 107 & 9.1 & 14.3 & 292.0 & & & \\
\hline 108 & 9.1 & 14.3 & 292.0 & & & \\
\hline 109 & 9.2 & 14.3 & 291.0 & & & \\
\hline 110 & 7.9 & 14.3 & 260.0 & 7.9 & 13.7 & 270.0 \\
\hline 111 & 8.7 & 14.3 & 263.0 & 8.4 & 13.7 & 273.0 \\
\hline 112 & 9.2 & 14.3 & 266.0 & 8.8 & 13.7 & 276.0 \\
\hline 113 & 9.3 & 14.3 & 268.0 & 7.7 & 14.9 & 274.0 \\
\hline 114 & 9.0 & 14.3 & 270.0 & 8.1 & 14.9 & 276.0 \\
\hline 115 & 8.5 & 14.3 & 270.0 & 7.9 & 14.9 & 276.0 \\
\hline 116 & 8.1 & 14.3 & 271.0 & 7.3 & 13.7 & 280.0 \\
\hline 117 & 10.1 & 14.3 & 270.0 & 9.0 & 13.7 & 282.0 \\
\hline 118 & 9.8 & 14.3 & 270.0 & 9.2 & 13.7 & 279.0 \\
\hline 119 & 9.5 & 14.3 & 271.0 & 9.4 & 13.7 & 278.0 \\
\hline 120 & 9.4 & 14.3 & 269.0 & 8.2 & 13.7 & 277.0 \\
\hline 121 & 8.9 & 14.3 & 268.0 & 7.8 & 14.9 & 273.0 \\
\hline 122 & 8.6 & 14.3 & 267.0 & 7.4 & 14.9 & 272.0 \\
\hline 123 & 8.5 & 14.3 & 265.0 & 7.0 & 13.7 & 270.0 \\
\hline 124 & 8.0 & 14.3 & 263.0 & 6.9 & 14.9 & 269.0 \\
\hline 125 & 2.6 & 14.3 & 227.0 & 1.8 & 14.9 & 220.0 \\
\hline 126 & 2.7 & 14.3 & 225.0 & 1.7 & 14.9 & 222.0 \\
\hline 127 & 2.5 & 14.3 & 230.0 & 1.7 & 16.4 & 231.0 \\
\hline 128 & 2.2 & 14.3 & 236.0 & 1.6 & 14.9 & 232.0 \\
\hline 129 & 1.9 & 14.3 & 239.0 & 1.5 & 16.4 & 238.0 \\
\hline & & & & & & eet 4 of \\
\hline
\end{tabular}


Table A2. Concluded.

\begin{tabular}{|l|l|l|l|l|l|l|}
\hline \multirow{2}{*}{ Location No. } & \multicolumn{3}{|c}{ STWAVE } & \multicolumn{3}{c|}{ BOUSS-2D } \\
\cline { 2 - 7 } & $H_{s}, \mathrm{~m}$ & $T_{p}, \mathrm{sec}$ & $\theta_{\mathrm{m}}, \mathrm{deg}$ & $H_{s}, \mathrm{~m}$ & $T_{p}, \mathrm{sec}$ & $\theta_{p}, \mathrm{deg}$ \\
\hline 130 & 1.8 & 14.3 & 242.0 & 1.3 & 16.4 & 234.0 \\
\hline 131 & 1.5 & 14.3 & 235.0 & 1.3 & 16.4 & 222.0 \\
\hline 132 & 1.1 & 14.3 & 199.0 & 1.3 & 16.4 & 192.0 \\
\hline 133 & 0.1 & 14.3 & 211.0 & 1.1 & 14.9 & 173.0 \\
\hline 134 & 3.9 & 14.3 & 241.0 & 2.6 & 18.2 & 229.0 \\
\hline 135 & 5.0 & 14.3 & 242.0 & 5.1 & 18.2 & 234.0 \\
\hline 136 & 6.2 & 14.3 & 242.0 & 5.1 & 14.9 & 281.0 \\
\hline 137 & 7.8 & 14.3 & 230.0 & 6.5 & 16.4 & 277.0 \\
\hline 138 & 6.6 & 14.3 & 238.0 & 5.2 & 18.2 & 267.0 \\
\hline 139 & 6.4 & 14.3 & 254.0 & 5.5 & 14.9 & 290.0 \\
\hline 140 & 7.2 & 14.3 & 266.0 & 6.9 & 14.9 & 291.0 \\
\hline 141 & 8.3 & 14.3 & 274.0 & 6.7 & 16.4 & 288.0 \\
\hline 142 & 8.6 & 14.3 & 276.0 & 10.0 & 16.4 & 292.0 \\
\hline 143 & 9.2 & 14.3 & 276.0 & 9.0 & 14.9 & 288.0 \\
\hline 144 & 8.5 & 14.3 & 263.0 & 8.7 & 14.9 & 277.0 \\
\hline 145 & 8.7 & 14.3 & 264.0 & 8.3 & 18.2 & 276.0 \\
\hline 146 & 6.9 & 14.3 & 271.0 & 8.9 & 16.4 & 285.0 \\
\hline 147 & 8.7 & 14.3 & 268.0 & 8.7 & 13.7 & 277.0 \\
\hline 148 & 8.4 & 14.3 & 267.0 & 7.6 & 13.7 & 273.0 \\
\hline & & & & & & $($ Sheet 5 of 5) \\
\hline
\end{tabular}


Table A3. Event 6 results for existing configuration.

\begin{tabular}{|c|c|c|c|c|c|c|}
\hline \multirow[b]{2}{*}{ Location No. } & \multicolumn{3}{|c|}{ STWAVE } & \multicolumn{3}{|c|}{ BOUSS-2D } \\
\hline & $H_{s, m}$ & $T_{p}, \mathrm{sec}$ & $\theta_{m}$, deg & $H_{s}, \mathrm{~m}$ & $T_{p}, \mathrm{sec}$ & $\theta_{p}$, deg \\
\hline 1 & 6.3 & 16.7 & 229.0 & 6.8 & 16.5 & 228.0 \\
\hline 2 & 4.8 & 16.7 & 225.0 & 5.8 & 16.5 & 228.0 \\
\hline 3 & 5.7 & 16.7 & 250.0 & 5.4 & 16.5 & 252.0 \\
\hline 4 & 8.9 & 16.7 & 262.0 & 6.5 & 22.8 & 256.0 \\
\hline 5 & 4.0 & 16.7 & 249.0 & 3.6 & 20.2 & 253.0 \\
\hline 6 & 8.1 & 16.7 & 272.0 & 6.3 & 16.5 & 266.0 \\
\hline 7 & 13.8 & 16.7 & 232.0 & 13.9 & 16.5 & 231.0 \\
\hline 8 & 12.6 & 16.7 & 237.0 & 12.8 & 16.5 & 235.0 \\
\hline 9 & 9.4 & 16.7 & 228.0 & 8.2 & 18.2 & 237.0 \\
\hline 10 & 12.2 & 16.7 & 238.0 & 12.2 & 16.5 & 232.0 \\
\hline 11 & 9.7 & 16.7 & 233.0 & 9.7 & 20.2 & 228.0 \\
\hline 12 & 2.8 & 16.7 & 269.0 & 4.0 & 364.1 & 252.0 \\
\hline 13 & 3.5 & 16.7 & 263.0 & 4.4 & 364.1 & 248.0 \\
\hline 14 & 3.2 & 16.7 & 252.0 & 4.1 & 182.0 & 240.0 \\
\hline 15 & 4.0 & 16.7 & 242.0 & 3.2 & 364.1 & 225.0 \\
\hline 16 & 3.8 & 16.7 & 237.0 & 2.7 & 364.1 & 233.0 \\
\hline 17 & 5.6 & 16.7 & 223.0 & 5.5 & 22.8 & 213.0 \\
\hline 18 & 3.2 & 16.7 & 207.0 & 7.0 & 20.2 & 201.0 \\
\hline 19 & 4.7 & 16.7 & 222.0 & 5.1 & 13.0 & 222.0 \\
\hline 20 & 5.3 & 16.7 & 230.0 & 4.9 & 13.0 & 228.0 \\
\hline 21 & 4.8 & 16.7 & 233.0 & 4.3 & 16.5 & 226.0 \\
\hline 22 & 4.0 & 16.7 & 232.0 & 3.6 & 16.5 & 221.0 \\
\hline 23 & 4.1 & 16.7 & 219.0 & 3.8 & 22.8 & 209.0 \\
\hline 24 & 2.3 & 16.7 & 210.0 & 1.1 & 182.0 & 150.0 \\
\hline 25 & 4.1 & 16.7 & 227.0 & 2.6 & 16.5 & 208.0 \\
\hline 26 & 5.2 & 16.7 & 231.0 & 3.6 & 13.0 & 220.0 \\
\hline 27 & 4.9 & 16.7 & 232.0 & 4.4 & 13.0 & 228.0 \\
\hline 28 & 4.3 & 16.7 & 234.0 & 4.8 & 14.0 & 231.0 \\
\hline 29 & 3.8 & 16.7 & 234.0 & 5.0 & 16.5 & 234.0 \\
\hline 30 & 4.0 & 16.7 & 233.0 & 5.4 & 16.5 & 234.0 \\
\hline 31 & 2.8 & 16.7 & 202.0 & 1.4 & 182.0 & 158.0 \\
\hline 32 & 4.0 & 16.7 & 223.0 & 2.5 & 13.0 & 208.0 \\
\hline 33 & 5.0 & 16.7 & 230.0 & 3.6 & 13.0 & 221.0 \\
\hline 34 & 4.3 & 16.7 & 234.0 & 4.6 & 16.5 & 229.0 \\
\hline 35 & 1.7 & 16.7 & 222.0 & 1.2 & 182.0 & 156.0 \\
\hline & & & & & & eeet 1 of \\
\hline
\end{tabular}


Table A3. Continued.

\begin{tabular}{|c|c|c|c|c|c|c|}
\hline \multirow[b]{2}{*}{ Location No. } & \multicolumn{3}{|c|}{ STWAVE } & \multicolumn{3}{|c|}{ BOUSS-2D } \\
\hline & $H_{s}, \mathrm{~m}$ & $T_{p}$, sec & $\theta_{m}$, deg & $H_{s}, \mathrm{~m}$ & $T_{p}, \mathrm{sec}$ & $\theta_{p}$, deg \\
\hline 36 & 4.2 & 16.7 & 230.0 & 2.8 & 13.0 & 210.0 \\
\hline 37 & 5.3 & 16.7 & 231.0 & 3.8 & 13.0 & 222.0 \\
\hline 38 & 5.0 & 16.7 & 232.0 & 4.6 & 13.0 & 228.0 \\
\hline 39 & 4.3 & 16.7 & 233.0 & 5.0 & 13.0 & 231.0 \\
\hline 40 & 2.9 & 16.7 & 311.0 & 2.0 & 18.2 & 314.0 \\
\hline 41 & 2.5 & 16.7 & 314.0 & 1.7 & 18.2 & 307.0 \\
\hline 42 & 1.8 & 16.7 & 298.0 & 1.5 & 26.0 & 297.0 \\
\hline 43 & 1.1 & 16.7 & 278.0 & 1.0 & 364.1 & 291.0 \\
\hline 44 & 1.2 & 16.7 & 263.0 & 1.3 & 364.1 & 294.0 \\
\hline 45 & 2.3 & 16.7 & 244.0 & 2.6 & 22.8 & 263.0 \\
\hline 46 & 5.0 & 16.7 & 230.0 & 6.0 & 20.2 & 242.0 \\
\hline 47 & 5.1 & 16.7 & 219.0 & 8.1 & 20.2 & 241.0 \\
\hline 48 & 9.2 & 16.7 & 234.0 & 9.2 & 18.2 & 233.0 \\
\hline 49 & 8.9 & 16.7 & 234.0 & 9.0 & 20.2 & 231.0 \\
\hline 50 & 8.4 & 16.7 & 231.0 & 8.7 & 20.2 & 224.0 \\
\hline 51 & 7.9 & 16.7 & 231.0 & 8.0 & 20.2 & 233.0 \\
\hline 52 & 7.2 & 16.7 & 232.0 & 8.0 & 20.2 & 231.0 \\
\hline 53 & 6.3 & 16.7 & 230.0 & 6.2 & 20.2 & 224.0 \\
\hline 54 & 5.9 & 16.7 & 231.0 & 5.0 & 20.2 & 226.0 \\
\hline 55 & 4.8 & 16.7 & 234.0 & 4.5 & 22.8 & 219.0 \\
\hline 56 & 3.8 & 16.7 & 237.0 & 4.2 & 16.5 & 223.0 \\
\hline 57 & 3.4 & 16.7 & 237.0 & 4.7 & 364.1 & 232.0 \\
\hline 58 & 2.8 & 16.7 & 238.0 & 4.5 & 364.1 & 237.0 \\
\hline 59 & 2.7 & 16.7 & 246.0 & 4.1 & 182.0 & 230.0 \\
\hline 60 & 1.8 & 16.7 & 323.0 & 0.8 & 364.1 & 345.0 \\
\hline 61 & 2.1 & 16.7 & 318.0 & 1.4 & 14.0 & 313.0 \\
\hline 62 & 2.9 & 16.7 & 310.0 & 1.9 & 18.2 & 304.0 \\
\hline 63 & 3.3 & 16.7 & 308.0 & 2.1 & 16.5 & 301.0 \\
\hline 64 & 3.9 & 16.7 & 303.0 & 2.6 & 22.8 & 296.0 \\
\hline 65 & 4.2 & 16.7 & 297.0 & 2.8 & 26.0 & 296.0 \\
\hline 66 & 1.6 & 16.7 & 319.0 & 0.8 & 364.1 & 347.0 \\
\hline 67 & 1.8 & 16.7 & 314.0 & 1.3 & 14.0 & 310.0 \\
\hline 68 & 2.2 & 16.7 & 310.0 & 1.6 & 22.8 & 304.0 \\
\hline 69 & 2.7 & 16.7 & 306.0 & 1.9 & 18.2 & 300.0 \\
\hline 70 & 3.0 & 16.7 & 303.0 & 2.2 & 16.5 & 297.0 \\
\hline & & & & & & eet 2 of \\
\hline
\end{tabular}


Table A3. Continued.

\begin{tabular}{|c|c|c|c|c|c|c|}
\hline \multirow[b]{2}{*}{ Location No. } & \multicolumn{3}{|c|}{ STWAVE } & \multicolumn{3}{|c|}{ BOUSS-2D } \\
\hline & $H_{s, m}$ & $T_{p}, \mathrm{sec}$ & $\theta_{m}$, deg & $H_{s}, \mathrm{~m}$ & $T_{p}, \mathrm{sec}$ & $\theta_{p}$, deg \\
\hline 71 & 2.1 & 16.7 & 323.0 & 0.8 & 364.1 & 353.0 \\
\hline 72 & 2.4 & 16.7 & 316.0 & 1.5 & 18.2 & 314.0 \\
\hline 73 & 2.7 & 16.7 & 315.0 & 1.8 & 22.8 & 310.0 \\
\hline 74 & 3.0 & 16.7 & 312.0 & 2.0 & 22.8 & 307.0 \\
\hline 75 & 3.3 & 16.7 & 308.0 & 2.2 & 16.5 & 306.0 \\
\hline 76 & 2.3 & 16.7 & 256.0 & 2.7 & 15.2 & 260.0 \\
\hline 77 & 4.2 & 16.7 & 249.0 & 4.1 & 16.5 & 252.0 \\
\hline 78 & 6.5 & 16.7 & 250.0 & 7.0 & 16.5 & 250.0 \\
\hline 79 & 7.3 & 16.7 & 247.0 & 9.6 & 16.5 & 241.0 \\
\hline 80 & 7.1 & 16.7 & 244.0 & 8.6 & 16.5 & 245.0 \\
\hline 81 & 8.7 & 16.7 & 240.0 & 10.2 & 16.5 & 239.0 \\
\hline 82 & 9.3 & 16.7 & 237.0 & 10.4 & 16.5 & 232.0 \\
\hline 83 & 9.9 & 16.7 & 236.0 & 11.2 & 18.2 & 232.0 \\
\hline 84 & 10.9 & 16.7 & 234.0 & 11.6 & 18.2 & 227.0 \\
\hline 85 & 11.5 & 16.7 & 234.0 & 12.8 & 18.2 & 232.0 \\
\hline 86 & 12.4 & 16.7 & 235.0 & 12.6 & 18.2 & 233.0 \\
\hline 87 & 13.2 & 16.7 & 236.0 & 13.0 & 16.5 & 235.0 \\
\hline 88 & 6.5 & 16.7 & 208.0 & 7.9 & 20.2 & 212.0 \\
\hline 89 & 7.7 & 16.7 & 211.0 & 8.6 & 20.2 & 213.0 \\
\hline 90 & 8.9 & 16.7 & 212.0 & 8.0 & 20.2 & 219.0 \\
\hline 91 & 10.1 & 16.7 & 214.0 & 7.7 & 20.2 & 224.0 \\
\hline 92 & 10.0 & 16.7 & 216.0 & 8.2 & 20.2 & 226.0 \\
\hline 93 & 9.9 & 16.7 & 220.0 & 8.5 & 20.2 & 228.0 \\
\hline 94 & 9.7 & 16.7 & 224.0 & 8.7 & 20.2 & 232.0 \\
\hline 95 & 9.4 & 16.7 & 228.0 & 9.2 & 18.2 & 234.0 \\
\hline 96 & 10.0 & 16.7 & 230.0 & 9.5 & 18.2 & 237.0 \\
\hline 97 & 12.8 & 16.7 & 235.0 & 13.3 & 16.5 & 232.0 \\
\hline 98 & 12.9 & 16.7 & 235.0 & 13.4 & 16.5 & 232.0 \\
\hline 99 & 12.8 & 16.7 & 235.0 & 13.3 & 16.5 & 233.0 \\
\hline 100 & 12.6 & 16.7 & 235.0 & 13.3 & 16.5 & 232.0 \\
\hline 101 & 12.6 & 16.7 & 235.0 & 13.4 & 16.5 & 232.0 \\
\hline 102 & 12.6 & 16.7 & 234.0 & 13.8 & 16.5 & 232.0 \\
\hline 103 & 12.6 & 16.7 & 234.0 & 13.8 & 16.5 & 232.0 \\
\hline 104 & 12.7 & 16.7 & 234.0 & & & \\
\hline 105 & 12.7 & 16.7 & 234.0 & & & \\
\hline & & & & & & neet 3 of \\
\hline
\end{tabular}


Table A3. Continued.

\begin{tabular}{|c|c|c|c|c|c|c|}
\hline \multirow[b]{2}{*}{ Location No. } & \multicolumn{3}{|c|}{ STWAVE } & \multicolumn{3}{|c|}{ BOUSS-2D } \\
\hline & $H_{s, m}$ & $T_{p}, \sec$ & $\theta_{m}$, deg & $H_{s}, \mathrm{~m}$ & $T_{p}, \mathrm{sec}$ & $\theta_{p}$, deg \\
\hline 106 & 12.6 & 16.7 & 234.0 & & & \\
\hline 107 & 12.6 & 16.7 & 235.0 & 13.0 & 16.5 & 232.0 \\
\hline 108 & 12.6 & 16.7 & 235.0 & 13.3 & 16.5 & 232.0 \\
\hline 109 & 12.5 & 16.7 & 234.0 & 13.1 & 16.5 & 231.0 \\
\hline 110 & 8.2 & 16.7 & 233.0 & 8.1 & 18.2 & 220.0 \\
\hline 111 & 8.9 & 16.7 & 233.0 & 9.2 & 20.2 & 221.0 \\
\hline 112 & 9.5 & 16.7 & 233.0 & 11.1 & 20.2 & 227.0 \\
\hline 113 & 10.0 & 16.7 & 233.0 & 11.6 & 20.2 & 225.0 \\
\hline 114 & 10.4 & 16.7 & 233.0 & 10.9 & 20.2 & 221.0 \\
\hline 115 & 10.6 & 16.7 & 233.0 & 10.8 & 16.5 & 223.0 \\
\hline 116 & 11.1 & 16.7 & 235.0 & 12.4 & 16.5 & 230.0 \\
\hline 117 & 10.0 & 16.7 & 233.0 & 10.5 & 20.2 & 233.0 \\
\hline 118 & 10.6 & 16.7 & 235.0 & 11.2 & 20.2 & 229.0 \\
\hline 119 & 10.3 & 16.7 & 234.0 & 9.5 & 20.2 & 229.0 \\
\hline 120 & 10.0 & 16.7 & 234.0 & 9.6 & 18.2 & 232.0 \\
\hline 121 & 9.7 & 16.7 & 234.0 & 8.3 & 18.2 & 224.0 \\
\hline 122 & 9.4 & 16.7 & 233.0 & 8.6 & 20.2 & 234.0 \\
\hline 123 & 8.8 & 16.7 & 234.0 & 9.2 & 16.5 & 235.0 \\
\hline 124 & 8.2 & 16.7 & 235.0 & 9.4 & 16.5 & 232.0 \\
\hline 125 & 4.8 & 16.7 & 217.0 & 5.1 & 15.2 & 219.0 \\
\hline 126 & 4.6 & 16.7 & 221.0 & 4.7 & 15.2 & 224.0 \\
\hline 127 & 3.9 & 16.7 & 223.0 & 4.1 & 15.2 & 227.0 \\
\hline 128 & 3.4 & 16.7 & 230.0 & 3.5 & 15.2 & 234.0 \\
\hline 129 & 2.8 & 16.7 & 234.0 & 3.0 & 15.2 & 246.0 \\
\hline 130 & 2.6 & 16.7 & 238.0 & 2.7 & 15.2 & 238.0 \\
\hline 131 & 2.3 & 16.7 & 232.0 & 3.1 & 15.2 & 231.0 \\
\hline 132 & 1.3 & 16.7 & 198.0 & 2.8 & 15.2 & 197.0 \\
\hline 133 & 0.1 & 16.7 & 213.0 & 2.0 & 22.8 & 177.0 \\
\hline 134 & 5.1 & 16.7 & 216.0 & 5.2 & 15.2 & 217.0 \\
\hline 135 & 5.1 & 16.7 & 224.0 & 6.3 & 22.8 & 222.0 \\
\hline 136 & 5.6 & 16.7 & 210.0 & 7.1 & 20.2 & 210.0 \\
\hline 137 & 5.8 & 16.7 & 205.0 & 7.2 & 20.2 & 210.0 \\
\hline 138 & 4.5 & 16.7 & 214.0 & 5.2 & 20.2 & 212.0 \\
\hline 139 & 6.5 & 16.7 & 207.0 & 6.8 & 22.8 & 206.0 \\
\hline 140 & 7.4 & 16.7 & 210.0 & 6.1 & 22.8 & 219.0 \\
\hline & & & & & & eeet 4 of \\
\hline
\end{tabular}


Table A3. Concluded.

\begin{tabular}{|l|c|l|l|c|c|l|}
\hline \multirow{2}{*}{ Location No. } & \multicolumn{3}{|c|}{ STWAVE } & \multicolumn{3}{c|}{ BOUSS-2D } \\
\cline { 2 - 7 } & $H_{s}, \mathrm{~m}$ & $T_{p}, \mathrm{sec}$ & $\theta_{\mathrm{m}}, \mathrm{deg}$ & $H_{s}, \mathrm{~m}$ & $T_{p}, \mathrm{sec}$ & $\theta_{p}, \mathrm{deg}$ \\
\hline 141 & 8.9 & 16.7 & 225.0 & 6.6 & 20.2 & 229.0 \\
\hline 142 & 8.6 & 16.7 & 234.0 & 7.8 & 20.2 & 233.0 \\
\hline 143 & 9.5 & 16.7 & 236.0 & 10.0 & 18.2 & 231.0 \\
\hline 144 & 5.8 & 16.7 & 228.0 & 7.0 & 20.2 & 239.0 \\
\hline 145 & 6.6 & 16.7 & 230.0 & 7.4 & 20.2 & 239.0 \\
\hline 146 & 7.0 & 16.7 & 223.0 & 8.9 & 20.2 & 239.0 \\
\hline 147 & 10.7 & 16.7 & 233.0 & 6.6 & 20.2 & 231.0 \\
\hline 148 & 9.9 & 16.7 & 233.0 & 7.4 & 18.2 & 234.0 \\
\hline \multicolumn{7}{|l|}{} \\
\hline
\end{tabular}

Table A4. Statistics of wave parameters (STWAVE versus BOUSS-2D) for existing configuration.

\begin{tabular}{|c|c|c|c|c|c|c|c|}
\hline $\begin{array}{l}\text { Area } \\
\text { ID }\end{array}$ & $N$ & $\begin{array}{l}\Delta\left(H_{s}\right) \\
\mathrm{m}\end{array}$ & $\begin{array}{l}\varepsilon_{r m s}\left(H_{s}\right) \\
\mathrm{m}\end{array}$ & $\begin{array}{l}\Delta\left(T_{p}\right) \\
\text { sec }\end{array}$ & $\begin{array}{l}\varepsilon_{r m s}\left(T_{p}\right) \\
\sec \end{array}$ & $\begin{array}{l}\Delta\left(\theta_{p}\right) \\
\operatorname{deg}\end{array}$ & $\begin{array}{l}\varepsilon_{r m s}(\theta) \\
\operatorname{deg}\end{array}$ \\
\hline \multicolumn{8}{|c|}{ Event 4} \\
\hline 1 & 6 & 1.2 & 1.6 & \begin{tabular}{|l|} 
\\
\end{tabular} & 2.4 & -6.5 & 8 \\
\hline 2 & 5 & -1 & 1.1 & -5.1 & 7.1 & -24 & 25.5 \\
\hline 3 & 27 & 1.7 & 2.1 & -3.4 & 6.3 & 0.8 & 22.1 \\
\hline 4 & 37 & 1.1 & 1.7 & -1.7 & 5.2 & -4.6 & 9.6 \\
\hline 5 & 2 & -1.4 & 1.5 & -2.1 & 2.1 & -7.5 & 7.5 \\
\hline 6 & 13 & 0.5 & 0.6 & -0.8 & 1.3 & -7.9 & 9.7 \\
\hline 7 & 11 & 1.1 & 1.6 & -2.7 & 3 & -27.3 & 29.5 \\
\hline \multicolumn{8}{|l|}{8} \\
\hline 9 & 16 & 0.8 & 0.9 & 0.2 & 0.6 & -7.8 & 8.1 \\
\hline 10 & 11 & 0.4 & 0.7 & -1.9 & 2.2 & 9.1 & 13.5 \\
\hline All & 132 & 0.9 & 1.5 & -2 & 4.4 & -5.9 & 15.9 \\
\hline \multicolumn{8}{|c|}{ Event 6} \\
\hline 1 & 6 & 0.6 & 1.3 & -1.5 & 2.9 & 0.7 & 4.1 \\
\hline 2 & 5 & -0.2 & 1 & -16.7 & 16.7 & 13 & 13.9 \\
\hline 3 & 27 & 0.1 & 1.2 & -1.9 & 7.2 & 11.7 & 20.8 \\
\hline 4 & 37 & 0.4 & 1.2 & -5 & 7.3 & -2.9 & 12.2 \\
\hline 5 & 4 & -1.2 & 1.3 & -12.5 & 14.5 & 9 & 10.9 \\
\hline 6 & 13 & -0.8 & 1.1 & -0.2 & 0.9 & 1.4 & 3.6 \\
\hline 7 & 11 & 0.5 & 1.3 & -3 & 3.1 & -6.9 & 7.3 \\
\hline 8 & 10 & -0.7 & 0.8 & 0.2 & 0.2 & 2.7 & 2.7 \\
\hline 9 & 16 & -0.3 & 0.9 & -2.2 & 2.7 & 5.9 & 7.4 \\
\hline 10 & 11 & -0.6 & 0.9 & 0.1 & 2.9 & 1.3 & 11.6 \\
\hline All & 145 & 0 & 1.1 & -3.1 & 6.3 & 2.7 & 12.3 \\
\hline
\end{tabular}




\section{Appendix B: North Jetty Breach Results}

Table B1. Event 4 results for north jetty breach configuration.

\begin{tabular}{|c|c|c|c|c|c|c|}
\hline \multirow{2}{*}{$\begin{array}{l}\text { Location } \\
\text { No. }\end{array}$} & \multicolumn{3}{|c|}{ STWAVE } & \multicolumn{3}{|c|}{ BOUSS-2D } \\
\hline & $H_{s}, \mathrm{~m}$ & $T_{p}, \mathrm{sec}$ & $\theta_{m}, \operatorname{deg}$ & $H_{s}, \mathrm{~m}$ & $T_{p}, \sec$ & $\theta_{p}$, deg \\
\hline 1 & 3.5 & 14.3 & 226.0 & 1.8 & 18.2 & 219.0 \\
\hline 2 & 3.7 & 14.3 & 226.0 & 3.2 & 18.2 & 241.0 \\
\hline 3 & 3.2 & 14.3 & 255.0 & 2.8 & 16.4 & 264.0 \\
\hline 4 & 6.8 & 14.3 & 276.0 & 3.9 & 13.7 & 281.0 \\
\hline 5 & 6.5 & 14.3 & 266.0 & 6.1 & 18.2 & 276.0 \\
\hline 6 & 4.9 & 14.3 & 276.0 & 3.2 & 14.9 & 279.0 \\
\hline 7 & 9.5 & 14.3 & 275.0 & 9.0 & 14.9 & 285.0 \\
\hline 8 & 9.0 & 14.3 & 285.0 & 9.1 & 14.9 & 294.0 \\
\hline 9 & 8.9 & 14.3 & 270.0 & 9.9 & 18.2 & 285.0 \\
\hline 10 & 8.2 & 14.3 & 278.0 & & & \\
\hline 11 & 9.2 & 14.3 & 266.0 & 9.1 & 13.7 & 276.0 \\
\hline 12 & 2.8 & 14.3 & 287.0 & 4.1 & 18.2 & 301.0 \\
\hline 13 & 3.5 & 14.3 & 287.0 & 4.8 & 20.5 & 298.0 \\
\hline 14 & 3.2 & 14.3 & 280.0 & 4.2 & 14.9 & 299.0 \\
\hline 15 & 3.9 & 14.3 & 277.0 & 4.2 & 18.2 & 308.0 \\
\hline 16 & 3.8 & 14.3 & 266.0 & 5.0 & 13.7 & 295.0 \\
\hline 17 & 5.9 & 14.3 & 267.0 & 5.9 & 14.9 & 288.0 \\
\hline 18 & 6.0 & 14.3 & 213.0 & 6.6 & 16.4 & 267.0 \\
\hline 19 & 6.5 & 14.3 & 241.0 & 4.5 & 14.9 & 257.0 \\
\hline 20 & 4.5 & 14.3 & 243.0 & 2.6 & 14.9 & 233.0 \\
\hline 21 & 3.0 & 14.3 & 229.0 & 1.6 & 20.5 & 222.0 \\
\hline 22 & 1.7 & 14.3 & 232.0 & 1.0 & 18.2 & 198.0 \\
\hline 23 & 2.0 & 14.3 & 209.0 & 1.3 & 18.2 & 210.0 \\
\hline 24 & 1.9 & 14.3 & 282.0 & 1.5 & 163.8 & 317.0 \\
\hline 25 & 1.8 & 14.3 & 237.0 & 1.6 & 18.2 & 198.0 \\
\hline 26 & 2.7 & 14.3 & 230.0 & 1.9 & 16.4 & 224.0 \\
\hline 27 & 3.4 & 14.3 & 216.0 & 2.0 & 16.4 & 207.0 \\
\hline 28 & 3.8 & 14.3 & 234.0 & 1.9 & 14.9 & 235.0 \\
\hline 29 & 3.8 & 14.3 & 245.0 & 2.0 & 14.9 & 247.0 \\
\hline 30 & 3.6 & 14.3 & 250.0 & 2.4 & 18.2 & 245.0 \\
\hline 31 & 1.8 & 14.3 & 278.0 & 1.4 & 23.4 & 269.0 \\
\hline
\end{tabular}


Table B1. Continued.

\begin{tabular}{|c|c|c|c|c|c|c|}
\hline \multirow{2}{*}{$\begin{array}{l}\text { Location } \\
\text { No. }\end{array}$} & \multicolumn{3}{|c|}{ STWAVE } & \multicolumn{3}{|c|}{ BOUSS-2D } \\
\hline & $H_{s}, \mathrm{~m}$ & $T_{p}, \sec$ & $\theta_{m}$, deg & $H_{s}, \mathrm{~m}$ & $T_{p}, \sec$ & $\theta_{p}$, deg \\
\hline 32 & 1.7 & 14.3 & 259.0 & 1.5 & 16.4 & 206.0 \\
\hline 33 & 2.6 & 14.3 & 225.0 & 1.7 & 16.4 & 216.0 \\
\hline 34 & 3.3 & 14.3 & 235.0 & 1.5 & 14.9 & 230.0 \\
\hline 35 & 0.8 & 14.3 & 246.0 & 0.7 & 163.8 & 19.0 \\
\hline 36 & 1.5 & 14.3 & 244.0 & 1.3 & 327.6 & 189.0 \\
\hline 37 & 2.6 & 14.3 & 229.0 & 1.9 & 14.9 & 213.0 \\
\hline 38 & 4.0 & 14.3 & 232.0 & 2.4 & 14.9 & 226.0 \\
\hline 39 & 4.3 & 14.3 & 235.0 & 2.4 & 14.9 & 233.0 \\
\hline 40 & 3.5 & 14.3 & 303.0 & 2.1 & 13.7 & 298.0 \\
\hline 41 & 3.7 & 14.3 & 299.0 & 2.1 & 11.7 & 292.0 \\
\hline 42 & 4.2 & 14.3 & 287.0 & 2.6 & 18.2 & 282.0 \\
\hline 43 & 4.5 & 14.3 & 284.0 & 3.2 & 18.2 & 284.0 \\
\hline 44 & 5.0 & 14.3 & 277.0 & 4.4 & 18.2 & 285.0 \\
\hline 45 & 6.2 & 14.3 & 269.0 & 6.0 & 18.2 & 278.0 \\
\hline 46 & 8.1 & 14.3 & 261.0 & 8.8 & 18.2 & 278.0 \\
\hline 47 & 5.0 & 14.3 & 252.0 & 7.7 & 16.4 & 273.0 \\
\hline 48 & 8.1 & 14.3 & 262.0 & 5.7 & 13.7 & 272.0 \\
\hline 49 & 8.4 & 14.3 & 259.0 & 5.1 & 14.9 & 273.0 \\
\hline 50 & 8.2 & 14.3 & 255.0 & 4.1 & 16.4 & 266.0 \\
\hline 51 & 7.7 & 14.3 & 254.0 & 4.5 & 13.7 & 265.0 \\
\hline 52 & 7.0 & 14.3 & 254.0 & 4.2 & 13.7 & 264.0 \\
\hline 53 & 6.2 & 14.3 & 252.0 & 6.2 & 14.9 & 259.0 \\
\hline 54 & 5.8 & 14.3 & 250.0 & 6.2 & 13.7 & 256.0 \\
\hline 55 & 4.7 & 14.3 & 253.0 & 5.8 & 16.4 & 258.0 \\
\hline 56 & 3.8 & 14.3 & 254.0 & 5.0 & 18.2 & 260.0 \\
\hline 57 & 3.3 & 14.3 & 253.0 & 5.0 & 18.2 & 260.0 \\
\hline 58 & 2.7 & 14.3 & 254.0 & & & \\
\hline 59 & 2.7 & 14.3 & 258.0 & & & \\
\hline 60 & 3.3 & 14.3 & 310.0 & 0.7 & 163.8 & 346.0 \\
\hline 61 & 3.3 & 14.3 & 304.0 & 1.6 & 11.7 & 301.0 \\
\hline 62 & 4.0 & 14.3 & 295.0 & 2.6 & 13.7 & 289.0 \\
\hline 63 & 4.2 & 14.3 & 292.0 & 2.8 & 13.7 & 288.0 \\
\hline 64 & 4.5 & 14.3 & 288.0 & 2.9 & 12.6 & 286.0 \\
\hline 65 & 4.4 & 14.3 & 288.0 & 3.0 & 12.6 & 286.0 \\
\hline 66 & 3.5 & 14.3 & 304.0 & 1.0 & 163.8 & 323.0 \\
\hline & & & & & & neet 2 of \\
\hline
\end{tabular}


Table B1. Continued.

\begin{tabular}{|c|c|c|c|c|c|c|}
\hline \multirow{2}{*}{$\begin{array}{l}\text { Location } \\
\text { No. }\end{array}$} & \multicolumn{3}{|c|}{ STWAVE } & \multicolumn{3}{|c|}{ BOUSS-2D } \\
\hline & $H_{s}, \mathrm{~m}$ & $T_{p}, \sec$ & $\theta_{m}$, deg & $H_{s}, \mathrm{~m}$ & $T_{p}, \sec$ & $\theta_{p}$, deg \\
\hline 67 & 3.6 & 14.3 & 299.0 & 1.9 & 14.9 & 294.0 \\
\hline 68 & 3.8 & 14.3 & 294.0 & 2.4 & 18.2 & 286.0 \\
\hline 69 & 4.2 & 14.3 & 289.0 & 2.7 & 18.2 & 287.0 \\
\hline 70 & 4.3 & 14.3 & 286.0 & 2.9 & 18.2 & 286.0 \\
\hline 71 & 3.2 & 14.3 & 315.0 & 0.7 & 163.8 & 344.0 \\
\hline 72 & 3.2 & 14.3 & 307.0 & 1.4 & 11.7 & 305.0 \\
\hline 73 & 3.6 & 14.3 & 304.0 & 2.0 & 11.7 & 296.0 \\
\hline 74 & 3.9 & 14.3 & 299.0 & 2.5 & 13.7 & 292.0 \\
\hline 75 & 4.1 & 14.3 & 294.0 & 2.6 & 13.7 & 290.0 \\
\hline 76 & 1.4 & 14.3 & 257.0 & 1.5 & 16.4 & 257.0 \\
\hline 77 & 2.4 & 14.3 & 253.0 & 2.3 & 16.4 & 258.0 \\
\hline 78 & 4.3 & 14.3 & 251.0 & 3.5 & 14.9 & 263.0 \\
\hline 79 & 4.8 & 14.3 & 266.0 & 4.2 & 14.9 & 273.0 \\
\hline 80 & 5.8 & 14.3 & 268.0 & 5.2 & 14.9 & 282.0 \\
\hline 81 & 7.6 & 14.3 & 272.0 & 6.9 & 14.9 & 281.0 \\
\hline 82 & 8.9 & 14.3 & 270.0 & 8.4 & 14.9 & 286.0 \\
\hline 83 & 9.5 & 14.3 & 269.0 & 8.4 & 18.2 & 283.0 \\
\hline 84 & 10.0 & 14.3 & 269.0 & 9.0 & 14.9 & 277.0 \\
\hline 85 & 9.6 & 14.3 & 269.0 & 9.5 & 14.9 & 273.0 \\
\hline 86 & 8.9 & 14.3 & 271.0 & 9.3 & 13.7 & 277.0 \\
\hline 87 & 7.8 & 14.3 & 272.0 & 8.3 & 13.7 & 280.0 \\
\hline 88 & 8.4 & 14.3 & 236.0 & 6.2 & 18.2 & 282.0 \\
\hline 89 & 9.1 & 14.3 & 245.0 & 6.1 & 14.9 & 284.0 \\
\hline 90 & 9.3 & 14.3 & 252.0 & 7.0 & 14.9 & 283.0 \\
\hline 91 & 9.1 & 14.3 & 261.0 & 6.8 & 16.4 & 281.0 \\
\hline 92 & 9.2 & 14.3 & 266.0 & 8.2 & 16.4 & 289.0 \\
\hline 93 & 9.1 & 14.3 & 268.0 & 8.9 & 18.2 & 287.0 \\
\hline 94 & 9.1 & 14.3 & 269.0 & 9.6 & 18.2 & 288.0 \\
\hline 95 & 9.1 & 14.3 & 268.0 & 9.0 & 13.7 & 288.0 \\
\hline 96 & 9.7 & 14.3 & 270.0 & 8.8 & 16.4 & 291.0 \\
\hline 97 & 9.1 & 14.3 & 291.0 & & & \\
\hline 98 & 9.1 & 14.3 & 292.0 & & & \\
\hline 99 & 9.1 & 14.3 & 292.0 & & & \\
\hline 100 & 9.2 & 14.3 & 292.0 & & & \\
\hline 101 & 9.3 & 14.3 & 293.0 & & & \\
\hline & & & & & & neet 3 o \\
\hline
\end{tabular}


Table B1. Continued.

\begin{tabular}{|c|c|c|c|c|c|c|}
\hline \multirow{2}{*}{$\begin{array}{l}\text { Location } \\
\text { No. }\end{array}$} & \multicolumn{3}{|c|}{ STWAVE } & \multicolumn{3}{|c|}{ BOUSS-2D } \\
\hline & $H_{s}, \mathrm{~m}$ & $T_{p}, \mathrm{sec}$ & $\theta_{m}$, deg & $H_{s}, \mathrm{~m}$ & $T_{p}, \sec$ & $\theta_{p}$, deg \\
\hline 102 & 9.3 & 14.3 & 293.0 & & & \\
\hline 103 & 9.4 & 14.3 & 294.0 & & & \\
\hline 104 & 9.5 & 14.3 & 294.0 & & & \\
\hline 105 & 9.6 & 14.3 & 295.0 & & & \\
\hline 106 & 9.6 & 14.3 & 295.0 & & & \\
\hline 107 & 9.1 & 14.3 & 292.0 & & & \\
\hline 108 & 9.1 & 14.3 & 292.0 & & & \\
\hline 109 & 9.2 & 14.3 & 291.0 & & & \\
\hline 110 & 7.9 & 14.3 & 260.0 & 7.4 & 13.7 & 268.0 \\
\hline 111 & 8.7 & 14.3 & 263.0 & 8.3 & 13.7 & 273.0 \\
\hline 112 & 9.2 & 14.3 & 266.0 & 9.0 & 13.7 & 277.0 \\
\hline 113 & 9.3 & 14.3 & 268.0 & 7.9 & 14.9 & 276.0 \\
\hline 114 & 9.0 & 14.3 & 270.0 & 8.1 & 14.9 & 276.0 \\
\hline 115 & 8.5 & 14.3 & 270.0 & 7.8 & 14.9 & 278.0 \\
\hline 116 & 8.1 & 14.3 & 271.0 & 7.2 & 13.7 & 280.0 \\
\hline 117 & 10.1 & 14.3 & 270.0 & 9.2 & 13.7 & 283.0 \\
\hline 118 & 9.8 & 14.3 & 270.0 & 9.4 & 13.7 & 281.0 \\
\hline 119 & 9.5 & 14.3 & 271.0 & 9.7 & 13.7 & 279.0 \\
\hline 120 & 9.4 & 14.3 & 269.0 & 8.6 & 13.7 & 278.0 \\
\hline 121 & 8.9 & 14.3 & 268.0 & 8.1 & 14.9 & 274.0 \\
\hline 122 & 8.6 & 14.3 & 267.0 & 7.5 & 14.9 & 273.0 \\
\hline 123 & 8.5 & 14.3 & 265.0 & 7.1 & 13.7 & 272.0 \\
\hline 124 & 8.0 & 14.3 & 263.0 & 6.9 & 13.7 & 271.0 \\
\hline 125 & 2.7 & 14.3 & 221.0 & 2.6 & 16.4 & 223.0 \\
\hline 126 & 2.6 & 14.3 & 224.0 & 2.4 & 16.4 & 225.0 \\
\hline 127 & 2.1 & 14.3 & 227.0 & 2.2 & 16.4 & 237.0 \\
\hline 128 & 1.9 & 14.3 & 234.0 & 2.1 & 16.4 & 237.0 \\
\hline 129 & 1.7 & 14.3 & 238.0 & 1.8 & 13.7 & 240.0 \\
\hline 130 & 1.6 & 14.3 & 241.0 & 1.6 & 13.7 & 239.0 \\
\hline 131 & 1.3 & 14.3 & 234.0 & 1.7 & 16.4 & 236.0 \\
\hline 132 & 0.9 & 14.3 & 199.0 & 1.6 & 13.7 & 196.0 \\
\hline 133 & 0.1 & 14.3 & 212.0 & 1.3 & 13.7 & 175.0 \\
\hline 134 & 2.9 & 14.3 & 221.0 & 3.0 & 16.4 & 223.0 \\
\hline 135 & 3.8 & 14.3 & 227.0 & 3.2 & 18.2 & 228.0 \\
\hline 136 & 5.8 & 14.3 & 237.0 & 5.7 & 13.7 & 280.0 \\
\hline & & & & & & neet 4 of \\
\hline
\end{tabular}


Table B1. Concluded.

\begin{tabular}{|l|l|l|l|l|l|l|}
\hline \multirow{2}{*}{$\begin{array}{l}\text { Location } \\
\text { No. }\end{array}$} & \multicolumn{3}{|c|}{ STWAVE } & \multicolumn{3}{c|}{ BOUSS-2D } \\
\cline { 2 - 7 } & $H_{s}, \mathrm{~m}$ & $T_{p}, \mathrm{sec}$ & $\theta_{m}, \mathrm{deg}$ & $H_{s}, \mathrm{~m}$ & $T_{p}, \mathrm{sec}$ & $\theta_{p}, \mathrm{deg}$ \\
\hline 137 & 7.8 & 14.3 & 230.0 & 6.7 & 16.4 & 277.0 \\
\hline 138 & 6.5 & 14.3 & 238.0 & 5.5 & 18.2 & 268.0 \\
\hline 139 & 6.4 & 14.3 & 254.0 & 6.1 & 14.9 & 291.0 \\
\hline 140 & 7.2 & 14.3 & 266.0 & 7.0 & 14.9 & 290.0 \\
\hline 141 & 8.3 & 14.3 & 274.0 & 6.8 & 16.4 & 288.0 \\
\hline 142 & 8.6 & 14.3 & 276.0 & 10.0 & 16.4 & 293.0 \\
\hline 143 & 9.2 & 14.3 & 276.0 & 9.1 & 14.9 & 288.0 \\
\hline 144 & 8.5 & 14.3 & 263.0 & 8.7 & 16.4 & 277.0 \\
\hline 145 & 8.7 & 14.3 & 264.0 & 8.3 & 10.9 & 276.0 \\
\hline 146 & 6.9 & 14.3 & 271.0 & 8.4 & 16.4 & 282.0 \\
\hline 147 & 8.7 & 14.3 & 268.0 & 7.6 & 13.7 & 276.0 \\
\hline 148 & 8.4 & 14.3 & 267.0 & 7.0 & 13.7 & 275.0 \\
\hline \multicolumn{7}{|c|}{} \\
\hline
\end{tabular}


Table B2. Event 6 results for north jetty breach configuration.

\begin{tabular}{|c|c|c|c|c|c|c|}
\hline \multirow{2}{*}{$\begin{array}{l}\text { Location } \\
\text { No. }\end{array}$} & \multicolumn{3}{|c|}{ STWAVE } & \multicolumn{3}{|c|}{ BOUSS-2D } \\
\hline & $H_{s}, \mathrm{~m}$ & $T_{p}, \mathrm{sec}$ & $\theta_{m}$, deg & $H_{s}, \mathrm{~m}$ & $T_{p}, \sec$ & $\theta_{p}$, deg \\
\hline 1 & 4.6 & 16.7 & 214.0 & 2.9 & 87.8 & 216.0 \\
\hline 2 & 5.3 & 16.7 & 217.0 & 5.1 & 21.9 & 223.0 \\
\hline 3 & 5.2 & 16.7 & 247.0 & 4.7 & 16.0 & 253.0 \\
\hline 4 & 8.9 & 16.7 & 262.0 & 6.5 & 21.9 & 256.0 \\
\hline 5 & 4.0 & 16.7 & 249.0 & 3.5 & 21.9 & 252.0 \\
\hline 6 & 7.5 & 16.7 & 269.0 & 6.3 & 21.9 & 263.0 \\
\hline 7 & 13.8 & 16.7 & 232.0 & 13.9 & 17.6 & 231.0 \\
\hline 8 & 12.6 & 16.7 & 237.0 & 12.8 & 16.0 & 235.0 \\
\hline 9 & 9.4 & 16.7 & 228.0 & 8.2 & 19.5 & 237.0 \\
\hline 10 & 12.2 & 16.7 & 238.0 & 12.2 & 16.0 & 233.0 \\
\hline 11 & 9.7 & 16.7 & 233.0 & 9.7 & 19.5 & 230.0 \\
\hline 12 & 2.8 & 16.7 & 269.0 & 4.0 & 351.1 & 252.0 \\
\hline 13 & 3.5 & 16.7 & 263.0 & 4.4 & 351.1 & 248.0 \\
\hline 14 & 3.3 & 16.7 & 252.0 & 4.1 & 25.1 & 240.0 \\
\hline 15 & 3.9 & 16.7 & 243.0 & 3.2 & 175.5 & 226.0 \\
\hline 16 & 3.9 & 16.7 & 237.0 & 2.6 & 25.1 & 235.0 \\
\hline 17 & 5.7 & 16.7 & 224.0 & 5.5 & 21.9 & 213.0 \\
\hline 18 & 3.2 & 16.7 & 207.0 & 6.6 & 19.5 & 199.0 \\
\hline 19 & 4.7 & 16.7 & 222.0 & 5.0 & 14.6 & 221.0 \\
\hline 20 & 4.6 & 16.7 & 236.0 & 5.1 & 14.6 & 232.0 \\
\hline 21 & 3.0 & 16.7 & 222.0 & 2.7 & 21.9 & 212.0 \\
\hline 22 & 1.8 & 16.7 & 228.0 & 2.0 & 87.8 & 202.0 \\
\hline 23 & 3.2 & 16.7 & 203.0 & 2.4 & 87.8 & 203.0 \\
\hline 24 & 1.7 & 16.7 & 263.0 & 1.9 & 175.5 & 211.0 \\
\hline 25 & 1.8 & 16.7 & 218.0 & 2.5 & 175.5 & 200.0 \\
\hline 26 & 2.7 & 16.7 & 223.0 & 2.9 & 19.5 & 208.0 \\
\hline 27 & 3.4 & 16.7 & 211.0 & 3.3 & 17.6 & 215.0 \\
\hline 28 & 3.6 & 16.7 & 228.0 & 3.4 & 87.8 & 223.0 \\
\hline 29 & 3.7 & 16.7 & 238.0 & 3.7 & 87.8 & 231.0 \\
\hline 30 & 3.7 & 16.7 & 241.0 & 3.8 & 87.8 & 229.0 \\
\hline 31 & 1.8 & 16.7 & 252.0 & 1.9 & 175.5 & 195.0 \\
\hline 32 & 1.5 & 16.7 & 238.0 & 2.3 & 19.5 & 203.0 \\
\hline 33 & 2.2 & 16.7 & 220.0 & 2.5 & 21.9 & 211.0 \\
\hline 34 & 3.1 & 16.7 & 230.0 & 2.8 & 87.8 & 219.0 \\
\hline 35 & 1.1 & 16.7 & 223.0 & 1.4 & 351.1 & 118.0 \\
\hline & & & & & & heet 1 of \\
\hline
\end{tabular}


Table B2. Continued.

\begin{tabular}{|c|c|c|c|c|c|c|}
\hline \multirow{2}{*}{$\begin{array}{l}\text { Location } \\
\text { No. }\end{array}$} & \multicolumn{3}{|c|}{ STWAVE } & \multicolumn{3}{|c|}{ BOUSS-2D } \\
\hline & $H_{s}, \mathrm{~m}$ & $T_{p}, \sec$ & $\theta_{m}, \operatorname{deg}$ & $H_{s}, \mathrm{~m}$ & $T_{p}, \sec$ & $\theta_{p}$, deg \\
\hline 36 & 2.4 & 16.7 & 241.0 & 2.6 & 351.1 & 199.0 \\
\hline 37 & 2.6 & 16.7 & 222.0 & 3.4 & 17.6 & 210.0 \\
\hline 38 & 4.1 & 16.7 & 225.0 & 3.7 & 17.6 & 220.0 \\
\hline 39 & 3.9 & 16.7 & 230.0 & 4.0 & 14.6 & 227.0 \\
\hline 40 & 2.8 & 16.7 & 311.0 & 2.0 & 19.5 & 311.0 \\
\hline 41 & 2.3 & 16.7 & 312.0 & 1.6 & 21.9 & 308.0 \\
\hline 42 & 1.7 & 16.7 & 297.0 & 1.4 & 25.1 & 300.0 \\
\hline 43 & 1.1 & 16.7 & 278.0 & 1.0 & 351.1 & 296.0 \\
\hline 44 & 1.2 & 16.7 & 263.0 & 1.2 & 351.1 & 292.0 \\
\hline 45 & 2.3 & 16.7 & 244.0 & 2.9 & 21.9 & 254.0 \\
\hline 46 & 5.0 & 16.7 & 230.0 & 6.0 & 19.5 & 241.0 \\
\hline 47 & 5.1 & 16.7 & 219.0 & 7.9 & 19.5 & 240.0 \\
\hline 48 & 9.2 & 16.7 & 234.0 & 9.0 & 17.6 & 233.0 \\
\hline 49 & 8.9 & 16.7 & 234.0 & 9.4 & 19.5 & 231.0 \\
\hline 50 & 8.4 & 16.7 & 231.0 & 8.9 & 21.9 & 224.0 \\
\hline 51 & 7.9 & 16.7 & 231.0 & 8.1 & 19.5 & 233.0 \\
\hline 52 & 7.2 & 16.7 & 232.0 & 7.8 & 19.5 & 232.0 \\
\hline 53 & 6.3 & 16.7 & 230.0 & 6.2 & 19.5 & 223.0 \\
\hline 54 & 5.9 & 16.7 & 231.0 & 5.0 & 19.5 & 226.0 \\
\hline 55 & 4.8 & 16.7 & 234.0 & 4.4 & 21.9 & 221.0 \\
\hline 56 & 3.8 & 16.7 & 237.0 & 4.3 & 351.1 & 223.0 \\
\hline 57 & 3.4 & 16.7 & 237.0 & 4.7 & 351.1 & 232.0 \\
\hline 58 & 2.8 & 16.7 & 238.0 & 4.5 & 351.1 & 238.0 \\
\hline 59 & 2.7 & 16.7 & 246.0 & 4.2 & 351.1 & 230.0 \\
\hline 60 & 1.7 & 16.7 & 321.0 & 0.8 & 351.1 & 345.0 \\
\hline 61 & 1.9 & 16.7 & 316.0 & 1.4 & 21.9 & 313.0 \\
\hline 62 & 2.7 & 16.7 & 309.0 & 1.9 & 21.9 & 303.0 \\
\hline 63 & 3.1 & 16.7 & 306.0 & 2.1 & 21.9 & 300.0 \\
\hline 64 & 3.8 & 16.7 & 301.0 & 2.5 & 25.1 & 296.0 \\
\hline 65 & 4.2 & 16.7 & 295.0 & 2.8 & 25.1 & 294.0 \\
\hline 66 & 1.6 & 16.7 & 317.0 & 0.8 & 351.1 & 346.0 \\
\hline 67 & 1.8 & 16.7 & 312.0 & 1.3 & 21.9 & 317.0 \\
\hline 68 & 2.1 & 16.7 & 308.0 & 1.6 & 21.9 & 305.0 \\
\hline 69 & 2.6 & 16.7 & 304.0 & 1.9 & 21.9 & 301.0 \\
\hline 70 & 2.9 & 16.7 & 301.0 & 2.1 & 21.9 & 297.0 \\
\hline & & & & & & neet 2 o \\
\hline
\end{tabular}


Table B2. Continued.

\begin{tabular}{|c|c|c|c|c|c|c|}
\hline \multirow{2}{*}{$\begin{array}{l}\text { Location } \\
\text { No. }\end{array}$} & \multicolumn{3}{|c|}{ STWAVE } & \multicolumn{3}{|c|}{ BOUSS-2D } \\
\hline & $H_{s}, \mathrm{~m}$ & $T_{p}, \mathrm{sec}$ & $\theta_{m}$, deg & $H_{s}, \mathrm{~m}$ & $T_{p}, \sec$ & $\theta_{p}, \operatorname{deg}$ \\
\hline 71 & 2.0 & 16.7 & 321.0 & 0.8 & 351.1 & 354.0 \\
\hline 72 & 2.2 & 16.7 & 314.0 & 1.5 & 21.9 & 315.0 \\
\hline 73 & 2.6 & 16.7 & 314.0 & 1.8 & 21.9 & 309.0 \\
\hline 74 & 2.9 & 16.7 & 310.0 & 2.0 & 21.9 & 306.0 \\
\hline 75 & 3.2 & 16.7 & 306.0 & 2.2 & 16.0 & 304.0 \\
\hline 76 & 2.1 & 16.7 & 255.0 & 2.6 & 16.0 & 261.0 \\
\hline 77 & 3.8 & 16.7 & 247.0 & 3.8 & 21.9 & 253.0 \\
\hline 78 & 7.1 & 16.7 & 237.0 & 6.8 & 16.0 & 241.0 \\
\hline 79 & 7.3 & 16.7 & 247.0 & 8.9 & 16.0 & 242.0 \\
\hline 80 & 7.1 & 16.7 & 244.0 & 8.5 & 16.0 & 246.0 \\
\hline 81 & 8.7 & 16.7 & 240.0 & 10.1 & 16.0 & 239.0 \\
\hline 82 & 9.3 & 16.7 & 237.0 & 10.2 & 16.0 & 232.0 \\
\hline 83 & 9.9 & 16.7 & 236.0 & 11.3 & 19.5 & 231.0 \\
\hline 84 & 10.9 & 16.7 & 234.0 & 11.6 & 17.6 & 227.0 \\
\hline 85 & 11.5 & 16.7 & 234.0 & 12.9 & 17.6 & 232.0 \\
\hline 86 & 12.4 & 16.7 & 235.0 & 12.6 & 17.6 & 233.0 \\
\hline 87 & 13.2 & 16.7 & 236.0 & 13.0 & 17.6 & 235.0 \\
\hline 88 & 6.5 & 16.7 & 208.0 & 7.6 & 19.5 & 212.0 \\
\hline 89 & 7.7 & 16.7 & 211.0 & 8.5 & 19.5 & 213.0 \\
\hline 90 & 8.9 & 16.7 & 212.0 & 8.2 & 19.5 & 218.0 \\
\hline 91 & 10.1 & 16.7 & 214.0 & 7.8 & 19.5 & 223.0 \\
\hline 92 & 10.0 & 16.7 & 216.0 & 8.2 & 19.5 & 225.0 \\
\hline 93 & 9.9 & 16.7 & 220.0 & 8.5 & 19.5 & 228.0 \\
\hline 94 & 9.7 & 16.7 & 224.0 & 8.9 & 19.5 & 231.0 \\
\hline 95 & 9.4 & 16.7 & 228.0 & 9.2 & 19.5 & 234.0 \\
\hline 96 & 10.0 & 16.7 & 230.0 & 9.3 & 19.5 & 237.0 \\
\hline 97 & 12.8 & 16.7 & 235.0 & 13.3 & 17.6 & 232.0 \\
\hline 98 & 12.9 & 16.7 & 235.0 & 13.4 & 17.6 & 232.0 \\
\hline 99 & 12.8 & 16.7 & 235.0 & 13.2 & 16.0 & 233.0 \\
\hline 100 & 12.6 & 16.7 & 235.0 & 13.2 & 16.0 & 232.0 \\
\hline 101 & 12.6 & 16.7 & 235.0 & 13.4 & 16.0 & 232.0 \\
\hline 102 & 12.6 & 16.7 & 234.0 & 14.2 & 16.0 & 232.0 \\
\hline 103 & 12.6 & 16.7 & 234.0 & 14.2 & 16.0 & 232.0 \\
\hline 104 & 12.7 & 16.7 & 234.0 & & & \\
\hline 105 & 12.7 & 16.7 & 234.0 & & & \\
\hline & & & & & & heet 3 of \\
\hline
\end{tabular}


Table B2. Continued.

\begin{tabular}{|c|c|c|c|c|c|c|}
\hline \multirow{2}{*}{$\begin{array}{l}\text { Location } \\
\text { No. }\end{array}$} & \multicolumn{3}{|c|}{ STWAVE } & \multicolumn{3}{|c|}{ BOUSS-2D } \\
\hline & $H_{s}, \mathrm{~m}$ & $T_{p}, \sec$ & $\theta_{m}$, deg & $H_{s}, \mathrm{~m}$ & $T_{p}, \sec$ & $\theta_{p}$, deg \\
\hline 106 & 12.6 & 16.7 & 234.0 & & & \\
\hline 107 & 12.6 & 16.7 & 235.0 & 13.0 & 16.0 & 232.0 \\
\hline 108 & 12.6 & 16.7 & 235.0 & 13.3 & 16.0 & 232.0 \\
\hline 109 & 12.5 & 16.7 & 234.0 & 13.1 & 16.0 & 231.0 \\
\hline 110 & 8.2 & 16.7 & 233.0 & 8.2 & 17.6 & 223.0 \\
\hline 111 & 8.9 & 16.7 & 233.0 & 9.1 & 19.5 & 222.0 \\
\hline 112 & 9.5 & 16.7 & 233.0 & 10.9 & 17.6 & 228.0 \\
\hline 113 & 10.0 & 16.7 & 233.0 & 11.3 & 19.5 & 226.0 \\
\hline 114 & 10.4 & 16.7 & 233.0 & 11.0 & 16.0 & 222.0 \\
\hline 115 & 10.6 & 16.7 & 233.0 & 10.8 & 16.0 & 224.0 \\
\hline 116 & 11.0 & 16.7 & 235.0 & 12.4 & 16.0 & 230.0 \\
\hline 117 & 10.0 & 16.7 & 233.0 & 10.5 & 19.5 & 233.0 \\
\hline 118 & 10.6 & 16.7 & 235.0 & 11.4 & 19.5 & 229.0 \\
\hline 119 & 10.3 & 16.7 & 234.0 & 9.6 & 17.6 & 229.0 \\
\hline 120 & 10.0 & 16.7 & 234.0 & 9.4 & 17.6 & 233.0 \\
\hline 121 & 9.7 & 16.7 & 234.0 & 8.4 & 19.5 & 223.0 \\
\hline 122 & 9.4 & 16.7 & 233.0 & 8.4 & 19.5 & 235.0 \\
\hline 123 & 8.8 & 16.7 & 234.0 & 9.2 & 16.0 & 235.0 \\
\hline 124 & 8.2 & 16.7 & 235.0 & 9.4 & 19.5 & 231.0 \\
\hline 125 & 4.1 & 16.7 & 215.0 & 3.7 & 21.9 & 218.0 \\
\hline 126 & 3.8 & 16.7 & 218.0 & 3.6 & 21.9 & 225.0 \\
\hline 127 & 3.1 & 16.7 & 220.0 & 3.4 & 16.0 & 231.0 \\
\hline 128 & 3.0 & 16.7 & 228.0 & 3.1 & 16.0 & 240.0 \\
\hline 129 & 2.5 & 16.7 & 233.0 & 2.7 & 16.0 & 246.0 \\
\hline 130 & 2.3 & 16.7 & 237.0 & 2.5 & 16.0 & 241.0 \\
\hline 131 & 2.1 & 16.7 & 231.0 & 2.8 & 16.0 & 232.0 \\
\hline 132 & 1.0 & 16.7 & 198.0 & 2.5 & 16.0 & 197.0 \\
\hline 133 & 0.1 & 16.7 & 214.0 & 1.9 & 21.9 & 174.0 \\
\hline 134 & 4.5 & 16.7 & 213.0 & 3.9 & 21.9 & 216.0 \\
\hline 135 & 4.9 & 16.7 & 219.0 & 4.6 & 21.9 & 221.0 \\
\hline 136 & 5.9 & 16.7 & 209.0 & 7.0 & 17.6 & 209.0 \\
\hline 137 & 5.8 & 16.7 & 205.0 & 6.9 & 17.6 & 208.0 \\
\hline 138 & 4.5 & 16.7 & 214.0 & 5.1 & 17.6 & 211.0 \\
\hline 139 & 6.5 & 16.7 & 207.0 & 6.9 & 25.1 & 207.0 \\
\hline 140 & 7.4 & 16.7 & 210.0 & 6.2 & 21.9 & 220.0 \\
\hline & & & & & & neet 4 of \\
\hline
\end{tabular}


Table B2. Concluded.

\begin{tabular}{|l|c|l|l|r|r|l|}
\hline \multirow{2}{*}{$\begin{array}{l}\text { Location } \\
\text { No. }\end{array}$} & \multicolumn{3}{|c|}{ STWAVE } & \multicolumn{3}{c|}{ BOUSS-2D } \\
\cline { 2 - 7 } & $H_{s}, \mathrm{~m}$ & $T_{p}, \mathrm{sec}$ & $\theta_{\mathrm{m}}, \mathrm{deg}$ & $H_{s}, \mathrm{~m}$ & $T_{p}, \mathrm{sec}$ & $\theta_{p}, \mathrm{deg}$ \\
\hline 141 & 8.5 & 16.7 & 225.0 & 6.4 & 16.0 & 229.0 \\
\hline 142 & 8.9 & 16.7 & 234.0 & 7.7 & 19.5 & 233.0 \\
\hline 143 & 9.5 & 16.7 & 236.0 & 10.1 & 19.5 & 231.0 \\
\hline 144 & 5.8 & 16.7 & 228.0 & 6.9 & 19.5 & 240.0 \\
\hline 145 & 6.6 & 16.7 & 230.0 & 7.5 & 19.5 & 239.0 \\
\hline 146 & 7.0 & 16.7 & 223.0 & 9.1 & 19.5 & 237.0 \\
\hline 147 & 10.6 & 16.7 & 233.0 & 6.4 & 19.5 & 231.0 \\
\hline 148 & 9.9 & 16.7 & 233.0 & 7.2 & 17.6 & 234.0 \\
\hline \multicolumn{7}{|l|}{} \\
\hline
\end{tabular}


Table B3. Statistics of wave parameters (STWAVE versus BOUSS-2D) for north jetty breach configuration.

\begin{tabular}{|c|c|c|c|c|c|c|c|}
\hline Area ID & $N$ & $\begin{array}{l}\Delta\left(H_{s}\right) \\
\mathrm{m}\end{array}$ & $\begin{array}{l}\varepsilon_{r m s}\left(H_{s}\right) \\
\mathrm{m}\end{array}$ & $\begin{array}{l}\Delta\left(T_{p}\right) \\
\sec \end{array}$ & $\begin{array}{l}\varepsilon_{r m s}\left(T_{p}\right) \\
\sec \end{array}$ & $\begin{array}{l}\Delta(\theta) \\
\operatorname{deg}\end{array}$ & $\begin{array}{l}\varepsilon_{r m s}(\theta) \\
\operatorname{deg}\end{array}$ \\
\hline \multicolumn{8}{|c|}{ Event 4} \\
\hline 1 & 6 & 1.3 & 1.5 & -2.3 & 2.9 & -5.8 & 9 \\
\hline 2 & 5 & -1 & 1.1 & -2.8 & 3.7 & -20.8 & 22.3 \\
\hline 3 & 27 & 0.8 & 1.2 & -3.5 & 5.6 & 7.9 & 51.4 \\
\hline 4 & 37 & 1.2 & 1.8 & -1.7 & 4.7 & -5.3 & 11.7 \\
\hline 5 & 2 & -1.4 & 1.5 & -3.9 & 3.9 & -6.5 & 6.5 \\
\hline 6 & 13 & 0.4 & 0.6 & -1 & 1.6 & -8.6 & 9.6 \\
\hline 7 & 11 & 1 & 1.6 & -2.2 & 2.7 & -27.3 & 29.4 \\
\hline \multicolumn{8}{|l|}{8} \\
\hline 9 & 16 & 0.7 & 0.8 & 0.2 & 0.6 & -8.6 & 8.8 \\
\hline 10 & 11 & -0.2 & 0.5 & -1.3 & 2 & 1.7 & 11.7 \\
\hline All & 132 & 0.7 & 1.3 & -1.9 & 3.9 & -5.3 & 26.5 \\
\hline \multicolumn{8}{|c|}{ Event 6} \\
\hline 1 & 6 & 1.1 & 1.3 & \begin{tabular}{|l|}
-6.1 \\
\end{tabular} & 8 & -0.8 & 5.1 \\
\hline 2 & 5 & -0.2 & 1 & -13.4 & 14 & 12.6 & 13.8 \\
\hline 3 & 27 & -0.3 & 0.9 & -8 & 11 & 16.5 & 28.6 \\
\hline 4 & 37 & 0.4 & 1.2 & -5.8 & 7.5 & -3.7 & 12 \\
\hline 5 & 4 & -1.2 & 1.3 & \begin{tabular}{|l|}
-16.7 \\
\end{tabular} & 16.7 & 8.8 & 10.9 \\
\hline 6 & 13 & -0.7 & 1 & -0.5 & 1.8 & 0.3 & 4.5 \\
\hline 7 & 11 & 0.6 & 1.2 & -2.6 & 2.7 & -6.4 & 6.8 \\
\hline 8 & 10 & -0.8 & 0.9 & 0.4 & 0.7 & 2.7 & 2.7 \\
\hline 9 & 16 & -0.3 & 0.9 & -1.4 & 2.1 & 5.3 & 6.8 \\
\hline 10 & 11 & -0.3 & 0.8 & -2 & 3.5 & -1.4 & 13.9 \\
\hline All & 145 & -0.1 & 1 & -4.7 & 7.5 & 3 & 15 \\
\hline
\end{tabular}


Table B4. Event 4 statistics for north jetty breach versus existing configuration.

\begin{tabular}{|c|c|c|c|c|c|c|c|}
\hline Area ID & $N$ & $\begin{array}{l}\Delta\left(H_{s}\right) \\
\mathrm{m}\end{array}$ & $\begin{array}{l}\varepsilon_{r m s}\left(H_{s}\right) \\
\mathrm{m}\end{array}$ & $\begin{array}{l}\Delta\left(T_{p}\right) \\
\sec \end{array}$ & $\begin{array}{l}\varepsilon_{r m s}\left(T_{p}\right) \\
\sec \end{array}$ & $\begin{array}{l}\Delta(\theta) \\
\operatorname{deg}\end{array}$ & $\begin{array}{l}\varepsilon_{r m s}(\theta) \\
\operatorname{deg}\end{array}$ \\
\hline \multicolumn{8}{|c|}{ STWAVE } \\
\hline 1 & 6 & -0.2 & 0.9 & 0 & 0 & -5.8 & 7.7 \\
\hline 2 & 5 & 0 & 0 & 0 & 0 & 0.4 & 0.6 \\
\hline 3 & 27 & -0.8 & 1.1 & 0 & 0 & 4.7 & 21.9 \\
\hline 4 & 37 & 0 & 0 & 0 & 0 & -0.5 & 0.8 \\
\hline 5 & 4 & 0 & 0 & 0 & 0 & 0 & 0 \\
\hline 6 & 13 & 0 & 0.1 & 0 & 0 & -1.8 & 4.3 \\
\hline 7 & 11 & 0 & 0 & 0 & 0 & 0 & 0 \\
\hline 8 & 13 & 0 & 0 & 0 & 0 & 0 & 0 \\
\hline 9 & 16 & 0 & 0 & 0 & 0 & 0 & 0 \\
\hline 10 & 11 & -0.3 & 0.5 & 0 & 0 & -4.5 & 7.9 \\
\hline All & 148 & -0.2 & 0.5 & 0 & 0 & 0.1 & 9.8 \\
\hline \multicolumn{8}{|c|}{ BOUSS-2D } \\
\hline 1 & 6 & -0.3 & 0.6 & 0.6 & 1 & -6.5 & 9 \\
\hline 2 & 5 & 0 & 0.1 & -2.5 & 6.7 & -2.8 & 3.3 \\
\hline 3 & 27 & 0.1 & 0.4 & -2.3 & 7.7 & -2.4 & 47.1 \\
\hline 4 & 37 & -0.2 & 0.4 & 0.2 & 2.8 & 0.2 & 3.8 \\
\hline 5 & 2 & 0 & 0 & 1.8 & 1.8 & -1 & 1 \\
\hline 6 & 13 & 0.1 & 0.1 & 0.2 & 0.6 & -1.2 & 4.1 \\
\hline 7 & 11 & 0 & 0.1 & -0.4 & 1.1 & 0 & 0.6 \\
\hline \multicolumn{8}{|l|}{8} \\
\hline 9 & 16 & 0.1 & 0.2 & -0.1 & 0.3 & 0.9 & 1.4 \\
\hline 10 & 11 & 0.2 & 0.7 & -0.6 & 1.7 & 2.9 & 6 \\
\hline All & 132 & 0 & 0.4 & -0.5 & 4.1 & -0.5 & 21.6 \\
\hline
\end{tabular}


Table B5. Event 6 statistics for north jetty breach versus existing configuration.

\begin{tabular}{|c|c|c|c|c|c|c|c|}
\hline \multicolumn{8}{|c|}{ STWAVE } \\
\hline Area ID & $N$ & $\begin{array}{l}\Delta\left(H_{s}\right) \\
\mathrm{m}\end{array}$ & $\begin{array}{l}\varepsilon_{r m s}\left(H_{s}\right) \\
\mathrm{m}\end{array}$ & $\begin{array}{l}\Delta\left(T_{p}\right) \\
\sec \end{array}$ & $\begin{array}{l}\varepsilon_{r m s}\left(T_{p}\right) \\
\sec \end{array}$ & $\begin{array}{l}\Delta(\theta) \\
\operatorname{deg}\end{array}$ & $\begin{array}{l}\varepsilon_{r m s}(\theta) \\
\operatorname{deg}\end{array}$ \\
\hline 1 & 6 & -0.4 & 0.8 & 0 & 0 & -4.8 & 7.2 \\
\hline 2 & 5 & 0 & 0 & 0 & 0 & 0.2 & 0.4 \\
\hline 3 & 27 & -1 & 1.4 & 0 & 0 & 1.5 & 16.2 \\
\hline 4 & 37 & -0.1 & 0.1 & 0 & 0 & -0.9 & 1.3 \\
\hline 5 & 4 & 0 & 0 & 0 & 0 & 0 & 0 \\
\hline 6 & 13 & 0 & 0.3 & 0 & 0 & -1.5 & 3.8 \\
\hline 7 & 11 & 0 & 0 & 0 & 0 & 0 & 0 \\
\hline 8 & 13 & 0 & 0 & 0 & 0 & 0 & 0 \\
\hline 9 & 16 & 0 & 0 & 0 & 0 & 0 & 0 \\
\hline 10 & 11 & -0.4 & 0.5 & 0 & 0 & -1.8 & 2.4 \\
\hline All & 148 & -0.2 & 0.6 & 0 & 0 & -0.4 & 7.2 \\
\hline \multicolumn{8}{|c|}{ BOUSS-2D } \\
\hline 1 & 6 & -0.9 & 1.7 & 5.2 & 8.8 & -3.3 & 5.5 \\
\hline 2 & 5 & 0 & 0 & -17.2 & 17.5 & 0.6 & 1 \\
\hline 3 & 27 & -0.6 & 0.9 & 6.8 & 12.7 & -3.3 & 17.4 \\
\hline 4 & 37 & 0 & 0.1 & -0.9 & 5.5 & -0.1 & 2.4 \\
\hline 5 & 4 & 0 & 0 & 3.5 & 16.9 & 0.2 & 0.5 \\
\hline 6 & 13 & -0.2 & 0.3 & 0.3 & 1.6 & -0.4 & 2.6 \\
\hline 7 & 11 & 0 & 0.2 & -0.3 & 1.2 & -0.5 & 0.9 \\
\hline 8 & 10 & 0.1 & 0.2 & -0.2 & 0.7 & 0 & 0 \\
\hline 9 & 16 & 0 & 0.1 & -0.8 & 1.7 & 0.6 & 1.2 \\
\hline 10 & 11 & -0.7 & 0.9 & 2.1 & 3.6 & 0.8 & 2.6 \\
\hline All & 145 & -0.2 & 0.6 & 1 & 7.6 & -0.7 & 7.8 \\
\hline
\end{tabular}




\section{Appendix C: South Jetty Breach Results}

Table C1. Event 4 results for south jetty breach configuration.

\begin{tabular}{|l|l|l|l|l|l|l|}
\hline \multirow{2}{*}{$\begin{array}{l}\text { Location } \\
\text { No. }\end{array}$} & \multicolumn{3}{|c|}{ STWAVE } & \multicolumn{3}{c|}{ BOUSS-2D } \\
\hline & $H_{s}, \mathrm{~m}$ & $T_{p}, \mathrm{sec}$ & $\theta_{m}, \mathrm{deg}$ & $H_{s}, \mathrm{~m}$ & $T_{p}, \mathrm{sec}$ & $\theta_{p}, \mathrm{deg}$ \\
\hline 1 & 5.3 & 14.3 & 241.0 & 3.1 & 18.2 & 237.0 \\
\hline 2 & 2.4 & 14.3 & 235.0 & 2.9 & 16.4 & 240.0 \\
\hline 3 & 3.4 & 14.3 & 261.0 & 2.6 & 14.9 & 268.0 \\
\hline 4 & 6.6 & 14.3 & 276.0 & 4.3 & 14.9 & 285.0 \\
\hline 5 & 6.7 & 14.3 & 267.0 & 6.7 & 18.2 & 278.0 \\
\hline 6 & 5.5 & 14.3 & 279.0 & 3.9 & 14.9 & 282.0 \\
\hline 7 & 9.5 & 14.3 & 275.0 & 9.0 & 14.9 & 285.0 \\
\hline 8 & 9.0 & 14.3 & 285.0 & 9.1 & 14.9 & 294.0 \\
\hline 9 & 8.9 & 14.3 & 270.0 & 9.8 & 16.4 & 285.0 \\
\hline 10 & 8.2 & 14.3 & 278.0 & & & \\
\hline 11 & 9.2 & 14.3 & 264.0 & 8.7 & 13.7 & 275.0 \\
\hline 12 & 2.8 & 14.3 & 287.0 & 4.3 & 18.2 & 303.0 \\
\hline 13 & 3.5 & 14.3 & 287.0 & 4.7 & 20.5 & 299.0 \\
\hline 14 & 3.2 & 14.3 & 279.0 & 4.1 & 14.9 & 305.0 \\
\hline 15 & 3.9 & 14.3 & 276.0 & 4.3 & 18.2 & 310.0 \\
\hline 16 & 3.8 & 14.3 & 266.0 & 4.9 & 13.7 & 298.0 \\
\hline 17 & 5.9 & 14.3 & 265.0 & 5.7 & 16.4 & 291.0 \\
\hline 18 & 6.0 & 14.3 & 214.0 & 6.1 & 16.4 & 263.0 \\
\hline 19 & 6.5 & 14.3 & 241.0 & 4.5 & 14.9 & 255.0 \\
\hline 20 & 5.9 & 14.3 & 239.0 & 2.5 & 14.9 & 229.0 \\
\hline 21 & 4.8 & 14.3 & 236.0 & 2.0 & 14.9 & 228.0 \\
\hline 22 & 3.5 & 14.3 & 237.0 & 1.3 & 14.9 & 230.0 \\
\hline 23 & 2.5 & 14.3 & 230.0 & 1.1 & 327.6 & 211.0 \\
\hline 24 & 1.1 & 14.3 & 213.0 & 0.7 & 327.6 & 194.0 \\
\hline 25 & 2.5 & 14.3 & 231.0 & 1.3 & 14.9 & 207.0 \\
\hline 26 & 4.2 & 14.3 & 234.0 & 1.7 & 14.9 & 220.0 \\
\hline 27 & 5.1 & 14.3 & 235.0 & 2.0 & 14.9 & 229.0 \\
\hline 28 & 5.3 & 14.3 & 238.0 & 2.3 & 14.9 & 234.0 \\
\hline 29 & 5.1 & 14.3 & 243.0 & 2.5 & 14.9 & 240.0 \\
\hline 30 & 4.9 & 14.3 & 248.0 & 2.7 & 16.4 & 245.0 \\
\hline & & & & & & $($ Sheet 1 of 5) \\
\hline
\end{tabular}


Table C1. Continued.

\begin{tabular}{|c|c|c|c|c|c|c|}
\hline \multirow{2}{*}{$\begin{array}{l}\text { Location } \\
\text { No. }\end{array}$} & \multicolumn{3}{|c|}{ STWAVE } & \multicolumn{3}{|c|}{ BOUSS-2D } \\
\hline & $H_{s}, \mathrm{~m}$ & $T_{p}, \sec$ & $\theta_{m}, \operatorname{deg}$ & $H_{s}, \mathrm{~m}$ & $T_{p}, \sec$ & $\theta_{p}$, deg \\
\hline 31 & 1.6 & 14.3 & 204.0 & 0.8 & 327.6 & 184.0 \\
\hline 32 & 2.5 & 14.3 & 226.0 & 1.2 & 14.9 & 206.0 \\
\hline 33 & 4.0 & 14.3 & 232.0 & 1.6 & 14.9 & 219.0 \\
\hline 34 & 5.1 & 14.3 & 238.0 & 2.2 & 14.9 & 234.0 \\
\hline 35 & 0.8 & 14.3 & 228.0 & 0.7 & 327.6 & 208.0 \\
\hline 36 & 2.6 & 14.3 & 234.0 & 1.3 & 327.6 & 207.0 \\
\hline 37 & 4.3 & 14.3 & 235.0 & 1.7 & 14.9 & 220.0 \\
\hline 38 & 5.4 & 14.3 & 237.0 & 2.2 & 14.9 & 228.0 \\
\hline 39 & 5.6 & 14.3 & 239.0 & 2.5 & 14.9 & 234.0 \\
\hline 40 & 3.9 & 14.3 & 307.0 & 2.9 & 12.6 & 302.0 \\
\hline 41 & 4.0 & 14.3 & 309.0 & 3.0 & 11.7 & 300.0 \\
\hline 42 & 4.9 & 14.3 & 296.0 & 3.2 & 18.2 & 293.0 \\
\hline 43 & 4.8 & 14.3 & 291.0 & 3.3 & 18.2 & 289.0 \\
\hline 44 & 4.7 & 14.3 & 278.0 & 3.9 & 18.2 & 287.0 \\
\hline 45 & 5.8 & 14.3 & 270.0 & 5.5 & 18.2 & 280.0 \\
\hline 46 & 7.9 & 14.3 & 259.0 & 8.1 & 18.2 & 276.0 \\
\hline 47 & 5.0 & 14.3 & 252.0 & 7.9 & 16.4 & 272.0 \\
\hline 48 & 8.0 & 14.3 & 262.0 & 6.1 & 13.7 & 272.0 \\
\hline 49 & 8.3 & 14.3 & 258.0 & 5.7 & 13.7 & 270.0 \\
\hline 50 & 6.9 & 14.3 & 255.0 & 4.3 & 13.7 & 266.0 \\
\hline 51 & 5.2 & 14.3 & 256.0 & 4.4 & 13.7 & 262.0 \\
\hline 52 & 3.5 & 14.3 & 256.0 & 4.1 & 14.9 & 256.0 \\
\hline 53 & 3.0 & 14.3 & 232.0 & 2.9 & 20.5 & 250.0 \\
\hline 54 & 3.1 & 14.3 & 230.0 & 3.1 & 13.7 & 247.0 \\
\hline 55 & 3.4 & 14.3 & 235.0 & 3.0 & 16.4 & 250.0 \\
\hline 56 & 3.5 & 14.3 & 240.0 & 3.5 & 16.4 & 252.0 \\
\hline 57 & 4.0 & 14.3 & 243.0 & 3.5 & 16.4 & 252.0 \\
\hline 58 & 4.6 & 14.3 & 246.0 & & & \\
\hline 59 & 5.2 & 14.3 & 254.0 & & & \\
\hline 60 & 3.0 & 14.3 & 296.0 & 2.3 & 163.8 & 274.0 \\
\hline 61 & 3.6 & 14.3 & 312.0 & 2.6 & 11.7 & 297.0 \\
\hline 62 & 4.2 & 14.3 & 301.0 & 3.5 & 12.6 & 291.0 \\
\hline 63 & 4.6 & 14.3 & 299.0 & 4.0 & 18.2 & 291.0 \\
\hline 64 & 5.0 & 14.3 & 300.0 & 3.8 & 12.6 & 297.0 \\
\hline 65 & 5.1 & 14.3 & 294.0 & 3.6 & 13.7 & 292.0 \\
\hline & & & & & & neet 2 of \\
\hline
\end{tabular}


Table C1. Continued.

\begin{tabular}{|c|c|c|c|c|c|c|}
\hline \multirow{2}{*}{$\begin{array}{l}\text { Location } \\
\text { No. }\end{array}$} & \multicolumn{3}{|c|}{ STWAVE } & \multicolumn{3}{|c|}{ BOUSS-2D } \\
\hline & $H_{s}, \mathrm{~m}$ & $T_{p}, \mathrm{sec}$ & $\theta_{m}$, deg & $H_{s}, \mathrm{~m}$ & $T_{p}, \sec$ & $\theta_{p}, \operatorname{deg}$ \\
\hline 66 & 3.0 & 14.3 & 308.0 & 2.2 & 163.8 & 308.0 \\
\hline 67 & 3.7 & 14.3 & 300.0 & 2.7 & 11.7 & 296.0 \\
\hline 68 & 4.7 & 14.3 & 295.0 & 3.3 & 18.2 & 288.0 \\
\hline 69 & 4.7 & 14.3 & 293.0 & 3.7 & 18.2 & 291.0 \\
\hline 70 & 4.9 & 14.3 & 298.0 & 3.9 & 18.2 & 293.0 \\
\hline 71 & 2.6 & 14.3 & 286.0 & 2.1 & 163.8 & 297.0 \\
\hline 72 & 2.8 & 14.3 & 316.0 & 2.4 & 20.5 & 301.0 \\
\hline 73 & 3.9 & 14.3 & 309.0 & 2.6 & 11.7 & 296.0 \\
\hline 74 & 4.1 & 14.3 & 302.0 & 3.3 & 11.7 & 296.0 \\
\hline 75 & 4.2 & 14.3 & 305.0 & 4.2 & 12.6 & 293.0 \\
\hline 76 & 1.6 & 14.3 & 258.0 & 1.3 & 14.9 & 248.0 \\
\hline 77 & 2.5 & 14.3 & 255.0 & 2.1 & 14.9 & 256.0 \\
\hline 78 & 4.0 & 14.3 & 265.0 & 3.3 & 14.9 & 274.0 \\
\hline 79 & 4.8 & 14.3 & 266.0 & 4.2 & 14.9 & 277.0 \\
\hline 80 & 5.8 & 14.3 & 268.0 & 5.1 & 14.9 & 282.0 \\
\hline 81 & 7.6 & 14.3 & 272.0 & 6.9 & 14.9 & 282.0 \\
\hline 82 & 8.9 & 14.3 & 270.0 & 8.6 & 14.9 & 285.0 \\
\hline 83 & 9.5 & 14.3 & 269.0 & 8.6 & 18.2 & 284.0 \\
\hline 84 & 10.0 & 14.3 & 269.0 & 9.0 & 14.9 & 276.0 \\
\hline 85 & 9.6 & 14.3 & 269.0 & 9.6 & 14.9 & 273.0 \\
\hline 86 & 8.9 & 14.3 & 271.0 & 9.3 & 14.9 & 276.0 \\
\hline 87 & 7.8 & 14.3 & 272.0 & 8.3 & 13.7 & 279.0 \\
\hline 88 & 8.4 & 14.3 & 236.0 & 6.2 & 18.2 & 283.0 \\
\hline 89 & 9.1 & 14.3 & 245.0 & 6.3 & 14.9 & 284.0 \\
\hline 90 & 9.3 & 14.3 & 252.0 & 6.9 & 16.4 & 283.0 \\
\hline 91 & 9.1 & 14.3 & 261.0 & 6.9 & 16.4 & 281.0 \\
\hline 92 & 9.2 & 14.3 & 266.0 & 8.2 & 16.4 & 288.0 \\
\hline 93 & 9.1 & 14.3 & 268.0 & 9.0 & 18.2 & 289.0 \\
\hline 94 & 9.1 & 14.3 & 269.0 & 9.5 & 18.2 & 287.0 \\
\hline 95 & 9.1 & 14.3 & 268.0 & 9.0 & 13.7 & 287.0 \\
\hline 96 & 9.7 & 14.3 & 270.0 & 8.8 & 16.4 & 291.0 \\
\hline 97 & 9.1 & 14.3 & 291.0 & & & \\
\hline 98 & 9.1 & 14.3 & 292.0 & & & \\
\hline 99 & 9.1 & 14.3 & 292.0 & & & \\
\hline 100 & 9.2 & 14.3 & 292.0 & & & \\
\hline & & & & & & heet 3 of \\
\hline
\end{tabular}


Table C1. Continued.

\begin{tabular}{|c|c|c|c|c|c|c|}
\hline \multirow{2}{*}{$\begin{array}{l}\text { Location } \\
\text { No. }\end{array}$} & \multicolumn{3}{|c|}{ STWAVE } & \multicolumn{3}{|c|}{ BOUSS-2D } \\
\hline & $H_{s}, \mathrm{~m}$ & $T_{p}, \mathrm{sec}$ & $\theta_{m}, \operatorname{deg}$ & $H_{s}, \mathrm{~m}$ & $T_{p}, \sec$ & $\theta_{p}$, deg \\
\hline 101 & 9.3 & 14.3 & 293.0 & & & \\
\hline 102 & 9.3 & 14.3 & 293.0 & & & \\
\hline 103 & 9.4 & 14.3 & 294.0 & & & \\
\hline 104 & 9.5 & 14.3 & 294.0 & & & \\
\hline 105 & 9.6 & 14.3 & 295.0 & & & \\
\hline 106 & 9.6 & 14.3 & 295.0 & & & \\
\hline 107 & 9.1 & 14.3 & 292.0 & & & \\
\hline 108 & 9.1 & 14.3 & 292.0 & & & \\
\hline 109 & 9.2 & 14.3 & 291.0 & & & \\
\hline 110 & 6.0 & 14.3 & 247.0 & 6.6 & 13.7 & 265.0 \\
\hline 111 & 6.9 & 14.3 & 250.0 & 8.3 & 13.7 & 267.0 \\
\hline 112 & 9.1 & 14.3 & 264.0 & 8.6 & 13.7 & 275.0 \\
\hline 113 & 9.1 & 14.3 & 268.0 & 7.6 & 14.9 & 274.0 \\
\hline 114 & 8.7 & 14.3 & 270.0 & 8.0 & 13.7 & 276.0 \\
\hline 115 & 8.5 & 14.3 & 270.0 & 7.8 & 14.9 & 277.0 \\
\hline 116 & 8.1 & 14.3 & 272.0 & 7.3 & 13.7 & 281.0 \\
\hline 117 & 10.1 & 14.3 & 270.0 & 9.0 & 13.7 & 282.0 \\
\hline 118 & 9.7 & 14.3 & 270.0 & 9.2 & 13.7 & 280.0 \\
\hline 119 & 9.4 & 14.3 & 270.0 & 9.3 & 13.7 & 278.0 \\
\hline 120 & 9.3 & 14.3 & 268.0 & 8.0 & 13.7 & 276.0 \\
\hline 121 & 8.7 & 14.3 & 266.0 & 7.7 & 14.9 & 272.0 \\
\hline 122 & 8.2 & 14.3 & 265.0 & 7.1 & 14.9 & 272.0 \\
\hline 123 & 8.2 & 14.3 & 264.0 & 6.8 & 13.7 & 271.0 \\
\hline 124 & 8.1 & 14.3 & 263.0 & 6.9 & 13.7 & 269.0 \\
\hline 125 & 2.6 & 14.3 & 227.0 & 1.7 & 14.9 & 218.0 \\
\hline 126 & 2.7 & 14.3 & 225.0 & 1.7 & 16.4 & 219.0 \\
\hline 127 & 2.5 & 14.3 & 229.0 & 1.7 & 16.4 & 227.0 \\
\hline 128 & 2.2 & 14.3 & 236.0 & 1.6 & 16.4 & 230.0 \\
\hline 129 & 1.9 & 14.3 & 239.0 & 1.5 & 16.4 & 236.0 \\
\hline 130 & 1.8 & 14.3 & 242.0 & 1.3 & 14.9 & 234.0 \\
\hline 131 & 1.5 & 14.3 & 234.0 & 1.3 & 14.9 & 223.0 \\
\hline 132 & 1.1 & 14.3 & 199.0 & 1.3 & 16.4 & 192.0 \\
\hline 133 & 0.1 & 14.3 & 211.0 & 1.1 & 14.9 & 173.0 \\
\hline 134 & 3.9 & 14.3 & 241.0 & 2.6 & 18.2 & 232.0 \\
\hline 135 & 5.0 & 14.3 & 242.0 & 5.1 & 18.2 & 235.0 \\
\hline
\end{tabular}


Table C1. Concluded.

\begin{tabular}{|l|l|l|l|c|c|l|}
\hline \multirow{2}{*}{$\begin{array}{l}\text { Location } \\
\text { No. }\end{array}$} & \multicolumn{3}{|c|}{ STWAVE } & \multicolumn{3}{c|}{ BOUSS-2D } \\
\cline { 2 - 7 } & $H_{s}, \mathrm{~m}$ & $T_{p}, \mathrm{sec}$ & $\theta_{\mathrm{m}}, \mathrm{deg}$ & $H_{s}, \mathrm{~m}$ & $T_{p}, \mathrm{sec}$ & $\theta_{p}, \mathrm{deg}$ \\
\hline 136 & 6.2 & 14.3 & 242.0 & 5.2 & 14.9 & 283.0 \\
\hline 137 & 7.8 & 14.3 & 230.0 & 6.4 & 16.4 & 277.0 \\
\hline 138 & 6.6 & 14.3 & 238.0 & 5.1 & 18.2 & 268.0 \\
\hline 139 & 6.4 & 14.3 & 254.0 & 5.5 & 14.9 & 292.0 \\
\hline 140 & 7.2 & 14.3 & 266.0 & 6.8 & 14.9 & 291.0 \\
\hline 141 & 8.3 & 14.3 & 274.0 & 6.8 & 16.4 & 288.0 \\
\hline 142 & 8.6 & 14.3 & 276.0 & 10.1 & 16.4 & 293.0 \\
\hline 143 & 9.2 & 14.3 & 276.0 & 9.0 & 14.9 & 288.0 \\
\hline 144 & 8.2 & 14.3 & 261.0 & 8.4 & 18.2 & 276.0 \\
\hline 145 & 8.6 & 14.3 & 263.0 & 8.3 & 18.2 & 277.0 \\
\hline 146 & 6.9 & 14.3 & 271.0 & 8.8 & 16.4 & 287.0 \\
\hline 147 & 8.7 & 14.3 & 268.0 & 8.7 & 13.7 & 277.0 \\
\hline 148 & 8.6 & 14.3 & 266.0 & 7.6 & 13.7 & 273.0 \\
\hline \multicolumn{7}{|l|}{} \\
\hline
\end{tabular}


Table C2. Event 6 results for south jetty breach configuration.

\begin{tabular}{|c|c|c|c|c|c|c|}
\hline \multirow[b]{2}{*}{ Location No. } & \multicolumn{3}{|c|}{ STWAVE } & \multicolumn{3}{|c|}{ BOUSS-2D } \\
\hline & $H_{s}, \mathrm{~m}$ & $T_{p}, \sec$ & $\theta_{m}$, deg & $H_{s}, \mathrm{~m}$ & $T_{p}, \mathrm{sec}$ & $\theta_{p}, \operatorname{deg}$ \\
\hline 1 & 6.2 & 16.7 & 229.0 & 6.5 & 16.0 & 229.0 \\
\hline 2 & 4.6 & 16.7 & 225.0 & 5.1 & 16.0 & 228.0 \\
\hline 3 & 5.6 & 16.7 & 249.0 & 5.4 & 16.0 & 252.0 \\
\hline 4 & 8.9 & 16.7 & 261.0 & 6.5 & 21.9 & 253.0 \\
\hline 5 & 3.8 & 16.7 & 249.0 & 3.5 & 21.9 & 251.0 \\
\hline 6 & 8.0 & 16.7 & 270.0 & 6.2 & 21.9 & 263.0 \\
\hline 7 & 13.8 & 16.7 & 232.0 & 13.9 & 17.6 & 231.0 \\
\hline 8 & 12.6 & 16.7 & 237.0 & 12.8 & 16.0 & 235.0 \\
\hline 9 & 9.4 & 16.7 & 228.0 & 8.1 & 19.5 & 238.0 \\
\hline 10 & 12.2 & 16.7 & 238.0 & 11.9 & 16.0 & 233.0 \\
\hline 11 & 9.6 & 16.7 & 232.0 & 10.1 & 19.5 & 229.0 \\
\hline 12 & 2.8 & 16.7 & 269.0 & 4.0 & 351.1 & 252.0 \\
\hline 13 & 3.5 & 16.7 & 263.0 & 4.4 & 351.1 & 248.0 \\
\hline 14 & 3.2 & 16.7 & 252.0 & 4.1 & 175.5 & 239.0 \\
\hline 15 & 4.0 & 16.7 & 242.0 & 3.2 & 175.5 & 224.0 \\
\hline 16 & 3.8 & 16.7 & 237.0 & 2.8 & 25.1 & 234.0 \\
\hline 17 & 5.6 & 16.7 & 223.0 & 5.6 & 17.6 & 214.0 \\
\hline 18 & 3.2 & 16.7 & 207.0 & 6.6 & 19.5 & 200.0 \\
\hline 19 & 4.7 & 16.7 & 222.0 & 5.1 & 17.6 & 221.0 \\
\hline 20 & 5.3 & 16.7 & 230.0 & 5.0 & 14.6 & 228.0 \\
\hline 21 & 4.7 & 16.7 & 234.0 & 4.4 & 16.0 & 225.0 \\
\hline 22 & 3.9 & 16.7 & 232.0 & 3.5 & 21.9 & 223.0 \\
\hline 23 & 3.9 & 16.7 & 219.0 & 3.9 & 21.9 & 210.0 \\
\hline 24 & 2.3 & 16.7 & 210.0 & 1.2 & 175.5 & 150.0 \\
\hline 25 & 4.1 & 16.7 & 227.0 & 2.8 & 16.0 & 206.0 \\
\hline 26 & 5.2 & 16.7 & 231.0 & 3.8 & 16.0 & 218.0 \\
\hline 27 & 4.9 & 16.7 & 232.0 & 4.7 & 16.0 & 226.0 \\
\hline 28 & 4.2 & 16.7 & 234.0 & 4.9 & 14.6 & 231.0 \\
\hline 29 & 3.8 & 16.7 & 235.0 & 5.0 & 14.6 & 235.0 \\
\hline 30 & 3.8 & 16.7 & 233.0 & 5.5 & 14.6 & 234.0 \\
\hline 31 & 2.8 & 16.7 & 202.0 & 1.4 & 19.5 & 161.0 \\
\hline 32 & 3.9 & 16.7 & 224.0 & 2.7 & 17.6 & 205.0 \\
\hline 33 & 5.0 & 16.7 & 230.0 & 3.9 & 16.0 & 219.0 \\
\hline 34 & 4.2 & 16.7 & 234.0 & 4.6 & 14.6 & 230.0 \\
\hline 35 & 1.7 & 16.7 & 222.0 & 1.2 & 175.5 & 154.0 \\
\hline & & & & & & eeet 1 of \\
\hline
\end{tabular}


Table C2. Continued.

\begin{tabular}{|c|c|c|c|c|c|c|}
\hline \multirow[b]{2}{*}{ Location No. } & \multicolumn{3}{|c|}{ STWAVE } & \multicolumn{3}{|c|}{ BOUSS-2D } \\
\hline & $H_{s}, \mathrm{~m}$ & $T_{p}, \sec$ & $\theta_{m}, \operatorname{deg}$ & $H_{s}, \mathrm{~m}$ & $T_{p}, \mathrm{sec}$ & $\theta_{p}$, deg \\
\hline 36 & 4.1 & 16.7 & 230.0 & 2.9 & 16.0 & 208.0 \\
\hline 37 & 5.3 & 16.7 & 231.0 & 4.0 & 16.0 & 221.0 \\
\hline 38 & 5.0 & 16.7 & 232.0 & 4.9 & 16.0 & 227.0 \\
\hline 39 & 4.2 & 16.7 & 233.0 & 5.1 & 14.6 & 230.0 \\
\hline 40 & 3.4 & 16.7 & 311.0 & 1.2 & 21.9 & 316.0 \\
\hline 41 & 3.2 & 16.7 & 294.0 & 1.8 & 21.9 & 235.0 \\
\hline 42 & 2.0 & 16.7 & 305.0 & 1.6 & 351.1 & 304.0 \\
\hline 43 & 1.3 & 16.7 & 291.0 & 1.2 & 351.1 & 299.0 \\
\hline 44 & 1.2 & 16.7 & 264.0 & 1.2 & 351.1 & 288.0 \\
\hline 45 & 2.3 & 16.7 & 243.0 & 2.8 & 21.9 & 252.0 \\
\hline 46 & 4.9 & 16.7 & 229.0 & 6.1 & 19.5 & 240.0 \\
\hline 47 & 5.1 & 16.7 & 219.0 & 7.7 & 19.5 & 237.0 \\
\hline 48 & 9.2 & 16.7 & 233.0 & 8.8 & 17.6 & 232.0 \\
\hline 49 & 8.9 & 16.7 & 234.0 & 9.6 & 19.5 & 230.0 \\
\hline 50 & 7.0 & 16.7 & 233.0 & 8.1 & 21.9 & 223.0 \\
\hline 51 & 5.3 & 16.7 & 233.0 & 5.3 & 19.5 & 236.0 \\
\hline 52 & 3.6 & 16.7 & 230.0 & 3.5 & 19.5 & 238.0 \\
\hline 53 & 3.0 & 16.7 & 213.0 & 3.1 & 19.5 & 225.0 \\
\hline 54 & 3.1 & 16.7 & 215.0 & 3.5 & 175.5 & 226.0 \\
\hline 55 & 3.3 & 16.7 & 221.0 & 3.4 & 351.1 & 223.0 \\
\hline 56 & 3.5 & 16.7 & 225.0 & 3.9 & 351.1 & 230.0 \\
\hline 57 & 4.1 & 16.7 & 226.0 & 4.9 & 351.1 & 237.0 \\
\hline 58 & 4.7 & 16.7 & 229.0 & 5.4 & 351.1 & 242.0 \\
\hline 59 & 5.3 & 16.7 & 238.0 & 6.3 & 21.9 & 233.0 \\
\hline 60 & 3.0 & 16.7 & 269.0 & 2.1 & 19.5 & 223.0 \\
\hline 61 & 3.3 & 16.7 & 293.0 & 2.0 & 19.5 & 233.0 \\
\hline 62 & 3.3 & 16.7 & 294.0 & 1.8 & 21.9 & 242.0 \\
\hline 63 & 3.8 & 16.7 & 299.0 & 2.0 & 21.9 & 252.0 \\
\hline 64 & 3.8 & 16.7 & 302.0 & 2.0 & 25.1 & 259.0 \\
\hline 65 & 4.1 & 16.7 & 300.0 & 2.0 & 21.9 & 265.0 \\
\hline 66 & 2.6 & 16.7 & 285.0 & 1.6 & 19.5 & 213.0 \\
\hline 67 & 2.3 & 16.7 & 298.0 & 1.8 & 21.9 & 221.0 \\
\hline 68 & 2.5 & 16.7 & 302.0 & 1.9 & 19.5 & 250.0 \\
\hline 69 & 3.0 & 16.7 & 301.0 & 2.0 & 21.9 & 268.0 \\
\hline 70 & 3.1 & 16.7 & 303.0 & 2.1 & 21.9 & 280.0 \\
\hline & & & & & & eeet 2 of \\
\hline
\end{tabular}


Table C2. Continued.

\begin{tabular}{|c|c|c|c|c|c|c|}
\hline \multirow[b]{2}{*}{ Location No. } & \multicolumn{3}{|c|}{ STWAVE } & \multicolumn{3}{|c|}{ BOUSS-2D } \\
\hline & $H_{s}, \mathrm{~m}$ & $T_{p}, \sec$ & $\theta_{m}, \operatorname{deg}$ & $H_{s}, \mathrm{~m}$ & $T_{p}, \mathrm{sec}$ & $\theta_{p}$, deg \\
\hline 71 & 2.2 & 16.7 & 284.0 & 1.8 & 21.9 & 246.0 \\
\hline 72 & 1.9 & 16.7 & 309.0 & 1.7 & 25.1 & 230.0 \\
\hline 73 & 3.0 & 16.7 & 307.0 & 1.6 & 19.5 & 232.0 \\
\hline 74 & 3.8 & 16.7 & 301.0 & 1.7 & 21.9 & 240.0 \\
\hline 75 & 3.9 & 16.7 & 302.0 & 1.7 & 21.9 & 253.0 \\
\hline 76 & 2.3 & 16.7 & 255.0 & 2.8 & 16.0 & 257.0 \\
\hline 77 & 4.1 & 16.7 & 248.0 & 4.3 & 16.0 & 251.0 \\
\hline 78 & 6.3 & 16.7 & 249.0 & 6.5 & 16.0 & 251.0 \\
\hline 79 & 6.9 & 16.7 & 247.0 & 8.6 & 16.0 & 241.0 \\
\hline 80 & 7.1 & 16.7 & 244.0 & 8.7 & 16.0 & 245.0 \\
\hline 81 & 8.7 & 16.7 & 240.0 & 10.1 & 16.0 & 238.0 \\
\hline 82 & 9.3 & 16.7 & 237.0 & 10.3 & 16.0 & 232.0 \\
\hline 83 & 9.9 & 16.7 & 236.0 & 11.2 & 19.5 & 231.0 \\
\hline 84 & 10.9 & 16.7 & 234.0 & 11.7 & 17.6 & 227.0 \\
\hline 85 & 11.5 & 16.7 & 234.0 & 12.9 & 17.6 & 233.0 \\
\hline 86 & 12.4 & 16.7 & 235.0 & 12.6 & 17.6 & 233.0 \\
\hline 87 & 13.2 & 16.7 & 236.0 & 13.1 & 17.6 & 234.0 \\
\hline 88 & 6.5 & 16.7 & 208.0 & 7.6 & 19.5 & 212.0 \\
\hline 89 & 7.7 & 16.7 & 211.0 & 8.5 & 19.5 & 213.0 \\
\hline 90 & 8.9 & 16.7 & 212.0 & 8.1 & 19.5 & 218.0 \\
\hline 91 & 10.1 & 16.7 & 214.0 & 7.8 & 19.5 & 223.0 \\
\hline 92 & 10.0 & 16.7 & 216.0 & 8.2 & 19.5 & 224.0 \\
\hline 93 & 9.9 & 16.7 & 220.0 & 8.5 & 19.5 & 227.0 \\
\hline 94 & 9.7 & 16.7 & 224.0 & 8.9 & 19.5 & 231.0 \\
\hline 95 & 9.4 & 16.7 & 228.0 & 9.1 & 19.5 & 234.0 \\
\hline 96 & 10.0 & 16.7 & 230.0 & 9.3 & 19.5 & 236.0 \\
\hline 97 & 12.8 & 16.7 & 235.0 & 13.3 & 17.6 & 232.0 \\
\hline 98 & 12.9 & 16.7 & 235.0 & 13.4 & 17.6 & 232.0 \\
\hline 99 & 12.8 & 16.7 & 235.0 & 13.2 & 16.0 & 233.0 \\
\hline 100 & 12.6 & 16.7 & 235.0 & 13.3 & 16.0 & 232.0 \\
\hline 101 & 12.6 & 16.7 & 235.0 & 13.4 & 16.0 & 232.0 \\
\hline 102 & 12.6 & 16.7 & 234.0 & 13.9 & 16.0 & 232.0 \\
\hline 103 & 12.6 & 16.7 & 234.0 & 13.9 & 16.0 & 232.0 \\
\hline 104 & 12.7 & 16.7 & 234.0 & & & \\
\hline 105 & 12.7 & 16.7 & 234.0 & & & \\
\hline & & & & & & eeet 3 of \\
\hline
\end{tabular}


Table C2. Continued.

\begin{tabular}{|c|c|c|c|c|c|c|}
\hline \multirow[b]{2}{*}{ Location No. } & \multicolumn{3}{|c|}{ STWAVE } & \multicolumn{3}{|c|}{ BOUSS-2D } \\
\hline & $H_{s}, \mathrm{~m}$ & $T_{p}, \sec$ & $\theta_{m}, \operatorname{deg}$ & $H_{s}, \mathrm{~m}$ & $T_{p}, \mathrm{sec}$ & $\theta_{p}$, deg \\
\hline 106 & 12.6 & 16.7 & 234.0 & & & \\
\hline 107 & 12.6 & 16.7 & 235.0 & 13.0 & 16.0 & 232.0 \\
\hline 108 & 12.6 & 16.7 & 235.0 & 13.3 & 16.0 & 232.0 \\
\hline 109 & 12.5 & 16.7 & 234.0 & 13.1 & 16.0 & 231.0 \\
\hline 110 & 6.2 & 16.7 & 225.0 & 6.6 & 19.5 & 220.0 \\
\hline 111 & 7.0 & 16.7 & 227.0 & 9.6 & 19.5 & 224.0 \\
\hline 112 & 9.7 & 16.7 & 232.0 & 11.1 & 17.6 & 228.0 \\
\hline 113 & 10.2 & 16.7 & 234.0 & 10.7 & 19.5 & 225.0 \\
\hline 114 & 10.4 & 16.7 & 234.0 & 10.2 & 16.0 & 224.0 \\
\hline 115 & 10.9 & 16.7 & 234.0 & 10.9 & 16.0 & 226.0 \\
\hline 116 & 11.1 & 16.7 & 235.0 & 12.6 & 16.0 & 230.0 \\
\hline 117 & 9.9 & 16.7 & 233.0 & 10.1 & 19.5 & 233.0 \\
\hline 118 & 10.6 & 16.7 & 235.0 & 11.4 & 19.5 & 229.0 \\
\hline 119 & 10.4 & 16.7 & 234.0 & 9.5 & 17.6 & 228.0 \\
\hline 120 & 10.4 & 16.7 & 233.0 & 9.5 & 17.6 & 232.0 \\
\hline 121 & 10.2 & 16.7 & 232.0 & 8.7 & 17.6 & 225.0 \\
\hline 122 & 10.0 & 16.7 & 232.0 & 9.5 & 19.5 & 235.0 \\
\hline 123 & 9.7 & 16.7 & 233.0 & 10.4 & 19.5 & 234.0 \\
\hline 124 & 9.2 & 16.7 & 235.0 & 10.3 & 19.5 & 230.0 \\
\hline 125 & 4.6 & 16.7 & 216.0 & 4.8 & 16.0 & 217.0 \\
\hline 126 & 4.5 & 16.7 & 220.0 & 4.6 & 16.0 & 223.0 \\
\hline 127 & 3.6 & 16.7 & 222.0 & 4.1 & 16.0 & 226.0 \\
\hline 128 & 3.3 & 16.7 & 229.0 & 3.6 & 16.0 & 231.0 \\
\hline 129 & 2.8 & 16.7 & 234.0 & 3.1 & 16.0 & 231.0 \\
\hline 130 & 2.6 & 16.7 & 238.0 & 2.8 & 16.0 & 234.0 \\
\hline 131 & 2.3 & 16.7 & 231.0 & 3.1 & 16.0 & 228.0 \\
\hline 132 & 1.2 & 16.7 & 198.0 & 2.8 & 16.0 & 197.0 \\
\hline 133 & 0.1 & 16.7 & 213.0 & 2.0 & 16.0 & 177.0 \\
\hline 134 & 4.9 & 16.7 & 216.0 & 4.7 & 21.9 & 216.0 \\
\hline 135 & 5.1 & 16.7 & 225.0 & 5.7 & 21.9 & 223.0 \\
\hline 136 & 5.6 & 16.7 & 210.0 & 7.0 & 17.6 & 210.0 \\
\hline 137 & 5.8 & 16.7 & 205.0 & 6.8 & 17.6 & 209.0 \\
\hline 138 & 4.5 & 16.7 & 214.0 & 5.1 & 17.6 & 214.0 \\
\hline 139 & 6.5 & 16.7 & 207.0 & 6.9 & 25.1 & 207.0 \\
\hline 140 & 7.4 & 16.7 & 210.0 & 6.3 & 21.9 & 220.0 \\
\hline & & & & & & eeet 4 of \\
\hline
\end{tabular}


Table C2. Concluded.

\begin{tabular}{|l|c|l|l|c|c|l|}
\hline \multirow{2}{*}{ Location No. } & \multicolumn{3}{|c|}{ STWAVE } & \multicolumn{3}{c|}{ BOUSS-2D } \\
\cline { 2 - 7 } & $H_{s}, \mathrm{~m}$ & $T_{p}, \mathrm{sec}$ & $\theta_{\mathrm{m}}, \mathrm{deg}$ & $H_{s}, \mathrm{~m}$ & $T_{p}, \mathrm{sec}$ & $\theta_{p}, \mathrm{deg}$ \\
\hline 141 & 8.5 & 16.7 & 225.0 & 6.6 & 19.5 & 229.0 \\
\hline 142 & 8.9 & 16.7 & 234.0 & 7.8 & 19.5 & 233.0 \\
\hline 143 & 9.5 & 16.7 & 236.0 & 9.9 & 19.5 & 231.0 \\
\hline 144 & 5.8 & 16.7 & 228.0 & 7.1 & 19.5 & 238.0 \\
\hline 145 & 6.7 & 16.7 & 230.0 & 7.7 & 19.5 & 237.0 \\
\hline 146 & 7.0 & 16.7 & 223.0 & 9.0 & 21.9 & 235.0 \\
\hline 147 & 10.5 & 16.7 & 234.0 & 6.4 & 19.5 & 230.0 \\
\hline 148 & 9.9 & 16.7 & 232.0 & 7.0 & 17.6 & 233.0 \\
\hline \multicolumn{7}{|l|}{} \\
\hline
\end{tabular}


Table C3. Statistics of wave parameters (STWAVE versus BOUSS-2D) for south jetty breach configuration.

\begin{tabular}{|c|c|c|c|c|c|c|c|}
\hline \multicolumn{8}{|c|}{ Event 4} \\
\hline Area ID & $N$ & $\begin{array}{l}\Delta\left(H_{s}\right) \\
\mathrm{m}\end{array}$ & $\begin{array}{l}\varepsilon_{r m s}\left(H_{s}\right) \\
\mathrm{m}\end{array}$ & $\begin{array}{l}\Delta\left(T_{p}\right) \\
\sec \end{array}$ & $\begin{array}{l}\varepsilon_{r m s}\left(T_{p}\right) \\
\sec \end{array}$ & $\begin{array}{l}\Delta(\theta) \\
\operatorname{deg}\end{array}$ & $\begin{array}{l}\varepsilon_{r m s}(\theta) \\
\operatorname{deg}\end{array}$ \\
\hline \multicolumn{8}{|c|}{ Event 4} \\
\hline 1 & 6 & 1.1 & 1.5 & -1.9 & 2.4 & -5.2 & 7.1 \\
\hline 2 & 5 & -1 & 1.1 & -2.8 & 3.7 & -24 & 25.5 \\
\hline 3 & 27 & 1.8 & 2.1 & -3.4 & 6.3 & 0.4 & 22.2 \\
\hline 4 & 37 & 0.7 & 1.2 & -2.2 & 5 & -2 & 11.3 \\
\hline 5 & 2 & 0.3 & 0.4 & -2.1 & 2.1 & -10.5 & 10.6 \\
\hline 6 & 13 & 0.4 & 0.6 & -0.8 & 1.2 & -7.3 & 9.8 \\
\hline 7 & 11 & 1.1 & 1.6 & -2.2 & 2.6 & -27.3 & 29.5 \\
\hline \multicolumn{8}{|l|}{8} \\
\hline 9 & 16 & 0.6 & 1 & 0.3 & 0.6 & -9.3 & 10 \\
\hline 10 & 11 & 0.4 & 0.7 & -1.9 & 2.2 & 9.6 & 13.4 \\
\hline All & 132 & 0.8 & 1.4 & -2 & 4.1 & -5.4 & 16.5 \\
\hline \multicolumn{8}{|c|}{ Event 6} \\
\hline 1 & 6 & 0.7 & 1.3 & -2.2 & 3.7 & 1.2 & 4.7 \\
\hline 2 & 5 & -0.2 & 1 & -15 & 15.4 & 13.2 & 14.3 \\
\hline 3 & 27 & 0 & 1.1 & -1.7 & 5.2 & 12.2 & 21.2 \\
\hline 4 & 37 & 0.5 & 1.5 & -5.8 & 7.4 & 21.1 & 38.2 \\
\hline 5 & 4 & -0.7 & 0.7 & -13.8 & 14.7 & -6 & 9.2 \\
\hline 6 & 13 & -0.8 & 1 & -0.1 & 1.1 & 1.5 & 3.7 \\
\hline 7 & 11 & 0.6 & 1.3 & -2.6 & 2.7 & -6.3 & 6.7 \\
\hline 8 & 10 & -0.7 & 0.8 & 0.4 & 0.7 & 2.7 & 2.7 \\
\hline 9 & 16 & -0.4 & 1.1 & -1.7 & 2.2 & 4.2 & 5.5 \\
\hline 10 & 11 & -0.6 & 0.8 & -0.4 & 2.3 & 3.5 & 11.1 \\
\hline All & 145 & 0 & 1.2 & -3.3 & 6 & 8.6 & 22 \\
\hline
\end{tabular}


Table C4. Event 4 statistics for south jetty breach versus existing configuration.

\begin{tabular}{|c|c|c|c|c|c|c|c|}
\hline Area ID & $N$ & $\begin{array}{l}\Delta\left(H_{s}\right) \\
\mathrm{m}\end{array}$ & $\begin{array}{l}\varepsilon_{r m s}\left(H_{s}\right) \\
\mathrm{m}\end{array}$ & $\begin{array}{l}\Delta\left(T_{p}\right) \\
\sec \end{array}$ & $\begin{array}{l}\varepsilon_{r m s}\left(T_{p}\right) \\
\sec \end{array}$ & $\begin{array}{l}\Delta(\theta) \\
\operatorname{deg}\end{array}$ & $\begin{array}{l}\varepsilon_{r m s}(\theta) \\
\operatorname{deg}\end{array}$ \\
\hline \multicolumn{8}{|c|}{ STWAVE } \\
\hline 1 & 6 & 0 & 0.1 & 0 & 0 & -0.2 & 0.7 \\
\hline 2 & 5 & 0 & 0 & 0 & 0 & 0 & 0 \\
\hline 3 & 27 & 0 & 0 & 0 & 0 & -0.1 & 0.3 \\
\hline 4 & 37 & -0.3 & 1.1 & 0 & 0 & -0.1 & 9.1 \\
\hline 5 & 4 & 1.2 & 1.6 & 0 & 0 & -9 & 9.7 \\
\hline 6 & 13 & 0 & 0 & 0 & 0 & -0.1 & 0.3 \\
\hline 7 & 11 & 0 & 0 & 0 & 0 & 0 & 0 \\
\hline 8 & 13 & 0 & 0 & 0 & 0 & 0 & 0 \\
\hline 9 & 16 & -0.3 & 0.7 & 0 & 0 & -2.2 & 4.7 \\
\hline 10 & 11 & 0 & 0 & 0 & 0 & -0.2 & 0.4 \\
\hline All & 148 & -0.1 & 0.6 & 0 & 0 & -0.5 & 5.1 \\
\hline \multicolumn{8}{|c|}{ BOUSS-2D } \\
\hline 1 & 6 & 0.1 & 0.2 & 0.2 & 0.5 & -1.5 & 2.5 \\
\hline 2 & 5 & 0 & 0 & -2.5 & 6.7 & 0 & 0 \\
\hline 3 & 27 & 0 & 0 & 0 & 0 & 0.3 & 1 \\
\hline 4 & 37 & 0.1 & 1.2 & 0.2 & 3.7 & -2.7 & 12 \\
\hline 5 & 2 & -1.5 & 1.5 & 0 & 0 & -9 & 9 \\
\hline 6 & 13 & 0 & 0 & 0 & 0.5 & -0.7 & 1.5 \\
\hline 7 & 11 & 0 & 0.1 & -0.5 & 1.1 & 0 & 0.4 \\
\hline \multicolumn{8}{|l|}{8} \\
\hline 9 & 16 & -0.2 & 0.4 & -0.1 & 0.4 & -0.7 & 2.1 \\
\hline 10 & 11 & 0 & 0 & 0 & 0.9 & -0.7 & 2.1 \\
\hline All & 132 & 0 & 0.7 & -0.1 & 2.4 & -1.1 & 6.6 \\
\hline
\end{tabular}


Table C5. Event 6 statistics for south jetty breach versus existing configuration.

\begin{tabular}{|c|c|c|c|c|c|c|c|}
\hline Area ID & $N$ & $\begin{array}{l}\Delta\left(H_{s}\right) \\
\mathrm{m}\end{array}$ & $\begin{array}{l}\varepsilon_{r m s}\left(H_{s}\right) \\
\mathrm{m}\end{array}$ & $\begin{array}{l}\Delta\left(T_{p}\right) \\
\sec \end{array}$ & $\begin{array}{l}\varepsilon_{r m s}\left(T_{p}\right) \\
\sec \end{array}$ & $\begin{array}{l}\Delta(\theta) \\
\operatorname{deg}\end{array}$ & $\begin{array}{l}\varepsilon_{r m s}(\theta) \\
\operatorname{deg}\end{array}$ \\
\hline \multicolumn{8}{|c|}{ STWAVE } \\
\hline 1 & 6 & -0.1 & 0.1 & 0 & 0 & -0.7 & 1 \\
\hline 2 & 5 & 0 & 0 & 0 & 0 & 0 & 0 \\
\hline 3 & 27 & 0 & 0 & 0 & 0 & 0.1 & 0.3 \\
\hline 4 & 37 & -0.2 & 1.2 & 0 & 0 & -7.6 & 15.2 \\
\hline 5 & 4 & 1.2 & 1.7 & 0 & 0 & -10 & 10.1 \\
\hline 6 & 13 & -0.1 & 0.1 & 0 & 0 & -0.3 & 0.6 \\
\hline 7 & 11 & 0 & 0 & 0 & 0 & 0 & 0 \\
\hline 8 & 13 & 0 & 0 & 0 & 0 & 0 & 0 \\
\hline 9 & 16 & 0 & 0.8 & 0 & 0 & -1.1 & 2.6 \\
\hline 10 & 11 & -0.1 & 0.1 & 0 & 0 & -0.4 & 0.7 \\
\hline All & 148 & 0 & 0.7 & 0 & 0 & -2.4 & 7.8 \\
\hline \multicolumn{8}{|c|}{ BOUSS-2D } \\
\hline 1 & 6 & -0.2 & 0.3 & 0.8 & 2.4 & -1.2 & 2 \\
\hline 2 & 5 & 0 & 0.1 & -14.5 & 15.4 & -0.2 & 0.8 \\
\hline 3 & 27 & 0.1 & 0.2 & -1.4 & 6.3 & -0.4 & 1.5 \\
\hline 4 & 37 & -0.3 & 1.1 & 0.3 & 9.1 & -31.6 & 51.3 \\
\hline 5 & 4 & 0.7 & 1.2 & -6.5 & 16.9 & 5 & 5.2 \\
\hline 6 & 13 & -0.1 & 0.3 & -0.2 & 0.7 & -0.4 & 1.1 \\
\hline 7 & 11 & -0.1 & 0.2 & -0.3 & 1.2 & -0.6 & 1 \\
\hline 8 & 10 & 0 & 0 & -0.2 & 0.7 & 0 & 0 \\
\hline 9 & 16 & 0.1 & 0.7 & -0.5 & 1.9 & 0.6 & 1.5 \\
\hline 10 & 11 & -0.1 & 0.3 & 0.5 & 3 & -2.6 & 4.9 \\
\hline All & 145 & -0.1 & 0.7 & -0.7 & 6.6 & -8.3 & 26 \\
\hline
\end{tabular}




\section{Appendix D: North Jetty Length Rebuild Results}

Table D1. Event 4 results for north jetty length rebuild configuration.

\begin{tabular}{|c|c|c|c|c|c|c|}
\hline \multirow{2}{*}{$\begin{array}{l}\text { Location } \\
\text { No. }\end{array}$} & \multicolumn{3}{|c|}{ STWAVE } & \multicolumn{3}{|c|}{ BOUSS-2D } \\
\hline & $H_{s}, \mathrm{~m}$ & $T_{p}, \mathrm{sec}$ & $\theta_{m}, \operatorname{deg}$ & $H_{s}, \mathrm{~m}$ & $T_{p}, \sec$ & $\theta_{p}$, deg \\
\hline 1 & 5.3 & 14.3 & 241.0 & 3.5 & 16.4 & 237.0 \\
\hline 2 & 2.4 & 14.3 & 234.0 & 2.6 & 16.4 & 237.0 \\
\hline 3 & 3.4 & 14.3 & 261.0 & 2.6 & 14.9 & 270.0 \\
\hline 4 & 6.8 & 14.3 & 277.0 & 4.0 & 13.7 & 283.0 \\
\hline 5 & 6.5 & 14.3 & 266.0 & 6.2 & 18.2 & 276.0 \\
\hline 6 & 5.5 & 14.3 & 280.0 & 3.5 & 14.9 & 287.0 \\
\hline 7 & 9.5 & 14.3 & 275.0 & 9.0 & 14.9 & 285.0 \\
\hline 8 & 9.0 & 14.3 & 285.0 & 9.1 & 14.9 & 294.0 \\
\hline 9 & 8.9 & 14.3 & 270.0 & 9.9 & 18.2 & 284.0 \\
\hline 10 & 8.2 & 14.3 & 278.0 & & & \\
\hline 11 & 9.2 & 14.3 & 266.0 & 9.2 & 13.7 & 276.0 \\
\hline 12 & 2.8 & 14.3 & 287.0 & 4.2 & 18.2 & 301.0 \\
\hline 13 & 3.5 & 14.3 & 287.0 & 4.8 & 20.5 & 298.0 \\
\hline 14 & 3.2 & 14.3 & 279.0 & 4.2 & 14.9 & 300.0 \\
\hline 15 & 3.9 & 14.3 & 277.0 & 4.0 & 18.2 & 310.0 \\
\hline 16 & 3.8 & 14.3 & 271.0 & 4.8 & 13.7 & 299.0 \\
\hline 17 & 5.9 & 14.3 & 266.0 & 5.7 & 13.7 & 295.0 \\
\hline 18 & 4.1 & 14.3 & 204.0 & 1.7 & 16.4 & 210.0 \\
\hline 19 & 6.4 & 14.3 & 241.0 & 3.4 & 14.9 & 240.0 \\
\hline 20 & 5.9 & 14.3 & 239.0 & 2.4 & 14.9 & 228.0 \\
\hline 21 & 4.8 & 14.3 & 236.0 & 1.8 & 14.9 & 230.0 \\
\hline 22 & 3.5 & 14.3 & 237.0 & 1.2 & 14.9 & 230.0 \\
\hline 23 & 2.5 & 14.3 & 231.0 & 0.9 & 16.4 & 218.0 \\
\hline 24 & 1.1 & 14.3 & 213.0 & 0.4 & 327.6 & 160.0 \\
\hline 25 & 2.5 & 14.3 & 231.0 & 1.0 & 14.9 & 206.0 \\
\hline 26 & 4.2 & 14.3 & 233.0 & 1.5 & 14.9 & 222.0 \\
\hline 27 & 5.1 & 14.3 & 235.0 & 1.9 & 14.9 & 230.0 \\
\hline 28 & 5.3 & 14.3 & 238.0 & 2.2 & 16.4 & 235.0 \\
\hline 29 & 5.1 & 14.3 & 243.0 & 2.5 & 16.4 & 239.0 \\
\hline 30 & 4.9 & 14.3 & 248.0 & 2.8 & 16.4 & 242.0 \\
\hline
\end{tabular}


Table D1. Continued.

\begin{tabular}{|c|c|c|c|c|c|c|}
\hline \multirow{2}{*}{$\begin{array}{l}\text { Location } \\
\text { No. }\end{array}$} & \multicolumn{3}{|c|}{ STWAVE } & \multicolumn{3}{|c|}{ BOUSS-2D } \\
\hline & $H_{s}, \mathrm{~m}$ & $T_{p}$, sec & $\theta_{m}$, deg & $H_{s}, \mathrm{~m}$ & $T_{p}, \sec$ & $\theta_{p}$, deg \\
\hline 31 & 1.6 & 14.3 & 204.0 & 0.5 & 327.6 & 165.0 \\
\hline 32 & 2.5 & 14.3 & 226.0 & 0.9 & 14.9 & 204.0 \\
\hline 33 & 4.0 & 14.3 & 232.0 & 1.4 & 14.9 & 221.0 \\
\hline 34 & 5.1 & 14.3 & 238.0 & 2.1 & 16.4 & 235.0 \\
\hline 35 & 0.8 & 14.3 & 228.0 & 0.3 & 327.6 & 162.0 \\
\hline 36 & 2.6 & 14.3 & 234.0 & 1.0 & 16.4 & 204.0 \\
\hline 37 & 4.3 & 14.3 & 235.0 & 1.6 & 14.9 & 221.0 \\
\hline 38 & 5.4 & 14.3 & 237.0 & 2.1 & 14.9 & 230.0 \\
\hline 39 & 5.6 & 14.3 & 239.0 & 2.4 & 16.4 & 235.0 \\
\hline 40 & 3.5 & 14.3 & 303.0 & 1.9 & 14.9 & 300.0 \\
\hline 41 & 3.8 & 14.3 & 300.0 & 2.0 & 14.9 & 293.0 \\
\hline 42 & 4.2 & 14.3 & 287.0 & 2.5 & 18.2 & 282.0 \\
\hline 43 & 4.5 & 14.3 & 284.0 & 3.1 & 18.2 & 284.0 \\
\hline 44 & 5.0 & 14.3 & 277.0 & 4.3 & 18.2 & 285.0 \\
\hline 45 & 6.2 & 14.3 & 269.0 & 6.0 & 18.2 & 279.0 \\
\hline 46 & 8.1 & 14.3 & 261.0 & 9.1 & 18.2 & 278.0 \\
\hline 47 & 5.0 & 14.3 & 252.0 & 9.1 & 16.4 & 273.0 \\
\hline 48 & 8.1 & 14.3 & 262.0 & 5.4 & 13.7 & 272.0 \\
\hline 49 & 8.4 & 14.3 & 259.0 & 5.0 & 14.9 & 273.0 \\
\hline 50 & 8.2 & 14.3 & 255.0 & 3.8 & 16.4 & 266.0 \\
\hline 51 & 7.7 & 14.3 & 254.0 & 4.2 & 13.7 & 265.0 \\
\hline 52 & 7.0 & 14.3 & 254.0 & 3.9 & 13.7 & 264.0 \\
\hline 53 & 6.2 & 14.3 & 252.0 & 6.3 & 14.9 & 259.0 \\
\hline 54 & 5.8 & 14.3 & 250.0 & 6.4 & 13.7 & 257.0 \\
\hline 55 & 4.7 & 14.3 & 253.0 & 5.8 & 16.4 & 259.0 \\
\hline 56 & 3.8 & 14.3 & 254.0 & 4.6 & 18.2 & 260.0 \\
\hline 57 & 3.3 & 14.3 & 253.0 & 4.6 & 18.2 & 260.0 \\
\hline 58 & 2.7 & 14.3 & 254.0 & & & \\
\hline 59 & 2.7 & 14.3 & 258.0 & & & \\
\hline 60 & 3.4 & 14.3 & 311.0 & 0.8 & 163.8 & 346.0 \\
\hline 61 & 3.4 & 14.3 & 305.0 & 1.6 & 14.9 & 302.0 \\
\hline 62 & 4.0 & 14.3 & 297.0 & 2.4 & 13.7 & 289.0 \\
\hline 63 & 4.3 & 14.3 & 293.0 & 2.8 & 13.7 & 288.0 \\
\hline 64 & 4.5 & 14.3 & 290.0 & 3.3 & 13.7 & 288.0 \\
\hline 65 & 4.4 & 14.3 & 289.0 & 3.3 & 13.7 & 289.0 \\
\hline & & & & & & neet 2 of \\
\hline
\end{tabular}


Table D1. Continued.

\begin{tabular}{|c|c|c|c|c|c|c|}
\hline \multirow{2}{*}{$\begin{array}{l}\text { Location } \\
\text { No. }\end{array}$} & \multicolumn{3}{|c|}{ STWAVE } & \multicolumn{3}{|c|}{ BOUSS-2D } \\
\hline & $H_{s}, \mathrm{~m}$ & $T_{p}, \mathrm{sec}$ & $\theta_{m}$, deg & $H_{s}, \mathrm{~m}$ & $T_{p}$, sec & $\theta_{p}$, deg \\
\hline 66 & 3.5 & 14.3 & 305.0 & 1.0 & 14.9 & 325.0 \\
\hline 67 & 3.6 & 14.3 & 300.0 & 1.9 & 14.9 & 295.0 \\
\hline 68 & 3.9 & 14.3 & 295.0 & 2.3 & 14.9 & 287.0 \\
\hline 69 & 4.2 & 14.3 & 290.0 & 2.5 & 18.2 & 286.0 \\
\hline 70 & 4.3 & 14.3 & 287.0 & 3.0 & 18.2 & 286.0 \\
\hline 71 & 3.3 & 14.3 & 316.0 & 0.7 & 163.8 & 343.0 \\
\hline 72 & 3.2 & 14.3 & 308.0 & 1.4 & 14.9 & 304.0 \\
\hline 73 & 3.6 & 14.3 & 305.0 & 1.9 & 14.9 & 295.0 \\
\hline 74 & 3.9 & 14.3 & 300.0 & 2.4 & 13.7 & 292.0 \\
\hline 75 & 4.1 & 14.3 & 295.0 & 2.6 & 13.7 & 290.0 \\
\hline 76 & 1.6 & 14.3 & 258.0 & 1.3 & 16.4 & 256.0 \\
\hline 77 & 2.6 & 14.3 & 256.0 & 2.0 & 16.4 & 259.0 \\
\hline 78 & 4.0 & 14.3 & 265.0 & 3.4 & 14.9 & 274.0 \\
\hline 79 & 4.8 & 14.3 & 266.0 & 4.1 & 14.9 & 275.0 \\
\hline 80 & 5.8 & 14.3 & 268.0 & 5.0 & 14.9 & 282.0 \\
\hline 81 & 7.6 & 14.3 & 272.0 & 6.9 & 14.9 & 282.0 \\
\hline 82 & 8.9 & 14.3 & 270.0 & 8.5 & 14.9 & 286.0 \\
\hline 83 & 9.5 & 14.3 & 269.0 & 8.4 & 18.2 & 284.0 \\
\hline 84 & 10.0 & 14.3 & 269.0 & 8.9 & 14.9 & 277.0 \\
\hline 85 & 9.6 & 14.3 & 269.0 & 9.4 & 14.9 & 274.0 \\
\hline 86 & 8.9 & 14.3 & 271.0 & 9.3 & 14.9 & 276.0 \\
\hline 87 & 7.8 & 14.3 & 272.0 & 8.2 & 13.7 & 279.0 \\
\hline 88 & 8.4 & 14.3 & 236.0 & 5.9 & 18.2 & 282.0 \\
\hline 89 & 9.1 & 14.3 & 245.0 & 6.1 & 14.9 & 284.0 \\
\hline 90 & 9.3 & 14.3 & 252.0 & 7.1 & 14.9 & 282.0 \\
\hline 91 & 9.1 & 14.3 & 261.0 & 6.9 & 16.4 & 282.0 \\
\hline 92 & 9.2 & 14.3 & 266.0 & 8.1 & 16.4 & 289.0 \\
\hline 93 & 9.1 & 14.3 & 268.0 & 8.8 & 18.2 & 289.0 \\
\hline 94 & 9.1 & 14.3 & 269.0 & 9.7 & 18.2 & 288.0 \\
\hline 95 & 9.1 & 14.3 & 268.0 & 9.0 & 13.7 & 288.0 \\
\hline 96 & 9.7 & 14.3 & 270.0 & 8.7 & 16.4 & 291.0 \\
\hline 97 & 9.1 & 14.3 & 291.0 & & & \\
\hline 98 & 9.1 & 14.3 & 292.0 & & & \\
\hline 99 & 9.1 & 14.3 & 292.0 & & & \\
\hline 100 & 9.2 & 14.3 & 292.0 & & & \\
\hline & & & & & & heet 3 of \\
\hline
\end{tabular}


Table D1. Continued.

\begin{tabular}{|c|c|c|c|c|c|c|}
\hline \multirow{2}{*}{$\begin{array}{l}\text { Location } \\
\text { No. }\end{array}$} & \multicolumn{3}{|c|}{ STWAVE } & \multicolumn{3}{|c|}{ BOUSS-2D } \\
\hline & $H_{s}, \mathrm{~m}$ & $T_{p}, \mathrm{sec}$ & $\theta_{m}, \operatorname{deg}$ & $H_{s}, \mathrm{~m}$ & $T_{p}, \sec$ & $\theta_{p}$, deg \\
\hline 101 & 9.3 & 14.3 & 293.0 & & & \\
\hline 102 & 9.3 & 14.3 & 293.0 & & & \\
\hline 103 & 9.4 & 14.3 & 294.0 & & & \\
\hline 104 & 9.5 & 14.3 & 294.0 & & & \\
\hline 105 & 9.6 & 14.3 & 295.0 & & & \\
\hline 106 & 9.6 & 14.3 & 295.0 & & & \\
\hline 107 & 9.1 & 14.3 & 292.0 & & & \\
\hline 108 & 9.1 & 14.3 & 292.0 & & & \\
\hline 109 & 9.2 & 14.3 & 291.0 & & & \\
\hline 110 & 7.9 & 14.3 & 260.0 & 7.7 & 13.7 & 269.0 \\
\hline 111 & 8.7 & 14.3 & 263.0 & 8.0 & 12.6 & 272.0 \\
\hline 112 & 9.2 & 14.3 & 266.0 & 9.2 & 13.7 & 276.0 \\
\hline 113 & 9.3 & 14.3 & 268.0 & 7.8 & 14.9 & 276.0 \\
\hline 114 & 9.0 & 14.3 & 270.0 & 8.1 & 14.9 & 277.0 \\
\hline 115 & 8.5 & 14.3 & 270.0 & 7.9 & 14.9 & 279.0 \\
\hline 116 & 8.1 & 14.3 & 271.0 & 7.2 & 13.7 & 281.0 \\
\hline 117 & 10.1 & 14.3 & 270.0 & 9.2 & 13.7 & 284.0 \\
\hline 118 & 9.8 & 14.3 & 270.0 & 9.5 & 13.7 & 282.0 \\
\hline 119 & 9.5 & 14.3 & 271.0 & 10.0 & 13.7 & 279.0 \\
\hline 120 & 9.4 & 14.3 & 269.0 & 8.6 & 13.7 & 278.0 \\
\hline 121 & 8.9 & 14.3 & 268.0 & 8.1 & 14.9 & 274.0 \\
\hline 122 & 8.6 & 14.3 & 267.0 & 7.5 & 13.7 & 274.0 \\
\hline 123 & 8.5 & 14.3 & 265.0 & 7.0 & 13.7 & 273.0 \\
\hline 124 & 8.0 & 14.3 & 263.0 & 6.8 & 14.9 & 271.0 \\
\hline 125 & 2.6 & 14.3 & 227.0 & 1.8 & 16.4 & 223.0 \\
\hline 126 & 2.7 & 14.3 & 225.0 & 1.6 & 16.4 & 223.0 \\
\hline 127 & 2.5 & 14.3 & 230.0 & 1.6 & 16.4 & 232.0 \\
\hline 128 & 2.2 & 14.3 & 236.0 & 1.6 & 16.4 & 234.0 \\
\hline 129 & 1.9 & 14.3 & 239.0 & 1.4 & 16.4 & 237.0 \\
\hline 130 & 1.8 & 14.3 & 242.0 & 1.3 & 16.4 & 236.0 \\
\hline 131 & 1.5 & 14.3 & 235.0 & 1.3 & 16.4 & 228.0 \\
\hline 132 & 1.1 & 14.3 & 199.0 & 1.3 & 16.4 & 195.0 \\
\hline 133 & 0.1 & 14.3 & 211.0 & 1.1 & 16.4 & 174.0 \\
\hline 134 & 3.9 & 14.3 & 241.0 & 1.8 & 16.4 & 226.0 \\
\hline 135 & 5.0 & 14.3 & 242.0 & 4.9 & 18.2 & 236.0 \\
\hline & & & & & & neet 4 of \\
\hline
\end{tabular}


Table D1. Concluded.

\begin{tabular}{|l|c|l|l|l|l|l|}
\hline \multirow{2}{*}{$\begin{array}{l}\text { Location } \\
\text { No. }\end{array}$} & \multicolumn{3}{|c|}{ STWAVE } & \multicolumn{3}{c|}{ BOUSS-2D } \\
\cline { 2 - 7 } & $H_{s}, \mathrm{~m}$ & $T_{p}, \mathrm{sec}$ & $\theta_{\mathrm{m}}, \mathrm{deg}$ & $H_{s}, \mathrm{~m}$ & $T_{p}, \mathrm{sec}$ & $\theta_{p}, \mathrm{deg}$ \\
\hline 136 & 6.2 & 14.3 & 242.0 & 5.8 & 13.7 & 285.0 \\
\hline 137 & 7.8 & 14.3 & 230.0 & 6.7 & 16.4 & 272.0 \\
\hline 138 & 6.5 & 14.3 & 237.0 & 4.4 & 18.2 & 255.0 \\
\hline 139 & 6.4 & 14.3 & 254.0 & 6.0 & 13.7 & 292.0 \\
\hline 140 & 7.2 & 14.3 & 266.0 & 6.9 & 13.7 & 289.0 \\
\hline 141 & 8.3 & 14.3 & 274.0 & 6.9 & 16.4 & 288.0 \\
\hline 142 & 8.6 & 14.3 & 276.0 & 9.9 & 16.4 & 292.0 \\
\hline 143 & 9.2 & 14.3 & 276.0 & 9.0 & 14.9 & 288.0 \\
\hline 144 & 8.5 & 14.3 & 263.0 & 8.7 & 16.4 & 277.0 \\
\hline 145 & 8.7 & 14.3 & 264.0 & 8.3 & 10.9 & 276.0 \\
\hline 146 & 6.9 & 14.3 & 271.0 & 9.3 & 16.4 & 284.0 \\
\hline 147 & 8.7 & 14.3 & 268.0 & 7.7 & 13.7 & 276.0 \\
\hline 148 & 8.4 & 14.3 & 267.0 & 7.0 & 13.7 & 275.0 \\
\hline \multicolumn{7}{|l|}{} \\
\hline
\end{tabular}


Table D2. Event 6 results for north jetty length rebuild configuration.

\begin{tabular}{|c|c|c|c|c|c|c|}
\hline \multirow{2}{*}{$\begin{array}{l}\text { Location } \\
\text { No. }\end{array}$} & \multicolumn{3}{|c|}{ STWAVE } & \multicolumn{3}{|c|}{ BOUSS-2D } \\
\hline & $H_{s}, \mathrm{~m}$ & $T_{p}, \sec$ & $\theta_{m}$, deg & $H_{s}, \mathrm{~m}$ & $T_{p}, \sec$ & $\theta_{p}$, deg \\
\hline 1 & 6.3 & 16.7 & 229.0 & 7.0 & 16.0 & 228.0 \\
\hline 2 & 4.8 & 16.7 & 225.0 & 5.8 & 16.0 & 228.0 \\
\hline 3 & 5.7 & 16.7 & 250.0 & 5.4 & 16.0 & 252.0 \\
\hline 4 & 8.9 & 16.7 & 262.0 & 6.3 & 21.9 & 256.0 \\
\hline 5 & 4.0 & 16.7 & 249.0 & 3.6 & 21.9 & 252.0 \\
\hline 6 & 8.1 & 16.7 & 272.0 & 6.3 & 17.6 & 266.0 \\
\hline 7 & 13.8 & 16.7 & 232.0 & 13.9 & 17.6 & 231.0 \\
\hline 8 & 12.6 & 16.7 & 237.0 & 12.8 & 16.0 & 235.0 \\
\hline 9 & 9.4 & 16.7 & 228.0 & 8.2 & 19.5 & 238.0 \\
\hline 10 & 12.2 & 16.7 & 238.0 & 12.2 & 16.0 & 232.0 \\
\hline 11 & 9.7 & 16.7 & 233.0 & 9.6 & 19.5 & 229.0 \\
\hline 12 & 2.8 & 16.7 & 269.0 & 4.0 & 351.1 & 252.0 \\
\hline 13 & 3.5 & 16.7 & 263.0 & 4.3 & 351.1 & 250.0 \\
\hline 14 & 3.2 & 16.7 & 252.0 & 4.2 & 25.1 & 244.0 \\
\hline 15 & 4.0 & 16.7 & 243.0 & 3.0 & 351.1 & 235.0 \\
\hline 16 & 3.8 & 16.7 & 244.0 & 2.5 & 25.1 & 241.0 \\
\hline 17 & 5.5 & 16.7 & 224.0 & 3.9 & 16.0 & 232.0 \\
\hline 18 & 2.2 & 16.7 & 201.0 & 3.4 & 19.5 & 184.0 \\
\hline 19 & 4.6 & 16.7 & 221.0 & 5.3 & 14.6 & 225.0 \\
\hline 20 & 5.3 & 16.7 & 230.0 & 4.7 & 14.6 & 229.0 \\
\hline 21 & 4.8 & 16.7 & 233.0 & 4.2 & 17.6 & 225.0 \\
\hline 22 & 4.0 & 16.7 & 232.0 & 3.6 & 17.6 & 220.0 \\
\hline 23 & 4.1 & 16.7 & 219.0 & 3.8 & 21.9 & 210.0 \\
\hline 24 & 2.3 & 16.7 & 210.0 & 1.0 & 175.5 & 151.0 \\
\hline 25 & 4.1 & 16.7 & 227.0 & 2.5 & 16.0 & 207.0 \\
\hline 26 & 5.2 & 16.7 & 231.0 & 3.5 & 17.6 & 219.0 \\
\hline 27 & 4.9 & 16.7 & 232.0 & 4.4 & 17.6 & 227.0 \\
\hline 28 & 4.3 & 16.7 & 234.0 & 4.8 & 17.6 & 230.0 \\
\hline 29 & 3.8 & 16.7 & 234.0 & 5.1 & 17.6 & 234.0 \\
\hline 30 & 4.0 & 16.7 & 232.0 & 5.5 & 14.6 & 234.0 \\
\hline 31 & 2.8 & 16.7 & 202.0 & 1.3 & 175.5 & 161.0 \\
\hline 32 & 4.0 & 16.7 & 223.0 & 2.5 & 17.6 & 207.0 \\
\hline 33 & 5.0 & 16.7 & 230.0 & 3.5 & 17.6 & 220.0 \\
\hline 34 & 4.3 & 16.7 & 234.0 & 4.6 & 17.6 & 229.0 \\
\hline 35 & 1.7 & 16.7 & 222.0 & 1.1 & 175.5 & 157.0 \\
\hline & & & & & & neet 1 of \\
\hline
\end{tabular}


Table D2. Continued.

\begin{tabular}{|c|c|c|c|c|c|c|}
\hline \multirow{2}{*}{$\begin{array}{l}\text { Location } \\
\text { No. }\end{array}$} & \multicolumn{3}{|c|}{ STWAVE } & \multicolumn{3}{|c|}{ BOUSS-2D } \\
\hline & $H_{s}, \mathrm{~m}$ & $T_{p}, \mathrm{sec}$ & $\theta_{m}, \operatorname{deg}$ & $H_{s}, \mathrm{~m}$ & $T_{p}, \sec$ & $\theta_{p}, \operatorname{deg}$ \\
\hline 36 & 4.2 & 16.7 & 230.0 & 2.6 & 13.5 & 210.0 \\
\hline 37 & 5.3 & 16.7 & 231.0 & 3.6 & 13.5 & 221.0 \\
\hline 38 & 5.0 & 16.7 & 232.0 & 4.6 & 17.6 & 228.0 \\
\hline 39 & 4.2 & 16.7 & 233.0 & 5.0 & 17.6 & 231.0 \\
\hline 40 & 2.9 & 16.7 & 311.0 & 2.0 & 17.6 & 313.0 \\
\hline 41 & 2.5 & 16.7 & 314.0 & 1.6 & 21.9 & 307.0 \\
\hline 42 & 1.8 & 16.7 & 298.0 & 1.3 & 351.1 & 296.0 \\
\hline 43 & 1.1 & 16.7 & 278.0 & 1.0 & 351.1 & 288.0 \\
\hline 44 & 1.2 & 16.7 & 263.0 & 1.3 & 351.1 & 293.0 \\
\hline 45 & 2.3 & 16.7 & 244.0 & 2.6 & 21.9 & 264.0 \\
\hline 46 & 5.0 & 16.7 & 230.0 & 6.0 & 19.5 & 242.0 \\
\hline 47 & 5.1 & 16.7 & 219.0 & 8.2 & 19.5 & 241.0 \\
\hline 48 & 9.2 & 16.7 & 234.0 & 9.2 & 17.6 & 233.0 \\
\hline 49 & 8.9 & 16.7 & 234.0 & 9.3 & 19.5 & 231.0 \\
\hline 50 & 8.4 & 16.7 & 231.0 & 8.7 & 21.9 & 224.0 \\
\hline 51 & 7.9 & 16.7 & 231.0 & 8.0 & 19.5 & 234.0 \\
\hline 52 & 7.2 & 16.7 & 232.0 & 8.0 & 19.5 & 231.0 \\
\hline 53 & 6.3 & 16.7 & 230.0 & 6.2 & 19.5 & 224.0 \\
\hline 54 & 5.9 & 16.7 & 231.0 & 5.0 & 19.5 & 226.0 \\
\hline 55 & 4.8 & 16.7 & 234.0 & 4.5 & 21.9 & 220.0 \\
\hline 56 & 3.8 & 16.7 & 237.0 & 4.2 & 351.1 & 222.0 \\
\hline 57 & 3.4 & 16.7 & 237.0 & 4.7 & 351.1 & 233.0 \\
\hline 58 & 2.8 & 16.7 & 238.0 & 4.4 & 351.1 & 237.0 \\
\hline 59 & 2.7 & 16.7 & 246.0 & 4.2 & 175.5 & 230.0 \\
\hline 60 & 1.8 & 16.7 & 323.0 & 0.8 & 351.1 & 345.0 \\
\hline 61 & 2.1 & 16.7 & 318.0 & 1.3 & 21.9 & 314.0 \\
\hline 62 & 2.9 & 16.7 & 310.0 & 1.9 & 21.9 & 304.0 \\
\hline 63 & 3.3 & 16.7 & 308.0 & 2.1 & 21.9 & 301.0 \\
\hline 64 & 3.9 & 16.7 & 303.0 & 2.5 & 25.1 & 296.0 \\
\hline 65 & 4.2 & 16.7 & 297.0 & 2.8 & 25.1 & 296.0 \\
\hline 66 & 1.6 & 16.7 & 319.0 & 0.7 & 351.1 & 348.0 \\
\hline 67 & 1.8 & 16.7 & 314.0 & 1.2 & 21.9 & 309.0 \\
\hline 68 & 2.2 & 16.7 & 310.0 & 1.5 & 21.9 & 303.0 \\
\hline 69 & 2.7 & 16.7 & 306.0 & 1.8 & 21.9 & 300.0 \\
\hline 70 & 3.0 & 16.7 & 303.0 & 2.1 & 16.0 & 297.0 \\
\hline & & & & & & neet 2 of \\
\hline
\end{tabular}


Table D2. Continued.

\begin{tabular}{|c|c|c|c|c|c|c|}
\hline \multirow{2}{*}{$\begin{array}{l}\text { Location } \\
\text { No. }\end{array}$} & \multicolumn{3}{|c|}{ STWAVE } & \multicolumn{3}{|c|}{ BOUSS-2D } \\
\hline & $H_{s}, \mathrm{~m}$ & $T_{p}, \mathrm{sec}$ & $\theta_{m}$, deg & $H_{s}, \mathrm{~m}$ & $T_{p}, \mathrm{sec}$ & $\theta_{p}$, deg \\
\hline 71 & 2.1 & 16.7 & 323.0 & 0.7 & 351.1 & 354.0 \\
\hline 72 & 2.4 & 16.7 & 316.0 & 1.5 & 16.0 & 315.0 \\
\hline 73 & 2.7 & 16.7 & 315.0 & 1.8 & 21.9 & 309.0 \\
\hline 74 & 3.0 & 16.7 & 312.0 & 2.0 & 21.9 & 307.0 \\
\hline 75 & 3.3 & 16.7 & 308.0 & 2.2 & 17.6 & 306.0 \\
\hline 76 & 2.3 & 16.7 & 256.0 & 2.7 & 16.0 & 260.0 \\
\hline 77 & 4.2 & 16.7 & 249.0 & 4.0 & 16.0 & 252.0 \\
\hline 78 & 6.5 & 16.7 & 250.0 & 7.0 & 16.0 & 250.0 \\
\hline 79 & 7.3 & 16.7 & 247.0 & 9.5 & 16.0 & 241.0 \\
\hline 80 & 7.1 & 16.7 & 244.0 & 8.5 & 16.0 & 245.0 \\
\hline 81 & 8.7 & 16.7 & 240.0 & 10.0 & 16.0 & 239.0 \\
\hline 82 & 9.3 & 16.7 & 237.0 & 10.4 & 16.0 & 232.0 \\
\hline 83 & 9.9 & 16.7 & 236.0 & 11.4 & 19.5 & 231.0 \\
\hline 84 & 10.9 & 16.7 & 234.0 & 11.6 & 17.6 & 227.0 \\
\hline 85 & 11.5 & 16.7 & 234.0 & 12.9 & 17.6 & 232.0 \\
\hline 86 & 12.4 & 16.7 & 235.0 & 12.6 & 17.6 & 233.0 \\
\hline 87 & 13.2 & 16.7 & 236.0 & 13.1 & 17.6 & 234.0 \\
\hline 88 & 6.5 & 16.7 & 208.0 & 7.7 & 19.5 & 212.0 \\
\hline 89 & 7.7 & 16.7 & 211.0 & 8.4 & 19.5 & 214.0 \\
\hline 90 & 8.9 & 16.7 & 212.0 & 8.1 & 19.5 & 218.0 \\
\hline 91 & 10.1 & 16.7 & 214.0 & 7.9 & 19.5 & 224.0 \\
\hline 92 & 10.0 & 16.7 & 216.0 & 8.3 & 19.5 & 225.0 \\
\hline 93 & 9.9 & 16.7 & 220.0 & 8.5 & 19.5 & 228.0 \\
\hline 94 & 9.7 & 16.7 & 224.0 & 8.9 & 19.5 & 231.0 \\
\hline 95 & 9.4 & 16.7 & 228.0 & 9.1 & 19.5 & 234.0 \\
\hline 96 & 10.0 & 16.7 & 230.0 & 9.3 & 19.5 & 237.0 \\
\hline 97 & 12.8 & 16.7 & 235.0 & 13.3 & 17.6 & 232.0 \\
\hline 98 & 12.9 & 16.7 & 235.0 & 13.4 & 17.6 & 232.0 \\
\hline 99 & 12.8 & 16.7 & 235.0 & 13.3 & 16.0 & 233.0 \\
\hline 100 & 12.6 & 16.7 & 235.0 & 13.2 & 16.0 & 232.0 \\
\hline 101 & 12.6 & 16.7 & 235.0 & 13.4 & 16.0 & 232.0 \\
\hline 102 & 12.6 & 16.7 & 234.0 & 13.8 & 16.0 & 232.0 \\
\hline 103 & 12.6 & 16.7 & 234.0 & 13.8 & 16.0 & 232.0 \\
\hline 104 & 12.7 & 16.7 & 234.0 & & & \\
\hline 105 & 12.7 & 16.7 & 234.0 & & & \\
\hline & & & & & & heet 3 of \\
\hline
\end{tabular}


Table D2. Continued.

\begin{tabular}{|c|c|c|c|c|c|c|}
\hline \multirow{2}{*}{$\begin{array}{l}\text { Location } \\
\text { No. }\end{array}$} & \multicolumn{3}{|c|}{ STWAVE } & \multicolumn{3}{|c|}{ BOUSS-2D } \\
\hline & $H_{s}, \mathrm{~m}$ & $T_{p}, \sec$ & $\theta_{m}$, deg & $H_{s}, \mathrm{~m}$ & $T_{p}, \sec$ & $\theta_{p}$, deg \\
\hline 106 & 12.6 & 16.7 & 234.0 & & & \\
\hline 107 & 12.6 & 16.7 & 235.0 & 13.0 & 16.0 & 232.0 \\
\hline 108 & 12.6 & 16.7 & 235.0 & 13.3 & 16.0 & 232.0 \\
\hline 109 & 12.5 & 16.7 & 234.0 & 13.1 & 16.0 & 231.0 \\
\hline 110 & 8.2 & 16.7 & 233.0 & 8.1 & 17.6 & 221.0 \\
\hline 111 & 8.9 & 16.7 & 233.0 & 9.1 & 19.5 & 221.0 \\
\hline 112 & 9.5 & 16.7 & 233.0 & 10.9 & 17.6 & 227.0 \\
\hline 113 & 10.0 & 16.7 & 233.0 & 11.5 & 19.5 & 226.0 \\
\hline 114 & 10.4 & 16.7 & 233.0 & 11.0 & 16.0 & 222.0 \\
\hline 115 & 10.6 & 16.7 & 233.0 & 10.8 & 16.0 & 224.0 \\
\hline 116 & 11.0 & 16.7 & 235.0 & 12.4 & 16.0 & 230.0 \\
\hline 117 & 10.0 & 16.7 & 233.0 & 10.5 & 19.5 & 233.0 \\
\hline 118 & 10.6 & 16.7 & 235.0 & 11.3 & 19.5 & 229.0 \\
\hline 119 & 10.3 & 16.7 & 234.0 & 9.6 & 17.6 & 229.0 \\
\hline 120 & 10.0 & 16.7 & 234.0 & 9.4 & 17.6 & 232.0 \\
\hline 121 & 9.7 & 16.7 & 234.0 & 8.5 & 19.5 & 223.0 \\
\hline 122 & 9.4 & 16.7 & 233.0 & 8.4 & 19.5 & 233.0 \\
\hline 123 & 8.8 & 16.7 & 234.0 & 9.2 & 16.0 & 235.0 \\
\hline 124 & 8.2 & 16.7 & 235.0 & 9.4 & 19.5 & 232.0 \\
\hline 125 & 4.8 & 16.7 & 217.0 & 5.0 & 16.0 & 219.0 \\
\hline 126 & 4.6 & 16.7 & 221.0 & 4.7 & 16.0 & 223.0 \\
\hline 127 & 3.7 & 16.7 & 223.0 & 4.1 & 16.0 & 227.0 \\
\hline 128 & 3.4 & 16.7 & 230.0 & 3.4 & 16.0 & 236.0 \\
\hline 129 & 2.8 & 16.7 & 234.0 & 3.0 & 16.0 & 245.0 \\
\hline 130 & 2.6 & 16.7 & 238.0 & 2.6 & 16.0 & 237.0 \\
\hline 131 & 2.3 & 16.7 & 232.0 & 3.0 & 16.0 & 228.0 \\
\hline 132 & 1.3 & 16.7 & 198.0 & 2.7 & 16.0 & 196.0 \\
\hline 133 & 0.1 & 16.7 & 213.0 & 2.0 & 21.9 & 177.0 \\
\hline 134 & 5.0 & 16.7 & 216.0 & 5.2 & 16.0 & 216.0 \\
\hline 135 & 5.1 & 16.7 & 224.0 & 6.4 & 16.0 & 222.0 \\
\hline 136 & 5.6 & 16.7 & 210.0 & 5.7 & 17.6 & 221.0 \\
\hline 137 & 5.8 & 16.7 & 205.0 & 7.1 & 17.6 & 209.0 \\
\hline 138 & 4.5 & 16.7 & 214.0 & 5.2 & 19.5 & 213.0 \\
\hline 139 & 6.5 & 16.7 & 207.0 & 6.9 & 25.1 & 209.0 \\
\hline 140 & 7.4 & 16.7 & 210.0 & 6.2 & 21.9 & 221.0 \\
\hline & & & & & & neet 4 of \\
\hline
\end{tabular}


Table D2. Concluded.

\begin{tabular}{|l|c|l|l|r|c|l|}
\hline \multirow{2}{*}{$\begin{array}{l}\text { Location } \\
\text { No. }\end{array}$} & \multicolumn{3}{|c|}{ STWAVE } & \multicolumn{3}{c|}{ BOUSS-2D } \\
\cline { 2 - 7 } & $H_{s}, \mathrm{~m}$ & $T_{p}, \mathrm{sec}$ & $\theta_{\mathrm{m}}, \mathrm{deg}$ & $H_{s}, \mathrm{~m}$ & $T_{p}, \mathrm{sec}$ & $\theta_{p}, \mathrm{deg}$ \\
\hline 141 & 8.5 & 16.7 & 225.0 & 6.5 & 21.9 & 229.0 \\
\hline 142 & 8.9 & 16.7 & 234.0 & 7.9 & 19.5 & 233.0 \\
\hline 143 & 9.5 & 16.7 & 236.0 & 10.1 & 19.5 & 232.0 \\
\hline 144 & 5.8 & 16.7 & 228.0 & 6.9 & 19.5 & 239.0 \\
\hline 145 & 6.6 & 16.7 & 230.0 & 7.4 & 19.5 & 238.0 \\
\hline 146 & 7.0 & 16.7 & 223.0 & 9.1 & 21.9 & 239.0 \\
\hline 147 & 10.6 & 16.7 & 233.0 & 6.6 & 19.5 & 231.0 \\
\hline 148 & 9.9 & 16.7 & 233.0 & 7.4 & 17.6 & 234.0 \\
\hline \multicolumn{7}{|l|}{} \\
\hline
\end{tabular}

Table D3. Statistics of wave parameters (STWAVE versus BOUSS-2D) for north jetty length rebuild configuration.

\begin{tabular}{|c|c|c|c|c|c|c|c|}
\hline Area ID & $N$ & $\begin{array}{l}\Delta\left(H_{s}\right) \\
\mathrm{m}\end{array}$ & $\begin{array}{l}\varepsilon_{r m s}\left(H_{s}\right) \\
\mathrm{m}\end{array}$ & $\begin{array}{l}\Delta\left(T_{p}\right) \\
\sec \end{array}$ & $\begin{array}{l}\varepsilon_{r m s}\left(T_{p}\right) \\
\sec \end{array}$ & $\begin{array}{l}\Delta(\theta) \\
\operatorname{deg}\end{array}$ & $\begin{array}{l}\varepsilon_{r m s}(\theta) \\
\text { deg }\end{array}$ \\
\hline \multicolumn{8}{|c|}{ Event 4} \\
\hline 1 & 6 & 1.2 & 1.6 & -1.4 & 2 & -5.2 & 7 \\
\hline 2 & 5 & -1 & 1.1 & -2.8 & 3.7 & -21.4 & 22.9 \\
\hline 3 & 27 & 2 & 2.3 & -2.6 & 5 & 6.5 & 25.3 \\
\hline 4 & 37 & 1.3 & 1.9 & -1.7 & 3.9 & -5.2 & 11.8 \\
\hline 5 & 2 & -1.1 & 1.2 & -3.9 & 3.9 & -6.5 & 6.5 \\
\hline 6 & 13 & 0.5 & 0.7 & -1 & 1.5 & -8.3 & 9.6 \\
\hline 7 & 11 & 1.1 & 1.6 & -2.2 & 2.7 & -26.9 & 28.8 \\
\hline \multicolumn{8}{|l|}{8} \\
\hline 9 & 16 & 0.7 & 0.8 & 0.3 & 0.7 & -9 & 9.2 \\
\hline 10 & 11 & 0.5 & 0.9 & -2.3 & 2.3 & 7.5 & 12.7 \\
\hline All & 132 & 1 & 1.7 & -1.7 & 3.4 & -5.1 & 17.2 \\
\hline \multicolumn{8}{|c|}{ Event 6} \\
\hline 1 & 6 & 0.5 & 1.4 & -1.5 & 3.1 & 0.8 & 4 \\
\hline 2 & 5 & -0.1 & 1.1 & -13.4 & 14 & 9.8 & 10.9 \\
\hline 3 & 27 & 0.4 & 1.1 & -2.5 & 6.1 & 10.9 & 20.8 \\
\hline 4 & 37 & 0.4 & 1.3 & -5.8 & 7.8 & -2.9 & 12.2 \\
\hline 5 & 4 & -1.2 & 1.3 & -16.7 & 16.7 & 9 & 11.2 \\
\hline 6 & 13 & -0.8 & 1.1 & -0.1 & 1.1 & 1.5 & 3.7 \\
\hline 7 & 11 & 0.5 & 1.2 & -2.6 & 2.7 & -6.7 & 7.1 \\
\hline 8 & 10 & -0.7 & 0.8 & 0.4 & 0.7 & 2.7 & 2.7 \\
\hline 9 & 16 & -0.3 & 0.9 & -1.4 & 2.1 & 5.8 & 7.1 \\
\hline 10 & 11 & -0.6 & 0.9 & 0.2 & 1.7 & 1.8 & 11.7 \\
\hline All & 145 & 0 & 1.1 & -3.4 & 6.2 & 2.5 & 12.2 \\
\hline
\end{tabular}


Table D4. Statistics of wave parameters for Event 4 for north jetty length rebuild versus existing configuration.

\begin{tabular}{|c|c|c|c|c|c|c|c|}
\hline Area ID & $N$ & $\begin{array}{l}\Delta\left(H_{s}\right) \\
\mathrm{m}\end{array}$ & $\begin{array}{l}\varepsilon_{r m s}\left(H_{s}\right) \\
\mathrm{m}\end{array}$ & $\begin{array}{l}\Delta\left(T_{p}\right) \\
\sec \end{array}$ & $\begin{array}{l}\varepsilon_{r m s}\left(T_{p}\right) \\
\sec \end{array}$ & $\begin{array}{l}\Delta(\theta) \\
\operatorname{deg}\end{array}$ & $\begin{array}{l}\varepsilon_{r m s}(\theta) \\
\text { deg }\end{array}$ \\
\hline \multicolumn{8}{|c|}{ STWAVE } \\
\hline 1 & 6 & 0 & 0 & 0 & 0 & -0.2 & 0.4 \\
\hline 2 & 5 & 0 & 0 & 0 & 0 & 1.2 & 2.3 \\
\hline 3 & 27 & -0.1 & 0.4 & 0 & 0 & -0.3 & 2.2 \\
\hline 4 & 37 & 0 & 0 & 0 & 0 & 0 & 0 \\
\hline 5 & 4 & 0 & 0 & 0 & 0 & 0 & 0 \\
\hline 6 & 13 & 0 & 0 & 0 & 0 & 0 & 0 \\
\hline 7 & 11 & 0 & 0 & 0 & 0 & 0 & 0 \\
\hline 8 & 13 & 0 & 0 & 0 & 0 & 0 & 0 \\
\hline 9 & 16 & 0 & 0 & 0 & 0 & 0 & 0 \\
\hline 10 & 11 & 0 & 0 & 0 & 0 & 0 & 0 \\
\hline All & 148 & 0 & 0.2 & 0 & 0 & 0 & 0.9 \\
\hline \multicolumn{8}{|c|}{ BOUSS-2D } \\
\hline 1 & 6 & 0 & 0.2 & -0.3 & 0.7 & -1.5 & 2 \\
\hline 2 & 5 & -0.1 & 0.1 & -2.5 & 6.7 & -1.4 & 2.5 \\
\hline 3 & 27 & -0.3 & 0.8 & -1.1 & 4.5 & -6 & 15.9 \\
\hline 4 & 37 & -0.2 & 0.3 & -0.1 & 4 & 0.5 & 3.5 \\
\hline 5 & 2 & -0.3 & 0.3 & 1.8 & 1.8 & -1 & 1 \\
\hline 6 & 13 & 0 & 0.1 & 0.2 & 0.5 & 0.4 & 1.5 \\
\hline 7 & 11 & 0 & 0.1 & -0.4 & 1.1 & -0.4 & 1.7 \\
\hline \multicolumn{8}{|l|}{8} \\
\hline 9 & 16 & 0.1 & 0.2 & -0.1 & 0.4 & 1.2 & 1.8 \\
\hline 10 & 11 & -0.1 & 0.2 & 0.4 & 1.1 & 1.5 & 2.7 \\
\hline All & 132 & -0.1 & 0.4 & -0.4 & 3.3 & -0.9 & 7.5 \\
\hline
\end{tabular}


Table D5. Statistics of wave parameters for Event 6 for north jetty length rebuild versus existing configuration.

\begin{tabular}{|c|c|c|c|c|c|c|c|}
\hline Area ID & $N$ & $\begin{array}{l}\Delta\left(H_{s}\right) \\
\mathrm{m}\end{array}$ & $\begin{array}{l}\varepsilon_{r m s}\left(H_{s}\right) \\
\mathrm{m}\end{array}$ & $\begin{array}{l}\Delta\left(T_{p}\right) \\
\sec \end{array}$ & $\begin{array}{l}\varepsilon_{r m s}\left(T_{p}\right) \\
\sec \end{array}$ & $\begin{array}{l}\Delta(\theta) \\
\operatorname{deg}\end{array}$ & $\begin{array}{l}\varepsilon_{r m s}(\theta) \\
\operatorname{deg}\end{array}$ \\
\hline \multicolumn{8}{|c|}{ STWAVE } \\
\hline 1 & 6 & 0 & 0 & 0 & 0 & 0 & 0 \\
\hline 2 & 5 & 0 & 0 & 0 & 0 & 1.6 & 3.2 \\
\hline 3 & 27 & 0 & 0.2 & 0 & 0 & 0 & 1.8 \\
\hline 4 & 37 & 0 & 0 & 0 & 0 & 0 & 0 \\
\hline 5 & 4 & 0 & 0 & 0 & 0 & 0 & 0 \\
\hline 6 & 13 & 0 & 0 & 0 & 0 & 0 & 0 \\
\hline 7 & 11 & 0 & 0 & 0 & 0 & 0 & 0 \\
\hline 8 & 13 & 0 & 0 & 0 & 0 & 0 & 0 \\
\hline 9 & 16 & 0 & 0 & 0 & 0 & 0 & 0 \\
\hline 10 & 11 & 0 & 0 & 0 & 0 & 0 & 0 \\
\hline All & 148 & 0 & 0.1 & 0 & 0 & 0 & 0.8 \\
\hline \multicolumn{8}{|c|}{ BOUSS-2D } \\
\hline 1 & 6 & 0 & 0.1 & 0.1 & 1 & -0.2 & 0.4 \\
\hline 2 & 5 & -0.1 & 0.1 & -15.8 & 16.2 & 4.8 & 6.1 \\
\hline 3 & 27 & -0.3 & 0.8 & -0.6 & 5.2 & 0.8 & 5.7 \\
\hline 4 & 37 & 0 & 0.1 & -0.6 & 6.3 & -0.1 & 0.8 \\
\hline 5 & 4 & 0 & 0 & -3.1 & 14 & 0 & 0.7 \\
\hline 6 & 13 & 0 & 0.1 & -0.2 & 0.7 & -0.2 & 0.4 \\
\hline 7 & 11 & 0 & 0.2 & -0.3 & 1.2 & -0.2 & 0.7 \\
\hline 8 & 10 & 0 & 0 & -0.2 & 0.7 & 0 & 0 \\
\hline 9 & 16 & 0 & 0.1 & -0.8 & 1.7 & 0.2 & 0.7 \\
\hline 10 & 11 & 0 & 0.1 & 0 & 2.2 & -0.5 & 1.3 \\
\hline All & 145 & -0.1 & 0.3 & -0.9 & 5.3 & 0.2 & 2.7 \\
\hline
\end{tabular}




\section{Appendix E: South Jetty Length Rebuild Results}

Table E1. Event 4 results for south jetty length rebuild configuration.

\begin{tabular}{|c|c|c|c|c|c|c|}
\hline \multirow{2}{*}{$\begin{array}{l}\text { Location } \\
\text { No. }\end{array}$} & \multicolumn{3}{|c|}{ STWAVE } & \multicolumn{3}{|c|}{ BOUSS-2D } \\
\hline & $H_{s,} \mathrm{~m}$ & $T_{p}, \mathrm{sec}$ & $\theta_{m}$, deg & $H_{s,} \mathrm{~m}$ & $T_{p}$, sec & $\theta_{p}$, deg \\
\hline 1 & 5.3 & 14.3 & 241.0 & 3.0 & 17.6 & 238.0 \\
\hline 2 & 2.4 & 14.3 & 235.0 & 3.1 & 17.6 & 241.0 \\
\hline 3 & 3.4 & 14.3 & 262.0 & 2.7 & 14.6 & 271.0 \\
\hline 4 & 6.8 & 14.3 & 277.0 & 4.3 & 14.6 & 283.0 \\
\hline 5 & 6.5 & 14.3 & 268.0 & 6.2 & 17.6 & 276.0 \\
\hline 6 & 5.4 & 14.3 & 281.0 & 3.8 & 14.6 & 287.0 \\
\hline 7 & 9.5 & 14.3 & 275.0 & 9.0 & 14.6 & 285.0 \\
\hline 8 & 9.0 & 14.3 & 285.0 & 9.1 & 14.6 & 294.0 \\
\hline 9 & 8.9 & 14.3 & 270.0 & 9.8 & 16.0 & 284.0 \\
\hline 10 & 8.2 & 14.3 & 278.0 & & & \\
\hline 11 & 9.2 & 14.3 & 266.0 & 9.2 & 13.5 & 277.0 \\
\hline 12 & 2.8 & 14.3 & 287.0 & 4.2 & 19.5 & 301.0 \\
\hline 13 & 3.5 & 14.3 & 287.0 & 4.9 & 19.5 & 297.0 \\
\hline 14 & 3.2 & 14.3 & 279.0 & 4.3 & 14.6 & 301.0 \\
\hline 15 & 3.9 & 14.3 & 276.0 & 4.4 & 17.6 & 307.0 \\
\hline 16 & 3.8 & 14.3 & 266.0 & 4.7 & 13.5 & 300.0 \\
\hline 17 & 5.9 & 14.3 & 265.0 & 5.9 & 13.5 & 290.0 \\
\hline 18 & 6.0 & 14.3 & 214.0 & 6.9 & 16.0 & 266.0 \\
\hline 19 & 6.5 & 14.3 & 241.0 & 4.7 & 19.5 & 256.0 \\
\hline 20 & 5.9 & 14.3 & 239.0 & 2.3 & 17.6 & 228.0 \\
\hline 21 & 4.8 & 14.3 & 236.0 & 1.9 & 17.6 & 229.0 \\
\hline 22 & 3.5 & 14.3 & 237.0 & 1.3 & 17.6 & 229.0 \\
\hline 23 & 2.5 & 14.3 & 231.0 & 1.0 & 16.0 & 219.0 \\
\hline 24 & 1.1 & 14.3 & 213.0 & 0.4 & 351.1 & 158.0 \\
\hline 25 & 2.5 & 14.3 & 231.0 & 1.1 & 17.6 & 205.0 \\
\hline 26 & 4.2 & 14.3 & 234.0 & 1.5 & 17.6 & 220.0 \\
\hline 27 & 5.1 & 14.3 & 236.0 & 1.9 & 17.6 & 229.0 \\
\hline 28 & 5.3 & 14.3 & 239.0 & 2.2 & 17.6 & 233.0 \\
\hline 29 & 5.1 & 14.3 & 243.0 & 2.4 & 17.6 & 238.0 \\
\hline 30 & 4.9 & 14.3 & 248.0 & 2.6 & 17.6 & 242.0 \\
\hline
\end{tabular}


Table E1. Continued.

\begin{tabular}{|c|c|c|c|c|c|c|}
\hline \multirow{2}{*}{$\begin{array}{l}\text { Location } \\
\text { No. }\end{array}$} & \multicolumn{3}{|c|}{ STWAVE } & \multicolumn{3}{|c|}{ BOUSS-2D } \\
\hline & $H_{s}, \mathrm{~m}$ & $T_{p}, \mathrm{sec}$ & $\theta_{m}$, deg & $H_{s}, \mathrm{~m}$ & $T_{p}, \sec$ & $\theta_{p}$, deg \\
\hline 31 & 1.6 & 14.3 & 204.0 & 0.5 & 351.1 & 164.0 \\
\hline 32 & 2.5 & 14.3 & 226.0 & 1.0 & 17.6 & 203.0 \\
\hline 33 & 4.0 & 14.3 & 232.0 & 1.4 & 17.6 & 219.0 \\
\hline 34 & 5.1 & 14.3 & 238.0 & 2.1 & 17.6 & 234.0 \\
\hline 35 & 0.8 & 14.3 & 228.0 & 0.3 & 351.1 & 160.0 \\
\hline 36 & 2.6 & 14.3 & 234.0 & 1.0 & 17.6 & 202.0 \\
\hline 37 & 4.3 & 14.3 & 235.0 & 1.5 & 17.6 & 220.0 \\
\hline 38 & 5.4 & 14.3 & 237.0 & 2.1 & 17.6 & 228.0 \\
\hline 39 & 5.6 & 14.3 & 239.0 & 2.4 & 17.6 & 233.0 \\
\hline 40 & 3.5 & 14.3 & 303.0 & 1.9 & 13.5 & 302.0 \\
\hline 41 & 3.8 & 14.3 & 300.0 & 1.9 & 14.6 & 294.0 \\
\hline 42 & 4.2 & 14.3 & 287.0 & 2.3 & 14.6 & 282.0 \\
\hline 43 & 4.6 & 14.3 & 284.0 & 2.8 & 17.6 & 284.0 \\
\hline 44 & 5.1 & 14.3 & 277.0 & 3.7 & 17.6 & 285.0 \\
\hline 45 & 6.1 & 14.3 & 272.0 & 5.7 & 16.0 & 284.0 \\
\hline 46 & 7.8 & 14.3 & 264.0 & 9.0 & 14.6 & 276.0 \\
\hline 47 & 0.0 & 3.0 & 270.0 & 0.7 & 999.0 & 300.0 \\
\hline 48 & 7.9 & 14.3 & 260.0 & 5.1 & 13.5 & 268.0 \\
\hline 49 & 8.3 & 14.3 & 257.0 & 5.2 & 13.5 & 269.0 \\
\hline 50 & 8.2 & 14.3 & 254.0 & 4.9 & 17.6 & 268.0 \\
\hline 51 & 7.7 & 14.3 & 254.0 & 5.9 & 13.5 & 265.0 \\
\hline 52 & 7.0 & 14.3 & 254.0 & 5.2 & 14.6 & 264.0 \\
\hline 53 & 6.2 & 14.3 & 252.0 & 7.1 & 14.6 & 260.0 \\
\hline 54 & 5.8 & 14.3 & 250.0 & 6.5 & 14.6 & 258.0 \\
\hline 55 & 4.7 & 14.3 & 253.0 & 5.9 & 13.5 & 260.0 \\
\hline 56 & 3.8 & 14.3 & 254.0 & 5.1 & 17.6 & 260.0 \\
\hline 57 & 3.3 & 14.3 & 253.0 & 5.1 & 17.6 & 260.0 \\
\hline 58 & 2.7 & 14.3 & 254.0 & & & \\
\hline 59 & 2.7 & 14.3 & 258.0 & & & \\
\hline 60 & 3.4 & 14.3 & 311.0 & 0.6 & 175.5 & 348.0 \\
\hline 61 & 3.4 & 14.3 & 305.0 & 1.4 & 14.6 & 303.0 \\
\hline 62 & 4.1 & 14.3 & 296.0 & 2.3 & 13.5 & 289.0 \\
\hline 63 & 4.3 & 14.3 & 293.0 & 2.6 & 13.5 & 288.0 \\
\hline 64 & 4.5 & 14.3 & 289.0 & 3.0 & 13.5 & 289.0 \\
\hline 65 & 4.4 & 14.3 & 289.0 & 3.1 & 13.5 & 292.0 \\
\hline & & & & & & heet 2 of \\
\hline
\end{tabular}


Table E1. Continued.

\begin{tabular}{|c|c|c|c|c|c|c|}
\hline \multirow{2}{*}{$\begin{array}{l}\text { Location } \\
\text { No. }\end{array}$} & \multicolumn{3}{|c|}{ STWAVE } & \multicolumn{3}{|c|}{ BOUSS-2D } \\
\hline & $H_{s}, \mathrm{~m}$ & $T_{p}, \sec$ & $\theta_{m}$, deg & $H_{s}, \mathrm{~m}$ & $T_{p}, \sec$ & $\theta_{p}$, deg \\
\hline 66 & 3.5 & 14.3 & 305.0 & 0.8 & 175.5 & 334.0 \\
\hline 67 & 3.6 & 14.3 & 300.0 & 1.6 & 14.6 & 297.0 \\
\hline 68 & 3.9 & 14.3 & 295.0 & 2.1 & 14.6 & 287.0 \\
\hline 69 & 4.3 & 14.3 & 290.0 & 2.4 & 19.5 & 287.0 \\
\hline 70 & 4.4 & 14.3 & 287.0 & 2.7 & 19.5 & 286.0 \\
\hline 71 & 3.3 & 14.3 & 316.0 & 0.6 & 175.5 & 1.0 \\
\hline 72 & 3.3 & 14.3 & 308.0 & 1.3 & 16.0 & 307.0 \\
\hline 73 & 3.7 & 14.3 & 305.0 & 1.9 & 11.7 & 297.0 \\
\hline 74 & 4.0 & 14.3 & 300.0 & 2.2 & 13.5 & 294.0 \\
\hline 75 & 4.1 & 14.3 & 295.0 & 2.5 & 13.5 & 291.0 \\
\hline 76 & 1.6 & 14.3 & 259.0 & 1.4 & 16.0 & 256.0 \\
\hline 77 & 2.5 & 14.3 & 256.0 & 2.1 & 14.6 & 261.0 \\
\hline 78 & 4.0 & 14.3 & 266.0 & 3.5 & 14.6 & 276.0 \\
\hline 79 & 4.8 & 14.3 & 266.0 & 4.3 & 14.6 & 275.0 \\
\hline 80 & 5.8 & 14.3 & 268.0 & 5.1 & 14.6 & 281.0 \\
\hline 81 & 7.6 & 14.3 & 272.0 & 6.9 & 16.0 & 282.0 \\
\hline 82 & 8.9 & 14.3 & 270.0 & 8.5 & 14.6 & 286.0 \\
\hline 83 & 9.5 & 14.3 & 269.0 & 8.6 & 17.6 & 285.0 \\
\hline 84 & 10.0 & 14.3 & 269.0 & 9.1 & 14.6 & 277.0 \\
\hline 85 & 9.6 & 14.3 & 269.0 & 9.6 & 14.6 & 273.0 \\
\hline 86 & 8.9 & 14.3 & 271.0 & 9.3 & 14.6 & 276.0 \\
\hline 87 & 7.8 & 14.3 & 272.0 & 8.3 & 13.5 & 279.0 \\
\hline 88 & 8.4 & 14.3 & 236.0 & 5.9 & 17.6 & 282.0 \\
\hline 89 & 9.1 & 14.3 & 245.0 & 5.9 & 17.6 & 285.0 \\
\hline 90 & 9.3 & 14.3 & 252.0 & 6.9 & 16.0 & 282.0 \\
\hline 91 & 9.1 & 14.3 & 261.0 & 7.2 & 16.0 & 282.0 \\
\hline 92 & 9.2 & 14.3 & 266.0 & 8.0 & 16.0 & 288.0 \\
\hline 93 & 9.1 & 14.3 & 268.0 & 8.9 & 17.6 & 289.0 \\
\hline 94 & 9.1 & 14.3 & 269.0 & 9.8 & 17.6 & 288.0 \\
\hline 95 & 9.1 & 14.3 & 268.0 & 9.0 & 16.0 & 287.0 \\
\hline 96 & 9.7 & 14.3 & 270.0 & 8.8 & 16.0 & 291.0 \\
\hline 97 & 9.1 & 14.3 & 291.0 & & & \\
\hline 98 & 9.1 & 14.3 & 292.0 & & & \\
\hline 99 & 9.1 & 14.3 & 292.0 & & & \\
\hline 100 & 9.2 & 14.3 & 292.0 & & & \\
\hline & & & & & & neet 3 of \\
\hline
\end{tabular}


Table E1. Continued.

\begin{tabular}{|c|c|c|c|c|c|c|}
\hline \multirow{2}{*}{$\begin{array}{l}\text { Location } \\
\text { No. }\end{array}$} & \multicolumn{3}{|c|}{ STWAVE } & \multicolumn{3}{|c|}{ BOUSS-2D } \\
\hline & $H_{s}, \mathrm{~m}$ & $T_{p}, \mathrm{sec}$ & $\theta_{m}$, deg & $H_{s}, \mathrm{~m}$ & $T_{p}, \sec$ & $\theta_{p}, \operatorname{deg}$ \\
\hline 101 & 9.3 & 14.3 & 293.0 & & & \\
\hline 102 & 9.3 & 14.3 & 293.0 & & & \\
\hline 103 & 9.4 & 14.3 & 294.0 & & & \\
\hline 104 & 9.5 & 14.3 & 294.0 & & & \\
\hline 105 & 9.6 & 14.3 & 295.0 & & & \\
\hline 106 & 9.6 & 14.3 & 295.0 & & & \\
\hline 107 & 9.1 & 14.3 & 292.0 & & & \\
\hline 108 & 9.1 & 14.3 & 292.0 & & & \\
\hline 109 & 9.2 & 14.3 & 291.0 & & & \\
\hline 110 & 7.9 & 14.3 & 260.0 & 7.6 & 13.5 & 267.0 \\
\hline 111 & 8.7 & 14.3 & 263.0 & 8.1 & 13.5 & 272.0 \\
\hline 112 & 9.2 & 14.3 & 266.0 & 9.1 & 13.5 & 277.0 \\
\hline 113 & 9.2 & 14.3 & 268.0 & 7.8 & 14.6 & 277.0 \\
\hline 114 & 9.0 & 14.3 & 270.0 & 8.2 & 14.6 & 277.0 \\
\hline 115 & 8.5 & 14.3 & 270.0 & 7.9 & 14.6 & 279.0 \\
\hline 116 & 8.1 & 14.3 & 271.0 & 7.1 & 14.6 & 280.0 \\
\hline 117 & 10.1 & 14.3 & 270.0 & 9.3 & 13.5 & 283.0 \\
\hline 118 & 9.7 & 14.3 & 270.0 & 9.4 & 13.5 & 280.0 \\
\hline 119 & 9.5 & 14.3 & 270.0 & 9.7 & 13.5 & 278.0 \\
\hline 120 & 9.4 & 14.3 & 269.0 & 8.6 & 13.5 & 279.0 \\
\hline 121 & 8.9 & 14.3 & 268.0 & 8.0 & 14.6 & 274.0 \\
\hline 122 & 8.5 & 14.3 & 267.0 & 7.4 & 14.6 & 274.0 \\
\hline 123 & 8.5 & 14.3 & 265.0 & 7.2 & 13.5 & 273.0 \\
\hline 124 & 8.0 & 14.3 & 262.0 & 7.1 & 14.6 & 272.0 \\
\hline 125 & 2.6 & 14.3 & 228.0 & 1.8 & 14.6 & 221.0 \\
\hline 126 & 2.7 & 14.3 & 226.0 & 1.7 & 14.6 & 224.0 \\
\hline 127 & 2.4 & 14.3 & 230.0 & 1.7 & 14.6 & 232.0 \\
\hline 128 & 2.2 & 14.3 & 236.0 & 1.6 & 14.6 & 234.0 \\
\hline 129 & 1.9 & 14.3 & 240.0 & 1.5 & 14.6 & 237.0 \\
\hline 130 & 1.8 & 14.3 & 243.0 & 1.3 & 14.6 & 235.0 \\
\hline 131 & 1.5 & 14.3 & 235.0 & 1.4 & 16.0 & 228.0 \\
\hline 132 & 1.1 & 14.3 & 199.0 & 1.3 & 14.6 & 196.0 \\
\hline 133 & 0.1 & 14.3 & 211.0 & 1.1 & 14.6 & 174.0 \\
\hline 134 & 3.9 & 14.3 & 241.0 & 2.7 & 17.6 & 231.0 \\
\hline 135 & 5.0 & 14.3 & 243.0 & 5.0 & 17.6 & 235.0 \\
\hline & & & & & & heet 4 of \\
\hline
\end{tabular}


Table E1. Concluded.

\begin{tabular}{|l|c|l|l|c|c|c|}
\hline \multirow{2}{*}{$\begin{array}{l}\text { Location } \\
\text { No. }\end{array}$} & \multicolumn{3}{|c|}{ STWAVE } & \multicolumn{3}{c|}{ BOUSS-2D } \\
\cline { 2 - 7 } & $H_{s}, \mathrm{~m}$ & $T_{p}, \mathrm{sec}$ & $\theta_{\mathrm{m}}, \mathrm{deg}$ & $H_{s}, \mathrm{~m}$ & $T_{p}, \mathrm{sec}$ & $\theta_{p}, \mathrm{deg}$ \\
\hline 136 & 6.2 & 14.3 & 242.0 & 5.8 & 14.6 & 283.0 \\
\hline 137 & 7.8 & 14.3 & 230.0 & 6.6 & 16.0 & 276.0 \\
\hline 138 & 6.6 & 14.3 & 238.0 & 5.5 & 17.6 & 268.0 \\
\hline 139 & 6.4 & 14.3 & 254.0 & 6.2 & 13.5 & 292.0 \\
\hline 140 & 7.2 & 14.3 & 266.0 & 6.6 & 17.6 & 289.0 \\
\hline 141 & 8.3 & 14.3 & 274.0 & 6.6 & 16.0 & 288.0 \\
\hline 142 & 8.6 & 14.3 & 276.0 & 10.2 & 16.0 & 293.0 \\
\hline 143 & 9.2 & 14.3 & 276.0 & 9.1 & 16.0 & 288.0 \\
\hline 144 & 8.4 & 14.3 & 264.0 & 8.9 & 16.0 & 273.0 \\
\hline 145 & 8.7 & 14.3 & 264.0 & 8.7 & 11.0 & 277.0 \\
\hline 146 & 6.9 & 14.3 & 271.0 & 9.1 & 17.6 & 280.0 \\
\hline 147 & 8.7 & 14.3 & 268.0 & 8.3 & 13.5 & 279.0 \\
\hline 148 & 8.2 & 14.3 & 264.0 & 6.2 & 13.5 & 270.0 \\
\hline \multicolumn{7}{|l|}{} \\
\hline
\end{tabular}


Table E2. Event 6 results for south jetty length rebuild configuration.

\begin{tabular}{|c|c|c|c|c|c|c|}
\hline \multirow{2}{*}{$\begin{array}{l}\text { Location } \\
\text { No. }\end{array}$} & \multicolumn{3}{|c|}{ STWAVE } & \multicolumn{3}{|c|}{ BOUSS-2D } \\
\hline & $H_{s}, \mathrm{~m}$ & $T_{p}, \mathrm{sec}$ & $\theta_{m}, \operatorname{deg}$ & $H_{s}, \mathrm{~m}$ & $T_{p}, \sec$ & $\theta_{p}$, deg \\
\hline 1 & 6.3 & 16.7 & 230.0 & 7.0 & 16.0 & 228.0 \\
\hline 2 & 4.6 & 16.7 & 226.0 & 6.1 & 16.0 & 228.0 \\
\hline 3 & 5.6 & 16.7 & 251.0 & 6.0 & 16.0 & 251.0 \\
\hline 4 & 8.9 & 16.7 & 264.0 & 5.9 & 21.9 & 254.0 \\
\hline 5 & 3.1 & 16.7 & 257.0 & 2.6 & 21.9 & 269.0 \\
\hline 6 & 8.1 & 16.7 & 273.0 & 5.4 & 17.6 & 268.0 \\
\hline 7 & 13.8 & 16.7 & 232.0 & 13.9 & 17.6 & 231.0 \\
\hline 8 & 12.6 & 16.7 & 237.0 & 12.8 & 16.0 & 235.0 \\
\hline 9 & 9.4 & 16.7 & 228.0 & 8.2 & 19.5 & 237.0 \\
\hline 10 & 12.2 & 16.7 & 238.0 & 12.2 & 16.0 & 233.0 \\
\hline 11 & 9.7 & 16.7 & 233.0 & 9.6 & 19.5 & 230.0 \\
\hline 12 & 2.8 & 16.7 & 269.0 & 4.0 & 351.1 & 251.0 \\
\hline 13 & 3.5 & 16.7 & 263.0 & 4.4 & 351.1 & 248.0 \\
\hline 14 & 3.2 & 16.7 & 252.0 & 4.1 & 175.5 & 239.0 \\
\hline 15 & 4.0 & 16.7 & 242.0 & 3.1 & 351.1 & 225.0 \\
\hline 16 & 3.8 & 16.7 & 237.0 & 2.8 & 25.1 & 233.0 \\
\hline 17 & 5.6 & 16.7 & 223.0 & 5.6 & 21.9 & 212.0 \\
\hline 18 & 3.2 & 16.7 & 207.0 & 6.8 & 19.5 & 199.0 \\
\hline 19 & 4.7 & 16.7 & 222.0 & 5.0 & 14.6 & 222.0 \\
\hline 20 & 5.3 & 16.7 & 230.0 & 4.5 & 14.6 & 227.0 \\
\hline 21 & 4.7 & 16.7 & 234.0 & 3.8 & 17.6 & 227.0 \\
\hline 22 & 3.9 & 16.7 & 233.0 & 3.4 & 16.0 & 220.0 \\
\hline 23 & 3.9 & 16.7 & 220.0 & 3.8 & 21.9 & 210.0 \\
\hline 24 & 2.3 & 16.7 & 210.0 & 1.0 & 87.8 & 151.0 \\
\hline 25 & 4.1 & 16.7 & 227.0 & 2.4 & 13.5 & 208.0 \\
\hline 26 & 5.2 & 16.7 & 231.0 & 3.2 & 13.5 & 221.0 \\
\hline 27 & 4.9 & 16.7 & 232.0 & 3.9 & 17.6 & 229.0 \\
\hline 28 & 4.2 & 16.7 & 234.0 & 4.3 & 17.6 & 232.0 \\
\hline 29 & 3.8 & 16.7 & 235.0 & 4.7 & 14.6 & 234.0 \\
\hline 30 & 3.9 & 16.7 & 233.0 & 5.1 & 14.6 & 234.0 \\
\hline 31 & 2.8 & 16.7 & 202.0 & 1.2 & 87.8 & 161.0 \\
\hline 32 & 3.9 & 16.7 & 224.0 & 2.2 & 13.5 & 209.0 \\
\hline 33 & 5.0 & 16.7 & 230.0 & 3.1 & 17.6 & 222.0 \\
\hline 34 & 4.2 & 16.7 & 234.0 & 4.2 & 17.6 & 230.0 \\
\hline 35 & 1.7 & 16.7 & 222.0 & 1.1 & 87.8 & 157.0 \\
\hline 36 & 4.2 & 16.7 & 230.0 & 2.5 & 13.5 & 211.0 \\
\hline 37 & 5.3 & 16.7 & 231.0 & 3.4 & 13.5 & 223.0 \\
\hline
\end{tabular}


Table E2. Continued.

\begin{tabular}{|c|c|c|c|c|c|c|}
\hline \multirow{2}{*}{$\begin{array}{l}\text { Location } \\
\text { No. }\end{array}$} & \multicolumn{3}{|c|}{ STWAVE } & \multicolumn{3}{|c|}{ BOUSS-2D } \\
\hline & $H_{s}, \mathrm{~m}$ & $T_{p}, \sec$ & $\theta_{m}$, deg & $H_{s}, \mathrm{~m}$ & $T_{p}, \sec$ & $\theta_{p}$, deg \\
\hline 38 & 5.0 & 16.7 & 232.0 & 4.1 & 17.6 & 229.0 \\
\hline 39 & 4.2 & 16.7 & 233.0 & 4.5 & 17.6 & 232.0 \\
\hline 40 & 3.0 & 16.7 & 311.0 & 2.4 & 21.9 & 308.0 \\
\hline 41 & 2.5 & 16.7 & 314.0 & 2.1 & 21.9 & 298.0 \\
\hline 42 & 1.7 & 16.7 & 300.0 & 2.1 & 21.9 & 293.0 \\
\hline 43 & 0.9 & 16.7 & 283.0 & 1.5 & 17.6 & 293.0 \\
\hline 44 & 0.8 & 16.7 & 269.0 & 1.4 & 17.6 & 291.0 \\
\hline 45 & 1.2 & 16.7 & 262.0 & 1.8 & 19.5 & 287.0 \\
\hline 46 & 2.8 & 16.7 & 249.0 & 2.8 & 19.5 & 261.0 \\
\hline 47 & 0.1 & 3.0 & 270.0 & 1.6 & 999.0 & 230.0 \\
\hline 48 & 9.2 & 16.7 & 234.0 & 9.6 & 17.6 & 233.0 \\
\hline 49 & 8.9 & 16.7 & 234.0 & 9.2 & 19.5 & 229.0 \\
\hline 50 & 8.4 & 16.7 & 231.0 & 8.7 & 21.9 & 223.0 \\
\hline 51 & 7.9 & 16.7 & 231.0 & 7.8 & 19.5 & 234.0 \\
\hline 52 & 7.2 & 16.7 & 232.0 & 8.0 & 19.5 & 231.0 \\
\hline 53 & 6.3 & 16.7 & 230.0 & 6.1 & 19.5 & 224.0 \\
\hline 54 & 5.9 & 16.7 & 231.0 & 5.0 & 19.5 & 227.0 \\
\hline 55 & 4.8 & 16.7 & 234.0 & 4.5 & 21.9 & 220.0 \\
\hline 56 & 3.8 & 16.7 & 237.0 & 4.2 & 351.1 & 222.0 \\
\hline 57 & 3.4 & 16.7 & 237.0 & 4.6 & 351.1 & 231.0 \\
\hline 58 & 2.8 & 16.7 & 238.0 & 4.5 & 351.1 & 237.0 \\
\hline 59 & 2.7 & 16.7 & 246.0 & 4.1 & 175.5 & 230.0 \\
\hline 60 & 1.8 & 16.7 & 323.0 & 0.9 & 351.1 & 345.0 \\
\hline 61 & 2.1 & 16.7 & 318.0 & 1.7 & 17.6 & 307.0 \\
\hline 62 & 2.9 & 16.7 & 310.0 & 2.5 & 21.9 & 295.0 \\
\hline 63 & 3.3 & 16.7 & 307.0 & 2.8 & 21.9 & 294.0 \\
\hline 64 & 4.0 & 16.7 & 303.0 & 2.9 & 21.9 & 290.0 \\
\hline 65 & 4.3 & 16.7 & 297.0 & 3.2 & 17.6 & 289.0 \\
\hline 66 & 1.7 & 16.7 & 320.0 & 0.9 & 351.1 & 346.0 \\
\hline 67 & 1.9 & 16.7 & 314.0 & 1.7 & 17.6 & 302.0 \\
\hline 68 & 2.2 & 16.7 & 310.0 & 2.2 & 21.9 & 295.0 \\
\hline 69 & 2.7 & 16.7 & 306.0 & 2.5 & 21.9 & 292.0 \\
\hline 70 & 3.1 & 16.7 & 303.0 & 2.8 & 21.9 & 291.0 \\
\hline 71 & 2.1 & 16.7 & 323.0 & 0.8 & 351.1 & 354.0 \\
\hline 72 & 2.4 & 16.7 & 316.0 & 1.7 & 17.6 & 310.0 \\
\hline 73 & 2.8 & 16.7 & 315.0 & 2.2 & 21.9 & 303.0 \\
\hline 74 & 3.1 & 16.7 & 312.0 & 2.5 & 21.9 & 299.0 \\
\hline
\end{tabular}


Table E2. Continued.

\begin{tabular}{|c|c|c|c|c|c|c|}
\hline \multirow{2}{*}{$\begin{array}{l}\text { Location } \\
\text { No. }\end{array}$} & \multicolumn{3}{|c|}{ STWAVE } & \multicolumn{3}{|c|}{ BOUSS-2D } \\
\hline & $H_{s}, \mathrm{~m}$ & $T_{p}, \mathrm{sec}$ & $\theta_{m}, \operatorname{deg}$ & $H_{s}, \mathrm{~m}$ & $T_{p}, \sec$ & $\theta_{p}$, deg \\
\hline 75 & 3.4 & 16.7 & 307.0 & 2.8 & 21.9 & 296.0 \\
\hline 76 & 2.3 & 16.7 & 256.0 & 2.7 & 16.0 & 261.0 \\
\hline 77 & 4.1 & 16.7 & 250.0 & 4.2 & 16.0 & 252.0 \\
\hline 78 & 6.4 & 16.7 & 251.0 & 7.3 & 16.0 & 250.0 \\
\hline 79 & 7.2 & 16.7 & 247.0 & 9.7 & 16.0 & 242.0 \\
\hline 80 & 7.1 & 16.7 & 244.0 & 8.4 & 16.0 & 246.0 \\
\hline 81 & 8.7 & 16.7 & 240.0 & 9.9 & 16.0 & 239.0 \\
\hline 82 & 9.3 & 16.7 & 237.0 & 10.1 & 16.0 & 233.0 \\
\hline 83 & 9.9 & 16.7 & 236.0 & 11.2 & 19.5 & 232.0 \\
\hline 84 & 10.9 & 16.7 & 234.0 & 11.5 & 17.6 & 227.0 \\
\hline 85 & 11.5 & 16.7 & 234.0 & 12.9 & 17.6 & 232.0 \\
\hline 86 & 12.4 & 16.7 & 235.0 & 12.6 & 17.6 & 233.0 \\
\hline 87 & 13.2 & 16.7 & 236.0 & 13.1 & 17.6 & 235.0 \\
\hline 88 & 6.5 & 16.7 & 208.0 & 7.7 & 19.5 & 211.0 \\
\hline 89 & 7.7 & 16.7 & 211.0 & 8.4 & 19.5 & 213.0 \\
\hline 90 & 8.9 & 16.7 & 212.0 & 8.2 & 19.5 & 218.0 \\
\hline 91 & 10.1 & 16.7 & 214.0 & 7.8 & 19.5 & 223.0 \\
\hline 92 & 10.0 & 16.7 & 216.0 & 8.1 & 19.5 & 226.0 \\
\hline 93 & 9.9 & 16.7 & 220.0 & 8.5 & 19.5 & 229.0 \\
\hline 94 & 9.7 & 16.7 & 224.0 & 8.9 & 19.5 & 232.0 \\
\hline 95 & 9.4 & 16.7 & 228.0 & 9.2 & 19.5 & 234.0 \\
\hline 96 & 10.0 & 16.7 & 230.0 & 9.4 & 19.5 & 237.0 \\
\hline 97 & 12.8 & 16.7 & 235.0 & 13.3 & 17.6 & 232.0 \\
\hline 98 & 12.9 & 16.7 & 235.0 & 13.4 & 17.6 & 232.0 \\
\hline 99 & 12.8 & 16.7 & 235.0 & 13.3 & 16.0 & 233.0 \\
\hline 100 & 12.6 & 16.7 & 235.0 & 13.3 & 16.0 & 232.0 \\
\hline 101 & 12.6 & 16.7 & 235.0 & 13.4 & 16.0 & 232.0 \\
\hline 102 & 12.6 & 16.7 & 234.0 & 14.2 & 16.0 & 232.0 \\
\hline 103 & 12.6 & 16.7 & 234.0 & 14.2 & 16.0 & 232.0 \\
\hline 104 & 12.7 & 16.7 & 234.0 & & & \\
\hline 105 & 12.7 & 16.7 & 234.0 & & & \\
\hline 106 & 12.6 & 16.7 & 234.0 & & & \\
\hline 107 & 12.6 & 16.7 & 235.0 & 13.0 & 16.0 & 232.0 \\
\hline 108 & 12.6 & 16.7 & 235.0 & 13.3 & 16.0 & 232.0 \\
\hline 109 & 12.5 & 16.7 & 234.0 & 13.1 & 16.0 & 231.0 \\
\hline 110 & 8.2 & 16.7 & 233.0 & 7.8 & 17.6 & 221.0 \\
\hline 111 & 8.9 & 16.7 & 233.0 & 9.0 & 19.5 & 223.0 \\
\hline 112 & 9.5 & 16.7 & 233.0 & 10.7 & 17.6 & 227.0 \\
\hline
\end{tabular}


Table E2. Concluded.

\begin{tabular}{|c|c|c|c|c|c|c|}
\hline \multirow{2}{*}{$\begin{array}{l}\text { Location } \\
\text { No. }\end{array}$} & \multicolumn{3}{|c|}{ STWAVE } & \multicolumn{3}{|c|}{ BOUSS-2D } \\
\hline & $H_{s}, \mathrm{~m}$ & $T_{p}$, sec & $\theta_{m}, \operatorname{deg}$ & $H_{s}, \mathrm{~m}$ & $T_{p}, \sec$ & $\theta_{p}$, deg \\
\hline 113 & 10.0 & 16.7 & 233.0 & 11.6 & 19.5 & 227.0 \\
\hline 114 & 10.4 & 16.7 & 233.0 & 11.2 & 16.0 & 222.0 \\
\hline 115 & 10.6 & 16.7 & 233.0 & 10.7 & 16.0 & 224.0 \\
\hline 116 & 11.0 & 16.7 & 235.0 & 12.4 & 16.0 & 230.0 \\
\hline 117 & 10.0 & 16.7 & 233.0 & 10.4 & 19.5 & 232.0 \\
\hline 118 & 10.6 & 16.7 & 235.0 & 11.1 & 19.5 & 231.0 \\
\hline 119 & 10.3 & 16.7 & 234.0 & 9.7 & 17.6 & 230.0 \\
\hline 120 & 10.0 & 16.7 & 234.0 & 9.6 & 17.6 & 232.0 \\
\hline 121 & 9.7 & 16.7 & 234.0 & 8.3 & 19.5 & 222.0 \\
\hline 122 & 9.4 & 16.7 & 233.0 & 8.5 & 19.5 & 234.0 \\
\hline 123 & 8.8 & 16.7 & 234.0 & 9.1 & 16.0 & 235.0 \\
\hline 124 & 8.2 & 16.7 & 235.0 & 9.4 & 19.5 & 232.0 \\
\hline 125 & 4.7 & 16.7 & 217.0 & 5.5 & 16.0 & 217.0 \\
\hline 126 & 4.5 & 16.7 & 221.0 & 5.1 & 16.0 & 223.0 \\
\hline 127 & 3.6 & 16.7 & 223.0 & 4.5 & 16.0 & 228.0 \\
\hline 128 & 3.3 & 16.7 & 230.0 & 3.7 & 16.0 & 235.0 \\
\hline 129 & 2.8 & 16.7 & 234.0 & 3.2 & 16.0 & 238.0 \\
\hline 130 & 2.6 & 16.7 & 238.0 & 2.8 & 16.0 & 239.0 \\
\hline 131 & 2.3 & 16.7 & 232.0 & 3.2 & 16.0 & 230.0 \\
\hline 132 & 1.3 & 16.7 & 198.0 & 2.9 & 16.0 & 197.0 \\
\hline 133 & 0.1 & 16.7 & 213.0 & 2.0 & 16.0 & 178.0 \\
\hline 134 & 4.9 & 16.7 & 217.0 & 5.4 & 16.0 & 214.0 \\
\hline 135 & 5.1 & 16.7 & 226.0 & 6.6 & 21.9 & 222.0 \\
\hline 136 & 5.6 & 16.7 & 210.0 & 7.1 & 17.6 & 209.0 \\
\hline 137 & 5.8 & 16.7 & 205.0 & 7.1 & 17.6 & 208.0 \\
\hline 138 & 4.5 & 16.7 & 214.0 & 5.2 & 13.5 & 210.0 \\
\hline 139 & 6.5 & 16.7 & 207.0 & 7.0 & 21.9 & 207.0 \\
\hline 140 & 7.4 & 16.7 & 210.0 & 6.3 & 21.9 & 220.0 \\
\hline 141 & 8.5 & 16.7 & 225.0 & 6.5 & 21.9 & 228.0 \\
\hline 142 & 8.9 & 16.7 & 234.0 & 7.7 & 19.5 & 234.0 \\
\hline 143 & 9.5 & 16.7 & 236.0 & 10.0 & 19.5 & 232.0 \\
\hline 144 & 4.4 & 16.7 & 241.0 & 4.4 & 19.5 & 252.0 \\
\hline 145 & 6.6 & 16.7 & 230.0 & 7.2 & 19.5 & 236.0 \\
\hline 146 & 7.0 & 16.7 & 223.0 & 9.1 & 19.5 & 238.0 \\
\hline 147 & 10.6 & 16.7 & 233.0 & 6.7 & 19.5 & 232.0 \\
\hline 148 & 9.9 & 16.7 & 233.0 & 7.5 & 19.5 & 236.0 \\
\hline
\end{tabular}


Table E3. Statistics of wave parameters (STWAVE versus BOUSS-2D) for south jetty length rebuild configuration.

\begin{tabular}{|c|c|c|c|c|c|c|c|}
\hline Area ID & $N$ & $\begin{array}{l}\Delta\left(H_{s}\right) \\
\mathrm{m}\end{array}$ & $\begin{array}{l}\varepsilon_{r m s}\left(H_{s}\right) \\
\mathrm{m}\end{array}$ & $\begin{array}{l}\Delta\left(T_{p}\right) \\
\sec \end{array}$ & $\begin{array}{l}\varepsilon_{r m s}\left(T_{p}\right) \\
\sec \end{array}$ & $\begin{array}{l}\Delta(\theta) \\
\operatorname{deg}\end{array}$ & $\begin{array}{l}\varepsilon_{r m s}(\theta) \\
\operatorname{deg}\end{array}$ \\
\hline \multicolumn{8}{|c|}{ Event 4} \\
\hline 1 & 6 & 1.1 & 1.6 & -1.8 & 2.3 & -5.3 & 6.6 \\
\hline 2 & 5 & -1.1 & 1.1 & -2.6 & 3.6 & -22.2 & 24.1 \\
\hline 3 & 27 & 1.8 & 2.2 & -4 & 5.6 & 4.6 & 28.6 \\
\hline 4 & 37 & 1.3 & 1.9 & -1.6 & 4.5 & 3.2 & 53.1 \\
\hline 5 & 2 & -1.5 & 1.5 & -3.3 & 3.3 & -6.5 & 6.5 \\
\hline 6 & 13 & 0.4 & 0.6 & -0.7 & 1.2 & -8.4 & 9.7 \\
\hline 7 & 11 & 1.1 & 1.7 & -2.3 & 2.4 & -27.2 & 29.3 \\
\hline \multicolumn{8}{|l|}{8} \\
\hline 9 & 16 & 0.7 & 0.8 & 0.3 & 0.6 & -9 & 9.2 \\
\hline 10 & 11 & 0.4 & 0.7 & -1 & 1.5 & 7.7 & 12.5 \\
\hline All & 132 & 1 & 1.6 & -1.9 & 3.7 & -3.1 & 32.9 \\
\hline \multicolumn{8}{|c|}{ Event 6} \\
\hline 1 & 6 & 0.6 & 1.8 & -1.5 & 3.1 & 0.5 & 6.8 \\
\hline 2 & 5 & -0.2 & 1 & -15 & 15.4 & 13.4 & 14.3 \\
\hline 3 & 27 & 0.4 & 1.3 & -1.9 & 6.3 & 11.7 & 20.3 \\
\hline 4 & 37 & 0.3 & 1 & -4.5 & 6 & 2 & 14.8 \\
\hline 5 & 4 & -1.2 & 1.3 & -16.7 & 16.7 & 9.5 & 11.4 \\
\hline 6 & 13 & -0.8 & 1.1 & -0.1 & 1.1 & 1.4 & 3.4 \\
\hline 7 & 11 & 0.5 & 1.2 & -2.6 & 2.7 & -6.5 & 7.1 \\
\hline 8 & 10 & -0.8 & 0.9 & 0.4 & 0.7 & 2.7 & 2.7 \\
\hline 9 & 16 & -0.2 & 0.9 & -1.4 & 2.1 & 5.4 & 6.8 \\
\hline 10 & 11 & -0.9 & 1 & 0.2 & 1.7 & 2.5 & 11 \\
\hline All & 145 & 0 & 1.1 & -3 & 5.9 & 4 & 12.9 \\
\hline
\end{tabular}


Table E4. Statistics of wave parameters for Event 4 for south jetty length rebuild versus existing configuration.

\begin{tabular}{|c|c|c|c|c|c|c|c|}
\hline Area ID & $N$ & $\begin{array}{l}\Delta\left(H_{s}\right) \\
\mathrm{m}\end{array}$ & $\begin{array}{l}\varepsilon_{r m s}\left(H_{s}\right) \\
\mathrm{m}\end{array}$ & $\begin{array}{l}\Delta\left(T_{p}\right) \\
\sec \end{array}$ & $\begin{array}{l}\varepsilon_{r m s}\left(T_{p}\right) \\
\sec \end{array}$ & $\begin{array}{l}\Delta(\theta) \\
\operatorname{deg}\end{array}$ & $\begin{array}{l}\varepsilon_{r m s}(\theta) \\
\operatorname{deg}\end{array}$ \\
\hline \multicolumn{8}{|c|}{ STWAVE } \\
\hline 1 & 6 & 0 & 0 & 0 & 0 & 0.7 & 1 \\
\hline 2 & 5 & 0 & 0 & 0 & 0 & 0 & 0 \\
\hline 3 & 27 & 0 & 0 & 0 & 0 & 0 & 0.2 \\
\hline 4 & 37 & -0.1 & 0.8 & -0.1 & 0.5 & 0.4 & 3.1 \\
\hline 5 & 4 & 0 & 0 & 0 & 0 & 0 & 0 \\
\hline 6 & 13 & 0 & 0 & 0 & 0 & 0.2 & 0.5 \\
\hline 7 & 11 & 0 & 0 & 0 & 0 & 0 & 0 \\
\hline 8 & 13 & 0 & 0 & 0 & 0 & 0 & 0 \\
\hline 9 & 16 & 0 & 0 & 0 & 0 & -0.1 & 0.4 \\
\hline 10 & 11 & 0 & 0 & 0 & 0 & 0.5 & 0.7 \\
\hline All & 148 & 0 & 0.4 & 0 & 0.2 & 0.2 & 1.6 \\
\hline \multicolumn{8}{|c|}{ BOUSS-2D } \\
\hline 1 & 6 & 0.1 & 0.1 & 0.1 & 0.7 & -0.5 & 0.9 \\
\hline 2 & 5 & 0 & 0.2 & -2.6 & 6.6 & -1.8 & 2.7 \\
\hline 3 & 27 & -0.1 & 0.3 & 2.4 & 8.4 & -3.8 & 12.1 \\
\hline 4 & 37 & -0.4 & 1.3 & 1.3 & 5.8 & -7.4 & 54.4 \\
\hline 5 & 2 & 0.1 & 0.1 & 1.2 & 1.2 & -1 & 1 \\
\hline 6 & 13 & 0.1 & 0.1 & -0.1 & 0.5 & 0.7 & 1.7 \\
\hline 7 & 11 & 0 & 0.2 & -0.4 & 1.1 & -0.1 & 0.8 \\
\hline \multicolumn{8}{|l|}{8} \\
\hline 9 & 16 & 0.1 & 0.2 & -0.2 & 0.3 & 1.1 & 1.9 \\
\hline 10 & 11 & 0 & 0.1 & -0.9 & 1.1 & 1.8 & 2.5 \\
\hline All & 132 & -0.1 & 0.7 & 0.7 & 5.1 & -2.6 & 29.4 \\
\hline
\end{tabular}


Table E5. Statistics of wave parameters for Event 6 for south jetty length rebuild versus existing configuration.

\begin{tabular}{|c|c|c|c|c|c|c|c|}
\hline Area ID & $N$ & $\begin{array}{l}\Delta\left(H_{s}\right) \\
\mathrm{m}\end{array}$ & $\begin{array}{l}\varepsilon_{r m s}\left(H_{s}\right) \\
\mathrm{m}\end{array}$ & $\begin{array}{l}\Delta\left(T_{p}\right) \\
\sec \end{array}$ & $\begin{array}{l}\varepsilon_{r m s}\left(T_{p}\right) \\
\sec \end{array}$ & $\begin{array}{l}\Delta(\theta) \\
\operatorname{deg}\end{array}$ & $\begin{array}{l}\varepsilon_{r m s}(\theta) \\
\operatorname{deg}\end{array}$ \\
\hline \multicolumn{8}{|c|}{ STWAVE } \\
\hline 1 & 6 & -0.2 & 0.4 & 0 & 0 & 2.3 & 3.5 \\
\hline 2 & 5 & 0 & 0 & 0 & 0 & 0 & 0 \\
\hline 3 & 27 & 0 & 0 & 0 & 0 & 0.2 & 0.4 \\
\hline 4 & 37 & -0.3 & 1 & -0.1 & 0.5 & 3.1 & 9.8 \\
\hline 5 & 4 & 0 & 0 & 0 & 0 & 0 & 0 \\
\hline 6 & 13 & 0 & 0.1 & 0 & 0 & 0.2 & 0.5 \\
\hline 7 & 11 & 0 & 0 & 0 & 0 & 0 & 0 \\
\hline 8 & 13 & 0 & 0 & 0 & 0 & 0 & 0 \\
\hline 9 & 16 & 0 & 0 & 0 & 0 & 0 & 0 \\
\hline 10 & 11 & 0 & 0.1 & 0 & 0 & 0.3 & 0.7 \\
\hline All & 148 & -0.1 & 0.5 & 0 & 0.2 & 0.9 & 4.9 \\
\hline \multicolumn{8}{|c|}{ BOUSS-2D } \\
\hline 1 & 6 & -0.2 & 0.7 & 0.1 & 1 & 2.5 & 6.6 \\
\hline 2 & 5 & 0 & 0 & -13.1 & 13.8 & -0.4 & 0.6 \\
\hline 3 & 27 & -0.2 & 0.3 & -2.7 & 8.1 & 0.3 & 1.2 \\
\hline 4 & 37 & -0.1 & 1.3 & -1.1 & 7 & -1.9 & 7.6 \\
\hline 5 & 4 & 0 & 0 & -3.1 & 14 & -0.5 & 0.7 \\
\hline 6 & 13 & 0 & 0.2 & -0.2 & 0.7 & 0.2 & 0.6 \\
\hline 7 & 11 & 0 & 0.1 & -0.3 & 1.2 & -0.4 & 0.9 \\
\hline 8 & 10 & 0.1 & 0.2 & -0.2 & 0.7 & 0 & 0 \\
\hline 9 & 16 & -0.1 & 0.2 & -0.8 & 1.7 & 0.6 & 1.2 \\
\hline 10 & 11 & 0.2 & 0.2 & 0 & 2.2 & -1 & 2.7 \\
\hline All & 145 & -0.1 & 0.7 & -1.3 & 5.9 & -0.3 & 4.2 \\
\hline
\end{tabular}




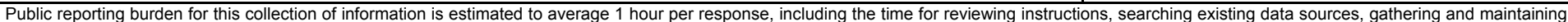

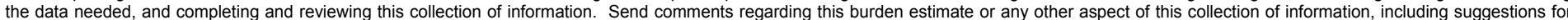

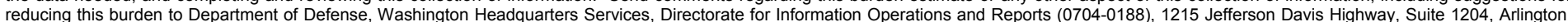

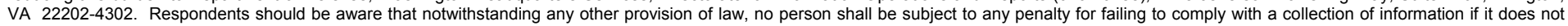
display a currently valid OMB control number. PLEASE DO NOT RETURN YOUR FORM TO THE ABOVE ADDRESS.

\begin{tabular}{l|l}
$\begin{array}{l}\text { 1. REPORT DATE (DD-MM-YYYY) } \\
\text { March } 2008\end{array}$ & $\begin{array}{c}\text { 2. REPORT TYPE } \\
\text { Final report }\end{array}$ \\
\hline
\end{tabular}

\section{TITLE AND SUBTITLE}

Wave Modeling for Jetty Rehabilitation at the Mouth of the Columbia River, Washington/Oregon, USA

3. DATES COVERED (From - To)

5a. CONTRACT NUMBER

5b. GRANT NUMBER

5c. PROGRAM ELEMENT NUMBER

\section{AUTHOR(S)}

\section{5d. PROJECT NUMBER}

Zeki Demirbilek, Lihwa Lin, and Okey G. Nwogu

5e. TASK NUMBER

\section{5f. WORK UNIT NUMBER}

7. PERFORMING ORGANIZATION NAME(S) AND ADDRESS(ES)

U.S. Army Engineer Research and Development Center

8. PERFORMING ORGANIZATION REPORT

Coastal and Hydraulics Laboratory

3909 Halls Ferry Road, Vicksburg, MS 39180-6199; NUMBER

University of Michigan

Department of Naval Architecture and Marine Engineering

2600 Draper Road, Ann Arbor, MI 48109-2145

9. SPONSORING / MONITORING AGENCY NAME(S) AND ADDRESS(ES)

U.S. Army Engineer District, Portland

P.O. Box 2946

Portland, OR 97208-2946

ERDC/CHL TR-08-

\section{DISTRIBUTION / AVAILABILITY STATEMENT}

Approved for public release; distribution is unlimited.

\section{SUPPLEMENTARY NOTES}

\section{ABSTRACT}

The U.S. Army Engineer District, Portland (NWP), maintains three rubble-mound jetties at the Mouth of the Columbia River (MCR) in support of the federal navigation project. The north and south entrance jetties constrain the current to scour the navigation channel, stabilize the location of the channel and entrance, and provide wave protection to vessels transiting the MCR. A third jetty (Jetty A) inside the MCR serves primarily as a training structure for the navigation channel to direct the flow away from the foundation of the north jetty. The jetties have significantly degraded during the past several decades. A maintenance plan is being developed to manage the jetties at the MCR to best support the federal navigation project.

The U.S. Army Engineer Research and Development Center's Coastal and Hydraulics Laboratory established numerical wave models for the MCR to evaluate the regional implications of potential future (no-action) conditions, jetty rehabilitation, and additional structures added to the jetties. The wave models were validated with NWP's "mega-transect" data obtained during August-September 2005. The validated models were operated to obtain estimates of typical winter storm effects from northwest

(Continued)

\section{SUBJECT TERMS}

See reverse.

16. SECURITY CLASSIFICATION OF:

a. REPORT

UNCLASSIFIED

b. ABSTRACT
UNCLASSIFIED

c. THIS PAGE

UNCLASSIFIED
17. LIMITATION OF ABSTRACT

\begin{tabular}{|c|} 
18. NUMBER \\
OF PAGES \\
\cline { 2 - 2 } \\
\cline { 2 - 2 }
\end{tabular}

19a. NAME OF RESPONSIBLE PERSON

19b. TELEPHONE NUMBER (include area code) 


\section{ABSTRACT (Concluded)}

and southwest. Modifications to the jetties, specifically jetty length rebuilds (north jetty and south jetty) and jetty breach in the north and south jetties, were evaluated with applicable models. The changes considered in jetty length were within the original authorized lengths of those jetties. This report provides wave estimates for each jetty modification by means of two wave models, BOUSS-2D and STWAVE.

\section{SUBJECT TERMS (Concluded)}

Boussinesq wave model

Buoys

Field data

Inlets

Jetty rehabilitation

Navigation

Spectral wave model

\section{Storms}

Wave propagation

Wave transformation

Winds 